MUNIR MOHAMED KASSAB

\title{
LOCALIZAÇÃO DE MODOS DE VIBRAÇÃO EM PAINÉIS MODULADOS DE LAJES PROTENDIDAS
}

Tese apresentada à Escola

Politécnica da Universidade de

São Paulo para a obtenção do

Título de Doutor em Engenharia

São Paulo 
MUNIR MOHAMED KASSAB

\section{LOCALIZAÇÃO DE MODOS DE VIBRAÇÃO EM PAINÉIS MODULADOS DE LAJES PROTENDIDAS}

Tese apresentada à Escola

Politécnica da Universidade de

São Paulo para a obtenção do

Título de Doutor em Engenharia

Área de Concentração

Engenharia de Estruturas

Orientador:

Prof. Doutor

Reyolando M. L. R. F. Brasil

São Paulo

2009 
FICHA CATALOGRÁFICA

Kassab, Munir Mohamed

Localização de modos de vibração em painéis modulados de lajes protendidas / M.M. Kassab. -- São Paulo, 2009.

$158 \mathrm{p}$.

Tese (Doutorado) - Escola Politécnica da Universidade de São Paulo. Departamento de Engenharia de Estruturas e geotécnica.

1. Dinâmica das estruturas 2. Método dos elementos finitos 3. Placas (Teoria) 4. Matlab I.Universidade de São Paulo. Escola Politécnica. Departamento de Engenharia de Estruturas e Geotécnica II. t. 
Aos meus pais, Mohamed Y. Kassab Virgínia F. de Souza Kassab. 
A Deus responsável maior pela força e coragem para enfrentar todas as dificuldades ao longo destes anos, sempre me amparando em todos os momentos difíceis da vida.

Ao Prof. Dr. Reyolando Manoel Lopes Rebello da Fonseca Brasil, pela valiosa orientação na realização deste trabalho, segurança, dedicação e também pela confiança depositada em mim.

Aos Professores do Departamento de Estruturas e Construção Civil da UFMS, Drs. João Pedro S. Zardo e Lauro Bulatty, pelo incentivo, amizade e recomendações, acreditando sempre que este sonho se tornaria uma realidade.

Ao amigo e Professor do curso de Engenharia Elétrica da UFMS, Dr. Luigi Galloto Júnior, pelos ensinamentos necessários ao aprendizado da linguagem de programação computacional.

À Elisa minha esposa pelo apoio, convivência, compreensão e paciência ao longo do desenvolvimento deste trabalho.

À minha irmã Dra. Nájla M. Kassab e seu esposo Dr. Marcos S. do Amaral pelo apoio e incentivo iniciais.

Ao amigo Ortopedista Dr. Roberto Antoniolli da Silva, pelos cuidados médicos dispensados.

A todos os demais colegas do curso de doutorado, em especial aos companheiros de turma André Maués Pereira Brabo, Jorge Saúl Suaznábar Velarde e Paulo de Sá Pereira Cavalcanti, que de forma direta ou indireta, contribuíram nesta caminhada.

A CAPES - Coordenação de Aperfeiçoamento de Pessoal de Nível Superior pelo apoio financeiro ao trabalho. 


\section{Resumo}

Nesta pesquisa, estuda-se o fenômeno de localização de modos de vibração em estruturas moduladas quase periódicas de comportamento linear e não-linear. Em particular, contempla-se uma aplicação na Engenharia Civil, os painéis de placas periódicos com pequenas imperfeições fracamente acoplados entre si através de viga de grande rigidez, e principalmente submetidos à variação de forças de membrana introduzidas por meio da protensão, o que só pode ser levado em conta introduzindo a rigidez geométrica no modelo matemático.

No caso de sistemas lineares, a presença de pequenas desordens nas características de rigidez ou massa de subsistemas fracamente acoplados pode causar confinamento espacial nas vibrações livres, conhecido como Localização de Modos, e pode inibir a propagação da resposta forçada. È o que tem sido mostrado na literatura técnica, em especial nas áreas de Engenharia Mecânica e Aeroespacial.

Os efeitos de localização serão obtidos numa perspectiva modal. O programa de elementos finitos DYMPLATE implementado pelo autor para análise dinâmica não-linear de estruturas de placas, será utilizado para modelar estruturas periódicas (ordenadas) e quase periódicas (desordenadas). Os modelos são linearizados em torno de configurações deformadas de referência. $O$ problema algébrico de autovalores é resolvido para obter as freqüências naturais e correspondentes modos de vibração.

Estruturas planas constituídas por placas protendidas com módulos repetidos, pequenas imperfeições e diferentes condições de apoio e de carregamento, serão utilizadas na investigação numérica da influência de diversos fatores na Localização de Modos, em especial as forças de membrana. 
In this research, the phenomenon of vibration modes localization in nearly periodic modular structures of linear and nonlinear behavior is studied. Of special interest is an application in Civil Engineering, lightly coupled periodic plate panels with small imperfections, mainly submitted to the variation of membrane forces introduced by prestress forces, which can be only considered by introducing geometric stiffness in the mathematical model.

In the linear case, the presence of small disorders in the stiffness or mass characteristics of lightly coupled sub-systems can cause spatial confinement of free vibrations, known as Mode Localization, and can inhibit the propagation of the forced response. That is what has been shown in the literature, especially in the areas of Mechanical and Aerospace Engineering.

The effects of localization are viewed from a modal perspective. DYMPLATE, a finite element software implemented by the author for nonlinear dynamic analysis of plates, will be utilized to model ordered and disordered plate periodic structures. The models are linearized about a deformed reference configuration. The algebraic eigenvalue problem is solved to obtain the natural frequencies and corresponding modes shapes.

Plane structures constituted by prestressed plates with repetitive dynamic characteristics, small imperfections and different boundary conditions and loads, will be utilized in the numerical investigation of the influence of numerous factors in the Mode Localization. 


\section{Lista de Figuras}

Figura 3.1 - Modelo de um sistema quase periódico de n lajes acopladas. ............................ 32

Figura 3.2 - Exemplo de um painel de lajes acopladas a vigas intermediárias....................... 37

Figura 4.1 - Equilíbrio dinâmico de um elemento de chapa................................................ 39

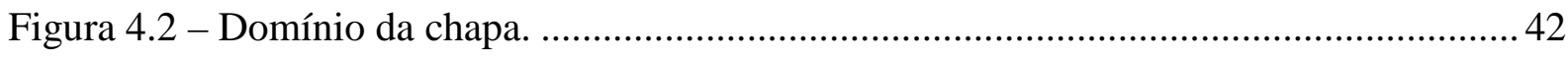

Figura 4.3 - Forças cortantes (por unidade de comprimento)........................................... 43

Figura 4.4 - Momentos fletores e de torção (por unidade de comprimento). ........................... 44

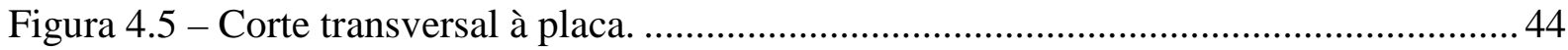

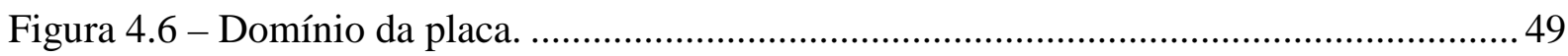

Figura 5.1 - Fluxograma de análise dinâmica pelo método dos elementos finitos.................. 76

Figura 5.2 - Fluxograma básico do programa computacional. ........................................... 79

Figura 5.3 - Interface gráfica principal do programa computacional. ................................... 85

Figura 5.4 - Interface gráfica "Placas" com destaque para os menus “drop down”................ 87

Figura 5.5 - Janela com exemplos de arquivos “Inputs” já modelados. ................................. 88

Figura 5.6 - Interface gráfica "Resultados em Primeira Ordem”......................................... 89

Figura 5.7 - Interface gráfica "Resultados em Segunda Ordem”........................................ 90

Figura 5.8 - Interface gráfica "Dinâmica em Primeira Ordem”............................................. 91

Figura 5.9 - Interface gráfica "Dinâmica em Segunda Ordem”.............................................. 92

Figura 5.10 - Interface gráfica “Desenhar Placas”.............................................................. 93

Figura 5.11 - Interface gráfica "Malha Indeformada". ....................................................... 94

Figura 5.12 - Interface gráfica "Malha Deformada".......................................................... 95

Figura 6.1 - Modelo de um sistema quase periódico de duas placas acopladas a uma mola de

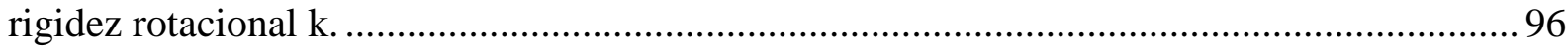

Figura 6.2 - Perspectiva do modelo físico real do painel de placas acopladas.......................97 
Figura 6.3 - Modelo estrutural simplificado do painel formado por duas placas. .98

Figura 6.4 - Vista em planta do painel formado por duas placas. 98

Figura 6.5 - Freqüências naturais versus grau de desordem na espessura. 100

Figura 6.6 - Frequiências naturais versus grau de desordem na rigidez flexional. 101

Figura 6.7 - Freqüências naturais versus grau de desordem na massa específica. 103

Figura 6.8 - Freqüências naturais versus grau de desordem na força de protensão. 105

Figura 6.9 - Primeiro modo de vibração das placas com espessuras iguais. 106

Figura 6.10 - Primeiro modo de vibração das placas com desordens na espessura. 107

Figura 6.11 - Segundo modo de vibração do sistema com espessuras iguais. 107

Figura 6.12 - Segundo modo de vibração do sistema com desordens na espessura. 108

Figura 6.13 - Primeiro modo de vibração do painel com forças de protensão iguais. 109

Figura 6.14 - Primeiro modo de vibração do painel com forças de protensão diferentes.. 110

Figura 6.15 - Segundo modo de vibração do painel com forças de protensão iguais 110

Figura 6.16 - Segundo modo de vibração do painel com forças de protensão diferentes...... 111

Figura 6.17 - Modelo de um sistema quase periódico de quatro placas alinhadas na direção longitudinal e acopladas a molas de rigidez rotacional " $\mathrm{k}$ " 112

Figura 6.18 - Modelo físico real do painel formado por quatro placas alinhadas. 112

Figura 6.19 - Modelo estrutural simplificado do painel com quatro placas acopladas 113

Figura 6.20 - Vista em planta do painel formado por quatro placas alinhadas. 113

Figura 6.21 - Primeiro modo de vibração das placas com espessuras iguais. 115

Figura 6.22 - Primeiro modo de vibração das placas com desordens nas espessuras. 115

Figura 6.23 - Segundo modo de vibração do sistema com espessuras iguais. 116

Figura 6.24 - Segundo modo de vibração do sistema com desordens nas espessuras. 116

Figura 6.25 - Primeiro modo de vibração do sistema de placas com protensão ordenada. ... 118 Figura 6.26 - Primeiro modo de vibração do sistema com desordens na protensão. 118 
Figura 6.27 - Segundo modo de vibração do sistema de placas com protensão ordenada... 119

Figura 6.28 - Segundo modo de vibração do sistema com desordens na protensão.

Figura 6.29 - Modelo físico real do painel formado por quatro placas acopladas................ 120

Figura 6.30 - Modelo estrutural simplificado do painel com quatro placas. ........................ 121

Figura 6.31 - Vista em Planta do painel formado por quatro placas. ................................... 121

Figura 6.32 - Primeiro modo de vibração das placas com espessuras iguais. ....................... 123

Figura 6.33 - Primeiro modo de vibração das placas com desordens nas espessuras............. 123

Figura 6.34 - Segundo modo de vibração das placas com espessuras iguais. ........................ 124

Figura 6.35 - Segundo modo de vibração das placas com desordens nas espessuras............. 124

Figura 6.36 - Primeiro modo de vibração do sistema de placas com protensão ordenada. ... 126

Figura 6.37 - Primeiro modo de vibração do sistema com desordens na protensão............... 126

Figura 6.38 - Segundo modo de vibração do sistema de placas com protensão ordenada. ... 127

Figura 6.39 - Segundo modo de vibração do sistema com desordens na protensão.............. 127

Figura 7.1 - Domínio “ $\Omega$ ” e contorno “ $\mathrm{C}$ “ a duas dimensões.............................................. 132 


\section{Lista de Tabelas}

Tabela 6.1 - Freqüências naturais versus grau de desordem na espessura............................99

Tabela 6.2 - Freqüências naturais versus grau de desordem na rigidez flexional.................. 101

Tabela 6.3 - Freqüências naturais versus grau de desordem na massa específica................ 102

Tabela 6.4 - Freqüências naturais versus grau de desordem na protensão. .......................... 104

Tabela 6.5 - Freqüências naturais obtidas com desordens na espessura............................... 105

Tabela 6.6 - Frequiências naturais de vibração para o sistema ordenado............................... 106

Tabela 6.7 - Freqüências naturais de vibração com protensão ordenada............................. 108

Tabela 6.8 - Freqüências naturais obtidas com desordens na protensão............................. 109

Tabela 6.9 - Freqüências naturais versus grau de desordem na espessura........................... 114

Tabela 6.10 - Freqüências naturais versus graus de desordem protensão............................ 117

Tabela 6.11 - Frequiências naturais versus grau de desordem na espessura........................... 122

Tabela 6.12 - Freqüências naturais versus grau de desordem na protensão. ........................ 125 


\section{Lista de Siglas e Softwares Utilizados}

$\begin{array}{ll}\text { ADINA } & \text { Automatic Dynamic Incremental Nonlinear Analysis } \\ \text { BASIC } & \text { Beginners All-Purpose Symbolic Instruction Code } \\ \text { CAD } & \text { Computer-Aided Design } \\ \text { CE } & \text { Constraint Equations } \\ \text { CST } & \text { Constant Strain Triangle } \\ \text { EXCEL } & \text { Microsoft Office Professional Excel 2003 } \\ \text { DYMPLATE } & \text { Placas Dinâmicas } \\ \text { FORTRAN } & \text { FORrmula TRANslation } \\ \text { GUI } & \text { Graphical User Interface } \\ \text { JAVA } & \text { Linguagem de Programação - Sun Micro systems } \\ \text { MATLAB } & \text { Matrix Laboratory Release 7.5a (2007) } \\ \text { PASCAL } & \text { Turbo Pascal - Linguagem de programação procedural } \\ \text { WORD } & \text { Microsoft Office Professional Word 2003 }\end{array}$




\section{Lista de Símbolos}

\section{Letras Romanas Maiúsculas}
$\mathbf{A}, \mathbf{B}, \mathbf{C}$
matrizes que dependem do vetor $\Phi$
$C_{d}$
contorno essencial da chapa (placa)
$C_{\sigma}$
contorno natural da chapa (placa)
$C^{o}$
funções que garantem a continuidade dos deslocamentos considerados
$C^{1}$ funções que garantem a continuidade dos deslocamentos considerados e suas derivadas primeiras
D
rigidez da placa à flexão
$\mathrm{E}$
módulo de elasticidade longitudinal
$\mathrm{F}_{i}^{x}, \mathrm{~F}_{i}^{y}, \mathrm{~F}_{i}^{z}$
forças nodais equivalentes para o sistema de eixos original
G
matriz componente de $\Delta \mathbf{K}_{0}$
$\mathbf{H}$
matriz componente de $\Delta \mathbf{K}_{0}$
K
matriz de rigidez secante
$\mathbf{K}_{\mathbf{T}}$
matriz de rigidez tangente
$\mathbf{K}_{\mathbf{o}}^{\mathbf{p}}$
matriz de rigidez de primeira ordem de chapa
$\mathbf{K}_{o}^{b}$
matriz de rigidez de primeira ordem de placa
$\Delta \mathbf{K}_{0}$
matriz de correção de coordenadas
$\mathbf{K}_{g}$
matriz de rigidez geométrica
$\mathbf{K}_{g}^{b}$
matriz componente de $\mathbf{K}_{g}$
$L_{1}, L_{2}, L_{3} \quad$ coordenadas naturais ou locais do triângulo
$\mathbf{M}^{\mathbf{P}} \quad$ matriz de massa de chapa
$\mathbf{M}^{\mathbf{b}} \quad$ matriz de massa de placa
$M_{i}^{x}, M_{i}^{y} \quad$ momentos nodais equivalentes para o sistema de eixos
$M_{n}, M_{n t} \quad$ momento de flexão e torção por unidade de comprimento em $C_{\sigma}$
$M_{x}, M_{y}, M_{x y} \quad$ momentos fletores e de torção solicitantes 


$\begin{array}{ll}N_{x}, N_{y}, N_{x y} & \text { forças de membrana no elemento infinitesimal } \\ P^{z} & \begin{array}{l}\text { carga concentrada vertical } \\ \text { forças cortantes em planos perpendiculares ao plano indeformado } \\ \text { da placa }\end{array} \\ Q_{x}, Q_{y}, Q_{x y} & \text { carga vertical de borda por unidade de comprimento em } C_{\sigma} \\ \mathrm{V}_{n} & \text { carga vertical de borda conhecida por unidade de } \\ \overline{\mathrm{V}}_{n} & \text { comprimento } C_{\sigma} \\ X, Y & \text { forças de volume } \\ \bar{X}, \bar{Y} & \text { forças de superfície aplicadas em } C_{\sigma}\end{array}$

\section{Letras Romanas Minúsculas}

$\begin{array}{ll}\mathbf{a} & \text { vetor de parâmetros nodais } \\ \mathbf{a}^{p} & \text { vetor de parâmetros nodais de chapa } \\ \mathbf{a}^{b} & \text { vetor de parâmetros nodais de placa } \\ \mathbf{f} & \text { vetor de esforços nodais equivalentes } \\ \mathbf{f}^{p} & \text { vetor de esforços nodais equivalentes de chapa } \\ \mathbf{f}^{b} & \text { vetor de esforços nodais equivalentes de placa } \\ h & \text { espessura da placa } \\ \vec{n} & \text { normal externa ao contorno da placa } \\ q & \text { carga transversal por unidade de área } \\ \vec{t} & \text { versor tangente ao contorno da placa } \\ \mathrm{u}, \mathrm{v}, \mathrm{w}^{2} & \text { deslocamentos dos pontos do plano médio da placa } \\ \mathrm{u}_{i}, \mathrm{v}_{i}, \mathrm{w}_{i} & \text { deslocamentos } \mathrm{u}, \mathrm{v}, \mathrm{w} \text { do nó } i \\ \mathrm{x}, y & \text { eixos originais }\end{array}$




\section{Letras Gregas Maiúsculas}

$\begin{array}{ll}\Gamma & \text { função de ponto contínua e derivável } \\ \Delta & \text { área do triângulo } \\ \Delta^{e} & \text { área do elemento e } \\ \Lambda & \text { função de ponto contínua e derivável } \\ \Sigma & \text { Somatório estendida a todos os elementos finitos } \\ \Omega & \text { domínio da placa } \\ \Omega^{e} & \text { domínio do elemento e }\end{array}$

\section{Letras Gregas Minúsculas}

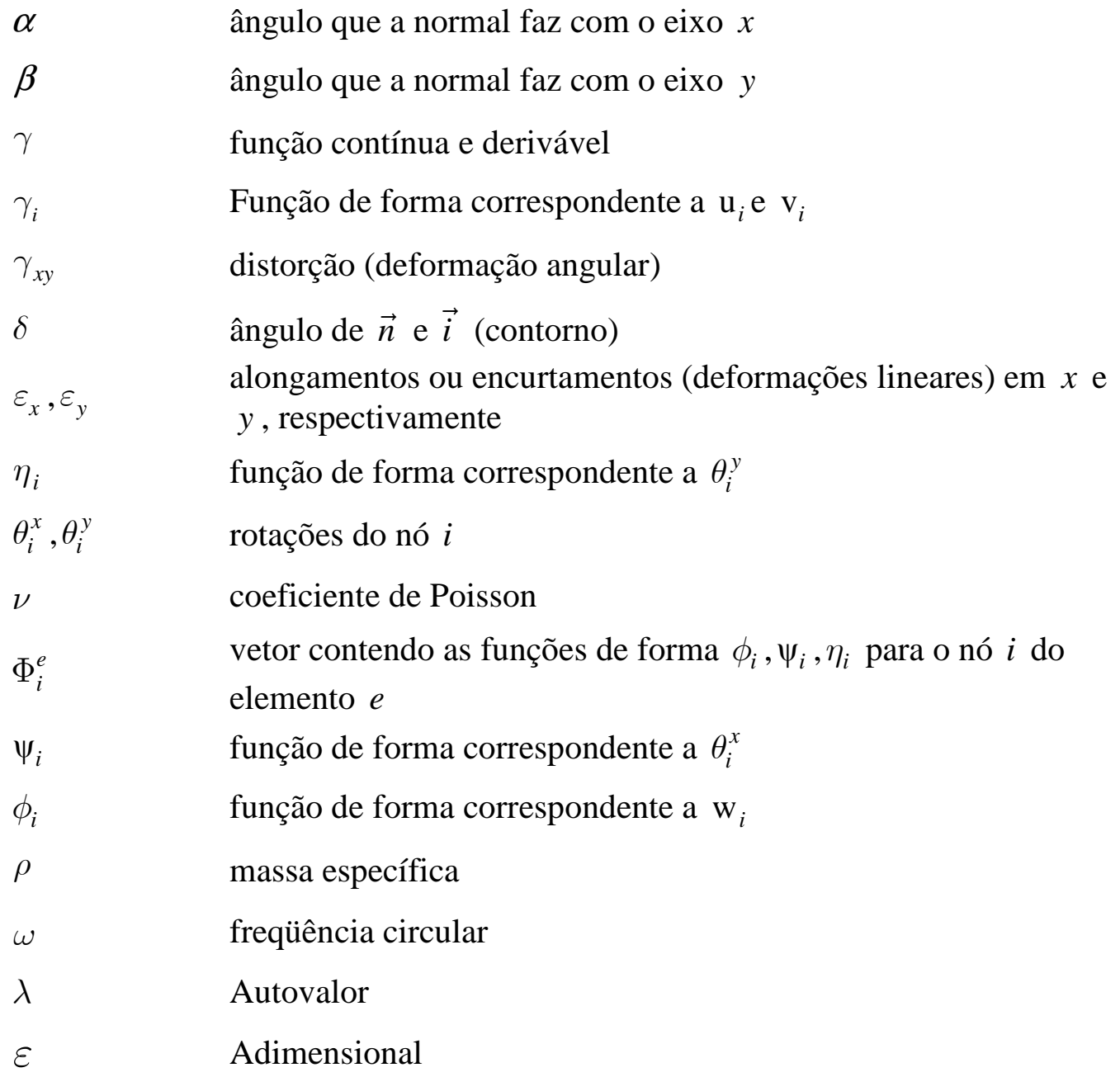




\section{Sumário}

Lista de Figuras i

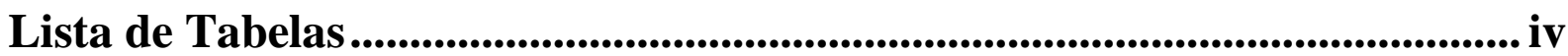

Lista de Siglas e Softwares Utilizados ............................................................. v

Lista de Símbolos...................................................................................................... vi

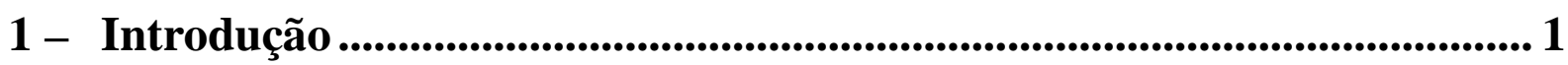

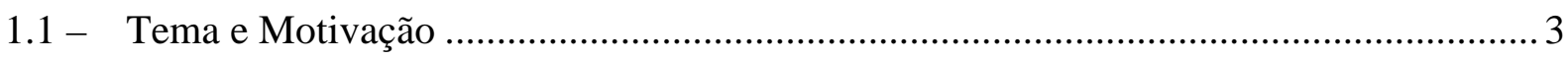

1.2 - Objetivos e Justificativas .............................................................................

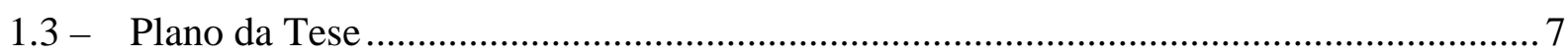

2 - Pesquisa Bibliográfica .................................................................................................... 10

2.1 - Localização de Modos .......................................................................................... 10

2.2 - Elementos Finitos para Modelagem Não-Linear de Placas ............................................ 17

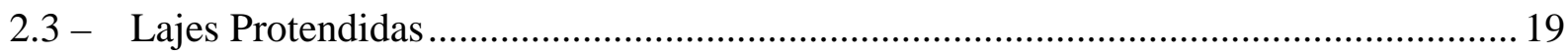

2.4 - Aspectos Históricos do Concreto Protendido ………………………………………......... 21

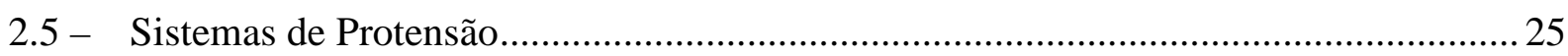

2.5.1 - Protensão com Aderência Inicial........................................................................2

2.5.2 - Protensão com Aderência Posterior …………………………………………….....2 26

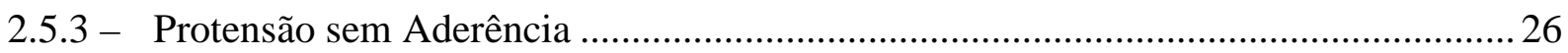

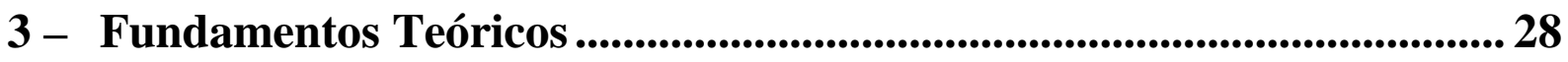

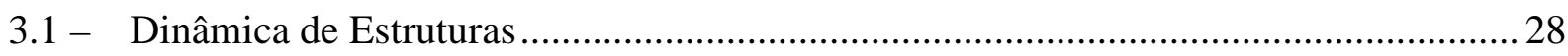

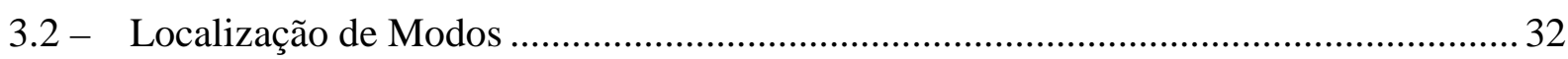

4 - Vibrações Não-Lineares de Placas.........................................................38

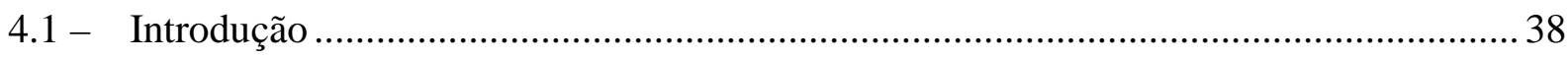


4.2 - Movimento no Plano.

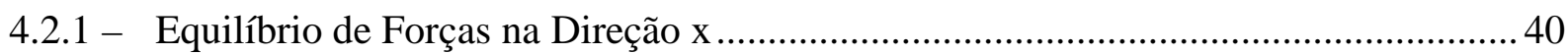

4.2.2 - Equilíbrio de Forças na Direção y ......................................................................... 40

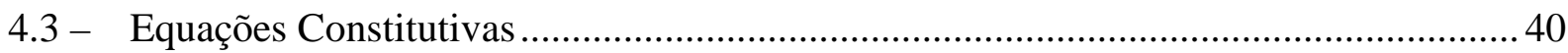

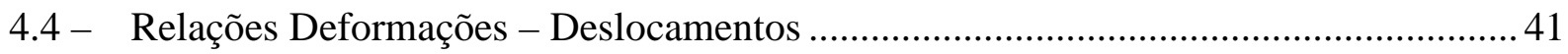

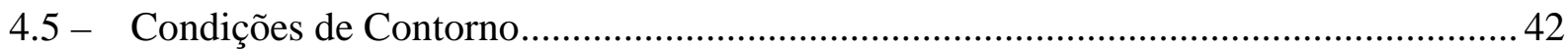

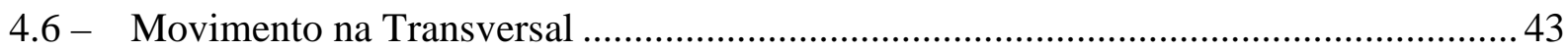

4.7 - Equilíbrio de Forças na Direção Transversal à Placa .................................................. 44

4.7.1 - Equilíbrio de Momentos em torno do eixo x.......................................................... 47

4.7.2 - Equilíbrio de Momentos em torno do eixo y ........................................................ 48

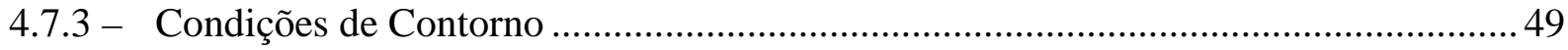

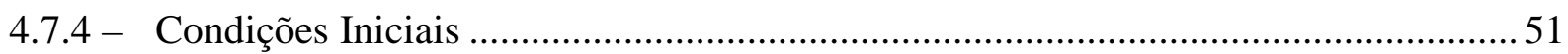

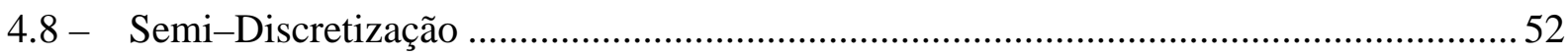

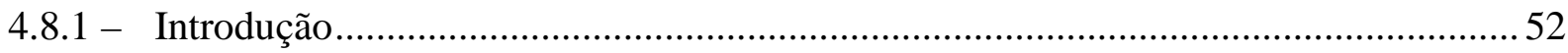

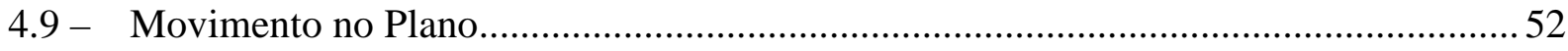

4.9.1 - Método dos Resíduos Ponderados (Hipótese de Galerkin) .........................................52

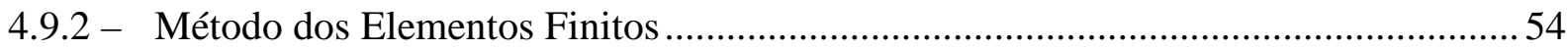

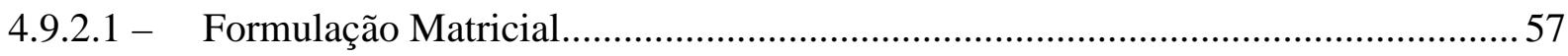

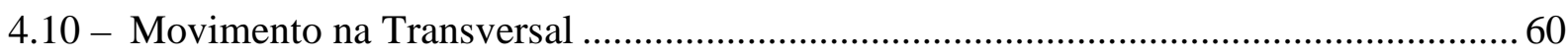

4.10.1 - Método dos Resíduos Ponderados (Hipótese de Galerkin) ….................................... 60

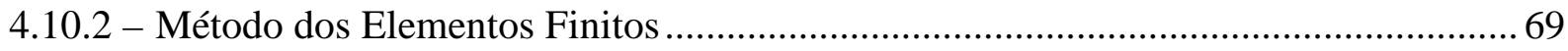

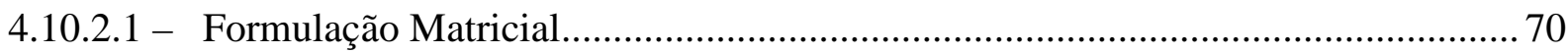

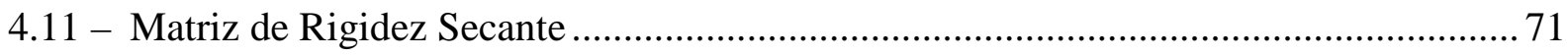

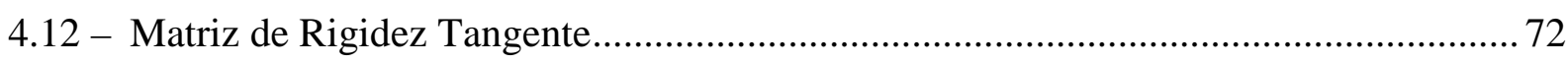


5.1 - Considerações Gerais sobre o Software MATLAB ….............................................. 73

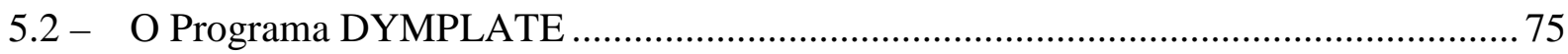

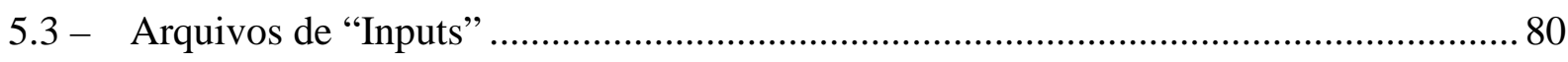

5.4 - Arquivo "Elemento Triangular de chapa/placa" .................................................... 82

5.5 - Arquivo “Análise por Elementos Finitos em Primeira Ordem” ................................. 83

5.6 - Arquivo “Análise por Elementos Finitos em Segunda Ordem” ................................. 84

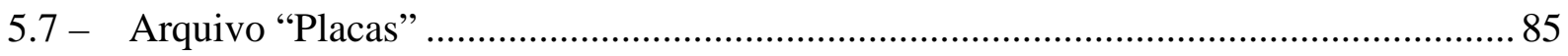

5.8 - Arquivo "Resultados em Primeira Ordem” "........................................................... 89

5.9 - Arquivo "Resultados em Segunda Ordem" .......................................................... 90

5.10 - Arquivo "Dinâmica em Primeira Ordem” ................................................................... 91

5.11 - Arquivo "Dinâmica em Segunda Ordem” ............................................................... 92

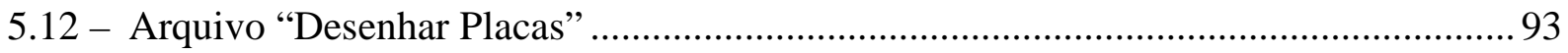

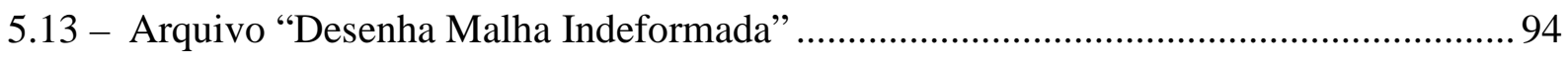

5.14 - Arquivo "Desenha Malha Deformada” .................................................................. 95

6 - Estudos Numéricos ................................................................................. 96

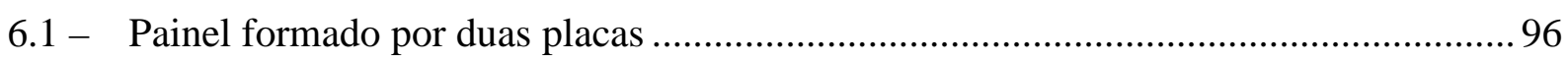

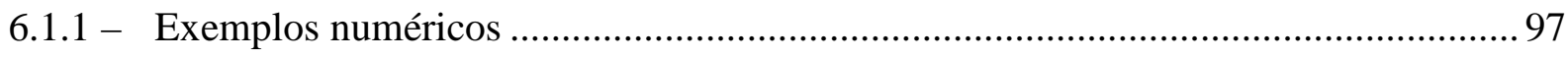

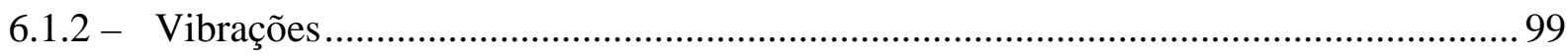

6.2 - Painel formado por quatro placas alinhadas ...................................................... 112

6.3 - Painel formado por quatro placas não alinhadas .............................................. 120

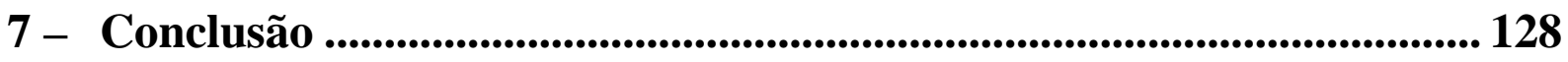

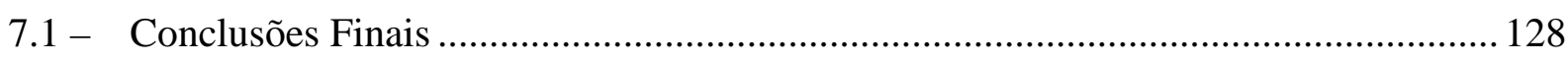

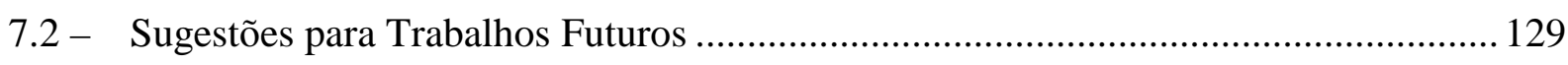




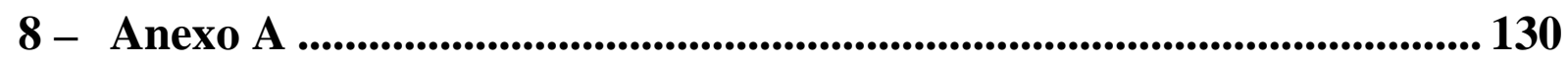

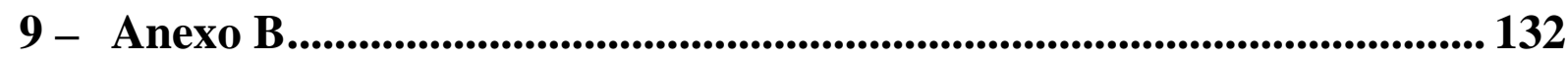

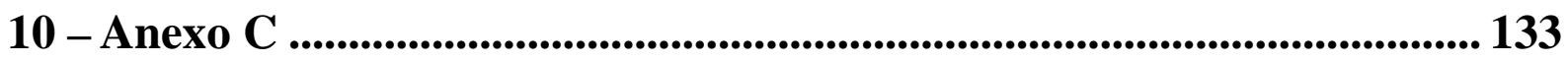

11 - Referências Bibliográficas ..................................................................... 134 


\section{Capítulo 1}

\section{Introdução}

Embora a teoria de Localização seja bem estabelecida no estudo da Física do Estado Sólido, onde foi uma área ativa de pesquisa durante os últimos 40 anos, os fenômenos correspondentes em dinâmica estrutural ainda são relativamente pouco estudados.

Uma razão para isto é de ordem matemática e não será aqui detalhada.

Por outro lado, o que existe na literatura sobre o assunto se espalha por diversos periódicos científicos que tratam de diferentes áreas, portanto pouco específicos.

Conseqüentemente, a maioria dos engenheiros que trabalham no campo da dinâmica das estruturas, são pouco familiarizados com a teoria de Localização de Modos e com os fenômenos relacionados, ficando freqüentemente surpresos quando confrontam, pela primeira vez, com uma manifestação de localização de modos num ensaio numérico ou experimental.

Sabe-se que pequenas divergências de periodicidade em grandes estruturas de engenharia podem ter efeitos drásticos em suas propriedades dinâmicas, levando à localização de vibração, na qual esta é confinada em certa região, podendo nela causar um aumento na amplitude dessa vibração.

A Localização de Modos de Vibração é importante porque a resposta dinâmica de um sistema desordenado pode ser consideravelmente maior do que de um sistema perfeito ou ordenado, conduzindo a níveis de vibrações mais altos e conseqüentemente maiores tensões. 
Além disso, uma estrutura periódica pode ser desordenada de propósito de forma que o comportamento da localização possa ser usado como um mecanismo de amortecimento. Embora desordem e dissipação ambos resultem em um decaimento de amplitude, a localização e o mecanismo de amortecimento são intrinsecamente distintos. Na Localização a energia de vibração está confinada em uma pequena região, enquanto que para o amortecedor a energia é dissipada conforme ela se propaga.

A Localização de Modos e o curve veering das freqüências são fenômeno relacionados a pequenas alterações nas características dinâmicas do sistema estrutural. Sua ocorrência sugere que o sistema dinâmico seja muito sensível a certo parâmetro estrutural. Deve ser dada atenção especial a essa significante sensibilidade.

As freqüências naturais (autovalores) e os modos de vibração (autovetores) são as principais características dinâmicas dos sistemas estruturais, ambos são funções da configuração geométrica e das propriedades dos materiais utilizados nas estruturas.

Sendo assim, este trabalho procura apresentar o fenômeno de Localização de Modos em dinâmica de estruturas constituídas de módulos com características lineares ou não lineares. Em particular, no campo da Engenharia Civil, estaremos contemplando aplicações relativas a painéis modulares de lajes protendidas, com imperfeições introduzidas, entre outras causas, por meio das forças de membrana. 


\section{1 - Tema e Motivação}

Nas diversas áreas de abrangência da Ciência da Engenharia, com aplicações em Mecânica, Aeroespacial, Naval, Elétrica, Civil, etc., é usual encontrarmos sistemas estruturais compostos de uma seqüência de módulos, nominalmente iguais em suas características de rigidez, massa e carregamentos, acoplados entre si. Tais sistemas são denominados de uma forma imprecisa como estruturas periódicas. Citam-se, a seguir, alguns exemplos, para ilustração:

- as pás de turbinas constituem uma estrutura com periodicidade cíclica levemente acoplada pelo rotor a que são elasticamente engastadas, os painéis modulados de chapa fixados a longarinas e cavernas de veículos terrestres longos, como ônibus, caso de embarcações de superfície e submarinas;

- as linhas de transmissão de energia quando as distâncias entre torres são aproximadamente iguais;

- estruturas treliçadas de todos os tipos, inclusive de plataforma espaciais, estruturas de edifícios altos em que os andares se repetem em grande número ao longo da altura, edifícios industriais compostos de estruturas aporticadas repetidas, pontes e viadutos de muitos tramos nominalmente iguais, painéis de lajes modulados, edifícios repetidos, essencialmente iguais, levemente acoplados pelo solo sobre o qual estão fundados.

- estruturas de aeronaves que supostamente possuem os lados esquerdo e direito idênticos ou simétricos, onde teoricamente seria necessário analisar apenas um desses lados, são sempre assimétricas ou desordenadas pois defeitos construtivos na fabricação e na montagem fazem com que sejam de grande importância prática investigar os efeitos de vários fatores de desordem na dinâmica das aeronaves, como um todo.

Ao estudar o comportamento dinâmico de tais sistemas, o engenheiro geralmente adota propriedades de rigidez, massa e amortecimento idênticas para os diversos segmentos. Também os carregamentos são considerados repetitivos. Os modos de vibração resultantes desses modelos, idealizados são globais por natureza, sendo que respostas modais se estendem ao longo de toda a estrutura. 
Entretanto nas estruturas reais, não há segmentos idênticos. Imperfeições construtivas, via de regra, geram pequenas variações de natureza aleatória, nas propriedades estruturais. As magnitudes dessas diferenças entre os trechos são determinadas pela tolerância de construção e variabilidade de carregamento.

À medida que essas desordens crescem e o acoplamento entre os modos diminui em intensidade, há probabilidade de que os modos resultantes mudem expressivamente com relação ao do modelo idealizado. A resposta pode ficar confinada a alguns segmentos, ou mesmo a um só, em contraste com o caso ordenado em que ela se estende por toda a estrutura.

Este é o denominado fenômeno de Localização de Modos de Vibração. O grau e a natureza das imperfeições determinam se essas localizações são benéficas como um mecanismo de amortecimento, ou catastrófica, quando leva a solicitações excessivas ou perda de estabilidade.

Surge de pronto, a promissora idéia de imposição proposital de desordem nesses sistemas como uma forma de controle passivo de vibrações nos mesmos. Eles seriam uma das mais simples formas do que se convenciona chamar estruturas inteligentes.

Recentemente, no estudo dos chamados Modos de Vibrar Não-Lineares de sistemas que exibem não-linearidades importantes, a possibilidade de bifurcações leva ao aparecimento de um fenômeno semelhante de localização de vibrações a uma região restrita da estrutura, mesmo que esta esteja isenta de imperfeições e que exista acoplamento de monta entre os subsistemas.

Dessa forma, a principal motivação para a escolha do tema, consiste no estudo do fenômeno da Localização de Modos na dinâmica de estruturas quase periódicas de comportamento linear ou não-linear (linearizadas em torno de uma configuração deformada de referência), tais como as estruturas planas de painéis de placas protendidas, de modo que venha futuramente utilizar o fenômeno como elemento de controle de vibrações. 


\section{2 - Objetivos e Justificativas}

Os principais objetivos a que se propõe esta Tese são, em suma:

- levantar o estado da arte do assunto tratado;

- deduzir os elementos da mecânica das estruturas pertinentes ao problema e apresentar os recursos numéricos necessários às análises linearizadas e nãolinearizadas que se apresentam;

- caracterizar o fenômeno da localização de modos de vibrar em estruturas periódicas e quase periódicas;

- incorporar ao problema o conceito de estado de carregamento de referência como fonte de perturbação da rigidez, o que só pode ser feito via uma teoria geometricamente não-linear para obtenção da matriz tangente nessa configuração deformada, a ser utilizada na determinação dos modos;

- elaborar um programa de cálculo computacional implementado para aplicações do Método dos Elementos Finitos, para análise estática ou dinâmica de estruturas de placas de comportamento linear e não-linear, tendo por base o desenvolvimento das equações pertinentes ao problema;

- apresentar exemplos relacionados à engenharia de estruturas civis tais como painéis de lajes protendidos inicialmente idênticas e com diferentes variações construtivas, conectados à vigas de diferentes rigidez;

- mostrar como o efeito das forças de protensão que são caracterizadas pelas forças de membrana e aplicadas diretamente nas placas, afetam principalmente suas matrizes de rigidez geométrica;

- mostrar a possibilidade de o fenômeno da localização de modos ser utilizado como controle passivo de vibrações em estruturas quase periódicas;

Neste trabalho, implementa-se também a formulação geometricamente nãolinear para um elemento finito triangular via Resíduos Ponderados (hipótese GALERKIN [34]), apresentado por COSTA [22] no contexto da estática. Todos os coeficientes das diversas matrizes são obtidos são obtidos de forma explicita, não requerendo integração numérica, utilizando-se o software MATLAB [53] para a implementação do programa de cálculo computacional desenvolvido pelo autor. 
O programa desenvolvido realiza uma análise não-linear pelo Método de Newton-Raphson para obtenção da configuração deformada de referência devida ao carregamento aplicado. Neste ponto, a última matriz de rigidez tangente computada é usada juntamente com a matriz de massa (em que se incluem as massas rotacionais), como entradas de dados de um problema generalizado de autovalores e autovetores que fornece as freqüências e os modos naturais de vibração.

Como se sabe, a possibilidade de se obter soluções fechadas para os modelos matemáticos que representam os problemas de engenharia é pequena e se esgotam rapidamente com o crescimento do porte dos mesmos. Desta forma, esta Tese apóia-se, quase sempre, nas soluções numéricas.

O método empregado com mais freqüência neste trabalho é a repetição de grande número de processamento para cada exemplo de modelo estrutural estudado. Variam-se, de cada vez, parâmetros de controle relacionados com os diversos fatores que influenciam a ocorrência e a importância do fenômeno da Localização de Modos, em especial o carregamento e seus reflexos sobre a rigidez. 


\section{3 - Plano da Tese}

Para facilitar o entendimento a Tese foi dividida em seis capítulos cujo conteúdo é apresentado a seguir.

No capítulo 2 uma revisão bibliográfica o mais completa possível é feita dos trabalhos existentes sobre o tema até o presente, ressaltando inclusive a produção mais recente, em parte de autoria do Orientador desta Tese. Procura-se também discutir, sistematizar e criticar as idéias, fundamentos, problemas e sugestões dos autores citados. O objetivo é a busca dos pontos em que a pesquisa publicada oferece campo para as contribuições apresentadas nesta Tese. Também no capítulo 2, é realizada uma breve revisão histórica do Método dos Elementos Finitos, seus principais idealizadores, tanto nos procedimentos utilizando cálculos Variacionais de RAYLEIGH-RITZ [66] [67] como nos de Resíduos Ponderados por GALERKIN [34].

$\mathrm{Na}$ parte final deste capítulo é apresentada uma pequena abordagem a respeito do concreto protendido, onde são resumidas algumas informações principais na utilização do mesmo. Os principais nomes no cenário nacional e mundial na história do desenvolvimento das técnicas de protensão são citados. Os tipos de protensões existentes (protensão com aderência inicial, aderência posterior e protensão sem aderência), os elementos estruturais de engenharia que são protendidos, em particular as vigas e lajes planas de edifícios, também são resumidos neste capítulo.

No capítulo 3 apresenta-se a obtenção das equações de movimento da Mecânica das Estruturas em vibrações livres não amortecidas para modelos matemáticos simples do tipo das estruturas periódicas e não periódicas em questão.

No capitulo 4 são obtidas as equações diferenciais do movimento para placas delgadas elásticas de comportamento geometricamente não-linear, mostrando com clareza o acoplamento existente entre os esforços de membrana e os de flexão. As correspondentes condições de contorno são também apresentadas.

Devido a se considerar o material com comportamento elástico linear, limites são impostos quanto à grandeza dos deslocamentos angulares e deformações admitidas, ou seja, as rotações são da ordem da raiz quadrada do módulo das deformações, levando à definição de aproximações com eles coerentes. 
$\mathrm{Na}$ formulação, inclui-se também o efeito da inércia de rotação. Ainda no mesmo capítulo 4, passa-se à aproximação da solução do problema contínuo equacionado utilizando o método dos Resíduos Ponderados, na variante GALERKIN [34], aplicado a uma discretização de elementos finitos triangulares. As matrizes de rigidez secante e tangente são todas explicitadas, identificando-se as parcelas linear, geométrica e de correção de coordenadas. Por fim, chega-se à matriz de massa necessária à solução numérica do problema dinâmico.

No capítulo 5 é apresentado o programa de cálculo computacional denominado DYMPLATE, implementado pelo autor utilizando recursos do LMC - Laboratório de Mecânica Computacional do Departamento de Engenharia de Estruturas e Geotécnica da Escola Politécnica da Universidade de São Paulo, com o uso de uma linguagem de alto nível presente no software MATLAB [53]. Trata-se da aplicação do Método dos Elementos Finitos à análise estática ou dinâmica de estruturas planas de placas com comportamento linear ou não-linear. São apresentados os principais módulos ou funções que compõem o programa, os fluxogramas iterativos e as interfaces gráficas de usuário.

O programa DYMPLATE é um software de código aberto, isto é, permite que qualquer programador introduza novas funções e rotinas. Uma vez que não é compilado em nenhum sistema específico, poderá ser executado em qualquer sistema onde o MATLAB [53] esteja instalado, tomando programa um software com características multi-plataforma.

Esquematiza-se, de forma resumida, o algoritmo básico do trabalho. De inicio, procede-se à solução do problema estático geometricamente não-linear, pelo método de Newton-Raphson, de forma incremental. Quando a carga estática final é atingida, no caso de se ter convergência, a matriz de rigidez tangente calculada no último passo é utilizada junto com a correspondente matriz de massa na composição de um problema generalizado de autovalores e autovetores.

No capítulo 6, aplicam-se as idéias já desenvolvidas anteriormente, através de exemplos didáticos de painéis de placas periódicos e com pequenas imperfeições fracamente acopladas entre si através de viga de grande rigidez, e principalmente submetidas à variação de forças de membrana introduzidas por meio da protensão, o que só pode ser levado em conta introduzindo a rigidez geométrica no modelo matemático. 
Os modelos utilizados são simples, mas usuais na prática da Engenharia Civil, mostram a ocorrência do fenômeno da Localização de Modos em estruturas periódicas (ordenadas) e quase periódicas (desordenadas), bem como 0 aparecimento do fenômeno de curve veering. Procura-se também mostrar, como o fenômeno se relaciona com o grau de acoplamento entre os módulos da estrutura e a ocorrência de pequenas desordens impostas ao sistema de maneira proposital, tais como: variação nas espessuras das placas, variação nos módulos de elasticidade flexional, variação na densidade do material e variação nas forças de protensão.

Os valores efetivamente obtidos para os diferentes painéis de placas exemplificados são apresentados em tabelas, gráficos e figuras, para melhor avaliar os efeitos da não-linearidade geométrica nas freqüências naturais e os correspondentes modos de vibração.

Uma das grandes contribuições apresentadas aqui nesta Tese é mostrar que o carregamento, em principio repetitivo, isto é, igual para cada módulo, pode ser, devido a pequenas variações, fonte de desordem e causador do fenômeno de Localização ao afetar a rigidez da estrutura.

Finalmente no capítulo 7 são enfeixadas as conclusões gerais obtidas ao longo do trabalho, alguns comentários são tecidos a respeito dos valores obtidos, sugestões quanto às ampliações e aperfeiçoamento do programa bem como possíveis rumos de trabalhos futuros são também citados. 


\section{Capítulo 2}

\section{Pesquisa Bibliográfica}

\section{1 - Localização de Modos}

O estudo de sistemas desordenados começou no campo da Física do estado sólido, com o trabalho de ANDERSON [3]. Este trabalho culminou com um Prêmio Nobel ANDERSON; MOTT [4].

Usou-se a idéia de localização para a explicação das propriedades de transporte de materiais cristalinos, isto é, se os vetores de estado ou modos próprios da equação de onda de Schrödinger, que governa os movimentos de elétrons num sólido, se tornarem localizados, a condutibilidade metálica se torna impossível. Assim, um sólido "ordenado", isto é, com ligações cristalinas regulares, pode mudar abruptamente de um condutor metálico para um semicondutor uma vez que essa ordem seja destruída por imperfeições ou impurezas, ou quando um sólido se torna amorfo. Parte importante da indústria eletrônica moderna deve sua existência a esse fenômeno.

Em 1963, BRILLOUIN [14], estudou a propagação de ondas em estruturas periódicas, fato este que tem sido um tópico de considerável interesse para os estudiosos da mecânica. Os modos para uma estrutura periódica idealizada ou ordenada são agrupados em faixas de freqüência chamadas bandas de passagem.

Dentro de uma banda de passagem, energia vibratória é transmitida ao longo de uma estrutura não-amortecida sem atenuação. Para estruturas finitas, surgem ondas que tem a aparência de modos estendido a toda a estrutura. Entre as bandas de passagem existem bandas de parada, que são associadas a faixas de freqüências em que ocorre transmissão de energia nula. 
Também em 1963, DEAN; BACON [24] estudaram a localização de modos de vibração para modelos analíticos de cadeias desordenadas de átomos. Eles notaram que os modos relacionados às freqüências mais baixas tinham uma característica ondulada enquanto que os correspondentes às mais elevadas eram fortemente localizados.

SOONG; BOGDANOFF [73] em 1964 aplicaram técnicas de perturbação em matrizes de transferência para investigar propriedades estatísticas das freqüências naturais, funções de admitância e funções de resposta de freqüência para cadeias desordenadas de osciladores mecânicos de um grau de liberdade.

Em 1969, BLIEVEN; SOONG [9] usaram métodos semelhantes para estudar um modelo de parâmetros discretos de uma viga simplesmente apoiada com $\mathbf{n}$ vãos e rigidez de variação aleatória.

DYE; HENRY [26] também em 1969, derivaram uma equação aproximada para a resposta de pás de turbina usando um modelo de parâmetros discretos de um conjunto rotor-turbina, incorporando pequenas diferenças nas freqüências naturais das pás. Soluções numéricas foram obtidas para essa equação aproximada. Para distribuições de freqüências realizáveis na prática, a localização de resposta prevista era grande o suficiente para causar solicitações 35 por cento em uma pá do que nas outras.

No inicio da década de 70, MEAD [54] investigou a propagação de ondas em estruturas periódicas para sistemas mono e multi-acoplados. As freqüências limitantes para as bandas de passagem e parada são obtidas de equações que modelam estruturas periódicas por meio de matrizes de receptância características.

Outra pesquisa relacionada com as propriedades estatísticas das freqüências e modos naturais de sistemas desordenados foi realizada em 1974 por LYN; YANG [48] onde o comprimento dos tramos e rigidez flexional para uma viga de $n$ vãos sobre apoios simples foram perturbados aleatoriamente. Esses estudos precursores não detectaram o fenômeno da localização por terem usado ferramentas estatísticas para obtenção das respostas médias para as estruturas. ANDERSON [3] já havia notado que nenhum sistema individual comporta-se como a média do conjunto. Sendo assim, conclui-se que os valores médios pouco têm a dizer a respeito dos problemas físicos reais. 
Uma análise de vibrações de um rotor com 24 pás, feita em 1975, por ELBAYOUMI; SRINIVASAN [27], conclui que as tensões nas pás eram uma função da distribuição de frequêencias e do desvio dessas freqüências de um valor médio. Eles também determinaram que a lâmina de máximo desvio não necessariamente experimenta as máximas solicitações.

Um estudo teórico e experimental realizado no ano de 1976 por EWINS [30], demonstrou boa correlação entre as freqüências preditas e medidas e os modos de discos com padrões de desordens.

Os efeitos de flutuação de freqüências no "flutter" de lâminas de turbinas foi também matéria de considerável interesse. No início da década de 80 KAZA; KIELB [43] mostraram que falta de sintonia tem efeito benéfico na velocidade do "flutter" associada à flexo-torção. Na resposta forçada, entretanto, resultados favoráveis ou prejudiciais dependiam da ordem da excitação.

Muitos pesquisadores têm usado matrizes de transferência como base para soluções para o problema de propagação de ondas. ENGELS [29] em 1980 usou os autovalores da matriz de transferência para analisar a resposta de estruturas periódicas infinitas e semi-infinitas a cargas harmônicas. A vantagem desse método é que o esquema computacional independe do número de subestruturas.

Em 1982, HODGES [38] foi o primeiro a usar a expressão localização de modos ao estudar seus aspectos acústicos. Usando dois modelos, uma série de pêndulos acoplados e uma corda vibratória com massas pontuais e molas, ele determinou que o grau de localização dependesse da razão entre o nível de desordem e a força de acoplamento. Já em 1983, HODGES; WOODHOUSE [39] demonstraram analítica e experimentalmente que atenuação de vibrações pode ser conseguida por uma variação das propriedades da estrutura periódica.

Os primeiros trabalhos realizados no campo da dinâmica estrutural, no que diz respeito à localização de modos de vibrar em estruturas com simetria cíclica, se relacionam com o estudo de turbinas, sendo estas pertencem a uma classe de estruturas ciclicamente simétricas com elementos fracamente acoplados, portanto suscetíveis à localização modal. A pesquisa tentava explicar rupturas por fadiga não previstas nas pás de turbinas. BENDIKSEN [8] em 1984 usou a idéia da localização dos modos para explicar o comportamento observado nesse tipo de problema. 
PIERRE; TANG; DOWELL [64] em 1987 realizaram estudos analíticos e experimentais de localização para uma viga Bernoulli-Euler de dois vãos. As imperfeições ou desordens foram conseguidas perturbando a posição do apoio central. Acoplamento variável entre os tramos foi introduzido pela alteração da rigidez de uma mola rotacional ligando a viga ao solo em sua seção sobre o apoio central.

Resultados analíticos foram obtidos por um método de perturbações modificado e uma técnica tipo RAYLEIGH-RITZ [45]. Curvas de localização foram criadas relacionando as respostas de cada tramo para cada modo como função das imperfeições geométricas e do acoplamento. Os resultados obtidos concordaram com HODGES [38] indicando que o grau de localização depende da razão entre a quantidade de desordem e a força de acoplamento.

Em 1987 e 1988, efeitos de acoplamento foram investigados em detalhe por PIERRE [65], para um sistema de vigas em balanço. Na mesma época, WEl; PIERRE [80] estenderam as investigações sobre o acoplamento para as vibrações livre e forçadas de estruturas assimétricas simulando turbinas.

Combinação de ondas e localização em estruturas periódicas foi estudada por KISSEL [44] em 1987. Localização foi determinada por técnicas probabilísticas. Usando o limite de FURSTENBERG [33], sobre o produto de matrizes aleatórias, primeiro aplicado a sistemas desordenados unidimensionais por ISHII [41] em 1973, fatores de localização podem ser calculados sem multiplicação das matrizes individuais para cada segmento desordenado. Entretanto, o teorema só dá informações úteis para matrizes de transferência $2 \times 2$ correspondentes a sistemas periódicos mono-acoplados, isto é, uma única coordenada de acoplamento entre os segmentos repetitivos. Assim, localização para sistemas periódicos com mais de uma coordenada de acoplamento não pode ser tratada por essa técnica.

Localização de vibrações para sistemas estruturais ciclicamente simétricos com subestruturas de múltiplos graus de liberdade foi estudada por CORNWELL; BENDIKSEN [20], no final da década de 80, usando técnicas de RAYLEIGH-RITZ [45]. 
Em 1990, CHA; PIERRE [15] adotou a abordagem de propagação de onda para calcular fatores de localização para subestruturas multimodais monoacopladas. Atenção foi dada à dependência da localização na freqüência e na força do acoplamento. Resultados de análises probabilísticas de perturbações foram comparados com simulações tipo Monte-Carlo.

No que diz respeito ao efeito de amortecimento sobre o fenômeno, NATSIAVAS [59], em 1993 reportou que a presença de dissipação de energia tende a diminuir a localização.

Também na década de 90, o orientador deste projeto, Prof. BRASIL [10], desenvolveu um estudo bastante compreensivo de aplicações do fenômeno de Localização de Modos de Vibrar e de Flambagem em estruturas civis, em colaboração com HAWWA [10] em 1996, MAZZILLI [11] em 1995 e BALTHASAR [6] em 1995. O trabalho completo encontra-se na Tese de Livre Docência do Prof. BRASIL [12].

Localização de Modos de Vibrações em estruturas desordenadas na engenharia aeronáutica foram estudas no ano de 2000 por LIU; CHAN [51].

Três modelos de vigas tipo $\mathrm{T}$ com desordem horizontal pertencentes à fuselagem traseira da aeronave, um modelo com dois pares desordenados de controladores de superfície e um modelo com desordens no armazenamento externo da aeronave foi adotado para a investigação teórica. Utilizaram a técnica de perturbação matricial para estudar como acontece o mecanismo do fenômeno da localização. Observou-se que quando a simetria estrutural da aeronave é modificada, ocorre a localização de modos e o fenômeno de curve veering. Quando a energia está restrita a alguns modos de vibração, a localização pode ser benéfica nos casos onde o confinamento de energia é requerido, ou ao contrário, poderá resultar em falhas criticas em alguns componentes estruturais, podendo causar efeitos drásticos nos projetos de controle estrutural. 
Em 2005, CHEN; XIE [17] estudaram a influência do efeito de pequenos erros na colocação de enrigecedores transversais em estruturas de placas de pequena espessura na localização dos modos, utilizando o método das faixas finitas na obtenção das freqüências naturais e os correspondentes modos. Na obtenção da resposta à vibração forçada para uma carga harmônica aplicada no centro da placa, utilizaram método de GALERKIN [34]. Verificou-se que uma pequena desordem nos enrigecedores da placa, afetou a localização dos modos de toda a placa de maneira bem significante.

Em 2006, CHALLAMEL; LANOS; CASANDJIAN [16] estudaram o fenômeno de localização e instabilidade em uma viga de dois vãos. Observaram que uma forte localização aparece para pequenos valores de rigidez da mola rotacional associada ao apoio intermediário, sendo que a mesma foi associada ao aumento da fissuração neste apoio devido ao confinamento das vibrações neste ponto. Assim, fizeram uma analogia entre a o tamanho das fissuras com a localização dos modos de vibração da viga.

Um critério quantitativo de localização foi estabelecido e comparado ao conhecido fenômeno de curve veering. Como a localização estava mais presente em uma parte da viga bastante danificada, isto pôde ser entendido como um indicador do nível de dano da estrutura global, e, conseqüentemente mostrar que o conceito de localização de modos pode ser usado como controle passivo da integridade estrutural, na mesma linha de pesquisa dos trabalhos de NAYFEH; HAWWA [60] no ano de 1994

Em 2007, no seu mais recente trabalho, BRASIL, et. al. [13] apresentaram um método simples e eficiente para estudar o problema das vibrações livres e localização de modos de vibração em uma viga de Bernoulli-Euler com $n$ vãos ordenados ou com pequenas desordens geométricas no comprimento dos vãos e, diferentes condições de acoplamento. Uma das vantagens da metodologia proposta, é que diferentes tipos de evolução de sistemas podem ser tratados sistematicamente numa forma compacta, de um modo conveniente para simulação numérica e tratamento de dados. 
Diferentemente da maioria dos trabalhos encontrados na literatura, esta metodologia é desenvolvida em seu próprio espaço físico, isto é, sem passar à denominada formulação espacial. A formulação obtida também é bastante útil na análise de estabilidade. Esta metodologia também pode ser aplicada a outros tipos de vigas que resultam de diversas aproximações tais como RAYLEIGH-RITZ [66] [67] ou vigas de TIMOSHENKO [75].

GATTULLI; LEPIDI [37] apresentaram um artigo (EURODYN 2008) no qual estudam um modelo seccional utilizado para realçar as diferentes condições de ressonância interna nas iterações cabo-tabuleiro de uma ponte estaiada. São investigados sistemas ressonantes com foco na sensibilidade das freqüências em relação aos parâmetros significantes. Um fator baseado em energia é usado para avaliar o nível de localização modal. Através do modelo discreto analítico, com 4 graus de liberdade, simularam o movimento linear vertical e de torção do tabuleiro (sistema principal) junto com o movimento transversal de dois cabos estaiados (sistemas secundários periódicos).

A solução modal obtida mostra que o fenômeno de curve veering existe entre as freqüências dos modos locais associados aos sistemas secundários e que a freqüência de torção aumenta a amplitude da curva, enquanto que o modo global é fortemente envolvido no processo de hibridação dos modos ressonantes envolvidos. 


\section{2 - Elementos Finitos para Modelagem Não-Linear de Placas}

$\mathrm{Na}$ engenharia, como em várias outras áreas do conhecimento, o tratamento de sistemas contínuos, geralmente, excede a capacidade de compreensão da mente humana. A alternativa natural encontrada foi a de dividir os sistemas em subsistemas, tratando-se cada um destes individualmente e, posteriormente construindo análise global do sistema.

A complexidade do modelo matemático que representa o comportamento de muitos problemas de engenharia levou ao desenvolvimento de métodos aproximados para sua solução, sendo que um dos métodos de discretização mais utilizados em engenharia é o chamado Método dos Elementos Finitos.

O Método dos Elementos Finitos, contribuição original da engenharia de estruturas ARGYRIS; KELSEY [5]; TURNER; CLOUGH; MARTIN; TOPP [77], CLOUGH [18] em 1960, entre outros, utilizando de início o Principio dos Trabalhos Virtuais, nada mais é que uma técnica de discretização de meios contínuos em um número finito de pequenas regiões denominadas elementos finitos, tornando o meio continuo em discreto, além de fazer uma aproximação numérica da solução de suas equações diferenciais.

A essa divisão do domínio dá-se o nome de malha de elementos finitos. A malha desse reticulado pode ser aumentada ou diminuída, ou seja, discretizada, variando o tamanho dos elementos finitos. Os pontos de intersecção das linhas dessa rede são chamados nós.

O Método dos Elementos Finitos está embasado nos procedimentos tipo trial functions utilizados nos Métodos Variacionais de RAYLEIGH- RITZ [66] [67] e nos de Resíduos Ponderados de GALERKIN [34].

O elemento finito retangular foi proposto pela primeira vez por ADINI [1] em 1961 e independentemente formulado por MELOSH [57] em 1963, ZIENKIEWICZ; CHEUNG [81] em 1964 e finalmente por DAWE [23] no ano de 1965. 
O elemento finito triangular surgiu em 1965, num artigo atribuído a BAZELEY; ZIENKIEWICZ; IRONS; CHEUNG [7]. Posteriormente, em 1968, ZIENKIEWICZ; CHEUNG [81] apresentaram uma formulação explícita para a matriz de rigidez desse elemento, mas que exigia um esforço computacional considerável.

SLYPER [72] em 1969 obteve as matrizes de massa e rigidez para o elemento em questão, considerando uma variação linear da espessura ao longo do domínio do elemento. Uma formulação explícita e otimizada para a matriz de rigidez surgiu em 1979 num artigo de JOSEPH; SINGA RAO [42].

Em 1986 COSTA [22] em sua Tese de Doutorado, abordou os conceitos básicos da teoria de primeira e segunda ordem das placas delgadas e de estruturas formadas por barras, através do Método dos Elementos Finitos. O elemento finito utilizado foi o triangulo de deformação constante (CST) de ZIENKIEWICZ [82].

GARZERI [36] em sua Dissertação de Mestrado analisou a teoria clássica das placas - Teoria de Kirchhoff - sob o ponto de vista dinâmico. A equação diferencial do movimento teve sua solução aproximada por meio do Método de GALERKIN [34] discretizados pelo Método dos Elementos Finitos. Dois tipos de elementos finitos foram utilizados: o elemento retangular de MELOSH [57] e o elemento triangular de ZIENKIEWICZ [82].

IDE [40], utilizando-se do Método dos Elementos Finitos, analisou numericamente as vibrações livres em torno de configurações deformadas de placas com comportamento geometricamente não-linear. Neste trabalho, ele programou uma formulação geometricamente não-linear para um elemento finito de placa via Resíduos Ponderados devido às COSTA [22]. Maiores detalhes encontram-se na sua Tese de Doutorado na Biblioteca da EPUSP. 


\section{3 - Lajes Protendidas}

A palavra protensão ou pré-tensão (presstressing em inglês) é um artifício que consiste em introduzir numa estrutura um estado prévio de tensões capaz de melhorar sua resistência ou seu comportamento, sob diversas condições de carregamento.

Nos últimos anos a arquitetura evoluiu na busca do ganho espacial dos ambientes construídos, mudando a dimensão do espaço projetado. A engenharia, por sua vez, vem buscando sempre tirar o máximo proveito dos materiais disponíveis e utilizar o que há de melhor entre as novas tecnologias. O concreto protendido vem evidenciando vantagens técnicas e econômicas à engenharia de estruturas, graças a um número apreciável de experiências feitas pelo mundo afora.

Concebido para libertar os projetistas das limitações, o concreto protendido permitiu a execução de obras antes somente imaginadas. Suas características possibilitaram projetos iniciais ousados de grandes vãos, tais como pontes, viadutos, estruturas de contenção, barragens, etc. Posteriormente a protensão também tem sido utilizada em obras residenciais de pequeno e médio porte, como lajes de edifícios comerciais, residenciais, reservatórios, galpões, peças pré-moldadas, e, até mais recentemente em pavimentos rígidos de concreto dos aeroportos.

A força de protensão age em sentido contrário ao carregamento e equilibra seus efeitos, diminuindo drasticamente as deformações e fissuração. Com a protensão é possível melhorar a capacidade de utilização da peça estrutural e controlar de modo mais eficiente a fissuração, podendo, em alguns casos até eliminá-la.

De acordo com as Normas, os critérios de segurança tomam por base os Estados Limites, sendo evidentemente desejável que a estrutura seja mais econômica possível, tanto na construção como na sua manutenção. Para as lajes protendidas valem as Normas usuais do concreto protendido, com destaque dos capítulos dedicados às lajes protendidas (NBR 7197, cap. 9.5). 
A solicitação correspondente ao Estado Limite Último (ELU) pode estar limitada pelo escoamento do aço ou esmagamento do concreto, instabilidade da estrutura ou fadiga do material. No caso das lajes verifica-se o ELU à flexão e ao puncionamento, servindo o Estado Limite de Utilização ou de Serviço (ELS) para o controle de fissuras, deformações, vibrações e para a verificação da resistência ao fogo e a proteção contra a corrosão.

No concreto armado convencional, a armadura é solicitada pela flexão, compondo o binário material resistente, o qual traciona a armadura e obriga o seu alongamento. Ao se alongar o concreto fissura. Em concreto protendido, utilizam-se aços de alta resistência, capazes de atingir tensões elevadas de trabalho sem depender de alongamentos exagerados do concreto, ficando livre das fissuras.

No presente trabalho, como a estrutura estará trabalhando apenas no Estádio I, caracterizado pelo Estado Limite de Formação de Fissuras (ELS-F) sem a presença de fissuras na seção protendida, então o mecanismo concebido não é o binário, mas de solicitações de alívio.

Nesse caso, o que se equilibra são as solicitações externas, gerando um mecanismo onde todos os pontos da peça solicitada estão em estado de tensão uniforme, que corrigido o estado de deformação através da protensão, sobrará apenas deformação do concreto, que é bastante reduzida e também corrigida.

No concreto protendido, a armadura ativa destinada à produção de forças de protensão, isto é, na qual se aplica um pré-alongamento inicial, é constituída por fios, barras e cordoalhas.

Entre os aços de protensão existentes atualmente, distinguem-se os de relaxação normal $(\mathrm{RN})$ e os de relaxação baixa $(\mathrm{RB})$. Com relação à sua resistência à tração, os mais comuns são os CP-175 e o CP-190. Entretanto, nas obras com lajes protendidas, o aço que vem sendo mais largamente empregado é o CP-190 $\mathrm{RB}$, tanto para o sistema de protensão aderentes como para os de sem aderência. 
A construção de estruturas protendidas requer um controle de qualidade do concreto muito rigoroso. Deve-se sempre realizar ensaios prévios, controle do cimento e dos agregados utilizados, bem como a fiscalização constante durante a elaboração do concreto. Normalmente, os concretos protendidos possuem resistência superior àquelas das peças de concreto armado, sendo recomendado por norma um $f_{c k} \geq 25 \mathrm{Mpa}$.

Existem várias razões que justificam a utilização de concretos de alta resistência em peças protendidas. A alta resistência, aliada ao fato de toda a seção da peça trabalhar, resistindo aos esforços atuantes, redunda em seções com dimensões menores que no concreto armado convencional, o que, em outras palavras, significa menor peso próprio. A diminuição do peso próprio viabiliza economicamente a execução de estruturas com grandes vãos.

\section{4 - Aspectos Históricos do Concreto Protendido}

Por volta do século 19, já se conhecia mundialmente a possibilidade de reforçar elementos de concreto através da armadura de aço. Com a fundação da primeira fábrica de cimento Portland alemã em 1855, o francês LAMBOT [63], desenvolveu e uma técnica para fabricação de embarcações de concreto armado. A partir de 1867, MONIER [78] começou a fabricar vasos, tubos, lajes e pontes, utilizando concreto com armadura de aço.

JACKSON [25] em 1886 foi o primeiro a propor a idéia de pré-tensionar o concreto em São Francisco (EUA). No mesmo ano o alemão KOENEN [79] desenvolveu um método de dimensionamento empírico para alguns tipos de construção de concreto armado, baseado em resultados de ensaios segundo o sistema MONIER [78], com intenção de eliminar a fissuração nas peças de concreto. Como ainda não existia aço de alta resistência, KOENEN [79] sistematizou a fabricação de peças estirando as armaduras com uma tensão $\sigma_{p}=6 \mathrm{~kg} / \mathrm{mm}^{2}$, obtendo uma deformação $\varepsilon_{s}=0,003 \mathrm{~mm} / \mathrm{m}$, alongamento que com o decorrer do tempo se perdia devido à retração e deformação lenta do concreto. 
Em 1905, MÖRSCH [47], desenvolveu a teoria iniciada por KOENEN [79], comprovando suas proposições através de inúmeros ensaios. Os conceitos desenvolvidos por MÖRSCH [47] constituíram ao longo de décadas e em quase todo o mundo, os fundamentos da teoria do concreto armado, e seus elementos essenciais ainda são válidos.

O americano STEINER [32] em 1908 sugeriu que se fizesse um re-estiramento após ocorrerem as perdas por retração e deformação lenta do concreto, a fim de recuperar tais perdas.

KOENEN e MÖRSCH [69] em 1912 reconheceram que o efeito de uma protensão reduzia com o decorrer do tempo devido à retração e deformação lenta do concreto.

Em 1919, K. WETTSTEIN [58] fabricou na Alemanha, painéis de concreto protendidos de pequena espessura (pranchas de WETTSTEIN [58], com cordas de aço de alta resistência para piano, fortemente tensionadas. Ele foi o primeiro a usar aço de alta resistência embora sem ter plena consciência de que estas eram as condições prévias decisivas para o êxito do concreto protendido.

O americano DILL [35] em 1923 foi o primeiro a reconhecer que se deveriam utilizar fios de alta resistência sob elevadas tensões para superar as perdas de protensão.

FREYSSINET [68], uma das figuras de maior destaque no desenvolvimento da tecnologia do concreto protendido, em 1928 apresentou seu primeiro trabalho consistente sobre concreto protendido, reconhecendo a importância da protensão da armadura na construção civil e também da importância das perdas na protensão, produzidas pela retração e deformação lenta do concreto. FREYSSINET [68] reconheceu que só é possível assegurar um efeito duradouro da protensão em um elemento estrutural, através da utilização de elevadas tensões no aço.

Em 1949, no Brasil, inicia-se o uso do concreto protendido com a construção da Ponte do Galeão, no Rio de Janeiro, sendo que, naquela época, a maior ponte em concreto protendido do mundo, com 380 m de comprimento. ALMEIDA [2]. 
Até a década de 50, o comportamento das lajes protendidas não era bem entendido, o que tornava necessário o uso de critérios conservadores e métodos de cálculos trabalhosos. Ainda nessa década, surgiram nos Estados Unidos, Austrália e Canadá, as primeiras lajes maciças de concreto protendido, as quais eram associadas ao método construtivo Lift-Slab, onde as lajes são moldadas no terreno e, posteriormente, içadas e ancoradas nas suas posições finais. SILVA [70].

Em 1956, nos Estados Unidos, deu-se o início da utilização de lajes protendidas sem aderência, com a construção de escolas em Nevada. ALMEIDA [2].

Foi na década de 60 que as lajes protendidas alcançaram um grande desenvolvimento em todo o mundo, principalmente nos Estados Unidos.

Diversos motivos colaboraram para esse desenvolvimento: incorporação do concreto protendido às Normas de edifícios nos Estados Unidos, desenvolvimento do Método das Cargas Equivalentes ("Load-Balancing Method"), grande número de pesquisas realizadas a partir de 1956, que vieram a responder diversas dúvidas referentes ao comportamento de peças protendidas; evolução dos materiais para a utilização da protensão, melhoria e simplificações nos processos de protensão e sistemas de fôrmas e o reconhecimento das vantagens econômicas que o sistema oferece.

Segundo SILVA [70], no Brasil destaca-se a colaboração de José Rudloff Manns e do Engenheiro José Carlos de Figueiredo Ferraz que, entre 1957 e 1973, desenvolveram um sistema de protensão utilizado em obras como o MASP - Museu de Artes de São Paulo, a ponte Cidade Universitária e o Viaduto Beneficência Portuguesa em São Paulo.

Em 1963, LIN [49] desenvolveu o Método de Balanceamento de Cargas, também conhecido como Carga Equivalente ("Load-Balancing Method"), no qual defende a idéia de que a força de protensão atuante na peça é tomada como um carregamento, sendo este no sentido da curvatura do cabo, que equilibra uma parcela do carregamento da peça. Esse novo conceito de protensão possibilitou um grande avanço na análise de estruturas de concreto protendido. 
LIN; BURN [50] em 1981 aprofundaram o estudo do conceito da Carga Equivalente, além de contemplar nesse estudo os projetos de vigas e elementos de barras, eles também dedicaram um capítulo exclusivo para o projeto de lajes protendidas.

COLLINS; MITCHELL [19] em 1987 desenvolveram um estudo contendo os conceitos básicos necessários para o entendimento de uma estrutura formada por lajes protendidas.

Vários artigos e relatórios técnicos são encontrados nas publicações da $\mathrm{ACl}$, como o Technical Report ํㅜ 43 - Concrete Society [28] que apresenta um manual de projetos para lajes de edifícios de concreto protendido.

No Brasil, SOUZA; CUNHA [74] em 1998, estudaram os conceitos de lajes em concreto armado e protendido. No mesmo ano SILVA [70] aborda em seus estudos os pontos principais no tocante ao projeto de lajes maciças protendidas.

Em 2001 FERNANDES [31], fez uma abordagem geral sobre os estudos relacionados ao puncionamento de lajes lisas por parte de CORRÊA; MELLO; MARTINS [21], por parte de MELGES; PINHEIRO; DUARTE [56] e também uma abordagem dos procedimentos básicos sobre o projeto e o dimensionamento de lajes de concreto com protensão sem aderência.

Em 2002, ALMEIDA [2] estudou a utilização da protensão não aderente em edifícios residenciais e comerciais de concreto.

No ano de 2003, SILVA; MELLO [71] analisaram a punção em lajes protendidas com cordoalha não aderente e pilares de várias dimensões.

Em 2005, LUCIA [52] em sua Dissertação de Mestrado, realizou um estudo sobre lajes lisas com protensão parcial e limitada, através de um modelo computacional empregando o uso de grelhas equivalentes no processo de cálculo e dimensionamento. Os processos de execução, levantamento das principais variáveis que intervém no procedimento e análise das principais diferenças existentes na determinação do número de cabos para protensão, também fizeram parte dos objetivos desta pesquisa. 
Portanto, embora bastante desenvolvida, principalmente nos Estados Unidos, a tecnologia de projetos e construção de pavimentos com lajes lisas usando a protensão está bastante incipiente no Brasil. Os estudos mais aprofundados e a produção de livros sobre protensão em lajes são, na sua maioria de origem norte americana, com pequenas quantidades de texto nacionais. Os enfoques dos textos brasileiros são voltados ao comportamento à flexão, ao esforço cortante, e ao estudo do desempenho de estruturas de edifícios em relação à aderência da cordoalha, tendo em sua minoria, o estudo do dimensionamento de lajes protendidas. SOUZA; CUNHA [74].

\section{5 - Sistemas de Protensão}

\subsection{1 - Protensão com Aderência Inicial}

A protensão com aderência inicial é muito empregada na fabricação de prémoldados de concreto protendido. Nas pistas de protensão, utilizam fios ou cordoalhas de aço especial, que são estirados ao ar livre com o auxilio de macacos hidráulicos, onde a armadura ativa é posicionada, ancorada em blocos nas cabeceiras e em seguida tracionada.

Posteriormente, a armadura passiva é colocada, o concreto é lançado e adensado, e a peça passa para a fase de cura. Após a cura, as formas são retiradas, os equipamentos que mantinham os cabos tracionados são liberados e os fios são cortados, transferindo a força de protensão para o concreto pela aderência ou atrito, que nessa ocasião já deve estar suficientemente desenvolvida.

Algumas vantagens do sistema com aderência inicial devem-se ao fato de que se aumenta a capacidade das seções no estado limite último, melhora o comportamento da peça entre os estágios de fissuração e de ruptura, além de que a falha de um cabo tem conseqüências restritas. 


\subsection{2 - Protensão com Aderência Posterior}

No caso de protensão com aderência posterior, a protensão é aplicada sobre uma peça de concreto já endurecido e a aderência se dá posteriormente, através da injeção de uma nata de cimento no interior das bainhas metálicas, com o auxílio de bombas injetoras. Geralmente, os cabos são pós-tracionados por meio de macacos hidráulicos especiais, apoiando-se nas próprias peças de concreto já endurecido. Quando a força de protensão já atinge o valor especificado, os cabos são ancorados por meio de dispositivos especiais. Nos sistemas mais comuns são utilizados placas de ancoragem com cunhas metálicas ou argamassa de alta resistência. Em outros processos, utilizam-se porcas especiais e até mesmo grandes blocos de concreto para ancoragem.

A solução com cabos ou cordoalhas aderentes, se comporta melhor quanto à distribuição das fissuras e à segurança contra ruptura para efeitos localizados, tais como: explosão, incêndios, demolição parcial, etc.

A influência da aderência no comportamento da fissuração e na resistência última das peças de concreto protendido tem assumido uma relevância considerável no meio profissional de modo que, mesmo diante das vantagens econômicas da protensão sem aderência, têm-se optado por utilizar cabos aderentes nos sistemas construtivos modernos.

\subsection{3 - Protensão sem Aderência}

A protensão é aplicada sobre uma peça de concreto já endurecido não havendo, entretanto, aderência entre os cabos e o concreto. A inexistência de aderência refere-se somente à armadura ativa, já que a armadura passiva sempre deve estar aderente ao concreto.

Em alguns sistemas de protensão sem aderência, a armadura ativa é colocada em dutos formados por bainhas metálicas engraxadas ou de plástico (PVC). Após a aplicação da força de protensão, nas bainhas são injetadas graxas para evitar a corrosão. 
Utilizam-se também outros sistemas de protensão sem aderência nos quais os cabos são colocados externamente à peça de concreto já moldada, como no caso de vigas armadas com tirantes externos. Essa solução é mais freqüente em obras de reforço de estruturas pré-existente, muito utilizada na recuperação de pontes.

Cabe ressaltar que a falta de aderência pode não impedir a fissuração da peça estrutural, sendo necessário utilizar uma armadura aderente passiva. Os cabos não aderentes funcionam apenas como elementos para aplicação da força de protensão. Em função da ausência de ligação entre o cabo e o concreto, sua contribuição para a resistência à ruptura da peça é limitada.

O emprego de cabos não aderentes fica limitado a situações em que a fissuração e a ruptura tenham importância secundária, ou ainda, a casos em que se deseja poder substituir alguns cabos. A NBR 7197, no item 4.3, prescreve que 0 concreto protendido sem aderência só pode ser empregado em casos especiais e sempre com protensão completa. Essa medida visa prevenir a formação de fissuras com grande abertura no concreto.

Durante a construção da hidrelétrica de Itaipu, a empresa Furnas reforçou todas as pontes do trajeto Rio-Foz do Iguaçu, por onde foram transportadas as turbinas da usina, a partir dos portos do Rio de Janeiro e de Santos, através da protensão de cabos externos sem aderência.

A utilização de armaduras de protensão não aderentes é relativamente polêmica. Alguns países possuem tradição no uso desta solução e outros não. Nos EUA a protensão sem aderência é muito utilizada. Esse sistema também foi bastante empregado na Austrália durante algum tempo, mas posteriormente foi abandonado. No Brasil existe pouca tradição na utilização deste sistema.

$\mathrm{Na}$ presente Tese, a estrutura plana formada por painéis de placas protendidas, se caracteriza por um sistema de protensão sem aderência. 


\section{Capítulo 3}

\section{Fundamentos Teóricos}

\section{1 - Dinâmica de Estruturas}

Modelos matemáticos de sistemas dinâmicos recaem, em geral, em duas classes. Na primeira delas, modelos espacialmente discretos, constituídos de partículas ou corpos rígidos, tem suas configurações definidas por variáveis dependentes apenas do tempo, enquanto que no outro grupo, em que se enquadram os contínuos estruturais, elas são definidas por variáveis dependentes do tempo e do espaço.

O movimento de sistemas discretos é descrito por equações diferenciais ordinárias enquanto que o dos sistemas contínuos, como nos caso das estruturas, é governado por equações de derivadas parciais. Neste último caso, a análise é, em geral, precedida de uma etapa de discretização parcial no espaço, permitindo também recair em sistemas de equações diferenciais ordinárias no tempo. Para obtenção das soluções desses sistemas, pode ainda ser conveniente a opção por métodos numéricos em que seja feita uma discretização da variável tempo.

Nesta exposição, supõe-se que uma discretização espacial do contínuo estrutural foi feita (por exemplo, pelo Método dos Elementos Finitos) de forma a recair em um sistema de equações diferenciais ordinárias na variável tempo. A configuração do sistema, em cada instante, pode ser completamente definida por um número mínimo $\mathrm{n}$, número de graus de liberdade do sistema, de variáveis dependentes do tempo $q_{i}(t)(i=1,2 \ldots n)$, denominadas coordenadas generalizadas. 
Nesta tese, serão analisados apenas os sistemas não-giroscópicos conservativos ou não-conservativos. Além disso, estaremos sempre considerando somente vibrações livres não-amortecidas, permitindo as simplificações que a seguir se fazem.

Para um sistema linear de vários graus de liberdade, não amortecido, em vibração livre, a equação do movimento pode ser escrita na seguinte forma

$$
[\mathbf{M}]\{\ddot{q}\}+[\mathbf{K}]\{q\}=\{0\}
$$

onde:

- $[\mathbf{M}]$ representa a matriz de massa

- $[\mathbf{K}]$ representa a matriz de rigidez

- $\{\ddot{q}\}$ é o vetor de aceleração

- $\{q\}$ é o vetor de deslocamento

Para determinar-se a possibilidade de movimentos sincrônicos, admite-se que a solução da equação (3.1) seja na forma exponencial dada por:

$$
q(t)=e^{s t} \hat{z}
$$

que substituída na equação do movimento resulta em:

$$
\mathbf{K} \hat{z}=\lambda \mathbf{M} \hat{z}
$$

um sistema de equações homogêneas que constituem um problema algébrico de autovalores e autovetores. Para que possua soluções não-triviais é necessário e suficiente que:

$$
\operatorname{det}[\mathbf{K}-\lambda \mathbf{M}]=0
$$

onde se tem o determinante característico que computado resulta na equação característica ou equação de freqüência fornecendo $\mathrm{n}$ autovalores $\lambda_{i}$, em geral distintos, que podem ser congregados na matriz de autovalores: 
$\Lambda=\left[\begin{array}{ccccc}\lambda_{1} & 0 & \cdot & \cdot & 0 \\ 0 & \lambda_{2} & \cdot & \cdot & 0 \\ \cdot & \cdot & \cdot & \cdot & \cdot \\ \cdot & \cdot & \cdot & \cdot & 0 \\ 0 & \cdot & \cdot & 0 & \lambda_{n}\end{array}\right]$

Reconhecendo-se que a cada autovalor $\lambda_{r}$ correspondem dois expoentes, $S_{r}= \pm \sqrt{-\lambda_{r}}$, conclui-se que as soluções obtidas são da forma:

$q_{r}(t)=\left(a_{r} e^{\sqrt{-\lambda_{r} t}}+b_{r} e^{-\sqrt{-\lambda_{r} t}}\right) \hat{z}_{r}, \quad r=1,2, \ldots n$

Assim, movimentos sincrônicos são possíveis, na forma acima. As constantes $a_{r}$ e $b_{r}$ dependem das condições iniciais do movimento. Como o sistema foi linearizado, a solução geral é uma combinação linear:

$q_{r}(t)=\sum_{r=1}^{n} q_{r}(t)$

O comportamento do sistema é controlado pela parte da solução dependente do tempo, ou seja, pelos expoentes $S_{r}$. Como a matriz de massa é sempre positiva definida, se a matriz de rigidez (tangente) for positiva definida, todos os autovalores serão reais e positivos de forma que $S_{r}= \pm i \omega_{r}$, onde $\omega_{r}=\sqrt{\lambda_{r}}$. Quando ela for positiva semi-definida, todos os autovalores são reais e não-negativos, isto é, alguns podem ser nulos e os demais positivos.

Em ambos os casos, os autovalores são reais, resultando que $b_{r}$ deve ser igual a $\bar{a}_{r}$, o complexo conjugado de $a_{r}$.

As quantidades $\omega_{r}$ representam as freqüências naturais do sistema, associadas aos vetores modais $\hat{z}_{r}$. O par constitui um modo natural de vibração, sendo que as freqüências naturais são colocadas em ordem crescente, de modo que a mais baixa se refere ao primeiro modo de vibração e assim por diante. 
Observa-se que os vetores das formas modais obtidos referem-se apenas à forma geométrica assumida pelo sistema em vibração livre naquela freqüência em particular, não possuindo qualquer relação com a amplitude das oscilações desenvolvidas.

Em termos de apenas quantidades reais, têm-se:

$$
q(t)=\sum_{r=1}^{n} c_{r} \cos \left(\omega_{r} t-\varphi_{r}\right) \hat{z}_{r}
$$

Além disso, os autovetores podem ser normalizados e reunidos em uma matriz modal dado por:

$$
\hat{\mathbf{z}}=\left[\begin{array}{ccccc}
\hat{z}_{11} & \cdot & \hat{z}_{1 r} & \cdot & \hat{z}_{1 n} \\
\cdot & \cdot & \cdot & \cdot & \cdot \\
\hat{z}_{m 1} & \cdot & \hat{z}_{m r} & \cdot & \hat{z}_{m n} \\
\cdot & \cdot & \cdot & \cdot & \cdot \\
\hat{z}_{n 1} & \cdot & \hat{z}_{n r} & \cdot & \hat{z}_{n n}
\end{array}\right]
$$

Dessa forma, o problema pode ser colocado da seguinte forma:

$$
\mathbf{K} \hat{\mathbf{Z}}=\Lambda \mathbf{M} \hat{\mathbf{Z}}
$$

Quando a matriz de rigidez (tangente) é positiva semi-definida, autovalores $\lambda_{s}$ nulos são possíveis, por exemplo:

$q_{s}(t)=\left(a_{s}+t b_{s}\right) \hat{z}_{s}$

que é divergente. Este é o caso de estruturas não vinculadas em que os modos associados a esses autovalores são chamados modos de corpo rígido.

Quando a matriz de rigidez tangente muda de sinal, obtêm-se também autovalores $\lambda_{s}$ negativos, e os expoentes $S_{r}$ correspondentes são reais de forma que se tem solução divergente, claramente instável, levando a deslocamentos que rapidamente se afastam da hipótese de pequenos movimentos. 


\section{2 - Localização de Modos}

A presença de irregularidades em estruturas nominalmente periódicas pode inibir a propagação de vibrações ou modificar sensivelmente suas características dinâmicas. Essas perturbações localizam os modos de vibração e, dependendo da magnitude da desordem e do grau de acoplamento entre os módulos do sistema, a energia nele injetada não pode propagar-se, confinando-se a certa região da estrutura. Este fenômeno é conhecido como de Localização de Modos Normais.

Estuda-se, nesta Tese, a Localização de Modos de Vibração para sistemas elásticos quase periódicos. Para obtenção de um entendimento do fenômeno por meio de um exemplo, considere-se uma estrutura modulada constituída de uma seqüência de subestruturas, nominalmente iguais levemente acopladas entre si

A Figura 3.1 mostra um modelo simples, mas bastante geral de um sistema quase periódico desse tipo. Constitui-se de um painel de placas de lajes solidarizados por vigas de grande rigidez a torção, as quais são representadas por molas. Pretende-se investigar os modos de vibração do conjunto quando o acoplamento se torna pequeno. Trataremos apenas de vibrações livres.

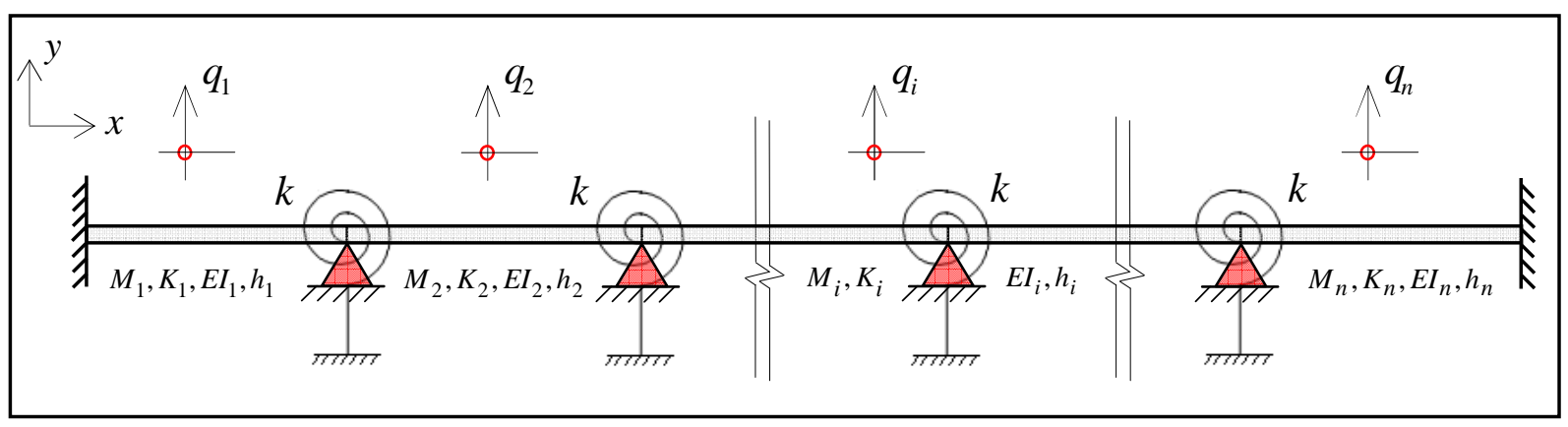

Figura 3.1 - Modelo de um sistema quase periódico de n lajes acopladas.

Considere-se a i-ésima placa, $K_{i}$ é a sua rigidez ao movimento vertical, $q_{i}$, cuja massa é $M_{i}$. A rigidez das molas de acoplamento é $k$. Desprezando-se, por exemplo, o peso próprio, a equação do movimento correspondente à coordenada generalizada $q_{i}$, para vibrações não-amortecidas, é dada por: 


$$
M_{i} \ddot{q}_{i}+K_{i} q_{i}+k\left(2 q_{i}-q_{i-1}-q_{i+1}\right)=0
$$

ou

$\ddot{q}_{i}+\bar{\lambda}_{i} q_{i}+r_{i}\left(2 q_{i}-q_{i-1}-q_{i+1}\right) / 2=0$

onde:

$\bar{\lambda}_{i}=K_{i} / M_{i}$ e $r_{i}=2 k_{i} / M_{i}$.

Já foi dito que a solução desse sistema homogêneo é a do problema de autovalores e autovetores da seguinte forma:

$$
\mathbf{A} \hat{\mathbf{z}}=\lambda \hat{\mathbf{z}}
$$

onde $\hat{z}$ são os autovetores (modos de vibração), $\lambda$ os autovalores (freqüências naturais de vibração ao quadrado) e, neste caso,

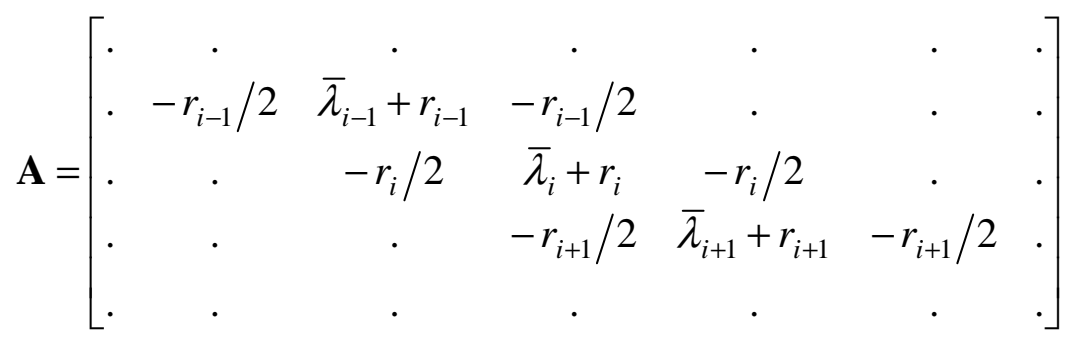

é uma matriz tridiagonal simétrica, que no que se segue será referida por matriz dinâmica.

Considere-se, inicialmente, que as placas estão desacopladas, isto é, $r_{i}=0$. Nesse caso, os elementos da diagonal principal $\bar{\lambda}_{i}$ são os próprios autovalores do problema.

Se as subestruturas forem idênticas, suas freqüências naturais individuais são iguais, na forma $\lambda_{i}=\bar{\lambda}_{0}=\bar{\omega}_{0}^{2}$. Além disso, fica claro que qualquer excitação aplicada a uma das placas não se transmitirá aos demais.

Introduzindo acoplamento entre eles $r_{i}=r$, independente de quão pequeno seja, os modos de vibração não são mais localizados, estendendo a todo sistema.

Neste caso, de subestruturas idênticas, a amplitude das oscilações verticais de cada placa varia sunusoidalmente no espaço com sua posição. 
Se uma pequena quantidade infinitesimal de acoplamento for imposta ao sistema, haverá uma quebra na multiplicidade das freqüências individuais iguais, mudando fundamentalmente as características dos modos, passando de um vibrador desacoplado para oscilações coletivas. Demonstra-se, como pode ser encontrado em PARLET [61], que neste caso, as freqüências, embora possam ser muito próximas, são sempre distintas. De fato, a matriz dinâmica [A] tem aqui a forma:

$\mathbf{B}=\left[\begin{array}{ccccccc}\cdot & \cdot & \cdot & \cdot & \cdot & \cdot & \cdot \\ \cdot & -r / 2 & \bar{\lambda}_{0}+r & -r / 2 & \cdot & \cdot & \cdot \\ \cdot & \cdot & -r / 2 & \bar{\lambda}_{0}+r & -r / 2 & \cdot & \cdot \\ \cdot & \cdot & -r / 2 & \bar{\lambda}_{0}+r & -r / 2 & . \\ \cdot & . & . & \cdot & . & \cdot & .\end{array}\right]$

e o teorema dos Círculos de GERSHGORIM [55] garante que cada autovalor está numa faixa com centro no valor do coeficiente da diagonal principal e raio igual à soma dos elementos fora da diagonal da correspondente linha da matriz. Essa faixa, aqui, é:

$\bar{\lambda}_{0} \leq \lambda_{i} \leq \bar{\lambda}_{0}+2 r$

mostrando, dessa maneira, que para pequenos acoplamentos a variabilidade dos autovalores é também pequena.

Considere-se a seguir, o caso onde as freqüências naturais individuais variam de uma forma qualquer, aleatória ou determinística. Para acoplamento nulo os modos de vibração consistem de oscilações dos pórticos individuais em freqüências variáveis, geralmente diferentes por pequenos valores, na forma $\lambda_{i}=\bar{\lambda}_{0}+\bar{p}_{i}=\bar{\omega}_{i}^{2}$.

Para pequeno acoplamento, ou seja, quando houver uma viga de grande rigidez entre as placas, os modos de vibração são uma perturbação das oscilações desacopladas. Em conseqüência, os modos permanecem localizados perto das placas individuais, e as freqüências naturais do sistema são próximas às freqüências naturais das placas isoladas.

A multiplicidade de autovalores do caso ordenado e desacoplado foi quebrada pela desordem, e a introdução de pequeno acoplamento não pode mais levar a oscilações coletivas. A matriz dinâmica $[\mathbf{A}]$ do problema toma a seguinte forma: 


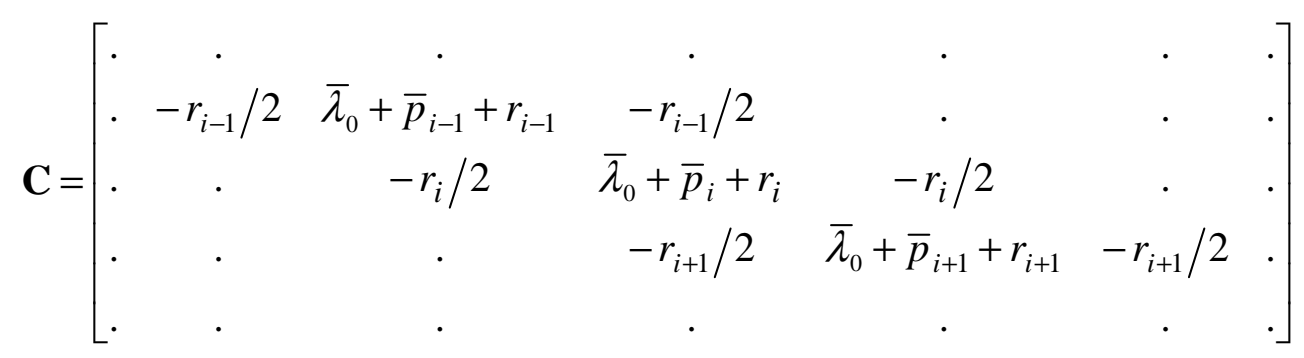

Agora o teorema dos Círculos de GERSHGORIM [55], leva a conclusões mais complexas quanto aos autovalores que dependem dos valores relativos das variações $\bar{p}_{i}$ e dos acoplamentos $r_{i}$. Cada um deles tanto pode estar solitário em faixas dadas por:

$$
\bar{\lambda}_{0}+\bar{p}_{i} \leq \lambda_{i} \leq \bar{\lambda}_{0}+\bar{p}_{i}+2 r_{i}
$$

dependendo de $P_{i}$ e $r_{i}$, como em grupos de valores situados em faixas dadas pela conexão de certos subdomínios.

Para ganhar algum sentimento físico do fenômeno, considere-se que uma particular placa é forçada periodicamente com freqüência próxima à sua freqüência natural. Esta particular placa oscilará com grandes amplitudes. Como o sistema é desordenado e o acoplamento é fraco, é provável que seus vizinhos mais próximos não experimentem tal ressonância, vibrando com menor amplitude. Da mesma forma, vizinhos mais distantes respondem com muito menor amplitude.

Em conclusão, para oscilações forçadas, a vibração permanece localizada perto do ponto forçado. Para oscilações livres, os modos permanecem próximos dos modos das placas individuais desacopladas.

Como a distribuição das freqüências individuais é variável, aleatoriamente ou não, pode também acontecer que a freqüência individual de uma placa particular e uma de suas vizinhas próximas sejam iguais ou muito semelhantes.

Neste caso, a localização não é restrita a uma única placa, sendo que as duas estruturas de freqüências individuais muito próximas oscilam com grandes amplitudes, comportando-se como um subsistema ordenado do sistema ordenado. 
Da discussão apresentada, pode-se notar a importância da intensidade do acoplamento entre os módulos: acoplamento mais fraco implica em modos de vibração mais localizados. Por outro lado, maior grau de desordem (variação de espessura, variação de massa, de carregamentos, etc.), leva a localização mais pronunciada.

De fato, pode-se especular intuitivamente que o grau de localização está relacionado com a relação entre o acoplamento e o grau de desordem. Questões interessantes referem-se aos valores dessa relação para os quais a localização ocorre e, para um dado acoplamento, o mínimo grau de desordem requerido para obtenção de modos localizados.

Chega-se, por via numérica, a conclusão de que a localização de modos ocorre com intensidade importante quando as variações (pequenas) $\bar{p}_{i}$ nas freqüências naturais das subestruturas isoladas são maiores, mas de mesma ordem de grandeza que os acoplamentos (pequenos) $r_{i}$. Por outro lado, também se pode concluir, ainda por via numérica, que o grau dessa localização depende do produto dessas duas grandezas. Mais precisamente, mantido esse produto, para várias relações entre elas, mantém-se também o grau de localização.

Considere-se agora, o caso usual em que cada uma das subestruturas é um subsistema de vários graus de liberdade. Como exemplo, tome o caso de um painel de lajes com vários panos ou subsistemas, onde cada subsistema tem muitos, a rigor infinitos, modos de vibração e freqüências naturais próprios.

No caso de subsistemas idênticos, se não estiverem acoplados, teremos para o conjunto autovalores que se repetem em grupos. O número desses grupos é igual ao de módulos. Um grupo seria, por exemplo, constituído pelos primeiros modos de vibrar de cada módulo, outro pelos segundos modos, e assim por diante.

$\mathrm{Na}$ presença de acoplamento, por menor que ele seja ainda teríamos a mesma característica de agrupamento de autovalores, a situação muda radicalmente, pois agora os modos se tornam globais, espalhando-se por todo o sistema acoplado. 
Admita-se, agora, que existam pequenas diferenças aleatórias ou determinísticas entre as características de cada módulo. $\mathrm{Na}$ ausência de acoplamento, os autovalores de novo se congregam em grupos, embora seus valores individuais já não sejam iguais devido às irregularidades introduzidas. Como no caso anterior, um grupo seria, por exemplo, constituído pelos primeiros modos de vibrar de cada módulo, outro pelos segundos, terceiros, etc. A Figura 3.2 a seguir, generaliza o conceito.

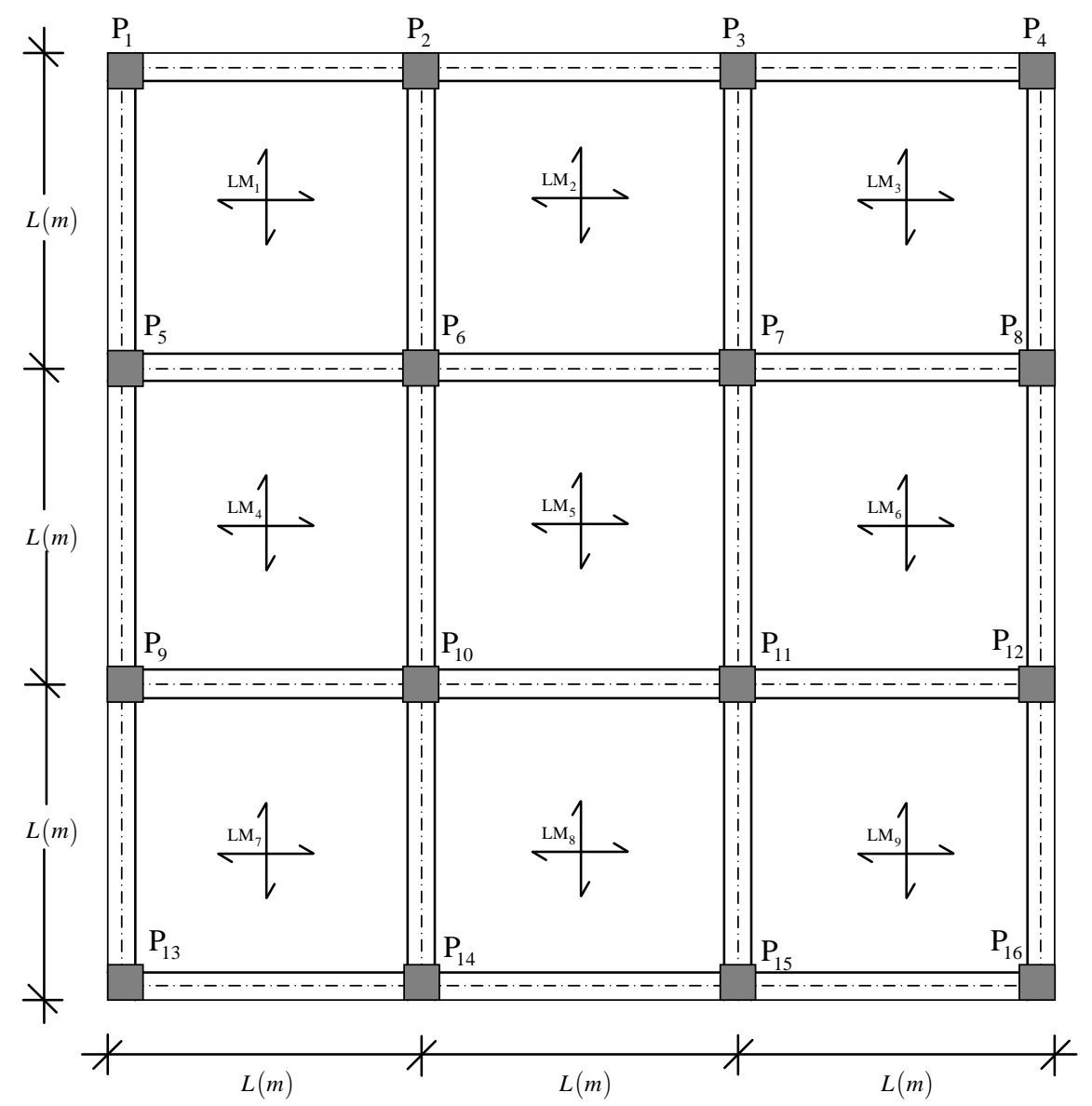

Figura 3.2 - Exemplo de um painel de lajes acopladas a vigas intermediárias.

$\mathrm{Na}$ presença de acoplamento, ainda teríamos a mesma característica de agrupamentos de autovalores, próximos, mas com dispersão sensível. Com relação aos autovetores, entretanto, não se repete o caso anterior de módulos idênticos em que se observam modos globais. O que se tem agora são modos localizados, com movimentos de amplitudes significativas confinados a certas regiões do sistema, às vezes mesmo em apenas um só módulo, ou uma laje individual. 


\section{Capítulo 4}

\section{Vibrações Não-Lineares de Placas}

\section{1 - Introdução}

Introduzem-se neste capítulo, as equações diferenciais que governam o problema das vibrações não-lineares de placas. Ressalta-se, porém, que este capítulo faz referência aos estudos iniciado por COSTA [22], PAPPALARDO [62] e IDE [40].

Considera-se a não-linearidade geométrica, assim como a inércia à rotação, com as seguintes hipóteses clássicas da Teoria de Segunda Ordem das placas:

a) espessura da placa h é pequena face às outras dimensões.

b) material homogêneo e isótropo.

c) o deslocamento w é da mesma ordem de grandeza da espessura $h$.

d) as tensões normais que atuam em planos paralelos ao plano médio podem ser desprezadas em relação às demais tensões.

e) linearidade física. Isto significa que as deformações serão imediatas e reversíveis, então as relações entre tensões e deformações (equações constitutivas) serão expressas por equações lineares, seguindo válida a Lei de Hooke.

f) as normais à seção transversal indeformada se conservam normais à seção transversal deformada e não há variação de espessura durante a deformação. 
g) as rotações $\theta_{x}$ e $\theta_{y}$ são da ordem da raiz quadrada do módulo das deformações ( $\sqrt{0,001} \cong 0,03)$, apesar de não serem grandes, têm intensidade suficiente para provocar efeitos de segunda ordem, assim pode-se admitir que $\operatorname{sen} \theta=\operatorname{tg} \theta=\theta$ e para o cosseno, adotar-se à $\cos \theta=1-\frac{\theta^{2}}{2}$ que corresponde aos dois primeiros termos da série de Mc-Laurin.

\section{2 - Movimento no Plano}

A Figura 4.1 mostrada abaixo representa as forças que atuam em um elemento plano de chapa nas direções $x$ e $y$. As faces do elemento são perpendiculares ao plano indeformado, e $\mathbf{X}$ e $\mathbf{Y}$ são as forças de volume.

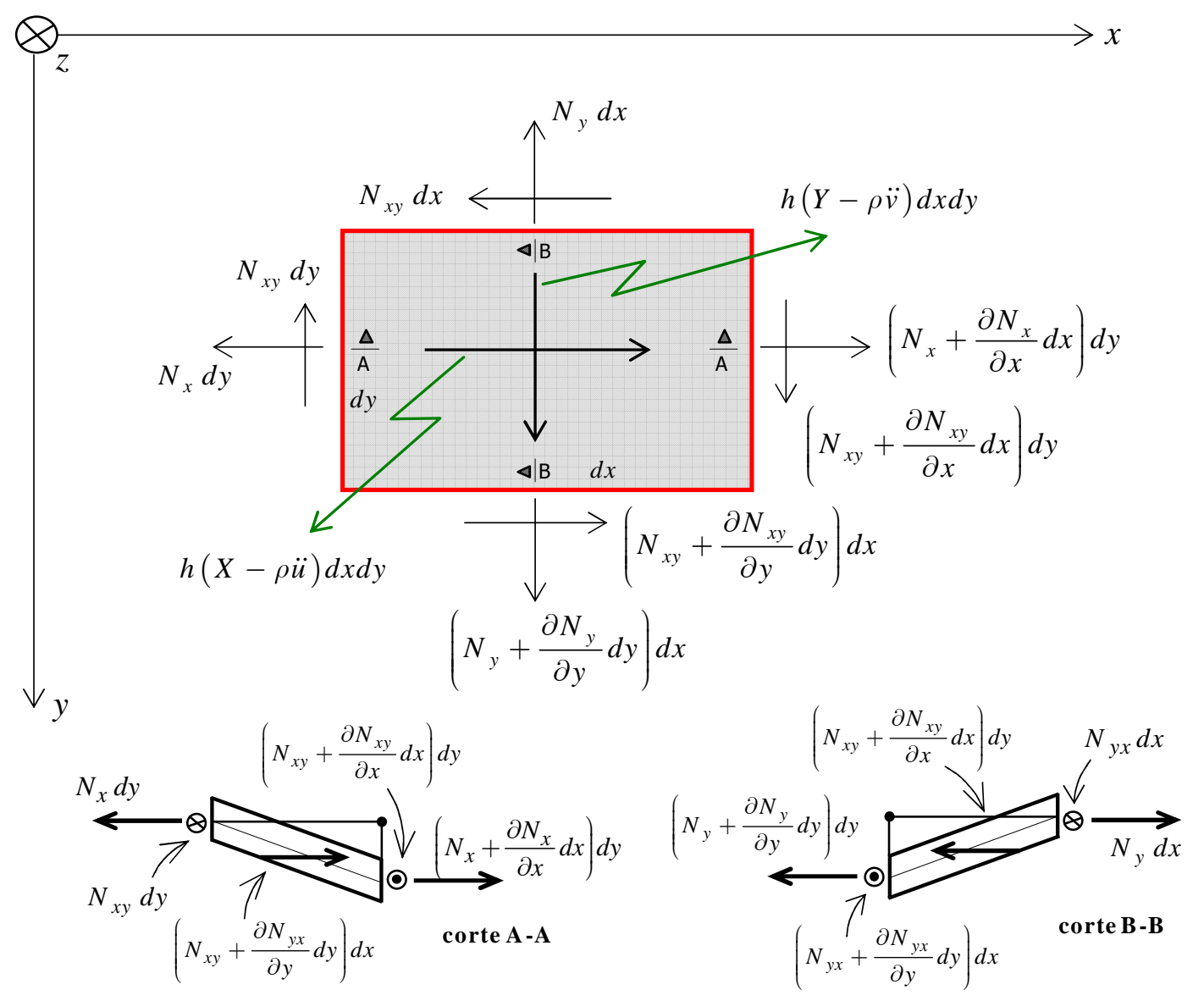

Figura 4.1 - Equilíbrio dinâmico de um elemento de chapa. 
4.2.1 - Equilíbrio de Forças na Direção x

$\left(N_{x}+\frac{\partial N_{x}}{\partial x} d x\right) d y+\left(N_{x y}+\frac{\partial N_{x y}}{\partial y} d y\right) d x+h(X-\rho \ddot{u}) d y d x-N_{x} d y-N_{x y} d x=0$

ou seja:

$\frac{\partial N_{x}}{\partial x}+\frac{\partial N_{x y}}{\partial y}+h(X-\rho \ddot{u})=0$

\subsection{2 - Equilíbrio de Forças na Direção y}

$\left(N_{y}+\frac{\partial N_{y}}{\partial y} d y\right) d x+\left(N_{x y}+\frac{\partial N_{x y}}{\partial x} d x\right) d y+h(Y-\rho \ddot{v}) d y d x-N_{y} d x-N_{x y} d y=0$

ou seja:

$\frac{\partial N_{y}}{\partial y}+\frac{\partial N_{x y}}{\partial x}+h(Y-\rho \ddot{v})=0$

\section{3 - Equações Constitutivas}

As forças de membrana em funções das deformações são dadas por:

$$
\begin{aligned}
& N_{x}=\frac{h E}{1-v^{2}}\left(\varepsilon_{x}+v \varepsilon_{y}\right) \\
& N_{y}=\frac{h E}{1-v^{2}}\left(\varepsilon_{y}+v \varepsilon_{x}\right) \\
& N_{x y}=\frac{h E}{2(1+v)} \gamma_{x y}
\end{aligned}
$$




\section{4 - Relações Deformações - Deslocamentos}

Considerando-se as deformações - deslocamentos não lineares:

$$
\begin{aligned}
& \varepsilon_{x}=\frac{\partial u}{\partial x}+\frac{1}{2}\left(\frac{\partial w}{\partial x}\right)^{2} \\
& \varepsilon_{y}=\frac{\partial v}{\partial y}+\frac{1}{2}\left(\frac{\partial w}{\partial y}\right)^{2} \\
& \gamma_{x y}=\frac{\partial u}{\partial y}+\frac{\partial v}{\partial x}+\left(\frac{\partial w}{\partial x}+\frac{\partial w}{\partial y}\right)
\end{aligned}
$$

Introduzindo as equações (4.4) nas equações (4.3), têm-se as forças de membrana em função dos deslocamentos:

$$
\begin{aligned}
& N_{x}=\frac{h E}{1-v^{2}}\left\{\frac{\partial u}{\partial x}+\frac{1}{2}\left(\frac{\partial w}{\partial x}\right)^{2}+v\left[\frac{\partial v}{\partial y}+\frac{1}{2}\left(\frac{\partial w}{\partial y}\right)^{2}\right]\right\} \\
& N_{y}=\frac{h E}{1-v^{2}}\left\{\frac{\partial v}{\partial y}+\frac{1}{2}\left(\frac{\partial w}{\partial y}\right)^{2}+v\left[\frac{\partial u}{\partial x}+\frac{1}{2}\left(\frac{\partial w}{\partial x}\right)^{2}\right]\right\} \\
& N_{x y}=\frac{h E}{1-v^{2}} \frac{1-v}{2}\left(\frac{\partial u}{\partial y}+\frac{\partial v}{\partial x}+\frac{\partial w}{\partial x}+\frac{\partial w}{\partial y}\right)
\end{aligned}
$$

Nota-se que as forças de membrana receberam uma parcela adicional devido à deformação da superfície média por efeito da flexão. 


\section{5 - Condições de Contorno}

Considere-se o contorno da superfície do plano da chapa dividido em duas partes, $C_{d}$ e $C_{\sigma}$, conforme a Figura 4.2, a seguir:

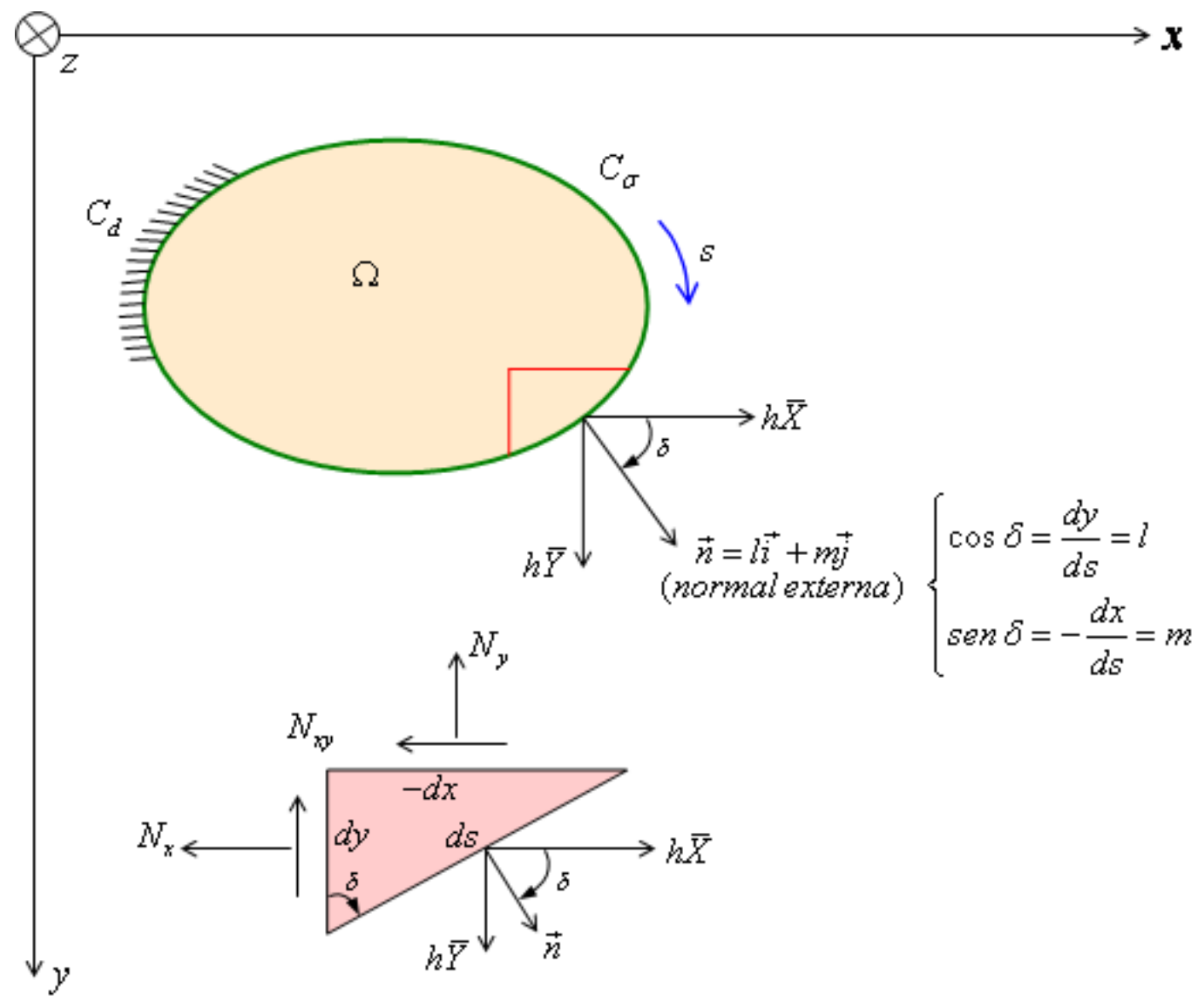

Figura 4.2 - Domínio da chapa.

a) em $C_{d}$ (região de apoio da chapa) os deslocamentos são conhecidos (condições essenciais ou geométricas):

$$
\begin{aligned}
& u=\bar{u}(x, y, t) \\
& v=\bar{v}(x, y, t)
\end{aligned}
$$


b) em $C_{\sigma}$ as forças de membrana se equilibram com o carregamento externo (condições naturais ou estáticas). Do equilíbrio da Figura 4.2, vêm:

$$
\begin{aligned}
& l N_{x}+m N_{x y}=h \bar{X}(x, y, t) \\
& m N_{y}+l N_{x y}=h \bar{Y}(x, y, t)
\end{aligned}
$$

\section{6 - Movimento na Transversal}

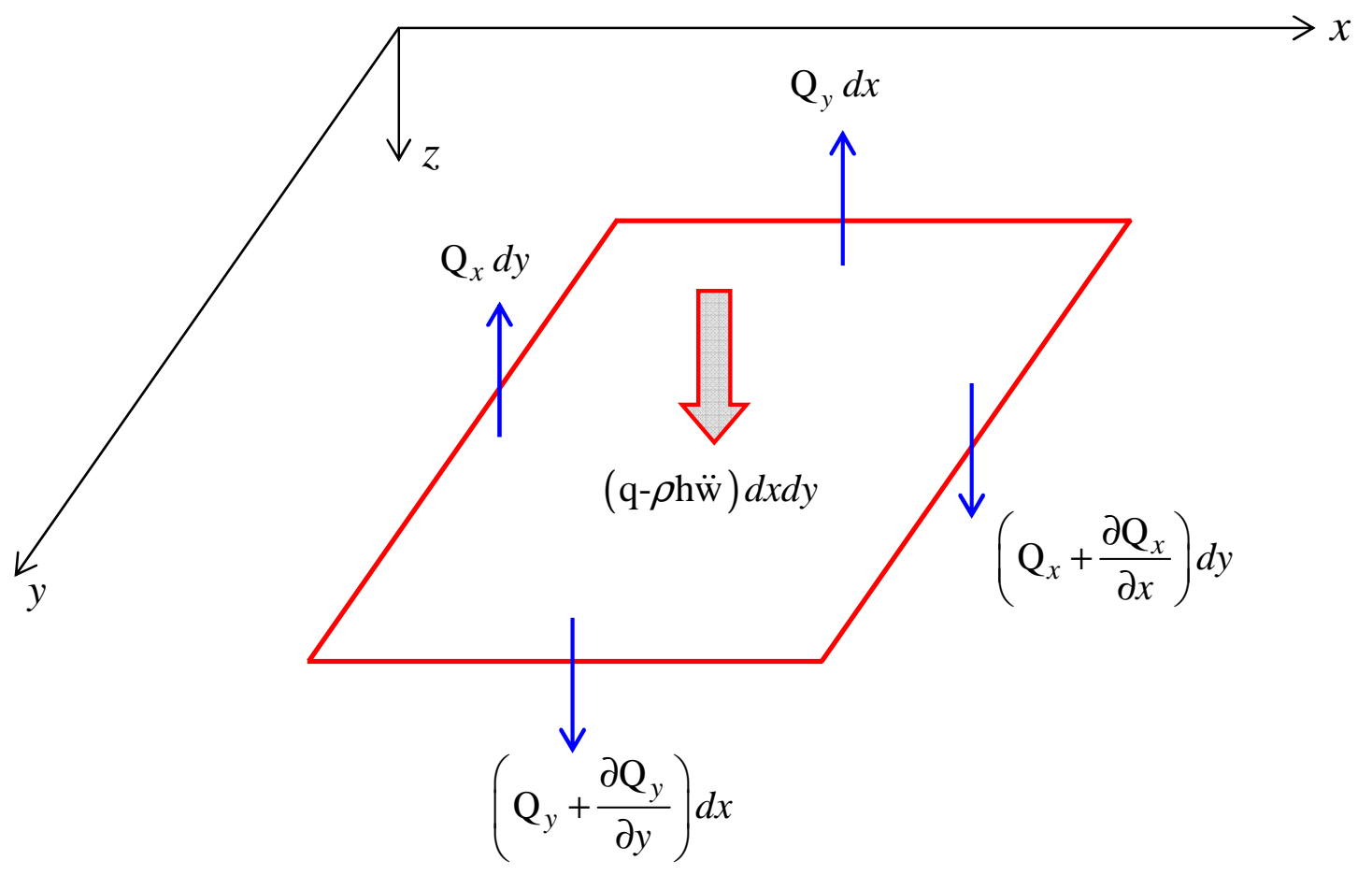

Figura 4.3 - Forças cortantes (por unidade de comprimento). 


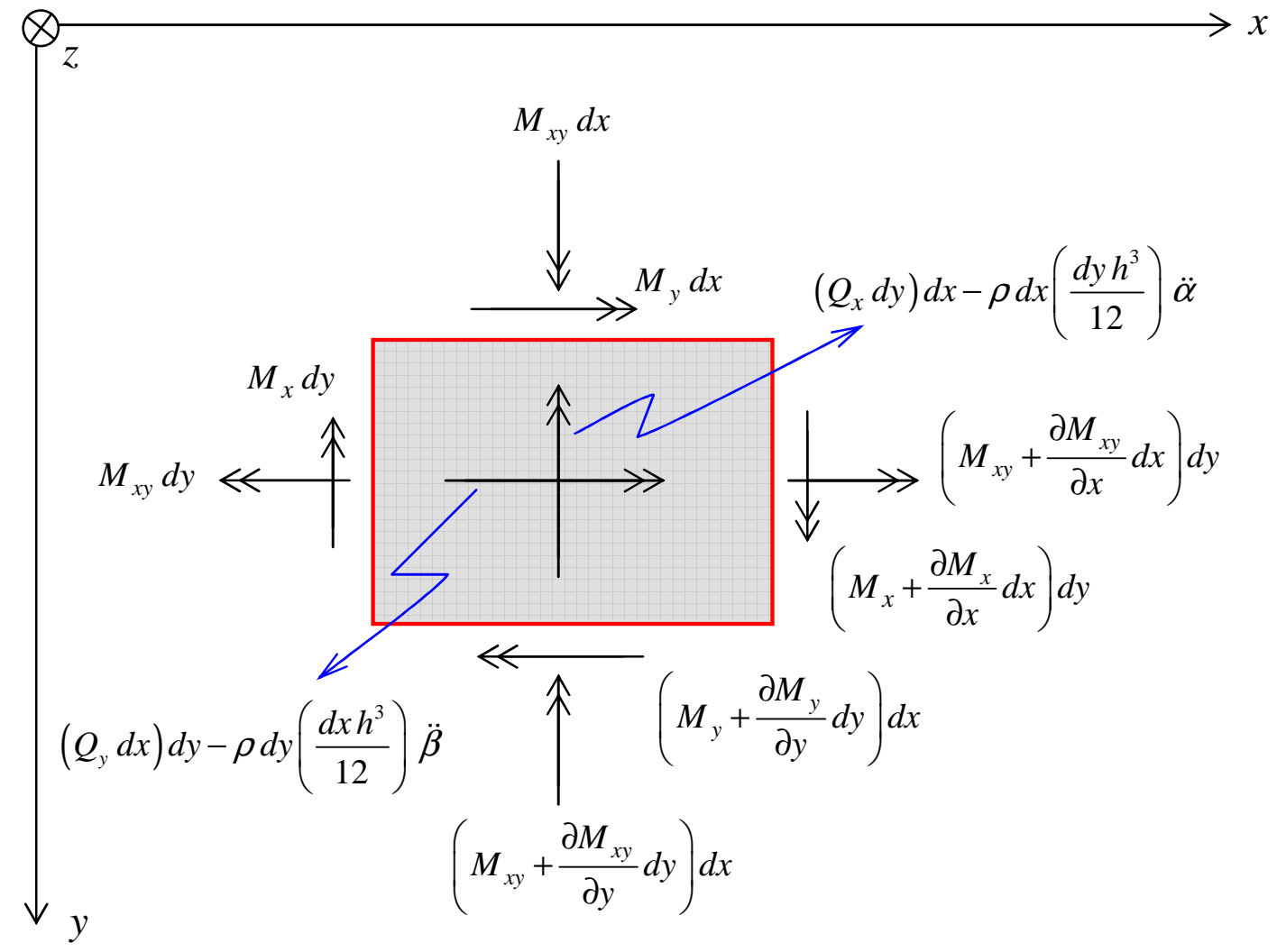

Figura 4.4 - Momentos fletores e de torção (por unidade de comprimento).

\section{7 - Equilíbrio de Forças na Direção Transversal à Placa}

Seja feito, na Figura 4.1 um corte no elemento $d x d y$, através de um plano perpendicular ao eixo $y$ :

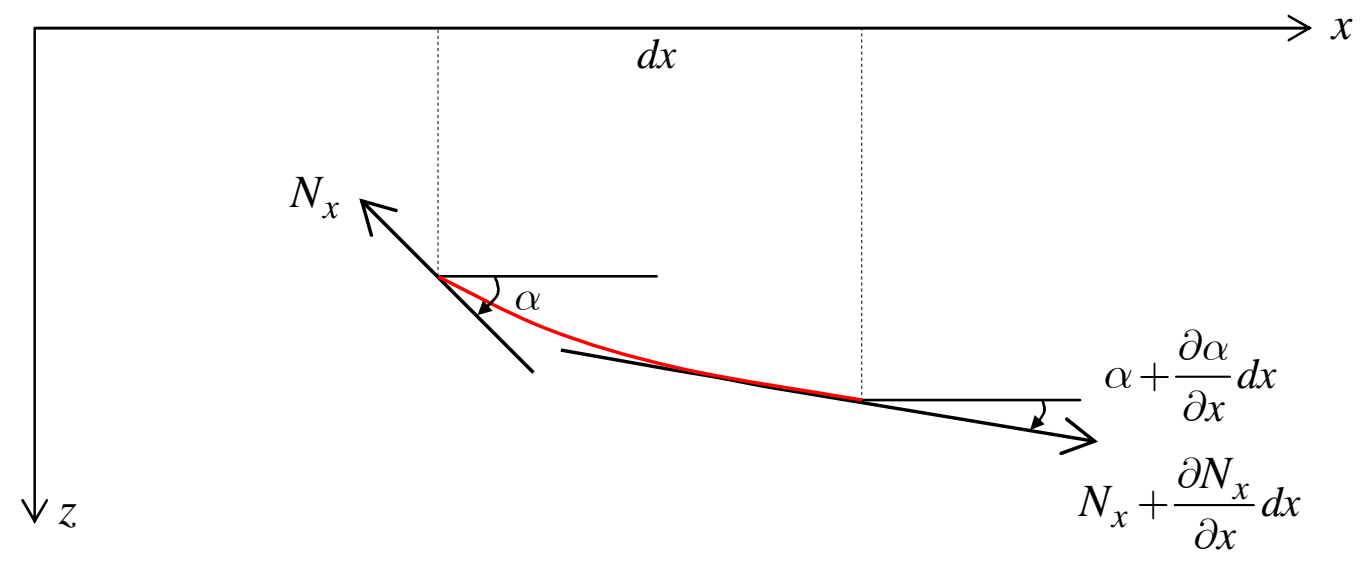

Figura 4.5 - Corte transversal à placa. 
Com base na Figura 4.5, a projeção das forças $N_{x}$ na direção $z$ produz:

$-N_{x} d y \operatorname{sen} \alpha+\left(N_{x}+\frac{\partial N_{x}}{\partial x} d x\right) d y \operatorname{sen}\left(\alpha+\frac{\partial \alpha}{\partial x} d x\right)$

como $\alpha \cong \operatorname{sen} \alpha \cong \operatorname{tg} \beta=\frac{\partial w}{\partial x}$, vem:

$-N_{x} d y \frac{\partial w}{\partial x}+\left(N_{x}+\frac{\partial N_{x}}{\partial x} d x\right) d y\left(\frac{\partial w}{\partial x}+\frac{\partial^{2} w}{\partial x^{2}} d x\right)=$

$=-N_{x} d y \frac{\partial w}{\partial x}+N_{x} \frac{\partial w}{\partial x} d y+N_{x} \frac{\partial^{2} w}{\partial x^{2}} d x d y+\frac{\partial N_{x}}{\partial x} d x d y \frac{\partial w}{\partial x}+\frac{\partial N_{x}}{\partial x} d x \frac{\partial^{2} w}{\partial x^{2}} d x d y$

Desprezando-se os termos de segunda ordem, a expressão fica:

$N_{x} \frac{\partial^{2} w}{\partial x^{2}} d x d y+\frac{\partial N_{x}}{\partial x} \frac{\partial w}{\partial x} d x d y$

Analogamente, a projeção das forças $N_{y}$ na direção $z$ reduz-se a:

$N_{y} \frac{\partial^{2} w}{\partial y^{2}} d x d y+\frac{\partial N_{y}}{\partial y} \frac{\partial w}{\partial y} d x d y$

Por outro lado, a projeção das forças $N_{x y}$ na direção $z$ reduz-se é:

$-N_{x y} d y \operatorname{sen} \beta+\left(N_{x y}+\frac{\partial N_{x y}}{\partial x} d x\right) d y \operatorname{sen}\left(\beta+\frac{\partial \beta}{\partial x} d x\right)$

como $\beta \cong \operatorname{sen} \beta \cong \operatorname{tg} \beta=\frac{\partial w}{\partial y}$, vêm:

$-N_{x y} d y \frac{\partial w}{\partial y}+\left(N_{x y}+\frac{\partial N_{x y}}{\partial x} d x\right) d y \operatorname{sen}\left(\frac{\partial w}{\partial y}+\frac{\partial^{2} w}{\partial x \partial y} d x\right)$ 
Desprezando-se os termos de segunda ordem, a expressão fica:

$$
N_{x y} \frac{\partial^{2} w}{\partial x \partial y} d x d y+\frac{\partial N_{x y}}{\partial x} \frac{\partial w}{\partial y} d x d y
$$

Uma expressão análoga pode ser obtida para a projeção das forças $N_{y x}=N_{x y}$ na vertical. A soma das projeções das forças $N_{y x}=N_{x y}$ resulta no seguinte:

$$
2 N_{x y} \frac{\partial^{2} w}{\partial x \partial y} d x d y+\left(\frac{\partial N_{x y}}{\partial x} \frac{\partial w}{\partial y}+\frac{\partial N_{x y}}{\partial y} \frac{\partial w}{\partial x}\right) d x d y
$$

Fazendo-se o equilíbrio na direção vertical para o carregamento transversal, obtém-se:

$$
\left(\mathrm{Q}_{x}+\frac{\partial \mathrm{Q}_{x}}{\partial x} d x\right) d y+\left(\mathrm{Q}_{y}+\frac{\partial \mathrm{Q}_{y}}{\partial y} d y\right) d x-\mathrm{Q}_{x} d y+\mathrm{Q}_{y} d x=-(q-\rho h \ddot{w}) d x d y
$$

simplificando vêm:

$$
\frac{\partial \mathrm{Q}_{x}}{\partial x}+\frac{\partial \mathrm{Q}_{y}}{\partial y}+q=\rho h \ddot{w}
$$

As expressões (4.10), (4.11) e (4.13) devem ser adicionadas à expressão (4.14). Fazendo-se isso, a equação de equilíbrio resultante será:

$$
\begin{aligned}
& \frac{\partial \mathrm{Q}_{x}}{\partial x} d x d y+\frac{\partial \mathrm{Q}_{y}}{\partial y} d x d y+q d x d y+N_{x} \frac{\partial^{2} w}{\partial x^{2}} d x d y+\frac{\partial N_{x}}{\partial x} \frac{\partial w}{\partial x} d x d y+N_{y} \frac{\partial^{2} w}{\partial y^{2}} d x d y+ \\
& \frac{\partial N_{y}}{\partial y} \frac{\partial w}{\partial y} d x d y+2 N_{x y} \frac{\partial^{2} w}{\partial x \partial y} d x d y+\left(\frac{\partial N_{x y}}{\partial x} \frac{\partial w}{\partial y}+\frac{\partial N_{x y}}{\partial y} \frac{\partial w}{\partial x}\right) d x d y=\rho h \frac{\partial^{2} w}{\partial t^{2}} d x d y
\end{aligned}
$$

simplificando vêm:

$$
\begin{aligned}
& \frac{\partial \mathrm{Q}_{x}}{\partial x}+\frac{\partial \mathrm{Q}_{y}}{\partial y}+q+N_{x} \frac{\partial^{2} w}{\partial x^{2}}+N_{y} \frac{\partial^{2} w}{\partial y^{2}}+\frac{\partial N_{x}}{\partial x} \frac{\partial w}{\partial x}+\frac{\partial N_{y}}{\partial y} \frac{\partial w}{\partial y}+ \\
& 2 N_{x y} \frac{\partial^{2} w}{\partial x \partial y}+\frac{\partial N_{x y}}{\partial x} \frac{\partial w}{\partial y}+\frac{\partial N_{x y}}{\partial y} \frac{\partial w}{\partial x}=\rho h \ddot{w}
\end{aligned}
$$




\subsection{1 - Equilíbrio de Momentos em torno do eixo x}

Pela $2^{\mathrm{a}}$ Lei de Newton, tem-se que:

$\sum M=I . \theta$

onde:

$\theta$ é a aceleração angular, dada por:

$\theta=\frac{\partial^{2} \beta}{\partial t^{2}}=\frac{\partial^{2}}{\partial t^{2}}\left(\frac{\partial w}{\partial y}\right)=\frac{\partial \ddot{w}}{\partial y}$

$\operatorname{com} \beta=\frac{\partial w}{\partial y}$

Com base nas Figuras (3.5) e (3.6), o equilíbrio de momentos em torno do eixo $x$ produz:

$-\frac{\partial M_{y}}{\partial y} d x d y+\frac{\partial M_{x y}}{\partial x} d x d y+Q_{y} d x d y+I . \theta=\frac{m h^{2}}{12} \theta=\rho d x d y h \frac{h^{2}}{12} \frac{\partial \ddot{w}}{\partial y}$

Simplificando, vêm:

$\frac{\partial M_{x y}}{\partial x}-\frac{\partial M_{y}}{\partial y}+\mathrm{Q}_{y}=\frac{\rho h^{3}}{12} \frac{\partial \ddot{w}}{\partial y}$ 


\subsection{2 - Equilíbrio de Momentos em torno do eixo y}

De maneira análoga ao equilíbrio em torno do eixo $x$, obtém-se:

$\frac{\partial M_{x y}}{\partial y}-\frac{\partial M_{x}}{\partial x}+\mathrm{Q}_{x}=\frac{\rho h^{3}}{12} \frac{\partial \ddot{w}}{\partial x}$

Derivando-se as expressões (4.18) e (4.17), em relação à $x$ e $y$ respectivamente, têm-se:

$$
\begin{aligned}
& \frac{\partial \mathrm{Q}_{x}}{\partial x}=\frac{\partial^{2} M_{x}}{\partial x^{2}}-\frac{\partial^{2} M_{x y}}{\partial x \partial y}+\frac{\rho h^{3}}{12} \frac{\partial^{2} \ddot{w}}{\partial x^{2}} \\
& \frac{\partial \mathrm{Q}_{y}}{\partial y}=\frac{\partial^{2} M_{y}}{\partial y^{2}}-\frac{\partial^{2} M_{x y}}{\partial x \partial y}+\frac{\rho h^{3}}{12} \frac{\partial^{2} \ddot{w}}{\partial y^{2}}
\end{aligned}
$$

Considerando-se as expressões (4.19) e (4.20), a expressão (4.16) se torna:

$$
\begin{aligned}
& \frac{\partial^{2} M_{x}}{\partial x^{2}}-\frac{\partial^{2} M_{x y}}{\partial x \partial y}+\frac{\rho h^{3}}{12} \frac{\partial^{2} \ddot{w}}{\partial x^{2}}+\frac{\partial^{2} M_{y}}{\partial y^{2}}-\frac{\partial^{2} M_{x y}}{\partial x \partial y}+\frac{\rho h^{3}}{12} \frac{\partial^{2} \ddot{w}}{\partial y^{2}}+N_{x} \frac{\partial^{2} w}{\partial x^{2}}+N_{y} \frac{\partial^{2} w}{\partial y^{2}}+ \\
& +q+2 N_{x y} \frac{\partial^{2} w}{\partial x \partial y}+\left(\frac{\partial N_{x}}{\partial x}+\frac{\partial N_{x y}}{\partial y}\right) \frac{\partial w}{\partial x}+\left(\frac{\partial N_{y}}{\partial y}+\frac{\partial N_{x y}}{\partial x}\right) \frac{\partial w}{\partial y}=\rho h \ddot{w}
\end{aligned}
$$

Simplificando essa expressão, teremos:

$$
\begin{aligned}
& \frac{\partial^{2} M_{x}}{\partial x^{2}}-2 \frac{\partial^{2} M_{x y}}{\partial x \partial y}+\frac{\partial^{2} M_{y}}{\partial y^{2}}=-\left[q-\rho h \ddot{w}+N_{x} \frac{\partial^{2} w}{\partial x^{2}}+N_{y} \frac{\partial^{2} w}{\partial y^{2}}+2 N_{x y} \frac{\partial^{2} w}{\partial x \partial y}+\right. \\
& \left.-h(X-\rho \ddot{u}) \frac{\partial w}{\partial x}-h(Y-\rho \ddot{v}) \frac{\partial w}{\partial y}+\frac{\rho h^{3}}{12}\left(\frac{\partial^{4} w}{\partial x^{2} \partial t^{2}}+\frac{\partial^{4} w}{\partial y^{2} \partial t^{2}}\right)\right]
\end{aligned}
$$




\subsection{3 - Condições de Contorno}

As condições de contorno que serão apresentadas a seguir são relativas à equação (4.21).

a) no contorno $C_{d}$ da Figura 4.6 estão as condições de contorno essenciais ou geométricas:

$$
\begin{aligned}
& \mathrm{w}=\overline{\mathrm{w}}(x, y, t) \\
& \frac{\partial \mathrm{w}}{\partial n}=\bar{\theta}(x, y, t)
\end{aligned}
$$

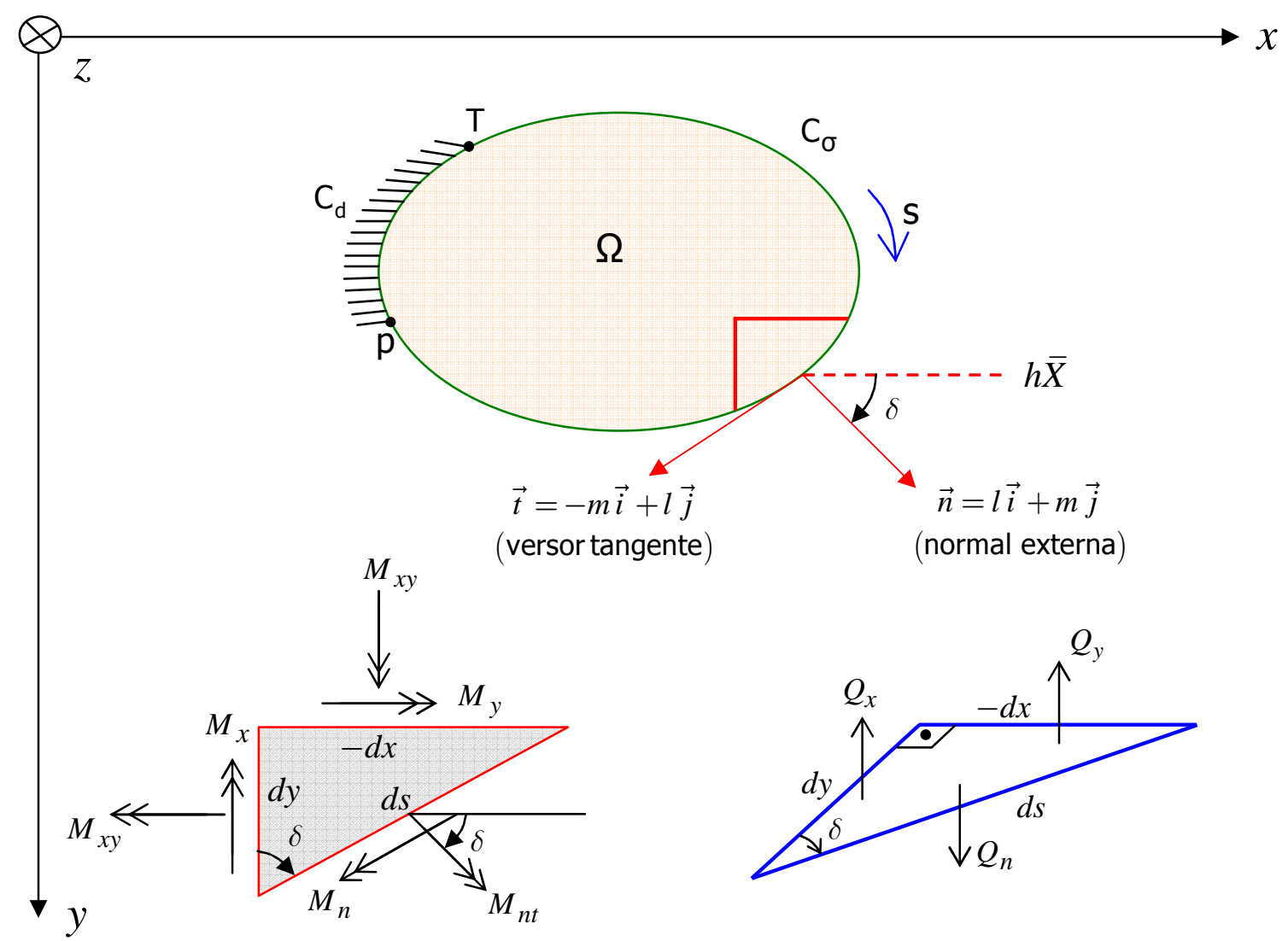

Figura 4.6 - Domínio da placa. 
b) no contorno $C_{\sigma}$ da Figura 4.6, permanecem as condições de contorno naturais ou estáticas:

$$
\begin{aligned}
& M_{n}=\bar{M}_{n}(s, t) \\
& \mathrm{V}_{n}=\overline{\mathrm{V}}_{n}(s, t)-h \bar{X} \frac{\partial w}{\partial x}-h \bar{Y} \frac{\partial w}{\partial y}
\end{aligned}
$$

onde:

$$
\mathrm{V}_{n}=Q_{n}-\frac{\partial M_{n t}}{\partial s}
$$

Serão úteis mais adiante as seguintes outras expressões obtidas no equilíbrio de um elemento infinitesimal em $C_{d}$ :

- Equilíbrio de forças na direção vertical:

$\mathrm{Q}_{n}=\mathrm{Q}_{x} \cos \delta+\mathrm{Q}_{y} \operatorname{sen} \delta$

- Equilíbrio de momentos em torno do eixo $x$ :

$M_{n t} \cos \delta-M_{n} \operatorname{sen} \delta=M_{x y} \cos \delta-M_{y} \operatorname{sen} \delta$

- Equilíbrio de momentos em torno do eixo $y$ :

$M_{n} \cos \delta-M_{n t} \operatorname{sen} \delta=M_{x} \cos \delta-M_{x y} \operatorname{sen} \delta$ 


\subsection{4 - Condições Iniciais}

No instante inicial $(t=0)$ devem ser conhecidos, ao longo do domínio $\Omega$ da placa, os deslocamentos e rotações:

$$
\begin{aligned}
& u(x, y, 0)=u_{0}(x, y) \\
& v(x, y, 0)=v_{0}(x, y) \\
& w(x, y, 0)=w_{0}(x, y) \\
& \theta_{0}^{y}=\frac{\partial w_{0}}{\partial x} \\
& \theta_{0}^{x}=\frac{\partial w_{0}}{\partial y}
\end{aligned}
$$

No instante inicial $(t=0)$ devem ser conhecidas, ao longo do domínio $\Omega$ da placa, as velocidades lineares e angulares:

$$
\begin{aligned}
& \dot{u}(x, y, 0)=\dot{u}_{0}(x, y) \\
& \dot{v}(x, y, 0)=\dot{v}_{0}(x, y) \\
& \dot{w}(x, y, 0)=\dot{w}_{0}(x, y) \\
& \dot{\theta}_{0}^{y}=\frac{\partial \dot{w}_{0}}{\partial x} \\
& \dot{\theta}_{0}^{x}=\frac{\partial \dot{w}_{0}}{\partial y}
\end{aligned}
$$




\section{8 - Semi-Discretização}

\subsection{1 - Introdução}

O Método dos Elementos Finitos é um procedimento para discretização de sistemas contínuos. A solução analítica das equações diferenciais é substituída por uma aproximação constituída de superposição de funções coordenadas, cujos coeficientes multiplicativos são determinados aplicando-se princípios variacionais ou o Método dos Resíduos Ponderados.

Neste trabalho, aplicou-se o Método dos Resíduos Ponderados às equações diferenciais deduzidas nos itens anteriores, levando-se em consideração a hipótese de GALERKIN [34] com relação à função peso. Em seguida, o problema foi discretizado pelo Método dos Elementos Finitos, resultando nas equações diferenciais ordinárias do movimento.

\section{9 - Movimento no Plano}

\subsection{1 - Método dos Resíduos Ponderados (Hipótese de Galerkin)}

As equações (4.1) e (4.2) referem-se a um elemento infinitesimal de área. È necessário transformá-las em equações integrais que, além de incorporarem as condições de contorno naturais (4.8) e (4.9) traduzem o mesmo fenômeno representado pelas equações diferenciais, mas referida agora para toda a chapa.

Para isso, considere-se $\lambda=\lambda(x, y, t)$ uma função arbitrária no espaço e no tempo, contínua e derivável no domínio da chapa, e tal que $\lambda=0$ na fronteira $C_{d}$ em todo qualquer instante.

Multiplicando-se as equações diferenciais (4.1) e (4.2) pela função $\lambda(x, y, t)$, e em seguida, por integração no domínio da chapa, obrem-se as seguintes expressões, respectivamente: 


$$
\begin{aligned}
& \iint_{\Omega} \gamma\left[\frac{\partial N_{x}}{\partial x}+\frac{\partial N_{x y}}{\partial y}+h(X-\rho \ddot{u})\right] d x d y=0 \\
& \iint_{\Omega} \gamma\left[\frac{\partial N_{y}}{\partial y}+\frac{\partial N_{x y}}{\partial x}+h(Y-\rho \ddot{v})\right] d x d y=0
\end{aligned}
$$

Demonstra-se em COSTA [22], se as equações integrais (4.32) e (4.33) se cumprem para qualquer função $\lambda(x, y, t)$, então as equações diferenciais (4.1) e (4.2) respectivamente, serão cumpridas em todo e qualquer ponto de $\Omega$ em qualquer instante (a recíproca é imediata).

Integrando-se por partes as duas primeiras parcelas de (4.32), ver o Anexo B, vêm:

$$
\begin{aligned}
& \iint_{\Omega} \gamma \frac{\partial N_{x}}{\partial x} d x d y=-\iint_{\Omega} \frac{\partial \gamma}{\partial x} N_{x} d x d y+\int_{C \sigma} \gamma N_{x} l d s \\
& \iint_{\Omega} \gamma \frac{\partial N_{x y}}{\partial y} d x d y=-\iint_{\Omega} \frac{\partial \gamma}{\partial y} N_{x y} d x d y+\int_{C \sigma} \gamma N_{x y} m d s
\end{aligned}
$$

Substituindo os resultados acima em (4.32) e (4.33), encontra-se:

$$
\begin{aligned}
& \iint_{\Omega}\left(\frac{\partial \gamma}{\partial x} N_{x}+\frac{\partial \gamma}{\partial y} N_{x y}\right) d x d y=h \iint_{\Omega} \gamma(X-\rho \ddot{u}) d x d y+\int_{C \sigma} \gamma \bar{X} d s \\
& \iint_{\Omega}\left(\frac{\partial \gamma}{\partial y} N_{y}+\frac{\partial \gamma}{\partial x} N_{x y}\right) d x d y=h \iint_{\Omega} \gamma(Y-\rho \ddot{v}) d x d y+\int_{C \sigma} \gamma \bar{Y} d s
\end{aligned}
$$

As equações integrais (4.34) e (4.35) são conhecidas como as formas fracas de (4.32) e (4.33) respectivamente, por serem menos rigorosas na ordem de continuidade na determinação das funções $N_{x}, N_{y}$ e $N_{x y}$. 


\subsection{2 - Método dos Elementos Finitos}

$\mathrm{Na}$ técnica dos elementos finitos o domino da chapa é dividido em pequenas regiões poligonais (elementos finitos), separados entre si pelos seus lados. Os vértices desses elementos são os pontos nodais e são numerados de 1 a n.

Até aqui não houve aproximações. Parte-se agora para a discretização do problema com a introdução dos campos de deslocamento. As variáveis $u$ e $v$ serão aproximadas em funções de seus deslocamentos nodais $u_{j}$ e $v_{j}$ pelas funções de forma $\lambda_{j}$ de classe $C^{o}$. Assim, em notação indicial, a seguinte solução aproximada será considerada:

$u=u_{j} \gamma_{j}$

$v=v_{j} \gamma_{j}$

Usa-se o elemento triangular de deformação constante de chapa em que as funções de forma variam linearmente e se confundem com as coordenadas naturais $L_{1}, L_{2}$ e $L_{3}$.

Para a variável $w$ têm-se outro conjunto de parâmetros nodais e suas respectivas funções de classe $C^{1}$, que são apresentadas no Anexo A.

Será utilizado o elemento de placa proposto por ZIENKIEWICS [82], que possui três deslocamentos por nó, direção $z$ (transversal à placa) e duas rotações segundo os eixos $x$ e $y$, conforme citado em COSTA [22]

Assim o campo de deslocamentos $w$ será aproximado por:

$$
\mathrm{w}=\left(\mathrm{a}^{b}\right)^{t} \Phi=\Phi \mathrm{a}^{b}
$$

sendo que:

$$
\mathbf{a}^{\mathrm{b}}=\left\{\begin{array}{c}
\mathbf{a}_{1}^{\mathrm{b}} \\
\vdots \\
\mathbf{a}_{\mathrm{n}}^{\mathrm{b}}
\end{array}\right\}
$$


é o vetor dos parâmetros nodais, e, cada termo deste vetor é formado pela seguinte seqüência:

$\mathbf{a}_{j}^{b}=\left\{\begin{array}{l}w_{j} \\ \boldsymbol{\theta}_{j}^{x} \\ \boldsymbol{\theta}_{j}^{y}\end{array}\right\}$

é um sub-vetor genérico, com:

$\theta_{j}^{y}=\frac{\partial \mathrm{w}}{\partial x}$ rotação em torno do eixo $\mathrm{x}$

$\theta_{j}^{x}=\frac{\partial \mathrm{w}}{\partial y}$ rotação em torno do eixo y

Temos também que:

$\Phi=\left\{\begin{array}{c}\Phi_{1} \\ \vdots \\ \Phi_{n}\end{array}\right\}$

é o vetor das funções de forma e o sub-vetor genérico é:

$\Phi_{j}=\left\{\begin{array}{l}\phi_{j} \\ \psi_{j} \\ \eta_{j}\end{array}\right\}$

Introduzindo-se (4.36), (4.37) e (4.38) nas expressões (4.5), obtém-se:

$$
\begin{aligned}
& N_{x}=\frac{h E}{1-v^{2}}\left[u_{j} \frac{\partial \gamma_{j}}{\partial x}+v v_{j} \frac{\partial \gamma_{j}}{\partial y}+\frac{1}{2}\left(\mathbf{a}^{b}\right)^{t} \mathbf{A} \mathbf{a}^{b}+\frac{v}{2} \mathbf{B} \mathbf{a}^{b}\right] \\
& N_{y}=\frac{h E}{1-v^{2}}\left[v_{j} \frac{\partial \gamma_{j}}{\partial y}+v u_{j} \frac{\partial \gamma_{j}}{\partial x}+\frac{1}{2}\left(\mathbf{a}^{b}\right)^{t} \mathbf{B} \mathbf{a}^{b}+\frac{v}{2} \mathbf{A} \mathbf{a}^{b}\right] \\
& N_{x y}=\frac{h E}{1-v^{2}} \frac{1-v}{2}\left[u_{j} \frac{\partial \gamma_{j}}{\partial y}+v_{j} \frac{\partial \gamma_{j}}{\partial x}+\frac{1}{2}\left(\mathbf{a}^{b}\right)^{t} \mathbf{C} \mathbf{a}^{b}\right]
\end{aligned}
$$


onde se definem:

$$
\begin{aligned}
& \mathbf{A}=\frac{\partial \Phi}{\partial x} \frac{\partial \Phi^{t}}{\partial x} \\
& \mathbf{B}=\frac{\partial \Phi}{\partial y} \frac{\partial \Phi^{t}}{\partial y} \\
& \mathbf{C}=\frac{\partial \Phi}{\partial x} \frac{\partial \Phi^{t}}{\partial y}+\frac{\partial \Phi}{\partial y} \frac{\partial \Phi^{t}}{\partial x}
\end{aligned}
$$

Substituindo-se as interpolações (4.36) e (4.37), bem como as expressões (4.43), (4.44) e (4.45), nas formas fracas (4.34) e (4.35), fazendo-se nestas últimas, sucessivamente, a função de ponderação $\lambda$ igual a cada uma das funções de forma $\lambda_{i}$ (hipótese de GALERKIN [34]), usadas para interpolar os deslocamentos no plano, pois se trata de equilíbrio no plano, obtém-se:

$$
\begin{aligned}
& \frac{h E}{1-\nu^{2}}\left[\iint_{\Omega} u_{j}\left(\frac{\partial \gamma_{i}}{\partial x} \frac{\partial \gamma_{j}}{\partial x}+\frac{1-\nu}{2} \frac{\partial \gamma_{i}}{\partial y} \frac{\partial \gamma_{j}}{\partial y}\right) d x d y+\iint_{\Omega} v_{j}\left(\nu \frac{\partial \gamma_{i}}{\partial x} \frac{\partial \gamma_{j}}{\partial y}+\frac{1-\nu}{2} \frac{\partial \gamma_{i}}{\partial y} \frac{\partial \gamma_{j}}{\partial x}\right) d x d y\right]+ \\
& +\frac{h E}{2\left(1-\nu^{2}\right)} \iint_{\Omega}\left[\frac{\partial \gamma_{i}}{\partial x}\left(\mathrm{a}^{b}\right)^{t} \frac{\partial \Phi}{\partial x} \frac{\partial \Phi^{t}}{\partial x} \mathrm{a}^{b}+\nu \frac{\partial \gamma_{i}}{\partial x}\left(\mathrm{a}^{b}\right)^{t} \frac{\partial \Phi}{\partial y} \frac{\partial \Phi^{t}}{\partial y} \mathrm{a}^{b}+\right. \\
& \left.\frac{1-\nu}{2} \frac{\partial \gamma_{i}}{\partial y}\left(\mathrm{a}^{b}\right)^{t}\left(\frac{\partial \Phi}{\partial x} \frac{\partial \Phi^{t}}{\partial y}+\frac{\partial \Phi}{\partial y} \frac{\partial \Phi^{t}}{\partial x}\right) \mathrm{a}^{b}\right] d x d y= \\
& =h \int_{\Omega} \gamma_{i} X d x d y+h \int_{C \sigma} \gamma_{i} \bar{X} d s-\rho h \iint_{\Omega} \gamma_{i} \gamma_{j} \frac{\partial^{2} u_{j}}{\partial t^{2}} d x d y
\end{aligned}
$$

$$
\begin{aligned}
& \frac{h E}{1-\nu^{2}}\left[\iint_{\Omega} u_{j}\left(\nu \frac{\partial \gamma_{i}}{\partial y} \frac{\partial \gamma_{j}}{\partial x}+\frac{1-\nu}{2} \frac{\partial \gamma_{i}}{\partial x} \frac{\partial \gamma_{j}}{\partial y}\right) d x d y+\iint_{\Omega} v_{j}\left(\frac{\partial \gamma_{i}}{\partial y} \frac{\partial \gamma_{j}}{\partial y}+\frac{1-\nu}{2} \frac{\partial \gamma_{i}}{\partial x} \frac{\partial \gamma_{j}}{\partial x}\right) d x d y\right]+ \\
& +\frac{h E}{2\left(1-\nu^{2}\right)} \iint_{\Omega}\left[\frac{\partial \gamma_{i}}{\partial y}\left(\mathbf{a}^{b}\right)^{t} \frac{\partial \Phi}{\partial y} \frac{\partial \Phi^{t}}{\partial y} \mathbf{a}^{b}+\nu \frac{\partial \gamma_{i}}{\partial y}\left(\mathbf{a}^{b}\right)^{t} \frac{\partial \Phi}{\partial x} \frac{\partial \Phi^{t}}{\partial x} \mathbf{a}^{b}+\right. \\
& \left.\frac{1-\nu}{2} \frac{\partial \gamma_{i}}{\partial x}\left(\mathbf{a}^{b}\right)^{t}\left(\frac{\partial \Phi}{\partial x} \frac{\partial \Phi^{t}}{\partial y}+\frac{\partial \Phi}{\partial y} \frac{\partial \Phi^{t}}{\partial x}\right) \mathbf{a}^{b}\right] d x d y= \\
& =h \iint_{\Omega} \gamma_{i} Y d x d y+h \int_{C \sigma} \gamma_{i} \bar{Y} d s-\rho h \iint_{\Omega} \gamma_{i} \gamma_{j} \frac{\partial^{2} v_{j}}{\partial t^{2}} d x d y
\end{aligned}
$$




\subsubsection{1 - Formulação Matricial}

O resultado, na forma matricial, será um sistema de $2 n$ equações diferenciais ordinárias e 5 incógnitas:

$$
[\mathbf{M}]^{p}\{\ddot{a}\}^{p}+[\mathbf{K}]_{o}^{p}\{a\}^{p}+[\mathbf{G}]\{a\}^{b}=\{\mathbf{f}\}^{p}
$$

sendo $[\mathbf{K}]_{o}^{p}$ a Matriz de Rigidez do estado plano de tensões dadas por:

$$
[\mathbf{K}]_{o}^{p}=\frac{h E}{1-\nu^{2}}\left[\begin{array}{ccc}
\left(\mathbf{k}_{o}^{p}\right)_{11} & \cdots & \left(\mathbf{k}_{o}^{p}\right)_{1 n} \\
\vdots & & \vdots \\
\left(\mathbf{k}_{o}^{p}\right)_{n 1} & \cdots & \left(\mathbf{k}_{o}^{p}\right)_{n n}
\end{array}\right]
$$

com:

$$
\left(\mathbf{k}_{o}^{p}\right)_{i j}=\left[\begin{array}{ll}
\left(k_{o}^{p}\right)_{i j}^{11} & \left(k_{o}^{p}\right)_{i j}^{12} \\
\left(k_{o}^{p}\right)_{i j}^{21} & \left(k_{o}^{p}\right)_{i j}^{22}
\end{array}\right]
$$

sendo:

$$
\begin{aligned}
\left(k_{o}^{p}\right)_{i j}^{11} & =\iint_{\Omega}\left(\frac{\partial \gamma_{i}}{\partial x} \frac{\partial \gamma_{j}}{\partial x}+\frac{1-\nu}{2} \frac{\partial \gamma_{i}}{\partial y} \frac{\partial \gamma_{j}}{\partial y}\right) d x d y \\
\left(k_{o}^{p}\right)_{i j}^{12} & =\iint_{\Omega}\left(\nu \frac{\partial \gamma_{i}}{\partial x} \frac{\partial \gamma_{j}}{\partial y}+\frac{1-\nu}{2} \frac{\partial \gamma_{i}}{\partial y} \frac{\partial \gamma_{j}}{\partial x}\right) d x d y \\
\left(k_{o}^{p}\right)_{i j}^{21} & =\iint_{\Omega}\left(\nu \frac{\partial \gamma_{i}}{\partial y} \frac{\partial \gamma_{j}}{\partial x}+\frac{1-\nu}{2} \frac{\partial \gamma_{i}}{\partial x} \frac{\partial \gamma_{j}}{\partial y}\right) d x d y \\
\left(k_{o}^{p}\right)_{i j}^{22} & =\iint_{\Omega}\left(\frac{\partial \gamma_{i}}{\partial y} \frac{\partial \gamma_{j}}{\partial y}+\frac{1-\nu}{2} \frac{\partial \gamma_{i}}{\partial x} \frac{\partial \gamma_{j}}{\partial x}\right) d x d y
\end{aligned}
$$


Por outro lado,

$$
\begin{array}{rlrl}
\mathbf{a}^{p} & =\left\{\begin{array}{c}
\mathbf{a}_{1}^{p} \\
\vdots \\
\mathbf{a}_{n}^{p}
\end{array}\right\} & \text { com } & \mathbf{a}_{j}^{p}=\left\{\begin{array}{c}
u_{j} \\
v_{j}
\end{array}\right\} \\
\mathbf{a}^{b}=\left\{\begin{array}{c}
\mathbf{a}_{1}^{b} \\
\vdots \\
\mathbf{a}_{n}^{b}
\end{array}\right\} & \text { com } & \mathbf{a}_{j}^{p}=\left\{\begin{array}{c}
w_{j} \\
\theta_{j}^{x} \\
\theta_{j}^{y}
\end{array}\right\}
\end{array}
$$

O vetor de carregamento é dado por:

$$
\mathbf{f}^{p}=\left\{\begin{array}{c}
\mathbf{f}_{1}{ }^{p} \\
\vdots \\
\mathbf{f}_{n}^{p}
\end{array}\right\} \quad \text { com } \quad \mathbf{f}_{j}^{p}=\left\{\begin{array}{l}
F_{i}{ }^{x} \\
F_{i}{ }^{p}
\end{array}\right\}
$$

sendo que:

$$
\begin{aligned}
F_{i}^{x} & =h \iint_{\Omega} \gamma_{i} X d x d y+h \int_{\Omega} \gamma_{i} \bar{X} d s \\
F_{i}^{y} & =h \iint_{\Omega} \gamma_{i} Y d x d y+h \int_{\Omega} \gamma_{i} \bar{Y} d s
\end{aligned}
$$

A matriz $[\mathbf{G}]$ e as submatrizes $\mathbf{G}_{i j}$, são dadas respectivamente por:

$$
\mathbf{G}=\left[\begin{array}{ccc}
\mathbf{G}_{11} & \cdots & \mathbf{G}_{1 n} \\
\vdots & & \vdots \\
\mathbf{G}_{n 1} & \cdots & \mathbf{G}_{n n}
\end{array}\right]
$$

onde:

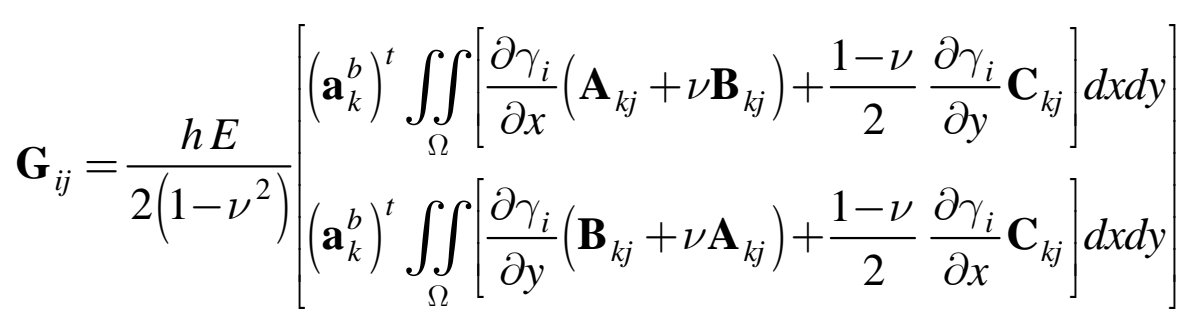


onde:
$\mathbf{A}_{k j}=\frac{\partial \Phi_{k}}{\partial x} \frac{\partial \Phi_{j}^{t}}{\partial x}$
$\mathbf{B}_{k j}=\frac{\partial \Phi_{k}}{\partial y} \frac{\partial \Phi_{j}^{t}}{\partial y}$
$\mathbf{C}_{k j}=\frac{\partial \Phi_{k}}{\partial x} \frac{\partial \Phi_{j}^{t}}{\partial y}+\frac{\partial \Phi_{k}}{\partial y} \frac{\partial \Phi_{j}^{t}}{\partial x}$

são submatrizez de ordem $3 \times 3$ de $\mathbf{A}, \mathbf{B}$ e $\mathbf{C}$.

Portanto $\mathbf{G}_{i j}$ é de ordem $2 \times 3$. A submatriz $\mathbf{G}_{i j}$ será diferente de zero apenas nos elementos que contenham $P_{i}$ e $P_{j}$ simultaneamente. Por outro lado, em cada elemento finito onde $\mathbf{G}_{i j} \neq 0$, o índice mudo $\mathrm{k}$, que comparece na expressão de $\mathbf{G}_{i j}$, assume apenas os valores correspondentes aos nós do elemento.

A matriz $[\mathbf{M}]^{p}$ é a conhecida como Matriz de Massa do estado plano de tensão:

$\mathbf{M}^{p}=\left[\begin{array}{ccc}\mathbf{M}_{11}^{p} & \cdots & \mathbf{M}_{1 n}^{p} \\ \vdots & & \vdots \\ \mathbf{M}_{n 1}^{p} & \cdots & \mathbf{M}_{n n}^{p}\end{array}\right]$

com:

$\mathbf{M}_{i j}^{p}=\left[\begin{array}{cc}\mathbf{M}_{i j}^{p} & 0 \\ 0 & \mathbf{M}_{i j}^{p}\end{array}\right]$

sendo:

$\mathbf{M}_{i j}^{p}=\rho h \iint_{\Omega} \gamma_{i} \gamma_{j} d x d y$ 


\subsection{0 - Movimento na Transversal}

\subsection{1 - Método dos Resíduos Ponderados (Hipótese de Galerkin)}

A aplicação do Método dos Elementos Finitos exige como condição prévia, a transformação da equação diferencial do movimento (4.21) em uma equação integral equivalente. Para isso, considere uma função $\psi=\psi(x, y, t)$, arbitrária no espaço e no tempo, contínua e duas vezes derivável no domínio da placa, e tal que, ao longo de $C_{d}$ em qualquer instante, ocorra:

$$
\psi=0 \quad \text { e } \quad \frac{\partial \psi}{\partial n}=0
$$

donde:

$$
\frac{\partial \psi}{\partial x}=\frac{\partial \psi}{\partial y}=0 \quad \text { em } \quad C_{d}
$$

Em seguida, multipliquem-se ambos os membros de (4.21) pela função $\psi$. Logo após, por integração no domínio da placa, obtém-se:

$$
\begin{aligned}
& \iint_{\Omega} \psi\left(\frac{\partial^{2} \mathbf{M}_{x}}{\partial x^{2}}-2 \frac{\partial^{2} \mathbf{M}_{x y}}{\partial x \partial y}+\frac{\partial^{2} \mathbf{M}_{x}}{\partial y^{2}}\right) d x d y+\iint_{\Omega} \psi q d x d y= \\
& =-\iint_{\Omega} \psi\left(N_{x} \frac{\partial^{2} \mathrm{w}}{\partial x^{2}}+N_{y} \frac{\partial^{2} \mathrm{w}}{\partial y^{2}}+2 N_{x y} \frac{\partial^{2} \mathrm{w}}{\partial x \partial y}\right) d x d y+\iint_{\Omega} \psi\left(h X \frac{\partial \mathrm{w}}{\partial x}+h Y \frac{\partial \mathrm{w}}{\partial y}\right) d x d y+ \\
& +\iint_{\Omega} \psi \rho h \frac{\partial^{2} \mathrm{w}}{\partial x^{2}} d x d y-\iint_{\Omega} \psi\left(\frac{\partial^{4} \mathrm{w}}{\partial y^{2} \partial t^{2}}+\frac{\partial^{4} \mathrm{w}}{\partial x^{2} \partial t^{2}}\right) \frac{\rho h^{3}}{12} d x d y+ \\
& -\iint_{\Omega} \psi \rho h\left(\frac{\partial^{2} u}{\partial t^{2}} \frac{\partial w}{\partial x}+\frac{\partial^{2} v}{\partial t^{2}} \frac{\partial w}{\partial y}\right) d x d y
\end{aligned}
$$


Agora é feita a integração por partes da primeira integral de (4.66), ou seja:

$$
\begin{aligned}
& \iint_{\Omega} \psi \frac{\partial^{2} \mathbf{M}_{x}}{\partial x^{2}} d x d y=\int_{C \sigma} \psi \frac{\partial \mathbf{M}_{x}}{\partial x} \cos \delta d s-\iint_{\Omega} \frac{\partial \psi}{\partial x} \frac{\partial \mathbf{M}_{x}}{\partial x} d x d y= \\
& =\int_{C \sigma} \psi \frac{\partial \mathbf{M}_{x}}{\partial x} \cos \delta d s-\int_{C \sigma} \frac{\partial \psi}{\partial x} \mathbf{M}_{x} \cos \delta d s+\iint_{\Omega} \frac{\partial^{2} \psi}{\partial x^{2}} \mathbf{M}_{x} d x d y \\
& \iint_{\Omega} \psi \frac{\partial^{2} \mathbf{M}_{y}}{\partial y^{2}} d x d y=\int_{C \sigma} \psi \frac{\partial \mathbf{M}_{y}}{\partial x} \operatorname{sen} \delta d s-\iint_{\Omega} \frac{\partial \psi}{\partial y} \frac{\partial \mathbf{M}_{y}}{\partial y} d x d y= \\
& =\int_{C \sigma} \psi \frac{\partial \mathbf{M}_{y}}{\partial y} \operatorname{sen} \delta d s-\int_{C \sigma} \frac{\partial \psi}{\partial y} \mathbf{M}_{y} \operatorname{sen} \delta d s+\iint_{\Omega} \frac{\partial^{2} \psi}{\partial y^{2}} \mathbf{M}_{y} d x d y \\
& \iint_{\Omega} \psi \frac{\partial^{2} \mathbf{M}_{x y}}{\partial x \partial y} d x d y=\int_{C \sigma} \psi \frac{\partial \mathbf{M}_{x y}}{\partial y} \cos \delta d s-\iint_{\Omega} \frac{\partial \psi}{\partial x} \frac{\partial \mathbf{M}_{x y}}{\partial y} d x d y= \\
& =\int_{C \sigma} \psi \frac{\partial \mathbf{M}_{x y}}{\partial y} \cos \delta d s-\int_{C \sigma} \frac{\partial \psi}{\partial x} \mathbf{M}_{x y} \operatorname{sen} \delta d s+\iint_{\Omega} \frac{\partial^{2} \psi}{\partial x \partial y} \mathbf{M}_{x y} d x d y \\
& \iint_{\Omega} \psi \frac{\partial^{2} \mathbf{M}_{x y}}{\partial y \partial x} d x d y=\int_{C \sigma} \psi \frac{\partial \mathbf{M}_{x y}}{\partial x} \operatorname{sen} \delta d s-\iint_{\Omega} \frac{\partial \psi}{\partial y} \frac{\partial \mathbf{M}_{x y}}{\partial x} d x d y= \\
& =\int_{C \sigma} \psi \frac{\partial \mathbf{M}_{x y}}{\partial x} \operatorname{sen} \delta d s-\int_{C \sigma} \frac{\partial \psi}{\partial y} \mathbf{M}_{x y} \cos \delta d s+\iint_{\Omega} \frac{\partial^{2} \psi}{\partial y \partial x} \mathbf{M}_{x y} d x d y
\end{aligned}
$$

Somando-se as duas últimas expressões, vêm:

$$
\begin{aligned}
& 2 \iint_{\Omega} \psi \frac{\partial^{2} \mathbf{M}_{x y}}{\partial x \partial y} d x d y=\int_{C \sigma} \psi\left(\frac{\partial \mathbf{M}_{x y}}{\partial y} \cos \delta+\frac{\partial \mathbf{M}_{x y}}{\partial x} \operatorname{sen} \delta\right) d s+ \\
& -\int_{C \sigma} \mathbf{M}_{x y}\left(\frac{\partial \psi}{\partial x} \operatorname{sen} \delta+\frac{\partial \psi}{\partial y} \cos \delta\right) d s+2 \iint_{\Omega} \frac{\partial^{2} \psi}{\partial x \partial y} \mathbf{M}_{x y} d x d y
\end{aligned}
$$


Com esses resultados, têm-se para o lado esquerdo de (4.66):

$$
\begin{aligned}
& \iint_{\Omega} \psi\left(\frac{\partial^{2} \mathbf{M}_{x}}{\partial x^{2}}-2 \frac{\partial^{2} \mathbf{M}_{x y}}{\partial x \partial y}+\frac{\partial^{2} \mathbf{M}_{y}}{\partial y^{2}}\right) d x d y+\iint_{\Omega} \psi q d x d y= \\
& =\iint_{\Omega}\left(\frac{\partial^{2} \psi}{\partial x^{2}} \mathbf{M}_{x}+\frac{\partial^{2} \psi}{\partial y^{2}} \mathbf{M}_{y}-2 \frac{\partial^{2} \psi}{\partial x \partial y} \mathbf{M}_{x y}\right) d x d y+ \\
& +\int_{C \sigma} \psi\left(\frac{\partial \mathbf{M}_{x}}{\partial x} \cos \delta+\frac{\partial \mathbf{M}_{y}}{\partial y} \operatorname{sen} \delta-\frac{\partial \mathbf{M}_{x y}}{\partial y} \cos \delta-\frac{\partial \mathbf{M}_{x y}}{\partial x} \operatorname{sen} \delta\right) d s+ \\
& -\int_{C \sigma} \frac{\partial \psi}{\partial x}\left(\mathbf{M}_{x} \cos \delta-\mathbf{M}_{x y} \operatorname{sen} \delta\right) d s-\int_{C \sigma} \frac{\partial \psi}{\partial y}\left(\mathbf{M}_{y} \operatorname{sen} \delta-\mathbf{M}_{x y} \cos \delta\right) d s+\iint_{\Omega} \psi q d x d y
\end{aligned}
$$

Substituindo-se no segundo membro dessa identidade, as expressões (4.27), (4.28) e (4.29) com (4.17) e (4.18), obtém-se:

$$
\begin{aligned}
& \iint_{\Omega} \psi\left(\frac{\partial^{2} \mathbf{M}_{x}}{\partial x^{2}}-2 \frac{\partial^{2} \mathbf{M}_{x y}}{\partial x \partial y}+\frac{\partial^{2} \mathbf{M}_{y}}{\partial y^{2}}\right) d x d y+\iint_{\Omega} \psi q d x d y= \\
& =\iint_{\Omega}\left(\frac{\partial^{2} \psi}{\partial x^{2}} \mathbf{M}_{x}+\frac{\partial^{2} \psi}{\partial y^{2}} \mathbf{M}_{y}-2 \frac{\partial^{2} \psi}{\partial x \partial y} \mathbf{M}_{x y}\right) d x d y-\int_{C \sigma}\left(\psi \frac{\rho h^{3}}{12} \frac{\partial^{3} w}{\partial x \partial t^{2}} \cos \delta\right) d s \\
& -\int_{C \sigma} \psi\left(Q_{n}-\frac{\rho h^{3}}{12} \frac{\partial^{3} w}{\partial x \partial t^{2}} \cos \delta-\frac{\rho h^{3}}{12} \frac{\partial^{3} w}{\partial x \partial t^{2}} \operatorname{sen} \delta\right) d s+ \\
& -\int_{C \sigma} \frac{\partial \psi}{\partial x}\left(M_{n} \cos \delta+M_{n t} \operatorname{sen} \delta\right) d s-\int_{C \sigma} \frac{\partial \psi}{\partial y}\left(M_{n} \operatorname{sen} \delta-M_{n t} \cos \delta\right) d s+\iint_{\Omega} \psi q d x d y
\end{aligned}
$$

Reorganizando-se os termos da identidade anterior, virá:

$$
\begin{aligned}
& \iint_{\Omega} \psi\left(\frac{\partial^{2} \mathbf{M}_{x}}{\partial x^{2}}-2 \frac{\partial^{2} \mathbf{M}_{x y}}{\partial x \partial y}+\frac{\partial^{2} \mathbf{M}_{y}}{\partial y^{2}}\right) d x d y+\iint_{\Omega} \psi q d x d y= \\
& =\iint_{\Omega}\left(\frac{\partial^{2} \psi}{\partial x^{2}} \mathbf{M}_{x}+\frac{\partial^{2} \psi}{\partial y^{2}} \mathbf{M}_{y}-2 \frac{\partial^{2} \psi}{\partial x \partial y} \mathbf{M}_{x y}\right) d x d y-\int_{C \sigma}\left(\psi \frac{\rho h^{3}}{12} \frac{\partial^{3} w}{\partial x \partial t^{2}} \cos \delta\right) d s \\
& -\int_{C \sigma} \psi \frac{\rho h^{3}}{12} \frac{\partial^{3} w}{\partial y \partial t^{2}} \operatorname{sen} \delta+\int_{C \sigma} \psi \mathbf{Q}_{n} d s-\int_{C \sigma} M_{n}\left(\frac{\partial \psi}{\partial x} \cos \delta+\frac{\partial \psi}{\partial y} \operatorname{sen} \delta\right) d s+ \\
& +\int_{C \sigma} M_{n t}\left(-\frac{\partial \psi}{\partial x} \operatorname{sen} \delta+\frac{\partial \psi}{\partial y} \cos \delta\right) d s+\iint_{\Omega} \psi q d x d y
\end{aligned}
$$


Considerando que (Figura 4.6):

$$
\left\{\begin{array}{l}
\vec{n}=\cos \delta \vec{i}+\operatorname{sen} \delta \vec{j} \\
\vec{t}=-\operatorname{sen} \delta \vec{i}+\cos \delta \vec{j}
\end{array}\right.
$$

teremos as seguintes expressões

$$
\left\{\begin{array}{l}
\frac{\partial \psi}{\partial n}=\operatorname{grad} \psi \times \vec{n}=\frac{\partial \psi}{\partial x} \cos \delta+\frac{\partial \psi}{\partial y} \operatorname{sen} \delta \\
\frac{\partial \psi}{\partial s}=\operatorname{grad} \psi \times \vec{t}=\frac{\partial \psi}{\partial x}(-\operatorname{sen} \delta)+\frac{\partial \psi}{\partial y} \cos \delta
\end{array}\right.
$$

que substituídas nas expressões integral anterior produzirão:

$$
\begin{aligned}
& \iint_{\Omega} \psi\left(\frac{\partial^{2} \mathbf{M}_{x}}{\partial x^{2}}-2 \frac{\partial^{2} \mathbf{M}_{x y}}{\partial x \partial y}+\frac{\partial^{2} \mathbf{M}_{y}}{\partial y^{2}}\right) d x d y+\iint_{\Omega} \psi q d x d y= \\
& =\iint_{\Omega}\left(\frac{\partial^{2} \psi}{\partial x^{2}} \mathbf{M}_{x}+\frac{\partial^{2} \psi}{\partial y^{2}} \mathbf{M}_{y}-2 \frac{\partial^{2} \psi}{\partial x \partial y} \mathbf{M}_{x y}\right) d x d y+\int_{C \sigma} \psi \mathrm{Q}_{n} d s+ \\
& -\int_{C \sigma} \psi \frac{\rho h^{3}}{12}\left(\frac{\partial^{3} \mathrm{w}}{\partial x \partial t^{2}} \cos \delta+\frac{\partial^{3} \mathrm{w}}{\partial y \partial t^{2}} \operatorname{sen} \delta\right) d s-\int_{C \sigma} \mathbf{M}_{n} \frac{\partial \psi}{\partial n} d s+\int_{C \sigma} \mathbf{M}_{n t} \frac{\partial \psi}{\partial s} d s+\iint_{\Omega} \psi \mathrm{qdxdy}
\end{aligned}
$$

Integrando-se por partes (Anexo B), na região $C_{\sigma}$ do contorno, a penúltima integral da expressão anterior, vêm:

$$
\int_{C \sigma} \frac{\partial \psi}{\partial s} \mathbf{M}_{n t} d s=\left[\psi \mathbf{M}_{n t}\right]_{P}^{T}-\int_{C \sigma} \psi \frac{\partial \mathbf{M}_{n t}}{\partial s} d s
$$

como:

$\psi=0$ em $C_{d}(T \leftrightarrow P)$

então:

$\left[\psi M_{n t}\right]_{P}^{T}=0$ 
Assim,

$$
\begin{aligned}
& \iint_{\Omega} \psi\left(\frac{\partial^{2} \mathbf{M}_{x}}{\partial x^{2}}-2 \frac{\partial^{2} \mathbf{M}_{x y}}{\partial x \partial y}+\frac{\partial^{2} \mathbf{M}_{y}}{\partial y^{2}}\right) d x d y+\iint_{\Omega} \psi q d x d y= \\
& =\iint_{\Omega}\left(\frac{\partial^{2} \psi}{\partial x^{2}} \mathbf{M}_{x}+\frac{\partial^{2} \psi}{\partial y^{2}} \mathbf{M}_{y}-2 \frac{\partial^{2} \psi}{\partial x \partial y} \mathbf{M}_{x y}\right) d x d y+\int_{C \sigma} \psi\left[\mathbf{Q}_{n}-\frac{\partial \mathbf{M}_{n t}}{\partial s}\right] d s+ \\
& -\int_{C \sigma} \mathbf{M}_{n t} \frac{\partial \psi}{\partial n} d s+\iint_{\Omega} \psi q d x d y-\frac{\rho h^{3}}{12} \int_{C \sigma} \psi\left(\frac{\partial^{3} \mathrm{w}}{\partial x \partial t^{2}} \cos \delta+\frac{\partial^{3} \mathrm{w}}{\partial y \partial t^{2}} \operatorname{sen} \delta\right) d s
\end{aligned}
$$

considerando que:

$\mathrm{V}_{n}=\mathrm{Q}_{n}-\frac{\partial \mathrm{M}_{n t}}{\partial s}$

a expressão anterior pode ser escrita na forma:

$$
\begin{aligned}
& \iint_{\Omega} \psi\left(\frac{\partial^{2} \mathbf{M}_{x}}{\partial x^{2}}-2 \frac{\partial^{2} \mathbf{M}_{x y}}{\partial x \partial y}+\frac{\partial^{2} \mathbf{M}_{y}}{\partial y^{2}}\right) d x d y+\iint_{\Omega} \psi q d x d y= \\
& \iint_{\Omega}\left(\frac{\partial^{2} \psi}{\partial x^{2}} \mathbf{M}_{x}+\frac{\partial^{2} \psi}{\partial y^{2}} \mathbf{M}_{y}-2 \frac{\partial^{2} \psi}{\partial x \partial y} \mathbf{M}_{x y}\right) d x d y+\int_{C \sigma} \mathbf{M}_{n t} \frac{\partial \psi}{\partial n} d s+ \\
& \int_{C \sigma} \psi \mathrm{V}_{n} d s+\iint_{\Omega} \psi q d x d y-\frac{\rho h^{3}}{12} \int_{C \sigma} \psi\left(\frac{\partial^{3} \mathrm{w}}{\partial x \partial t^{2}} \cos \delta+\frac{\partial^{3} \mathrm{w}}{\partial y \partial t^{2}} \operatorname{sen} \delta\right) d s
\end{aligned}
$$

Considerem agora as relações momento-curvatura, TIMOSHENKO[76]:

$$
\begin{aligned}
& \mathbf{M}_{x}=-D\left(\frac{\partial^{2} \mathrm{w}}{\partial x^{2}}+\nu \frac{\partial^{2} \mathrm{w}}{\partial y^{2}}\right) \\
& \mathbf{M}_{y}=-D\left(\frac{\partial^{2} \mathrm{w}}{\partial y^{2}}+\nu \frac{\partial^{2} \mathrm{w}}{\partial x^{2}}\right) \\
& \mathbf{M}_{x y}=D\left(1-\nu^{2}\right) \frac{\partial^{2} \mathrm{w}}{\partial x \partial y}
\end{aligned}
$$


onde, $D$ é a rigidez da placa a flexão, e é dada por:

$D=\frac{E h^{3}}{12\left(1-\nu^{2}\right)}$

Sejam também as seguintes condições de contorno naturais:

$\mathrm{M}_{n}=\overline{\mathrm{M}}_{n}(s, t)$

$\mathrm{V}_{n}=\overline{\mathrm{V}}_{n}(s, t)-h \bar{X} \frac{\partial \mathrm{w}}{\partial x}-h \bar{Y} \frac{\partial \mathrm{w}}{\partial y}$

Do equilíbrio transversal no elemento da Figura 4.2, resulta:

$\mathrm{V}_{n} d s=\overline{\mathrm{V}}_{n} d s-\left(N_{x} d s \cos \delta\right) \frac{\partial \mathrm{w}}{\partial x}-\left(N_{y} d s \operatorname{sen} \delta\right) \frac{\partial \mathrm{w}}{\partial y}-\left(N_{x y} d \operatorname{sen} \delta\right) \frac{\partial \mathrm{w}}{\partial x}-\left(N_{x y} d s \cos \delta\right) \frac{\partial \mathrm{w}}{\partial y}$

ou ainda:

$\mathrm{V}_{n}=\overline{\mathrm{V}}_{n}-\left(N_{x} \cos \delta+N_{x y} \operatorname{sen} \delta\right) \frac{\partial \mathrm{w}}{\partial x}-\left(N_{y} \operatorname{sen} \delta+N_{x y} \cos \delta\right) \frac{\partial \mathrm{w}}{\partial y}$

como:

$l N_{x}+m N_{x y}=h \bar{X}$

$m N_{y}+l N_{x y}=h \bar{Y}$

têm-se:

$\mathrm{V}_{n}=\overline{\mathrm{V}}_{n}-h \bar{X} \frac{\partial \mathrm{w}}{\partial x}-h \bar{Y} \frac{\partial \mathrm{w}}{\partial y}$ 
Com as equações (4.68), (4.69) e (4.70) e, também as condições de contorno naturais (4.71) e (4.72), a equação (4.67) torna-se:

$$
\begin{aligned}
& \iint_{\Omega} \psi\left[\frac{\partial^{2} \mathbf{M}_{x}}{\partial x^{2}}-2 \frac{\partial^{2} \mathbf{M}_{x y}}{\partial x \partial y}+\frac{\partial^{2} \mathbf{M}_{y}}{\partial y^{2}}\right] d x d y+\iint_{\Omega} \psi q d x d y= \\
& -D \iint_{\Omega}\left[\frac{\partial^{2} \psi}{\partial x^{2}} \frac{\partial^{2} \psi}{\partial x^{2}}+\nu \frac{\partial^{2} \psi}{\partial x^{2}} \frac{\partial^{2} \psi}{\partial y^{2}}+\frac{\partial^{2} \psi}{\partial y^{2}} \frac{\partial^{2} \psi}{\partial y^{2}}+\nu \frac{\partial^{2} \psi}{\partial y^{2}} \frac{\partial^{2} \psi}{\partial x^{2}}+\right. \\
& \left.+2(1-\nu) \frac{\partial^{2} \psi}{\partial x \partial y} \frac{\partial^{2} \psi}{\partial x \partial y}\right] d x d y-\int_{C \sigma} \frac{\partial \psi}{\partial n} \overline{\mathbf{M}}_{n} d s+\int_{C \sigma} \psi \overline{\mathrm{V}}_{n} d s+ \\
& -h \int_{C \sigma} \psi\left(\bar{X} \frac{\partial \mathrm{w}}{\partial x}+\bar{Y} \frac{\partial \mathrm{w}}{\partial y}\right) d s+\iint_{\Omega} \psi q d x d y-\frac{\rho h^{3}}{12} \int_{C \sigma} \psi\left(\frac{\partial \ddot{\mathrm{w}}}{\partial x} \cos \delta+\frac{\partial \ddot{\mathrm{w}}}{\partial y} \operatorname{sen} \delta\right) d s
\end{aligned}
$$

Devemos agora que integrar por partes as integrais que comparecem no segundo membro de (3.85). Assim teremos:

$$
\begin{aligned}
& -\iint_{\Omega} \psi\left(N_{x} \frac{\partial^{2} \mathrm{w}}{\partial x^{2}}\right) d x d y=-\iint_{\Omega}\left(\psi \mathrm{N}_{x}\right) \frac{\partial}{\partial x}\left(\frac{\partial \mathrm{w}}{\partial x}\right) d x d y= \\
& =\iint_{\Omega}\left(\psi \frac{\partial N_{x}}{\partial x}+\frac{\partial \psi}{\partial x} N_{x}\right) \frac{\partial \mathrm{w}}{\partial x} d x d y=-\int_{C \sigma} \psi \mathrm{N}_{x} \frac{\partial \mathrm{w}}{\partial x} \cos \delta d s \\
& -\iint_{\Omega} \psi\left(N_{y} \frac{\partial^{2} \mathrm{w}}{\partial y^{2}}\right) d x d y=-\iint_{\Omega}\left(\psi \mathrm{N}_{y}\right) \frac{\partial}{\partial y}\left(\frac{\partial \mathrm{w}}{\partial y}\right) d x d y= \\
& =\iint_{\Omega}\left(\psi \frac{\partial N_{y}}{\partial y}+\frac{\partial \psi}{\partial y} N_{y}\right) \frac{\partial \mathrm{w}}{\partial y} d x d y=-\int_{C \sigma} \psi \mathrm{N}_{y} \frac{\partial \mathrm{w}}{\partial y} \operatorname{sen} \delta d s \\
& -\iint_{\Omega} \psi\left(N_{x y} \frac{\partial^{2} \mathrm{w}}{\partial x \partial y}\right) d x d y=-\iint_{\Omega}\left(\psi \mathrm{N}_{x y}\right) \frac{\partial}{\partial x}\left(\frac{\partial \mathrm{w}}{\partial y}\right) d x d y= \\
& =\iint_{\Omega}\left(\psi \frac{\partial N_{x y}}{\partial y}+\frac{\partial \psi}{\partial x} N_{x y}\right) \frac{\partial \mathrm{w}}{\partial y} d x d y=-\int_{C \sigma} \psi \mathrm{N}_{x y} \frac{\partial \mathrm{w}}{\partial y} \cos \delta d s \\
& -\iint_{\Omega} \psi\left(N_{x y} \frac{\partial^{2} \mathrm{w}}{\partial y \partial x}\right) d x d y=-\iint_{\Omega}\left(\psi \mathrm{N}_{x y}\right) \frac{\partial}{\partial y}\left(\frac{\partial \mathrm{w}}{\partial x}\right) d x d y= \\
& =\iint_{\Omega}\left(\psi \frac{\partial N_{x y}}{\partial y}+\frac{\partial \psi}{\partial y} N_{x y}\right) \frac{\partial \mathrm{w}}{\partial x} d x d y=-\int_{C \sigma} \psi \mathrm{N}_{x y} \frac{\partial \mathrm{w}}{\partial x} \operatorname{sen} \delta d s
\end{aligned}
$$


Considerando-se esses resultados anteriores e também as equações (4.1), (4.2), (4.8) e (4.9), têm-se:

$$
\begin{aligned}
& -\iint_{\Omega} \psi\left(N_{x} \frac{\partial^{2} \mathrm{w}}{\partial x^{2}}+N_{y} \frac{\partial^{2} \mathrm{w}}{\partial y^{2}}+2 N_{x y} \frac{\partial^{2} \mathrm{w}}{\partial x \partial y}\right) d x d y= \\
& =\iint_{\Omega}\left[\frac{\partial \psi}{\partial x}\left(N_{x} \frac{\partial \mathrm{w}}{\partial x}+N_{x y} \frac{\partial \mathrm{w}}{\partial y}\right)+\frac{\partial \psi}{\partial y}\left(N_{y} \frac{\partial \mathrm{w}}{\partial y}+N_{x y} \frac{\partial \mathrm{w}}{\partial x}\right)\right] d x d y+ \\
& +\iint_{\Omega} \psi\left[\left(\frac{\partial N_{x}}{\partial x}+\frac{\partial N_{x y}}{\partial y}\right) \frac{\partial \mathrm{w}}{\partial x}+\psi\left(\frac{\partial N_{y}}{\partial y}+\frac{\partial N_{x y}}{\partial x} \frac{\partial \mathrm{w}}{\partial y}\right] d x d y+\right. \\
& -\int_{C \sigma} \psi \frac{\partial \mathrm{w}}{\partial x}\left(N_{x} \cos \delta+N_{x y} \operatorname{sen} \delta\right) d s-\int_{C \sigma} \psi \frac{\partial \mathrm{w}}{\partial y}\left(N_{y} \operatorname{sen} \delta+N_{x y} \cos \delta\right) d s= \\
& =\iint_{\Omega}\left[\frac{\partial \psi}{\partial x}\left(N_{x} \frac{\partial \mathrm{w}}{\partial x}+N_{x y} \frac{\partial \mathrm{w}}{\partial y}\right)+\frac{\partial \psi}{\partial y}\left(N_{y} \frac{\partial \mathrm{w}}{\partial y}+N_{x y} \frac{\partial \mathrm{w}}{\partial x}\right)\right] d x d y+ \\
& -h \int_{C \sigma} \psi\left(\bar{X} \frac{\partial \mathrm{w}}{\partial x}+\bar{Y} \frac{\partial \mathrm{w}}{\partial y}\right) d s-\iint_{\Omega} \psi\left(h X \frac{\partial \mathrm{w}}{\partial x}+h Y \frac{\partial \mathrm{w}}{\partial y}\right) d x d y+ \\
& +\rho h \int_{\Omega} \psi\left(\frac{\partial^{2} u}{\partial t^{2}} \frac{\partial \mathrm{w}}{\partial x}+\frac{\partial^{2} v}{\partial t^{2}} \frac{\partial \mathrm{w}}{\partial y}\right) d x d y
\end{aligned}
$$

Substituindo-se (4.74) e (4.75) em (4.66), vêm:

$$
\begin{aligned}
& -D \iint_{\Omega}\left[\frac{\partial^{2} \psi}{\partial x^{2}} \frac{\partial^{2} \mathrm{w}}{\partial x^{2}}+\nu \frac{\partial^{2} \psi}{\partial x^{2}} \frac{\partial^{2} \mathrm{w}}{\partial y^{2}}+\frac{\partial^{2} \psi}{\partial y^{2}} \frac{\partial^{2} \mathrm{w}}{\partial y^{2}}+\nu \frac{\partial^{2} \psi}{\partial y^{2}} \frac{\partial^{2} \mathrm{w}}{\partial x^{2}}+2(1-\nu) \frac{\partial^{2} \psi}{\partial x \partial y} \frac{\partial^{2} \mathrm{w}}{\partial x \partial y}\right] d x d y- \\
& -\int_{C \sigma} \frac{\partial \psi}{\partial n} \bar{M}_{n} d s+\int_{C \sigma} \psi \overline{\mathrm{V}}_{n} d s-h \int_{C \sigma} \psi\left(\bar{X} \frac{\partial \mathrm{w}}{\partial x}+\bar{Y} \frac{\partial \mathrm{w}}{\partial y}\right) d s+\iint_{\Omega} \psi \mathrm{q} d x d y= \\
& =\iint_{\Omega}\left[\frac{\partial \psi}{\partial x}\left(N_{x} \frac{\partial \mathrm{w}}{\partial x}+N_{x y} \frac{\partial \mathrm{w}}{\partial y}\right)+\frac{\partial \psi}{\partial y}\left(N_{y} \frac{\partial \mathrm{w}}{\partial y}+N_{x y} \frac{\partial \mathrm{w}}{\partial x}\right)\right] d x d y-h \int_{C \sigma} \psi\left(\bar{X} \frac{\partial \mathrm{w}}{\partial x}+\bar{Y} \frac{\partial \mathrm{w}}{\partial y}\right) d s+ \\
& -\iint_{\Omega} \psi\left(h X \frac{\partial \mathrm{w}}{\partial x}+h Y \frac{\partial \mathrm{w}}{\partial y}\right) d x d y+\rho h \iint_{\Omega} \psi\left(\frac{\partial^{2} u}{\partial t^{2}} \frac{\partial \mathrm{w}}{\partial x}+\frac{\partial^{2} v}{\partial t^{2}} \frac{\partial \mathrm{w}}{\partial y}\right) d x d y+ \\
& \frac{\rho h^{3}}{12} \int_{C \sigma} \psi\left(\frac{\partial \ddot{\mathrm{w}}}{\partial x} \cos \delta+\frac{\partial \ddot{\mathrm{w}}}{\partial y} \operatorname{sen} \delta\right) d s+\iint_{\Omega} \psi\left(h X \frac{\partial \mathrm{w}}{\partial x}+h Y \frac{\partial \mathrm{w}}{\partial y}\right) d x d y+\iint_{\Omega} \psi \rho \mathrm{h} \frac{\partial^{2} \mathrm{w}}{\partial t^{2}} d x d y+ \\
& -\iint_{\Omega} \psi\left(\frac{\partial^{4} \mathrm{w}}{\partial y^{2} \partial t^{2}}+\frac{\partial^{4} \mathrm{w}}{\partial x^{2} \partial t^{2}}\right) \frac{\rho h^{3}}{12} d x d y-\rho h \iint_{\Omega}\left(\psi \frac{\partial^{2} u}{\partial t^{2}} \frac{\partial \mathrm{w}}{\partial x}\right) d x d y-\rho h \iint_{\Omega}\left(\psi \frac{\partial^{2} v}{\partial t^{2}} \frac{\partial \mathrm{w}}{\partial y}\right) d x d y
\end{aligned}
$$


ou ainda:

$$
\begin{aligned}
& D \iint_{\Omega}\left[\frac{\partial^{2} \psi}{\partial x^{2}} \frac{\partial^{2} \mathrm{w}}{\partial x^{2}}+\nu \frac{\partial^{2} \psi}{\partial x^{2}} \frac{\partial^{2} \mathrm{w}}{\partial y^{2}}+\frac{\partial^{2} \psi}{\partial y^{2}} \frac{\partial^{2} \mathrm{w}}{\partial y^{2}}+\nu \frac{\partial^{2} \psi}{\partial y^{2}} \frac{\partial^{2} \mathrm{w}}{\partial x^{2}}+2(1-\nu) \frac{\partial^{2} \psi}{\partial x \partial y} \frac{\partial^{2} \mathrm{w}}{\partial x \partial y}\right] d x d y+ \\
& +\iint_{\Omega}\left[\frac{\partial \psi}{\partial x}\left(N_{x} \frac{\partial \mathrm{w}}{\partial x}+N_{x y} \frac{\partial \mathrm{w}}{\partial y}\right)+\frac{\partial \psi}{\partial y}\left(N_{y} \frac{\partial \mathrm{w}}{\partial y}+N_{x y} \frac{\partial \mathrm{w}}{\partial x}\right)\right] d x d y= \\
& =\iint_{\Omega} \psi q d x d y-\int_{C \sigma} \frac{\partial \psi}{\partial n} \overline{\mathrm{M}}_{n} d s+\int_{C \sigma} \psi \overline{\mathrm{V}}_{n} d s-\iint_{\Omega} \psi \rho h \frac{\partial^{2} \mathrm{w}}{\partial t^{2}} d x d y+ \\
& -\rho h \int_{\Omega} \psi\left(\frac{\partial^{2} u}{\partial t^{2}} \frac{\partial \mathrm{w}}{\partial x}+\frac{\partial^{2} v}{\partial t^{2}} \frac{\partial \mathrm{w}}{\partial y}\right) d x d y-\frac{\rho h^{3}}{12} \int_{C \sigma} \psi\left(\frac{\partial \ddot{\mathrm{w}}}{\partial x} \cos \delta+\frac{\partial \ddot{\mathrm{w}}}{\partial y} \operatorname{sen} \delta\right) d s+ \\
& +\iint_{\Omega} \psi\left(\frac{\partial^{4} \mathrm{w}}{\partial y^{2} \partial t^{2}}+\frac{\partial^{4} \mathrm{w}}{\partial x^{2} \partial t^{2}}\right) \frac{\rho h^{3}}{12} d x d y+\rho h \iint_{\Omega} \psi \frac{\partial^{2} u}{\partial t^{2} \partial x^{2}} d x d y+\rho h \iint_{\Omega} \psi \frac{\partial^{2} v}{\partial t^{2}} \frac{\partial \mathrm{w}}{\partial y} d x d y
\end{aligned}
$$

Integrando-se agora por partes, a antepenúltima das integrais do segundo membro de (4.76), temos:

$$
\begin{aligned}
& \iint_{\Omega} \psi \frac{\partial^{2} \ddot{\mathrm{w}}}{\partial x^{2}} d x d y=-\iint_{\Omega} \frac{\partial \psi}{\partial x} \frac{\partial \ddot{\mathrm{w}}}{\partial x} d x d y+\int_{C \sigma} \psi \frac{\partial \ddot{\mathrm{w}}}{\partial x} \cos \delta d s \\
& \iint_{\Omega} \psi \frac{\partial^{2} \ddot{\mathrm{w}}}{\partial y^{2}} d x d y=-\iint_{\Omega} \frac{\partial \psi}{\partial y} \frac{\partial \ddot{\mathrm{w}}}{\partial y} d x d y+\int_{C \sigma} \psi \frac{\partial \ddot{\mathrm{w}}}{\partial y} \operatorname{sen} \delta d s
\end{aligned}
$$

Substituindo-se esses resultados na expressão (4.76), finalmente teremos:

$$
\begin{aligned}
& D \iint_{\Omega}\left[\frac{\partial^{2} \psi}{\partial x^{2}} \frac{\partial^{2} \mathrm{w}}{\partial x^{2}}+\nu \frac{\partial^{2} \psi}{\partial x^{2}} \frac{\partial^{2} \mathrm{w}}{\partial y^{2}}+\frac{\partial^{2} \psi}{\partial y^{2}} \frac{\partial^{2} \mathrm{w}}{\partial y^{2}}+\nu \frac{\partial^{2} \psi}{\partial y^{2}} \frac{\partial^{2} \mathrm{w}}{\partial x^{2}}+2(1-\nu) \frac{\partial^{2} \psi}{\partial x \partial y} \frac{\partial^{2} \mathrm{w}}{\partial x \partial y}\right] d x d y+ \\
& +\iint_{\Omega}\left[\frac{\partial \psi}{\partial x}\left(N_{x} \frac{\partial \mathrm{w}}{\partial x}+N_{x y} \frac{\partial \mathrm{w}}{\partial y}\right)+\frac{\partial \psi}{\partial y}\left(N_{y} \frac{\partial \mathrm{w}}{\partial y}+N_{x y} \frac{\partial \mathrm{w}}{\partial x}\right)\right] d x d y= \\
& =\iint_{\Omega} \psi q d x d y-\int_{C \sigma} \frac{\partial \psi}{\partial n} \overline{\mathrm{M}}_{n} d s+\int_{C \sigma} \psi \overline{\mathrm{V}}_{n} d s-\iint_{\Omega} \psi \rho h \frac{\partial^{2} \mathrm{w}}{\partial t^{2}} d x d y+ \\
& -\frac{\rho h^{3}}{12} \iint_{\Omega}\left(\frac{\partial \psi}{\partial x} \frac{\partial \ddot{\mathrm{w}}}{\partial x}\right) d x d y-\frac{\rho h^{3}}{12} \iint_{\Omega}\left(\frac{\partial \psi}{\partial y} \frac{\partial \ddot{\mathrm{w}}}{\partial y}\right) d x d y
\end{aligned}
$$

A expressão (4.77) é a forma fraca de (4.66), porque exige menor ordem de continuidade na determinação das funções $M_{x}, M_{x y}$ e $M_{y}$. 


\subsection{2 - Método dos Elementos Finitos}

Utilizando-se das interpolações abaixo:

$$
\begin{aligned}
& u=u_{j} \gamma_{j} \\
& v=v_{j} \gamma_{j} \\
& w=\left(\mathbf{a}^{b}\right)^{t} \Phi=\Phi^{t} \mathbf{a}^{b}
\end{aligned}
$$

têm-se:

$\ddot{u}=\ddot{u}_{j} \gamma_{j}$

$\ddot{v}=\ddot{v}_{j} \gamma_{j}$

$\ddot{w}=\Phi^{t} \ddot{\mathbf{a}}^{b}$

Introduzindo-se as interpolações acima na equação (4.77), seguindo-se da aplicação da hipótese de GALERKIN [34], onde as funções de ponderação são as mesmas que foram usadas para interpolar os deslocamentos transversais, ou seja, $\psi \cong \Phi$, chega-se à:

$$
\begin{aligned}
& D \iint_{\Omega}\left[\frac{\partial^{2} \Phi}{\partial x^{2}} \frac{\partial^{2} \Phi^{t}}{\partial x^{2}}+\frac{\partial^{2} \Phi}{\partial y^{2}} \frac{\partial^{2} \Phi^{t}}{\partial y^{2}}+\nu\left(\frac{\partial^{2} \Phi}{\partial x^{2}} \frac{\partial^{2} \Phi^{t}}{\partial y^{2}}+\frac{\partial^{2} \Phi}{\partial y^{2}} \frac{\partial^{2} \Phi^{t}}{\partial x^{2}}\right)+2(1-\nu) \frac{\partial^{2} \Phi}{\partial x \partial y} \frac{\partial^{2} \Phi^{t}}{\partial x \partial y}\right] \mathbf{a}^{b} d x d y+ \\
& +\iint_{\Omega}\left[\frac{\partial \Phi}{\partial x}\left(N_{x} \frac{\partial \Phi^{t}}{\partial x}+N_{x y} \frac{\partial \Phi^{t}}{\partial y}\right)+\frac{\partial \Phi^{t}}{\partial y}\left(N_{y} \frac{\partial \Phi^{t}}{\partial y}+N_{x y} \frac{\partial \Phi^{t}}{\partial x}\right)\right] \mathbf{a}^{b} d x d y= \\
& =\iint_{\Omega} \Phi q d x d y-\int_{C \sigma} \frac{\partial \Phi}{\partial n} \bar{M}_{n} d s+\int_{C \sigma} \Phi \bar{V}_{n} d s-\iint_{\Omega}\left(\Phi \rho h \Phi^{t}\right) \ddot{\mathbf{a}}^{b} d x d y+ \\
& -\frac{\rho h^{3}}{12} \iint_{\Omega} \frac{\partial \Phi}{\partial x} \frac{\partial \Phi^{t}}{\partial x} d x d y \ddot{\mathbf{a}}^{b}-\frac{\rho h^{3}}{12} \iint_{\Omega} \frac{\partial \Phi}{\partial y} \frac{\partial \Phi^{t}}{\partial y} d x d y \ddot{\mathbf{a}}^{b}
\end{aligned}
$$




\subsubsection{1 - Formulação Matricial}

O resultado obtido no formato matricial será um sistema de $3 n$ equações, que são justamente as que faltavam para que o sistema possa ser resolvido:

$$
[\mathbf{M}]^{b}\{\ddot{\mathbf{a}}\}+\left([\mathbf{K}]_{0}^{b}+[\mathbf{K}]_{g}^{b}\right)\{\mathbf{a}\}^{b}=\{\mathbf{f}\}^{b}
$$

A matriz $[\mathbf{K}]_{o}^{b}$ é dada por:

$$
\begin{aligned}
& \mathbf{K}_{o}^{b}=D \iint_{\Omega}\left[\frac{\partial^{2} \Phi}{\partial x^{2}} \frac{\partial^{2} \Phi^{t}}{\partial x^{2}}+\frac{\partial^{2} \Phi}{\partial y^{2}} \frac{\partial^{2} \Phi^{t}}{\partial y^{2}}+\nu\left(\frac{\partial^{2} \Phi}{\partial x^{2}} \frac{\partial^{2} \Phi^{t}}{\partial y^{2}}+\frac{\partial^{2} \Phi}{\partial y^{2}} \frac{\partial^{2} \Phi^{t}}{\partial x^{2}}\right)+\right. \\
& \left.2(1-\nu) \frac{\partial^{2} \Phi}{\partial x \partial y} \frac{\partial^{2} \Phi^{t}}{\partial x \partial y}\right] d x d y
\end{aligned}
$$

A equação (4.83) representa a Matriz de Rigidez da placa em Teoria de Primeira Ordem.

Por outro lado, a matriz $[\mathbf{K}]_{g}^{b}$ é dada por:

$$
\mathbf{K}_{g}^{b}=\iint_{\Omega}\left(N_{x} \mathbf{A}+N_{y} \mathbf{B}+N_{x y} \mathbf{C}\right) d x d y
$$

A equação (4.84) representa a Matriz de Rigidez Geométrica da placa.

As forças de membrana são calculadas por (4.43), (4.44) e (4.45), e as matrizes A, B e C são as mesmas definidas em (4.46), (4.47) e (4.48).

$O$ vetor $\{\mathbf{f}\}^{b}$, caracterizado pelos esforços nodais equivalentes referentes ao carregamento transversal é definido por:

$$
\mathbf{f}^{b}=\iint_{\Omega} \Phi q d x d y+\int_{C \sigma}\left(\Phi \overline{\mathbf{V}}_{n}-\frac{\partial \Phi}{\partial n} \overline{\mathbf{M}}_{n}\right) d s
$$


que se constitui em uma força vertical e dois momentos aplicados nas direções $x$ e $y$, respectivamente. Assim,

$$
\mathbf{f}_{i}^{b}=\left\{\begin{array}{l}
F_{i}^{z} \\
M_{i}^{x} \\
M_{i}^{y}
\end{array}\right\}
$$

A matriz $[\mathbf{M}]^{b}$ é a Matriz de Massa da Placa, e é dada por:

$$
\mathbf{M}^{b}=\rho h \iint_{\Omega} \Phi \Phi^{t} d x d y+\frac{\rho h^{3}}{12} \iint_{\Omega}(\mathbf{A}+\mathbf{B}) d x d y
$$

$\mathrm{Na}$ expressão acima, a segunda parcela do lado direito, refere-se à contribuição da inércia à rotação.

\subsection{1 - Matriz de Rigidez Secante}

Os dois sistemas de equações, dados pelas expressões (4.51) e (4.82), são acoplados. De forma mais concisa, é possível escrevê-los como:

$$
[\mathbf{M}]\{\ddot{\mathbf{a}}\}+[\mathbf{K}]_{\mathbf{s}}\{\mathbf{a}\}=\{\mathbf{f}\}
$$

O acoplamento dos sistemas (4.51) e (4.82) é devido à existência da matriz $[\mathbf{G}]$, e também ao fato de que $[\mathbf{K}]_{g}^{b}$, sendo função de $N_{x}, N_{y}$ e $N_{x y}$, depende, conseqüentemente, não apenas de $\{\mathbf{a}\}^{b}$, mas também de $\{\mathbf{a}\}^{p}$.

A Matriz de Rigidez Secante $[\mathbf{K}]_{s}$ da estrutura é dada por:

$$
\mathbf{K}_{\mathbf{s}}=\left[\begin{array}{cc}
\mathbf{K}_{o}^{p} & \mathbf{G} \\
\mathbf{0} & \mathbf{K}_{o}^{b}+\mathbf{K}_{g}^{b}
\end{array}\right]
$$


Os vetores de deslocamentos nodais e de esforços são dados respectivamente por:

$$
\begin{aligned}
& \mathbf{a}=\left\{\begin{array}{l}
\mathbf{a}^{p} \\
\mathbf{a}^{b}
\end{array}\right\} \\
& \mathbf{f}=\left\{\begin{array}{l}
\mathbf{f}^{p} \\
\mathbf{f}^{b}
\end{array}\right\}
\end{aligned}
$$

A matriz $[\mathbf{M}]$ é a Matriz de Massa da estrutura, sendo dada por:

$$
\mathbf{M}=\left[\begin{array}{cc}
\mathbf{M}^{p} & 0 \\
0 & \mathbf{M}^{b}
\end{array}\right]
$$

\subsection{2 - Matriz de Rigidez Tangente}

A Matriz de Rigidez Tangente da estrutura é:

$$
\mathbf{K}_{\mathbf{T}}=\left[\begin{array}{cc}
\mathbf{K}_{o}^{p} & 2 \mathbf{G} \\
2 \mathbf{G}^{\mathbf{T}} & \mathbf{K}_{o}^{b}+\mathbf{K}_{g}^{b}+\mathbf{H}
\end{array}\right]
$$

onde a matriz $[\mathbf{H}]$ é dada por:

$$
\begin{aligned}
& \mathbf{H}=\frac{E h}{1-\nu^{2}} \iint_{\Omega}\left\{\mathbf{A} \mathbf{a}^{b}\left(\mathbf{a}^{b}\right)^{t} \mathbf{A}+\mathbf{B} \mathbf{a}^{b}\left(\mathbf{a}^{b}\right)^{t} \mathbf{B}+\right. \\
& \left.\nu\left[\mathbf{B} \mathbf{a}^{b}\left(\mathbf{a}^{b}\right)^{t} \mathbf{A}+\mathbf{A} \mathbf{a}^{b}\left(\mathbf{a}^{b}\right)^{t} \mathbf{B}\right]+\frac{1-\nu}{2} \mathbf{C} \mathbf{a}^{b}\left(\mathbf{a}^{b}\right)^{t} \mathbf{C}\right\} d x d y
\end{aligned}
$$

Costuma-se desmembrar $[\mathbf{K}]_{\mathrm{T}}$ em três parcelas, simétricas:

$$
\mathbf{K}_{\mathbf{T}}=\left[\begin{array}{cc}
\mathbf{K}_{o}^{p} & 0 \\
0 & \mathbf{K}_{o}^{b}
\end{array}\right]+\left[\begin{array}{cc}
0 & 0 \\
2 \mathbf{G}^{\mathbf{T}} & \mathbf{H}
\end{array}\right]+\left[\begin{array}{cc}
0 & 0 \\
0 & \mathbf{K}_{g}^{b}
\end{array}\right]
$$




\section{Capítulo 5}

\section{Programa de Cálculo Computacional}

\section{1 - Considerações Gerais sobre o Software MATLAB}

O MATLAB [53] (MATrix LABoratory) é um software interativo de alto desempenho voltado para análises matriciais. O MATLAB [53] integra análise numérica, cálculo com matrizes, processamento de sinais e construção de gráficos num ambiente simples de se utilizar.

A principal característica que distingue o MATLAB [53] dos outros sistemas similares de linguagens de programação é o fato de que o elemento básico de informação é sempre uma matriz de uma ou mais dimensões.

Esse sistema permite a resolução de muitos problemas numéricos em apenas uma fração do tempo em que se gastaria para escrever um programa semelhante em outras linguagens, como FORTRAN, BASIC ou C++. Além disso, as soluções dos problemas são expressas através do software MATLAB [53], quase exatamente como elas são escritas matematicamente.

O MATLAB [53] é uma combinação perfeita de muitas das linguagens mais utilizadas hoje no mundo acadêmico, citando-se dentre outras, as linguagens $\mathrm{C}_{++}$, JAVA, BASIC, PASCAL, etc. Esta linguagem segue então uma maneira muito fiel a maior parte dos aspectos das linguagens que estiveram na sua composição.

Outra grande vantagem do MATLAB [53] reside no fato de que um programador acostumado a lidar com códigos criados em $\mathrm{C}++$, por exemplo, não terá dificuldades em se adaptar a esta linguagem, visto que os códigos-fonte são muito parecidos; um programador de JAVA não terá grande dificuldade em se adaptar à construção de objetos GUI em MATLAB [53], pois o MATLAB [53] tem também uma ótima componente de interface não gráfica. 
No MATLAB [53] as funções ou rotinas desenvolvidas, são escritas em forma de arquivos textos ou $\mathrm{m}$-files os quais podem ser editados e/ou modificados em outro editor de texto qualquer, para que venha a satisfazer a necessidade do problema ao qual esteja sendo solicitado. Este fato possibilitou a criação de diversos conjuntos de funções específicas para determinadas áreas, tais como: matemática, física, química, engenharia, economia, estatística, além de outras.

Enquanto que o software MATLAB [53] depende da plataforma (Unix, Windows, Macintosh e Linux), os arquivos ".m" desenvolvidos, são independentes da plataforma e, portanto, podem ser executados em todas elas.

$O$ fato de ter sido escrito totalmente na linguagem técnica do MATLAB [53], torna o programa DYMPLATE um software de código aberto, isto é, permite que qualquer programador introduza novas funções e programas. Uma vez que não é compilado em nenhum sistema específico, poderá ser executado em qualquer sistema onde o MATLAB [53] esteja instalado, tomando o programa DYMPLATE, um software multi-plataforma.

Através do software MATLAB [53] é possível criar interfaces gráficas para usuário através da função GUI - Graphical User Interface, para integrar os programas de pré-processamento, análise estrutural e pós-processamento, facilitando assim, a operação do computador sem a necessidade de memorização de comandos.

Portanto, a decisão pela utilização do MATLAB [53] para implementação do programa DYMPLATE, se deu devido ao fato de o mesmo constituir-se numa ferramenta apropriada para computação científica, própria para trabalhar com grandes volumes de dados referentes a cálculos envolvendo sistemas matriciais e possuir uma linguagem de programação bastante ampla. 


\section{2 - O Programa DYMPLATE}

Escrito em uma linguagem de programação de alto nível presente no software MATLAB [53], o programa DYMPLATE segue o formato tradicional de um programa de elementos finitos para o cálculo dinâmico de estruturas de placas, sendo capaz de analisar placas homogêneas e isotrópicas cujo contorno seja uma curva qualquer com as mais variadas condições de apoio. O programa realiza o cálculo estático linear e não-linear, além do cálculo dinâmico do problema.

A análise de um problema pelo método dos elementos finitos envolve, além da formulação, algumas etapas fundamentais que se processam invariavelmente pela mesma ordem. São elas:

- discretização do domínio.

- geração da matriz de rigidez local para cada elemento.

- geração da matriz de rigidez global da estrutura.

- geração da matriz de massa local para cada elemento.

- geração da matriz de massa global da estrutura.

- introdução das condições de contorno.

- análise estática linear e não-linear.

- análise dinâmica linear.

- resolução do problema de autovalores e autovetores (freqüências naturais e modos de vibração).

- saída de resultados.

Considerando-se um algoritmo de cálculo tradicional para a análise dinâmica linear através do método dos elementos finitos, uma representação básica funcional de seu fluxograma é mostrada na Figura 5.1 a seguir: 


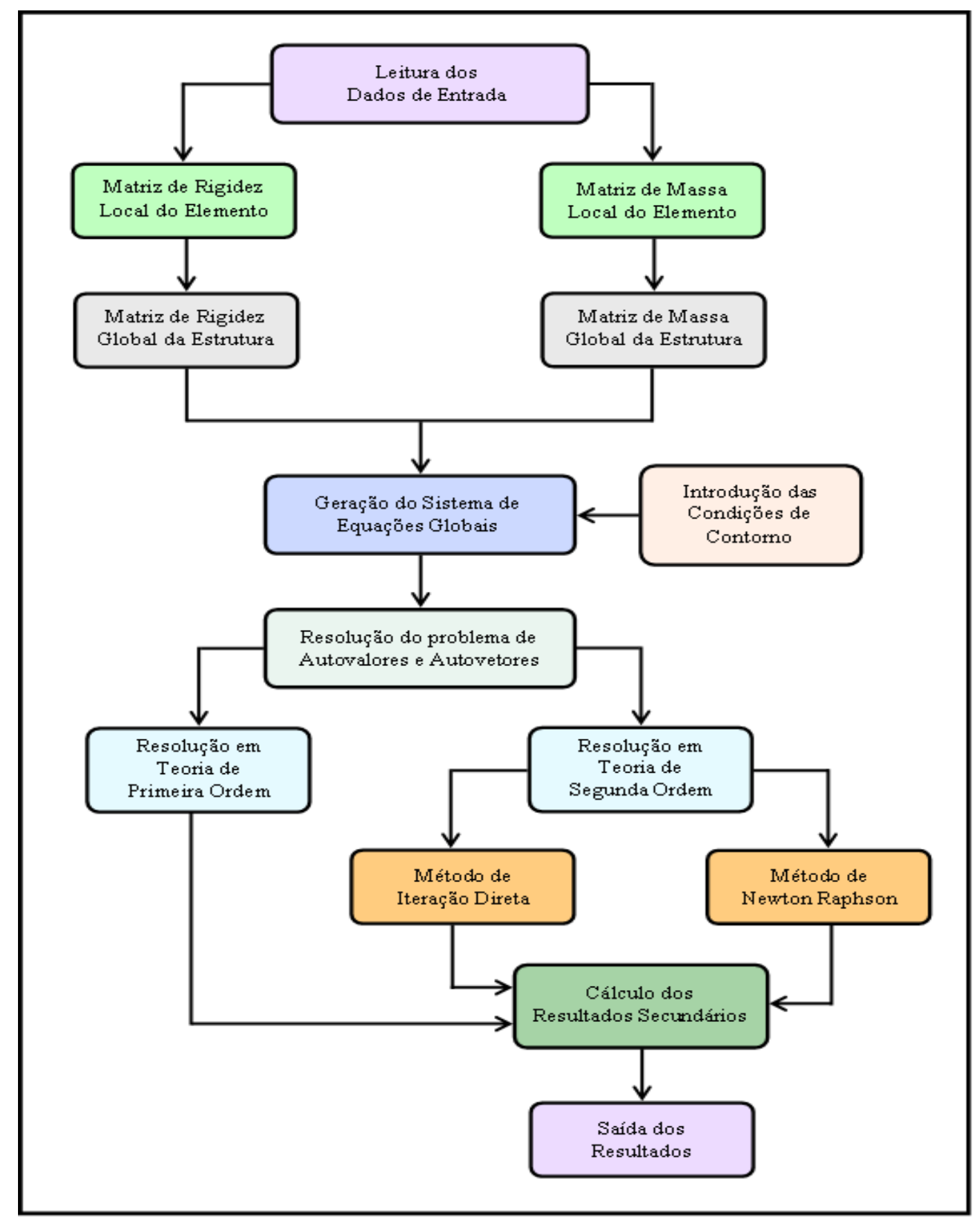

Figura 5.1 - Fluxograma de análise dinâmica pelo método dos elementos finitos.

O desenvolvimento de um programa de elementos finitos para análise estática ou dinâmica de estruturas é normalmente um trabalho de grandes proporções, mesmo quando enfrentado em equipe. A correta formulação do problema e sua idealização por uma discretização representativa pelo Método dos Elementos Finitos demandam uma base sólida e moderna em mecânica estrutural. 
Para solução das equações de equilíbrio no espaço e no tempo, técnicas estáveis e eficientes devem ser empregadas. $\mathrm{O}$ bom desempenho de um programa deste tipo depende muito da otimização de uso do "hardware" e "software" disponíveis.

Inicialmente, pelo método de Newton-Raphson, determina-se a solução do problema estático geometricamente não-linear. Quando a carga final estabelecida é atingida, caso haja convergência, a matriz de rigidez tangente calculada no último passo do processo é utilizada juntamente com a matriz de massa na composição de um problema generalizado de autovalores e autovetores, que darão respectivamente as freqüências naturais e os modos de vibração correspondentes.

O programa DYMPLATE (Dinâmica das Placas), é constituído basicamente de doze arquivos ou subprogramas ( $m$-files) denominados funções ou rotinas principais. Esses arquivos foram escritos na forma de arquivos textos, com a extensão ".m", característico das rotinas implementadas no ambiente do software MATLAB [53]:

- Arquivos "Inputs".m: rotinas para a realização do pré-processamento, dados de entrada, geração da malha de elementos finitos, tabela de incidência dos nós, conectividade dos elementos e condições de contorno.

- "Elemento Triangular Chapa / Placa”.m: rotinas para construção das matrizes de rigidez e de massa para cada elemento finito no sistema local.

- "Análise Elementos Finitos em Primeira Ordem".m: rotinas para obtenção das matrizes de rigidez e de massa no sistema global e resolver numericamente o problema de autovalores (freqüências naturais) e autovetores (modos de vibração) sob linearidade geométrica.

- “Análise Elementos Finitos em Segunda Ordem".m: rotinas para obtenção das matrizes de rigidez e de massa no sistema global e resolver numericamente 0 problema de autovalores (freqüências naturais) e autovetores (modos de vibração), sob não-linearidade geométrica, através dos métodos numéricos de cálculo iterativo ou por Newton-Raphson.

- "Placas".m: rotinas para construção da interface gráfica principal para usuário.

- "Desenha”.m: rotinas para construção de um ambiente gráfico, onde se podem desenvolver novos exemplos de aplicações com painéis de placas de contorno qualquer, inserção das coordenadas dos vértices, ligação entre os vértices, colocação das condições de contorno, geração e refinamento da malha de 
elementos finitos, sem a utilização de arquivos textos ".m" previamente elaborados.

- "Resultados Primeira Ordem".m: rotinas para exibição de uma interface gráfica que contém a listagem dos valores obtidos para as incógnitas nodais do problema estático linear, a partir dos cálculos realizados no processamento.

- "Resultados Segunda Ordem".m: rotinas para exibição de uma interface gráfica que contém a listagem dos valores obtidos para as incógnitas nodais do problema estático não-linear, a partir dos cálculos realizados no processamento.

- "Dinâmica Primeira Ordem".m: rotinas para exibição de uma interface de animação gráfica da análise dinâmica do problema da placas, bem como a listagem dos valores obtidos para as freqüências naturais e os respectivos modos de vibração associados, sob linearidade geométrica.

- "Dinâmica Segunda Ordem".m: rotinas para exibição de uma interface de animação gráfica da análise dinâmica do problema da placas, executadas por métodos numéricos de cálculo iterativo ou por Newton-Raphson, bem como a listagem dos valores obtidos para as freqüências naturais e os respectivos modos de vibração associados, sob não-linearidade geométrica.

- "Desenha malha Indeformada".m: rotinas para desenhar a malha indeformada.

- "Desenha malha Deformada”.m: rotinas para desenhar a malha deformada. 
A Figura 5.2 representa o fluxograma básico do programa computacional DYMPLATE, sendo que cada um dos blocos que compõe este fluxograma, é constituído por subrotinas ou subprogramas auxiliares que são os responsáveis pela interligação entre os mesmos. Esses subprogramas serão apresentados nas próximas seções onde se fornecem, resumidamente, os procedimentos envolvidos nas suas implementações.

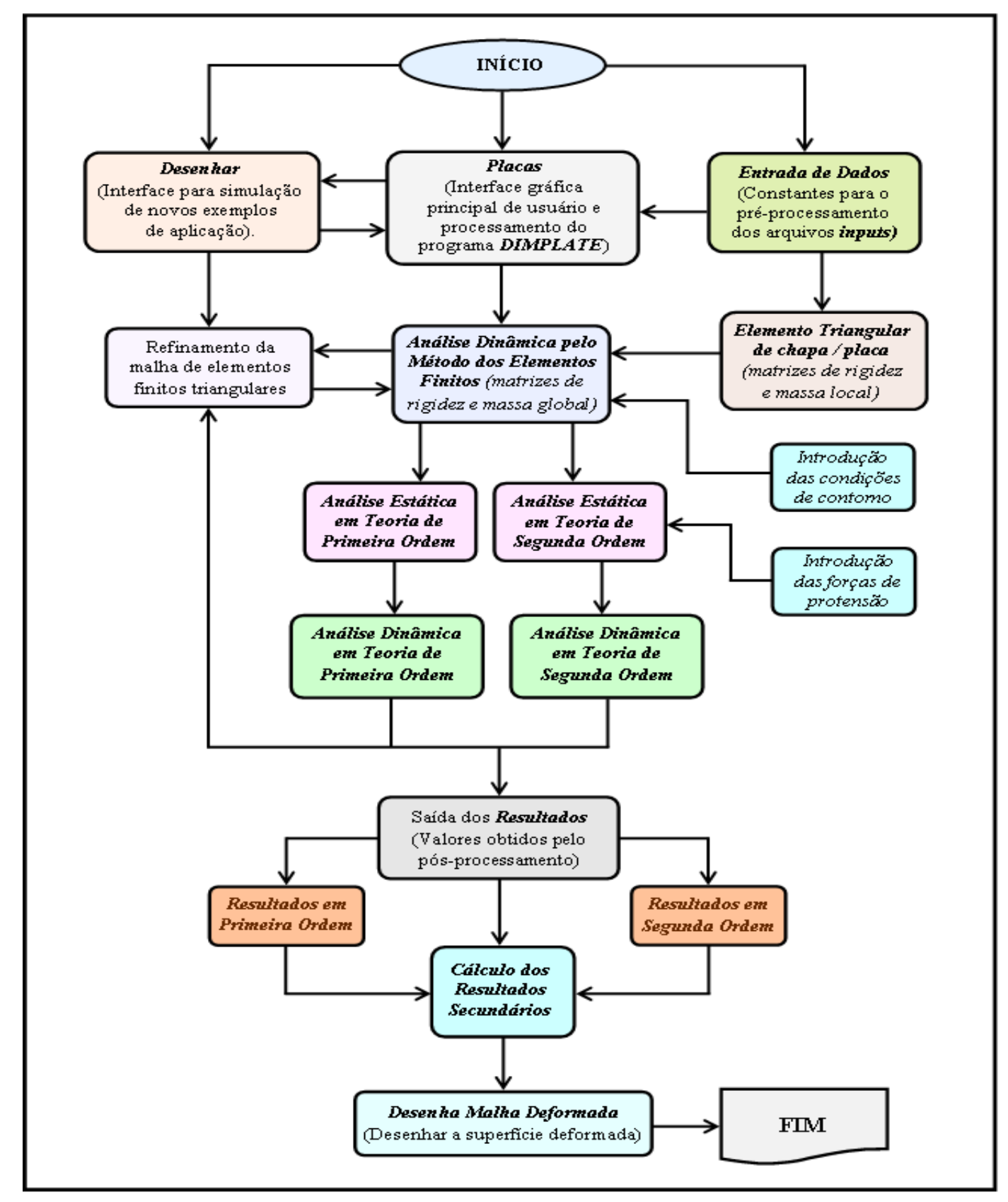

Figura 5.2 - Fluxograma básico do programa computacional. 


\section{3 - Arquivos de "Inputs"}

O primeiro procedimento a ser realizado pelo programa principal refere-se à leitura dos dados necessários para a análise do problema. $\mathrm{Na}$ análise pelo método dos elementos finitos, esses dados são basicamente os que definem a geometria do sistema estrutural. Eles se referem às propriedades do material que compõem a estrutura, como por exemplo, módulo de elasticidade e coeficiente de Poisson, e o carregamento externo atuante, que podem ser cargas concentradas ou uniformemente distribuídas sobre a superfície da placa, ou de protensão nas bordas da superfície.

Os arquivos de "inputs", são arquivos textos que possuem a extensão ".m", os quais podem ser gerados em qualquer editor de texto, e, constituem a etapa de préprocessamento inicial do programa DYMPLATE.

Para cada exemplo de placa a ser analisado, um novo arquivo texto necessita ser gerado. O pré-processamento são arquivos responsáveis por gerar a malha de elementos finitos, imposição de condições de contorno, carregamento, etc.

Os arquivos de "inputs" do programa DYMPLATE, são formados basicamente por duas subrotinas principais, que, após terem sido processadas, repassarão os dados armazenados também para as duas rotinas principais. Estas por sua vez, irão analisar o problema estático ou dinâmico em teoria de primeira ordem ("Análise por Elementos Finitos em Primeira Ordem"), ou em teoria de segunda ordem ("Análise por Elementos Finitos em Segunda Ordem"), conforme for o objetivo do cálculo.

A primeira subrotina principal para os dados de entrada do problema consiste exclusivamente das variáveis constantes do material de cada placa, ou seja:

- módulo de elasticidade do material (E).

- coeficiente de Poisson $(\mu)$.

- espessura da placa delgada (h).

- carregamento distribuído sobre a superfície da placa (P).

- densidade do material $(\rho)$.

- forças de volume $(X)$ e $(Y)$.

- forças de superfície (protensão) $(\bar{X})$ e $(\bar{Y})$. 
A segunda subrotina principal, diz respeito às características físicas de cada placa, ou seja, são funções inerentes à formação da malha de elementos finitos:

- dimensões das placas, $L x$ e $L y$, comprimento e largura respectivamente.

- identificação do número de nós na estrutura.

- identificação número de graus de liberdade total da estrutura.

- identificação dos elementos formados na estrutura.

- montagem da tabela de incidência.

- montagem da tabela de conectividade.

- geração da malha de elementos finitos.

- refinamento da malha de elementos finitos, ou seja, através de subdivisões ao longo do comprimento e da largura da placa, nas quantidades $(n x)$ e (ny), respectivamente.

- restrições nodais individuais para cada nó, ou para cada borda de uma placa separada, ou para todas as placas que formam um dado painel.

- as condições de carregamentos individuais poderão ser aplicadas em cada nó, ou em cada elemento, em todos os lados da placa ou para uma borda individual, ou ainda, poderá ser aplicada para todas as placas de um painel ao mesmo tempo. 


\section{4 - Arquivo "Elemento Triangular de chapa/placa"}

Este arquivo (rotina) é o responsável por todas as informações referentes a um único elemento finito de placa no sistema local, através das seguintes subrotinas:

- subrotina: obtém as coordenadas nodais do elemento no sistema local.

- subrotina: obtém a área do elemento finito triangular.

- subrotina: obtém as funções de forma (ou interpolação) e suas derivadas.

- subrotina: obtém a matriz de rigidez local do elemento de chapa $[k]_{o}^{p}$.

- subrotina: obtém a matriz de rigidez local do elemento de placa $[k]_{0}^{b}$.

- subrotina: obtém a matriz de rigidez geométrica local do elemento de placa $[k]_{g}^{b}$.

- subrotina: obtém a matriz de massa local do elemento de chapa $[M]^{p}$.

- subrotina: obtém a matriz de massa local do elemento de placa $[M]^{b}$.

- subrotina: obtém a matriz de ligação local do elemento de chapa / placa $[G]$.

- subrotina: obtém o vetor local de esforços do elemento de chapa $\{f\}^{p}$.

- subrotina: obtém o vetor local de esforços do elemento de placa $\{f\}^{b}$.

- subrotina: obtém a matriz local $[H]$.

- subrotina: obtém a matriz de rigidez secante $[K]_{S}$, no sistema local.

- subrotina: obtém a matriz de rigidez tangente $[K]_{T}$, no sistema local.

- subrotina: organização das matrizes global da estrutura, de acordo com os graus de liberdade de cada nó do elemento, através do conhecido Método da Colocação (Método de Análise Matricial).

- subrotina: organização do vetor global dos esforços da estrutura, de acordo com os graus de liberdade de cada nó através do Método da Colocação (Método de Análise Matricial). 


\section{5 - Arquivo "Análise por Elementos Finitos em Primeira Ordem"}

Esta rotina é responsável pelo processamento de todas as variáveis de entrada definidas, bem como da ligação entre as demais funções ou rotinas envolvidas nas etapas de montagem, resolução do problema estático e na resolução do problema dinâmico de autovalores e autovetores sob linearidade geométrica.

Todas as rotinas e subrotinas implementadas na formação deste arquivo são as responsáveis pela transferência das matrizes e vetores elementares, definidos no sistema local, para o sistema global da estrutura. Estas subrotinas são citadas a seguir:

- subrotina: determinação das coordenadas globais dos nós dos elementos.

- subrotina: determinação dos graus de liberdade total da estrutura.

- subrotina: obtém a matriz de rigidez global do elemento de chapa $[\mathbf{K}]_{0}^{p}$.

- subrotina: obtém a matriz de rigidez global do elemento de placa $[\mathbf{K}]_{0}^{b}$.

- subrotina: obtém a matriz de rigidez geométrica global da estrutura $[\mathbf{K}]_{\mathrm{g}}^{\mathbf{b}}$.

- subrotina: obtém a matriz de massa global do elemento de chapa $[\mathbf{M}]^{\mathbf{p}}$.

- subrotina: obtém a matriz de massa global do elemento de placa $[\mathbf{M}]^{\mathbf{b}}$.

- subrotina: obtém a matriz de ligação no sistema global, chapa / placa $[\mathbf{G}]$.

- subrotina: obtém o vetor global de esforços do elemento de chapa $\{\mathbf{f}\}^{p}$.

- subrotina: obtém o vetor global de esforços do elemento de placa $\{\mathbf{f}\}^{\mathbf{b}}$.

- subrotina: obtém a matriz $[\mathbf{H}]$ da estrutura no sistema global.

- subrotina: obtém a matriz de rigidez secante $[\mathbf{K}]_{\mathrm{S}}$ no sistema global.

- subrotina: obtém a matriz de rigidez tangente $[\mathbf{K}]_{\mathrm{T}}$ no sistema global.

- subrotina: impõem as condições de contorno no sistema de equações globais.

- subrotina: resolução do sistema de equações globais, $\left([\mathbf{K}]_{\mathrm{S}} \cdot\{\mathbf{a}\}=\{\mathbf{f}\}\right)$, para 0 cálculo estático do problema das placas, sendo que $[\mathbf{K}]_{\mathrm{S}}$ é a matriz de Rigidez Secante, $\{\mathbf{a}\}^{\mathbf{T}}=\left\{\begin{array}{ll}\mathbf{a}^{\mathbf{p}} & \mathbf{a}^{\mathbf{b}}\end{array}\right\}$ O vetor de incógnitas nodais e $\{\mathbf{f}\}^{\mathbf{T}}=\left\{\begin{array}{ll}\mathbf{f}^{\mathbf{p}} & \mathbf{f}^{\mathbf{b}}\end{array}\right\}$ O vetor 
de carregamentos, forças distribuídas na superfície, forças de superfície e de volume.

- subrotina: obtém os resultados secundários: momentos fletores $M_{x}, M_{y}$ e $M_{x y}$.

- subrotina: resolução do problema de autovalores e autovetores, freqüências naturais e modos de vibração respectivamente, em teoria de primeira ordem.

\section{6 - Arquivo “Análise por Elementos Finitos em Segunda Ordem”}

Todas as rotinas e subrotinas implementadas na formação deste arquivo são as responsáveis pela transferência das matrizes e vetores elementares, definidos no sistema local, para o sistema global da estrutura, bem com a resolução do problema estático e dinâmico das placas sob não-linearidade geométrica. Acrescenta-se às descritas no item anterior, as seguintes outras subrotinas:

- subrotina: cálculo numérico através do Método de Iteração Direta.

- subrotina: cálculo numérico através do Método de Newton-Raphson.

- subrotina: resolução do sistema de equações globais, $\left([\mathbf{K}]_{\mathbf{T}} \cdot\{\mathbf{a}\}=\{\mathbf{f}\}\right)$, para o cálculo estático não-linear do problema das placas, sendo que $[\mathbf{K}]_{\mathbf{T}}$ é a matriz de

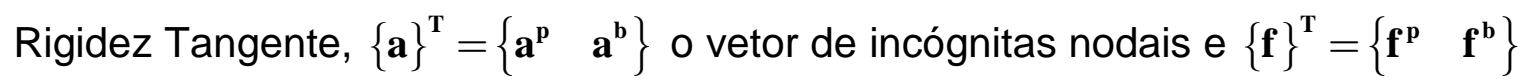
o vetor de carregamentos, forças distribuídas na superfície, forças de superfície e de volume.

- subrotina: resolução do problema de autovalores e autovetores, freqüências naturais e modos de vibração respectivamente, em teoria de segunda ordem. 


\section{7 - Arquivo "Placas"}

O arquivo "Placas".m, é o responsável pela criação da interface gráfica para usuário. Essa rotina foi elaborada tendo como base o pacote de funções intrínsecas pertencentes aos diretórios do MATLAB [53], para o desenvolvimento de interfaces gráficas, A função GUI - Graphical User Interface, também está presente no pacote de programas que compõem o MATLAB [53]. Cada uma dessas funções intrínsecas é adaptada às rotinas e subrotinas que fazem parte do código-fonte do programa DYMPLATE, de maneira a satisfazer o funcionamento adequado dos "callbacks" (menus, botões e textos) que constituem esta interface.

A Figura 5.3 a seguir, mostra a interface gráfica de usuário principal do programa DYMPLATE. Nela podem-se visualizar os menus e sub-menus em cascata (drop down) no topo da janela, uma barra de controle (tool bar), e também a seqüência de ícones para o gerenciamento da interface, as constantes de entrada, listagens das coordenadas de nós, conectividades dos elementos, campo das restrições nodais, etc.

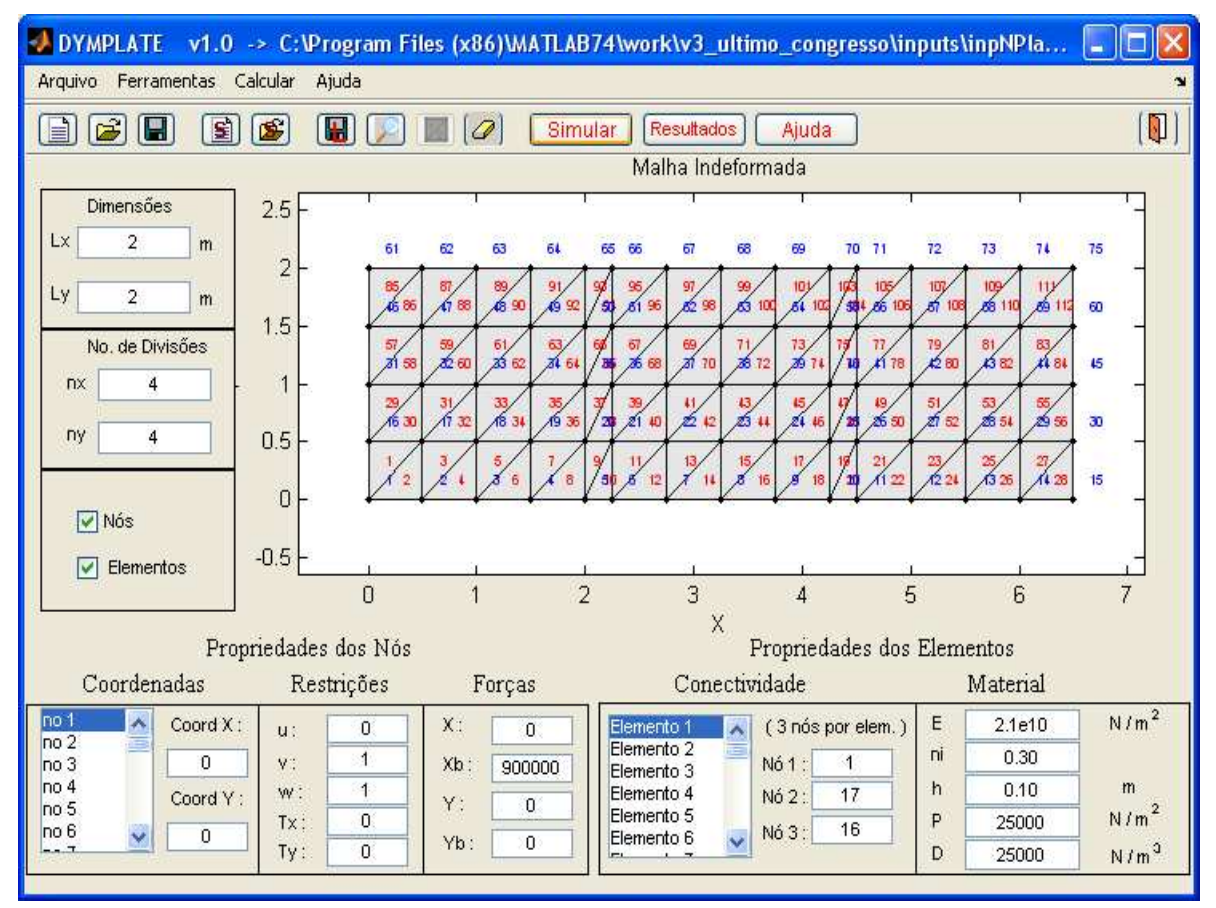

Figura 5.3 - Interface gráfica principal do programa computacional. 
A interface gráfica é de essencial importância para as mais diversas aplicações, pois ela permite que o usuário do programa tenha facilidade em realizar todas as análises e interpretação dos resultados, impondo mais dinamismo nas entradas e saídas de dados.

Com a interface gráfica "Placas".m, toda a estrutura de código-fonte do programa fica omitida e preservada, transparecendo apenas a aplicabilidade da ferramenta. Desta forma evita-se que altere o algoritmo fonte do programa, todas as vezes que for executar um novo cálculo e tenha que alterar as constantes de entrada características do material, deixando essa tarefa para os casos de modelagens bastante específicos.

Observa-se também, um sub-ambiente gráfico que mostra a malha gerada e também os botões para simulação do cálculo e de resultados. Através do acionamento do botão "Resultados", duas novas interfaces gráficas são acessadas, uma que exibirá os resultados obtidos pelos cálculos estáticos lineares e nãolineares e outra que mostrará os resultados do cálculo dinâmico.

O menu "Arquivo" do topo da interface gráfica contém opções para abrir arquivos de exemplos já compilados anteriormente e que foram salvos no diretório do programa. Esses arquivos, já compilados, possuem a extensão característica “.mat”, cuja listagem final podem ser editadas ou salvas numa planilha do Excel. 
A Figura 5.4 a seguir mostra o menu em cascata (drop down) do menu "Arquivo", pertencente a interface "Placas.m".

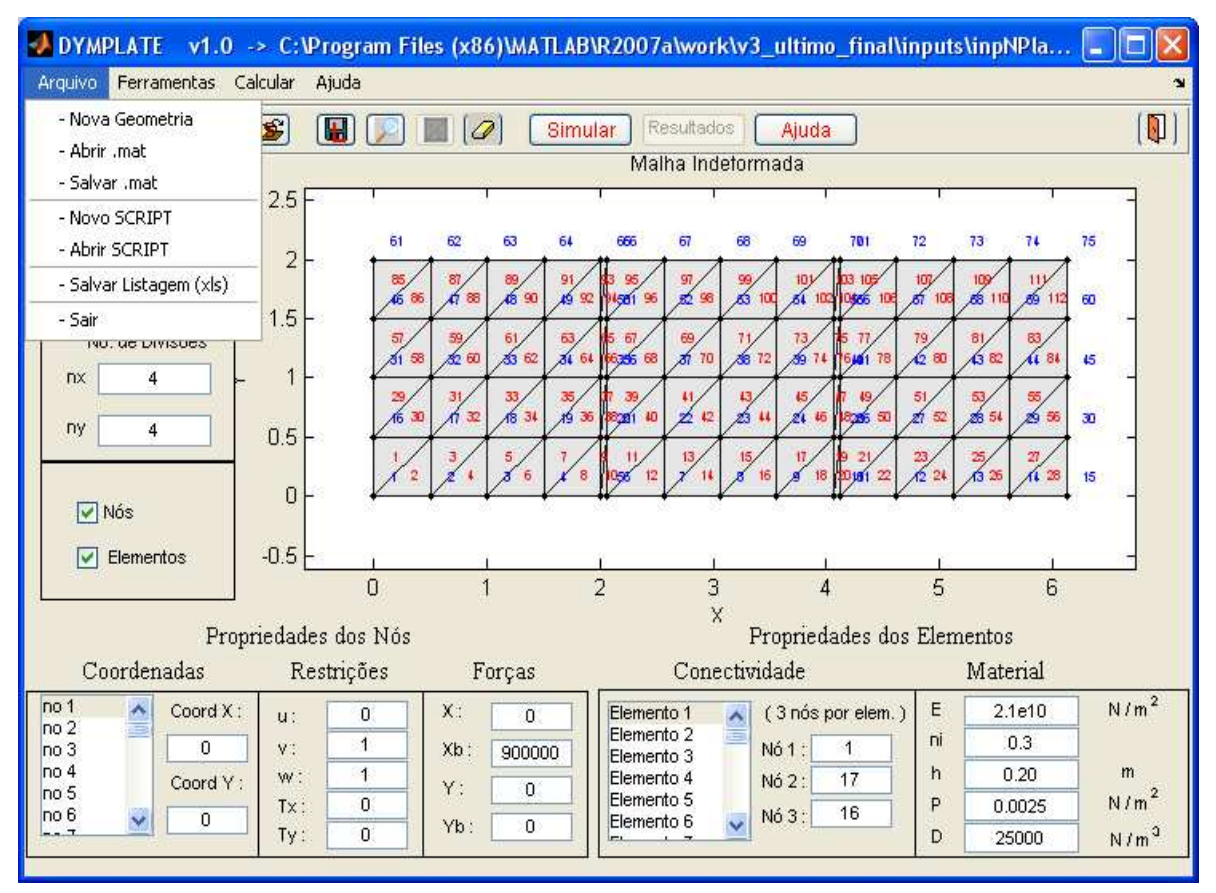

Figura 5.4 - Interface gráfica "Placas" com destaque para os menus "drop down".

Um importante sub-menu que está contido dentro do menu "Arquivo" é o comando "Nova Geometria", cuja função é o de acessar o módulo "Desenhar. m" que exibirá outra interface gráfica de usuário onde é possível criar novos exemplos de modelagens de placas iterativamente. O módulo "Desenhar" é apresentado com maiores detalhes logo mais adiante.

A barra de controle (tool bar) exibe quatro conjuntos de botões de gerenciamento da interface que são os responsáveis pela criação de novos exemplos de modelagens, abrir o aplicativo Excel contendo a listagem dos resultados, salvar arquivos, criar novos scripts textos, abrir e editar scripts textos já salvos na pasta de "inputs", salvar a listagem dos resultados obtidos com a extensão ".doc" no editor de texto MS Word, visualizar a malha indeformada, gerar a malha de elementos finitos, executar o programa, exibição dos resultados obtidos e carregar o tutorial do programa através do botão de ajuda. 
A Figura 5.5 a seguir, mostra a janela "Carregar placa", acessada através do botão "abrir e editar scripts", contendo alguns arquivos textos com diversos exemplos modelados de painéis de placas que foram salvos no diretório do programa, na pasta de arquivos de "inputs". Esses arquivos podem ser solicitados a qualquer instante pelo usuário.

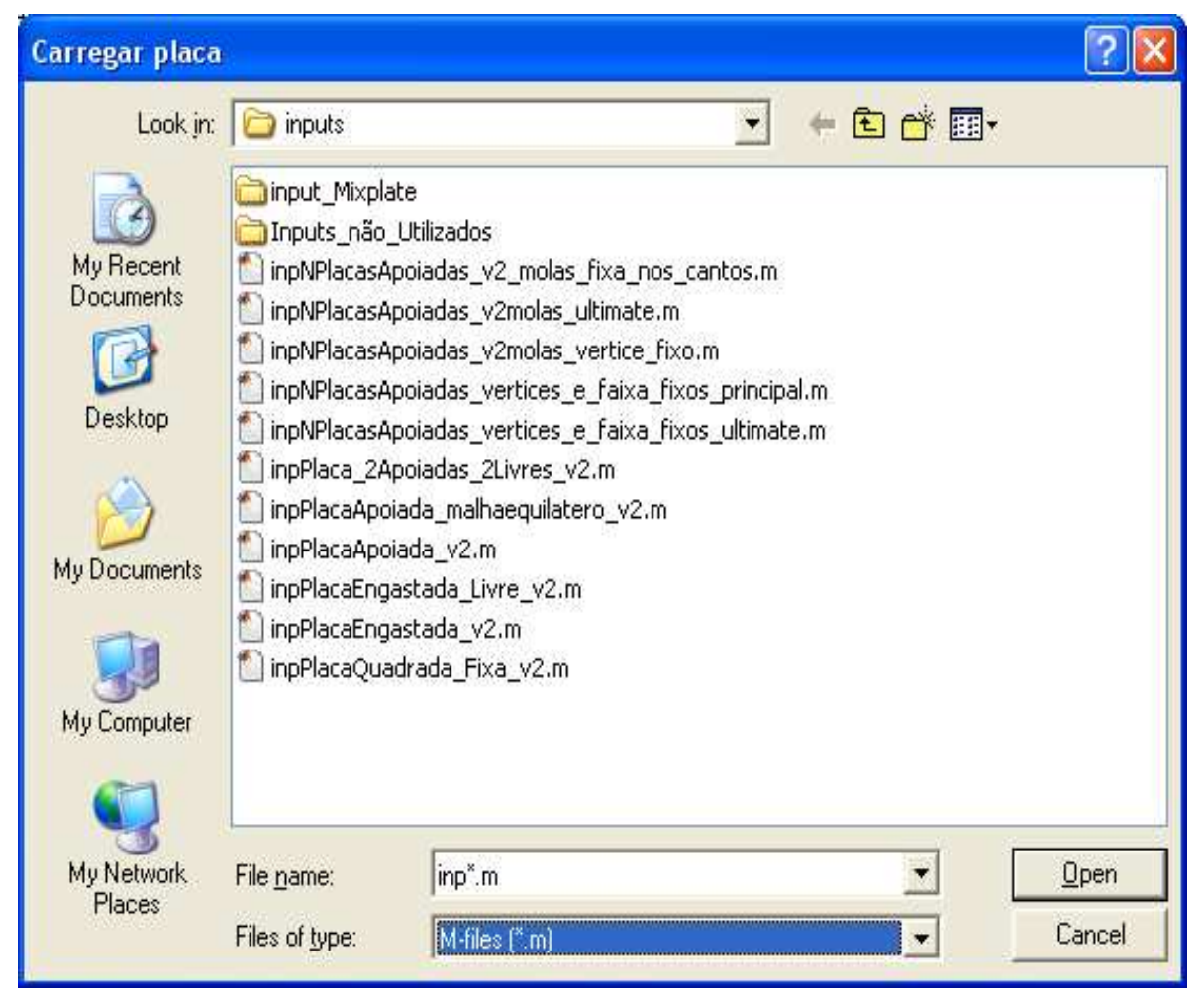

Figura 5.5 - Janela com exemplos de arquivos "Inputs" já modelados. 


\section{8 - Arquivo "Resultados em Primeira Ordem"}

O arquivo "Resultados em Primeira Ordem".m, é um arquivo texto que abre uma nova interface gráfica, que está contida na interface principal do programa DYMPLATE. Apresenta-se nesta janela, uma listagem contendo os valores máximos e mínimos obtidos para as incógnitas primárias e secundárias do problema estático linear, de cada ponto nodal. Visualiza-se também um sub-ambiente gráfico que mostra a superfície deformada da placa.

Cada botão e menu presente nesta janela, inclusive o próprio ambiente de visualização gráfica, possui um código-fonte intrínseco pertencente ao pacote de funções ou rotinas que compõem o software MATLAB [53]. Desta forma, torna-se possível adaptá-las a outras subrotinas necessárias para a resolução do problema ao qual esteja sendo solicitado. A Figura 5.6 a seguir, mostra o visual gráfico desta interface.

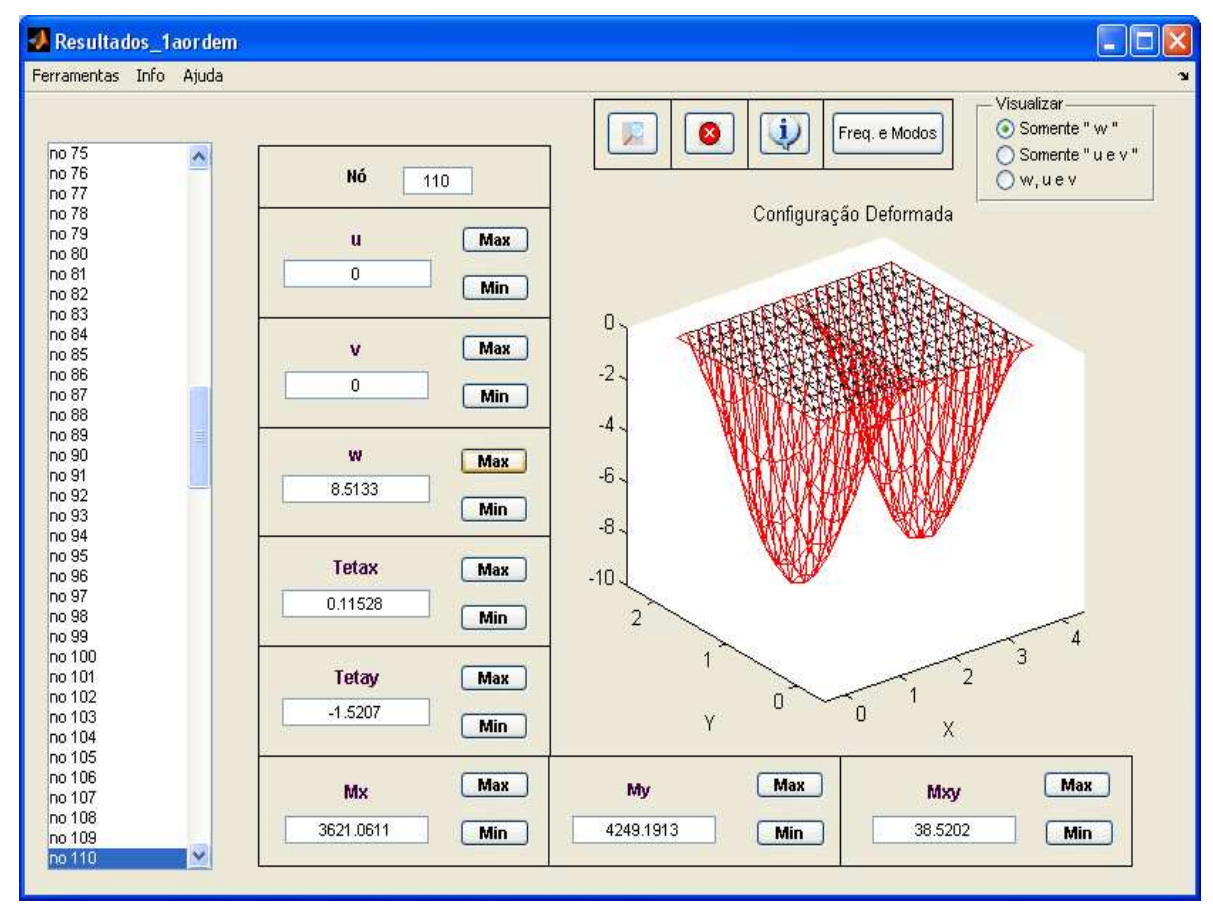

Figura 5.6 - Interface gráfica "Resultados em Primeira Ordem". 


\section{9 - Arquivo "Resultados em Segunda Ordem"}

Semelhante ao arquivo anterior, o arquivo "Resultados em Segunda Ordem".m, é um arquivo texto para implementação de uma interface gráfica, que também é acionada através da interface principal Placas.m, do programa DYMPLATE.

Apresenta-se nesta janela, uma listagem contendo os valores máximos e mínimos obtidos para as incógnitas primárias e secundárias do problema estático não-linear, correspondentes a cada ponto nodal. Visualiza-se também um subambiente gráfico que mostra a superfície deformada da placa e também o botão de acessibilidade para outra interface gráfica que mostrará os resultados obtidos pela análise dinâmica do problema em questão. A Figura 5.7 a seguir, mostra o visual gráfico desta interface.

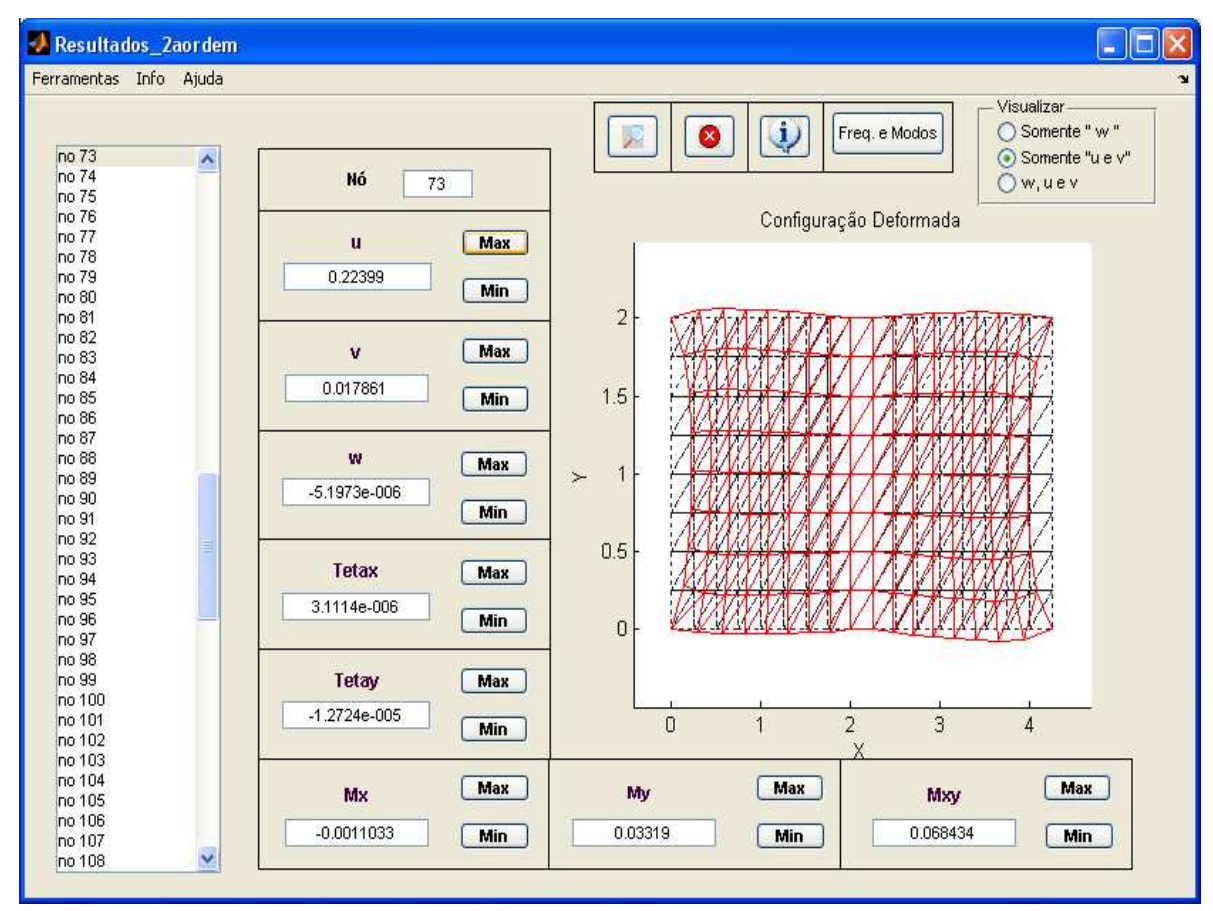

Figura 5.7 - Interface gráfica "Resultados em Segunda Ordem". 


\subsection{0 - Arquivo "Dinâmica em Primeira Ordem"}

O arquivo "Dinâmica em Primeira Ordem".m, gera uma interface gráfica que é acionada através da interface "Resultados em Primeira Ordem" que compõe o programa DYMPLATE. Nesta janela é apresentada a listagem dos valores obtidos pelo cálculo em teoria de primeira ordem, ou seja, sob linearidade geométrica, para as freqüências naturais em diferentes unidades de medidas.

Visualiza-se também nesta interface, um sub-ambiente gráfico que mostra a animação gráfica dos modos de vibração (autovetores) associados aos autovalores (freqüências naturais) do problema em questão. A velocidade de vibração da estrutura e também o número de repetições mostradas, podem ser alteradas por meio de botões de comando, que fazem parte do controle dos frames previamente definidos. A Figura 5.8 a seguir, mostra o visual gráfico desta interface.

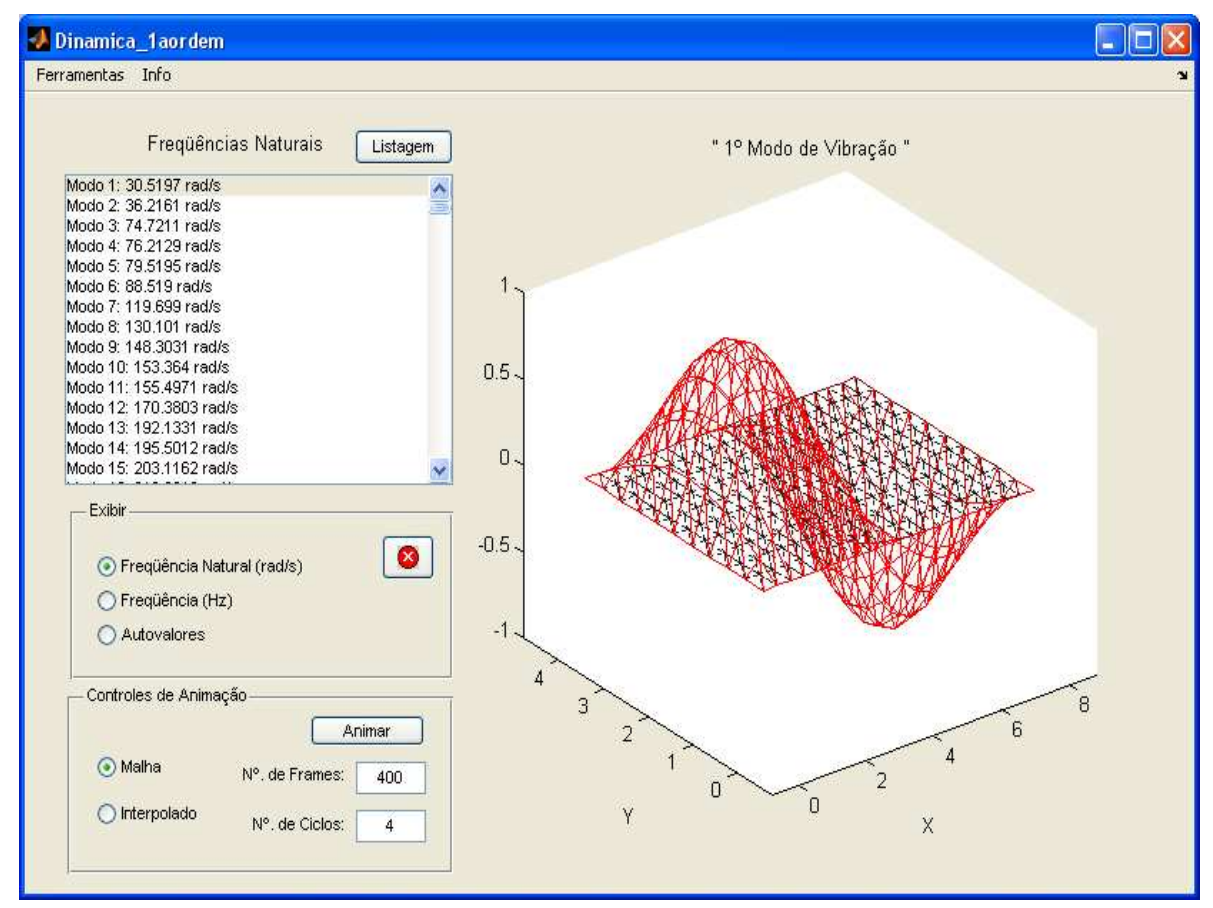

Figura 5.8 - Interface gráfica "Dinâmica em Primeira Ordem". 


\subsection{1 - Arquivo "Dinâmica em Segunda Ordem"}

Semelhante ao arquivo anterior, o arquivo "Dinâmica em Segunda Ordem".m, é um arquivo texto para implementação de uma interface gráfica, a qual é acessada através da interface "Resultados em Segunda Ordem" do programa DYMPLATE. Apresenta-se nesta janela a listagem com os valores do cálculo obtidos em teoria de segunda ordem, ou seja, sob não-linearidade geométrica, para as freqüências naturais em diferentes unidades de medidas. A Figura 5.9 a seguir, mostra o visual gráfico desta interface.

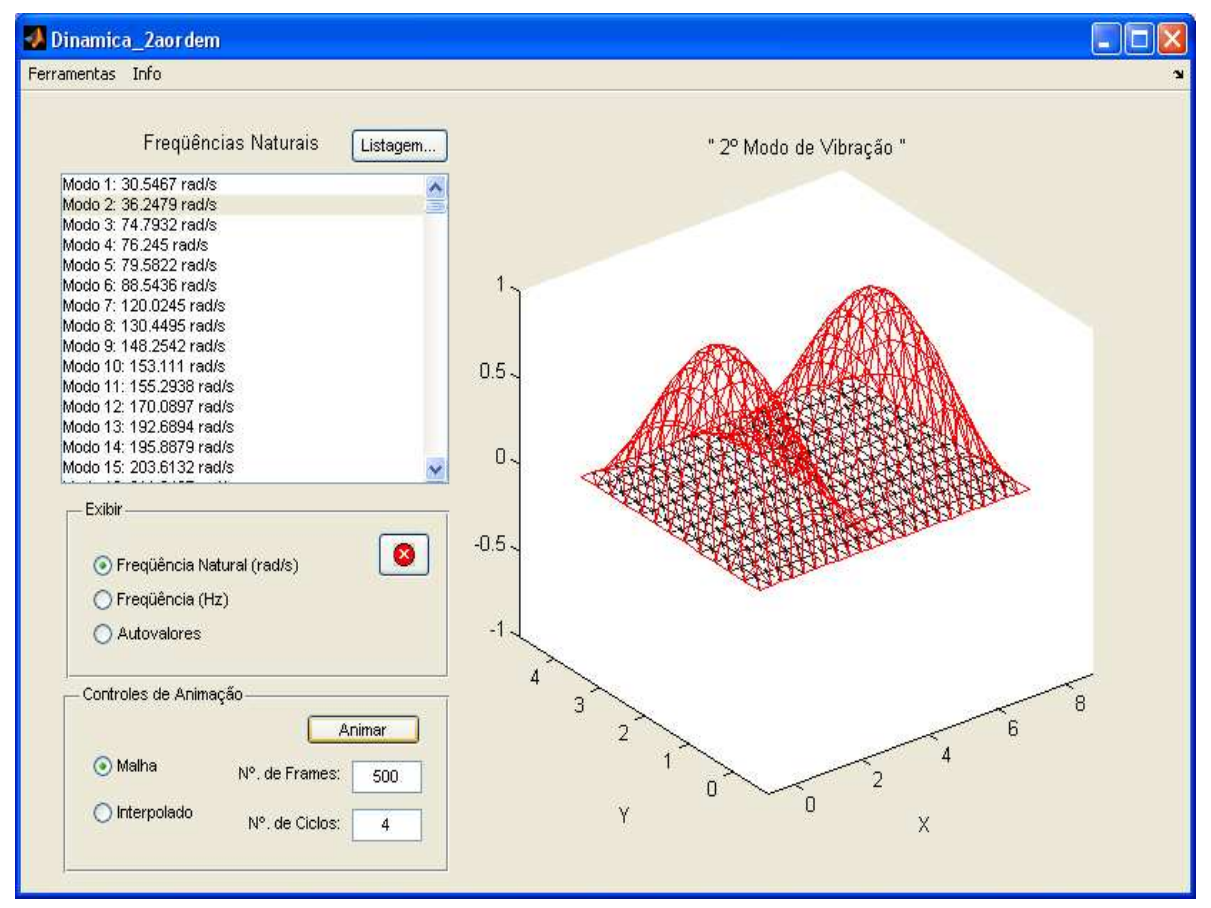

Figura 5.9 - Interface gráfica "Dinâmica em Segunda Ordem". 


\subsection{2 - Arquivo "Desenhar Placas"}

Trata-se de uma nova rotina para criação de um ambiente gráfico, onde é possível desenvolver diferentes exemplos de aplicações para superfícies de placas com formato qualquer, através da inserção de coordenadas que definem os pontos dos vértices, conexão entre esses pontos, criação e refinamento da malha de elementos finitos, além da aplicação das condições de contorno, via teclado ou mouse. Portanto, não se utiliza os arquivos textos de "inputs".m previamente elaborados.

Esta interface gráfica, é acionada através do "botão desenhar" que está presente no ambiente da interface "Placas".m. Após ter sido concluído a modelagem para uma nova aplicação, os dados que foram gerados são repassados de volta para a interface "Placas".m, onde se dará o processamento dos cálculos para as incógnitas do problema e fornecimento da listagem dos resultados finais. A Figura 5.10 , mostra esta interface.

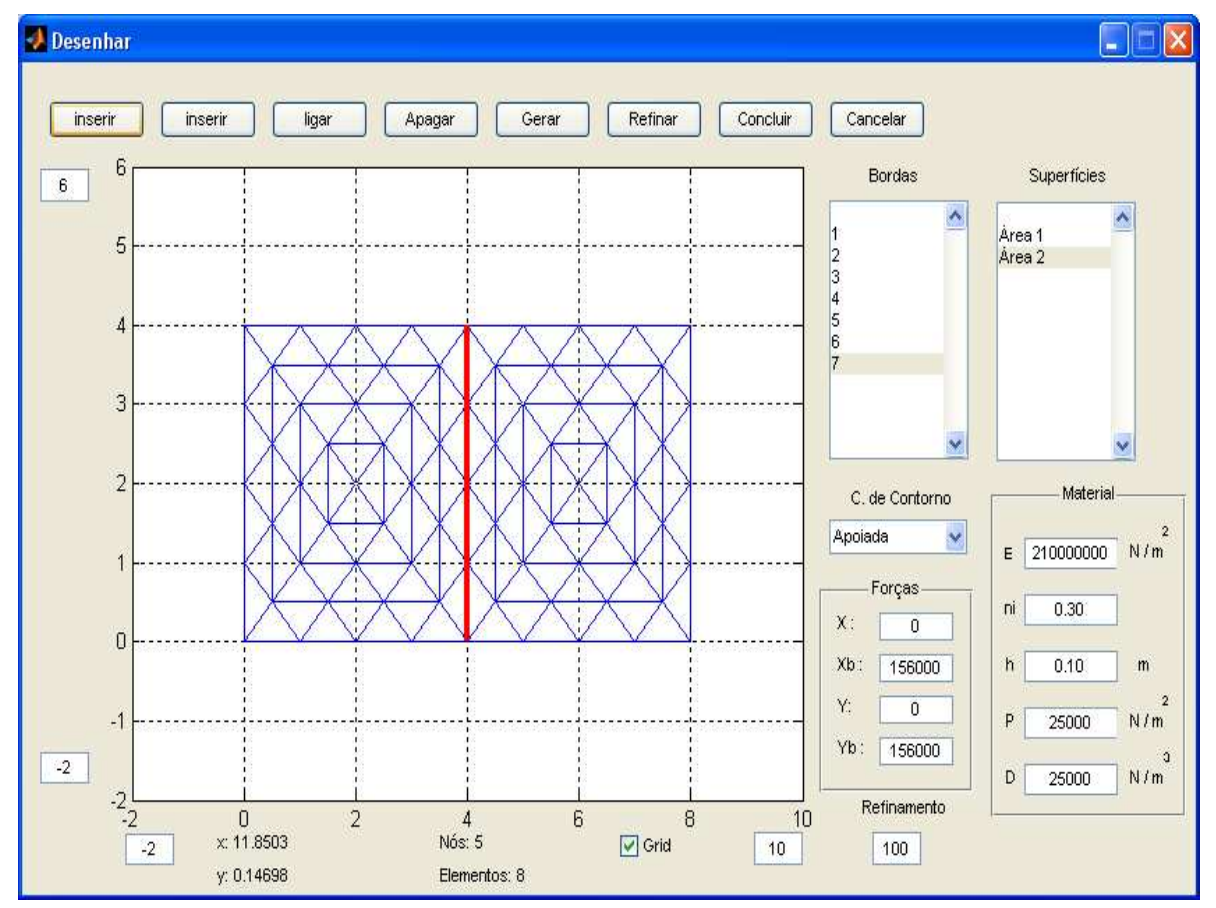

Figura 5.10 - Interface gráfica "Desenhar Placas". 


\subsection{3 - Arquivo "Desenha Malha Indeformada"}

Para desenhar a malha no seu estado indeformado, foram desenvolvidas algumas subrotinas, que também são compiladas através da rotina principal do programa DYMPLATE. Essas subrotinas são responsáveis pelos comandos necessários à abertura de uma janela gráfica com capacidade para utilização dos mais variados recursos e comandos intrínsecos que fazem parte das funções próprias do software MATLAB [53].

Através desses comandos, pode-se fazer o gerenciamento da figura que está compilada, como por exemplo: ampliar, reduzir, girar, editar gráfico, criar rótulos, colocar títulos e legendas, além de ter a opção de orientação dos eixos de referência nos sistemas cartesianos e polares. A Figura 5.11 a seguir, mostra o visual gráfico da malha indeformada.

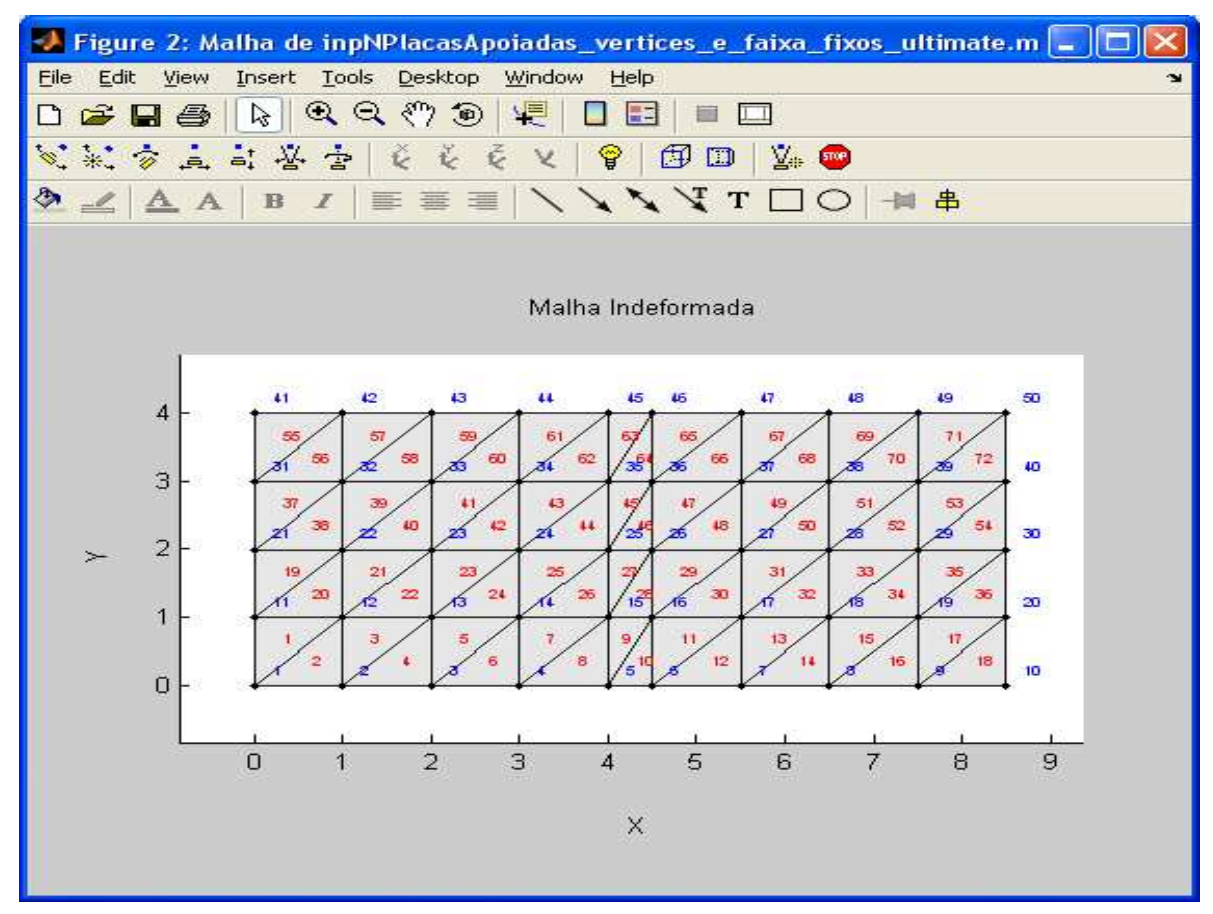

Figura 5.11 - Interface gráfica "Malha Indeformada". 


\subsection{4 - Arquivo "Desenha Malha Deformada"}

Para desenhar a malha no seu estado deformado, foram desenvolvidas algumas subrotinas, que também são compiladas através da rotina principal do programa DYMPLATE. Essas subrotinas são responsáveis pelos comandos necessários à abertura de uma janela gráfica com capacidade para utilização dos mais variados recursos e comandos intrínsecos que fazem parte das funções próprias do software MATLAB [53].

Através desses comandos, pode-se fazer o gerenciamento após a execução do programa, da figura no seu estado deformado, como por exemplo: ampliar, reduzir, girar, editar gráfico, criar rótulos, colocar títulos e legendas, além de ter a opção de orientação dos eixos de referência nos sistemas cartesianos e polares. A Figura 5.12 a seguir, mostra o visual gráfico da malha deformada.

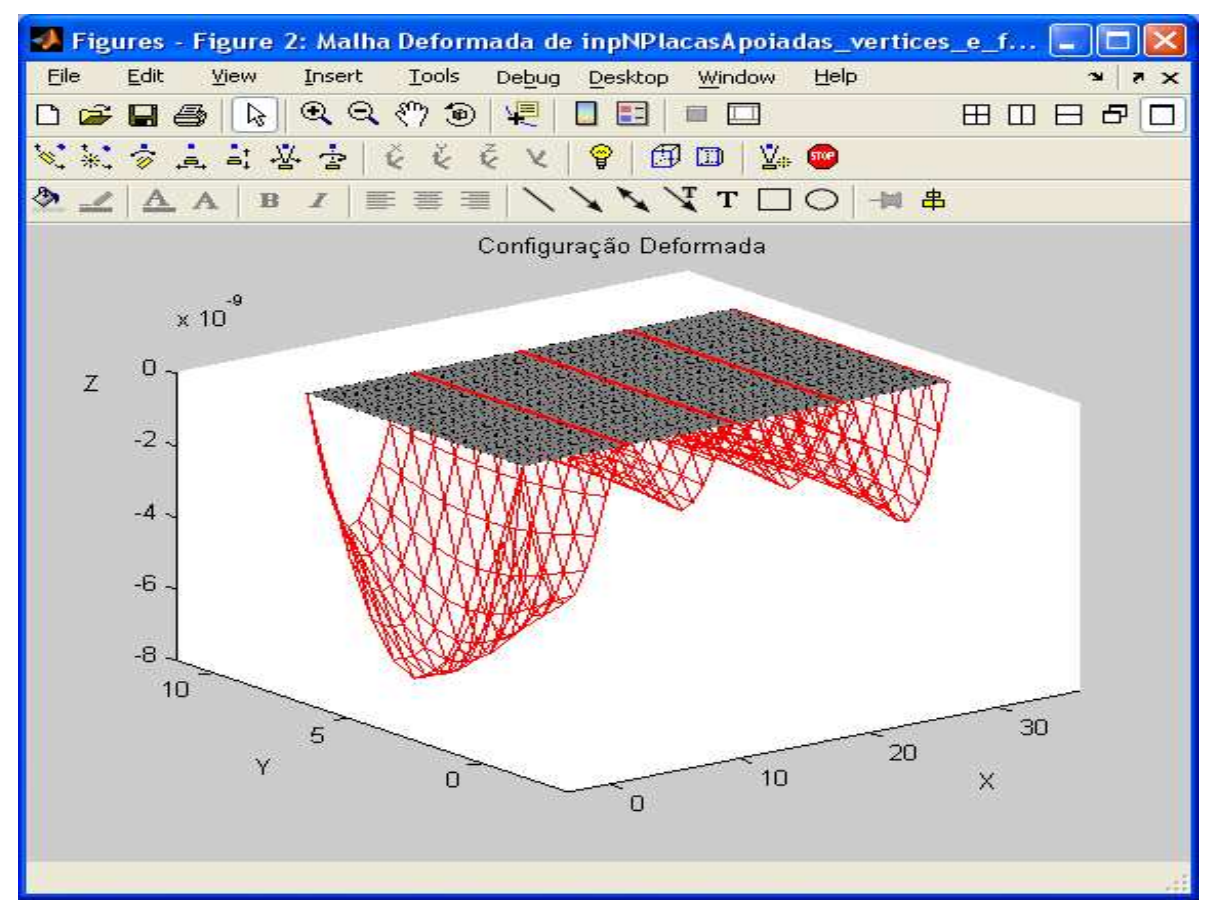

Figura 5.12 - Interface gráfica "Malha Deformada". 


\section{Capítulo 6}

\section{Estudos Numéricos}

\section{1 - Painel formado por duas placas}

Uma análise numérica do problema de vibrações de placas é apresentada nesta seção. Os valores obtidos serão apresentados em tabelas e gráficos. Trata-se nesta série de estudos, do problema da Localização dos Modos de Vibração e a obtenção das freqüências naturais, para vários tipos de desordens aplicadas de forma proposital nas características físicas e geométricas das placas.

Para iniciar-se um estudo qualitativo, uma estrutura quase periódica mínima, é obtida pela consideração de um painel formado por apenas duas placas quadradas homogêneas e isotrópicas, acopladas a uma viga de grande rigidez, a qual é representada por uma mola de rigidez rotacional, conforme é mostrado na Figura 6.1 a seguir:

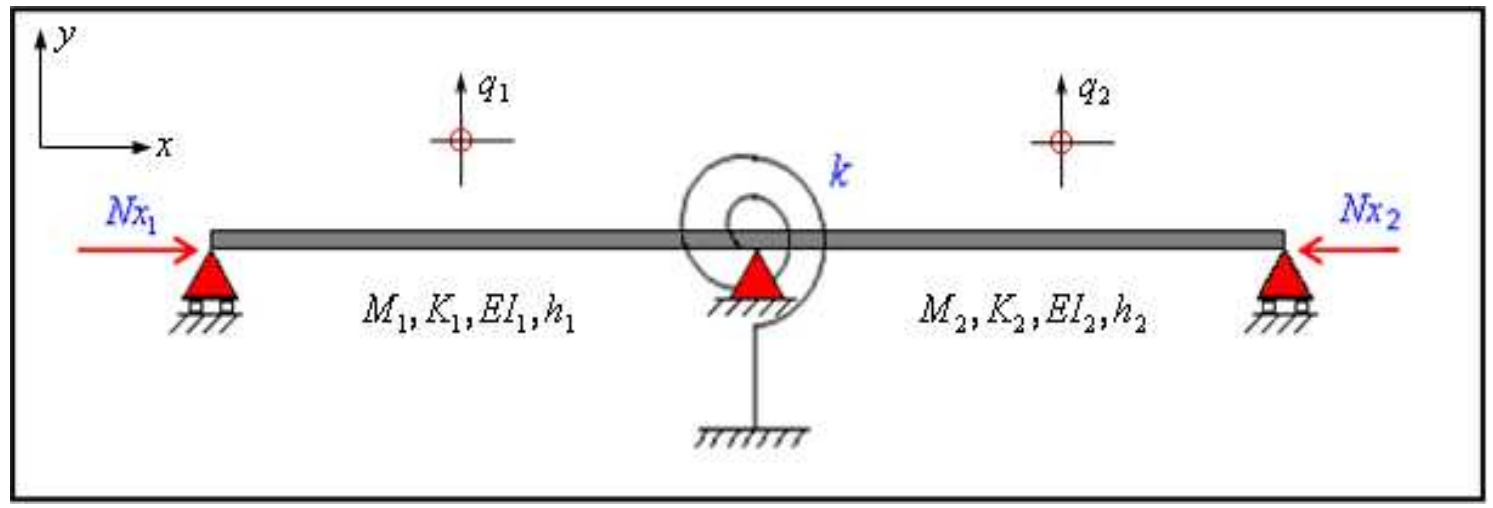

Figura 6.1 - Modelo de um sistema quase periódico de duas placas acopladas a uma mola de rigidez rotacional $\mathrm{k}$. 
Para o caso de sistemas reais, pequenas diferenças entre as características nas duas subestruturas, de natureza aleatória ou determinística, podem existir entre elas. No que se seguem essas propriedades são distinguidas por índices $i$, que assumem o valor 1 para a placa da esquerda e 2 para a da direita. A espessura das placas é $h_{i}$ e suas rigidezes flexionais são $E I_{i}$.

A rigidez " $k$ " da mola equivale a $2 \%$ da rigidez $K_{i}$ das placas, sendo que $M_{i}$ e $N x_{i}$, são respectivamente as massas e as forças de protensão aplicadas na direção longitudinal da placa, segundo o grau de liberdade horizontal $q_{i}$.

\subsection{1 - Exemplos numéricos}

Na ausência de desordem, o primeiro exemplo de um modelo físico real a ser analisado é o de um painel composto por duas placas quadradas de material homogêneo e isotrópico com dimensões $L x=L y=8,00 m$, módulo de elasticidade $E=2,1 \times 10^{10} \mathrm{~N} / \mathrm{m}^{2}$, espessura $\bar{h}=0,20 \mathrm{~m}$ e coeficiente de Poisson $v=0,25$. Este painel está simplesmente apoiado na viga intermediária de largura $\bar{l}_{x}=\frac{L x}{32}$ e cuja altura $h=0,60 m$, conforme e mostrado na Figura 6.2.

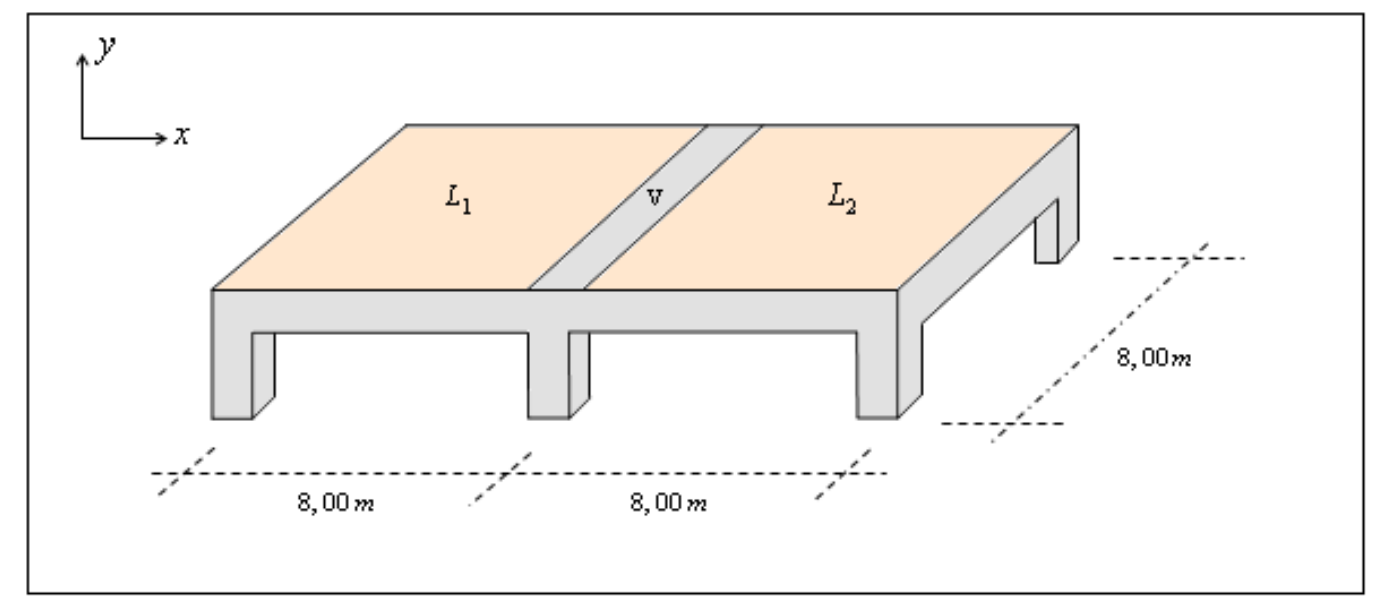

Figura 6.2 - Perspectiva do modelo físico real do painel de placas acopladas. 
A partir do Método dos Elementos Finitos, sabe-se que o sucesso obtido na elaboração de um modelo de cálculo está intimamente relacionado à capacidade de entender a natureza física do fenômeno que pretendemos representar. A identificação dos pontos relevantes do problema objeto de análise permite-nos tecer hipóteses sobre o seu comportamento.

A estrutura real que foi mostrada na Figura 6.2, é então substituída pelo modelo estrutural aproximado da Figura 6.3, desta forma, estaremos modelando de forma a não termos interferência da viga nas lajes e tornar o programa de cálculo de elementos finitos de maior tamanho e dificuldades.

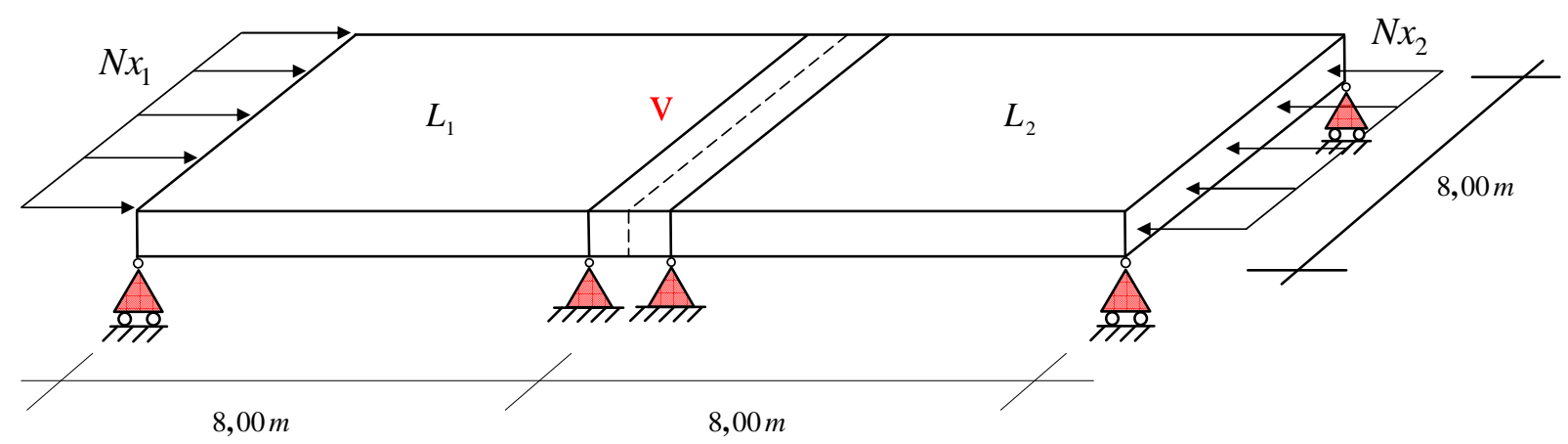

Figura 6.3 - Modelo estrutural simplificado do painel formado por duas placas.

A Figura 6.4 a seguir, mostra a vista em planta do painel formado por duas placas quadradas acopladas a uma viga de grande rigidez e com carregamento de protensão aplicado na direção do plano longitudinal " $x$ ".

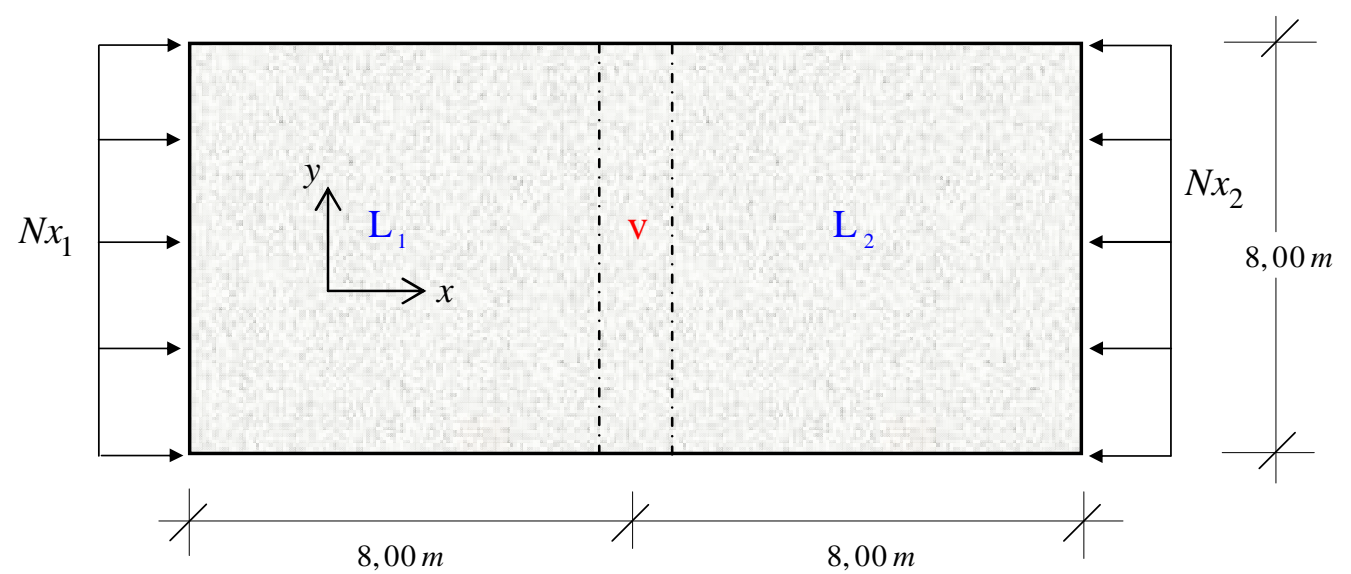

Figura 6.4 - Vista em planta do painel formado por duas placas. 


\subsection{2 - Vibrações}

Trata-se, nesta primeira série de estudos, do problema da Localização dos Modos de Vibração. Vários graus e tipos de desordem e intensidades de acoplamento são a seguir enumerados, ilustrados com figuras e comentados.

a) Estudo do efeito da variação da espessura de referência $(\bar{h})$ das placas na forma:

$$
\begin{aligned}
& h_{1}=\bar{h}(1+\varepsilon) \\
& h_{2}=\bar{h}(1-\varepsilon)
\end{aligned}
$$

onde se introduziu $\varepsilon$ um parâmetro pequeno relacionado com o grau de desordem, variando no intervalo de $-5 \%$ a $+5 \%$.

A Tabela 6.1 mostra os valores obtidos para as freqüências naturais dos dois primeiros modos de vibração, obtidos pelo programa DYMPLATE, para a variação na espessura de referência $(\bar{h}=0,20 \mathrm{~m})$ das placas.

\begin{tabular}{ccccc}
\hline $\begin{array}{c}\text { Grau de } \\
\text { desordem }\end{array}$ & $L_{1}$ & $L_{2}$ & \multicolumn{2}{c}{$\begin{array}{c}\text { Freqüências naturais } \\
(\mathrm{rad} / \mathrm{s})\end{array}$} \\
\hline $\mathcal{E}(\%)$ & $h_{1}(m)$ & $h_{2}(m)$ & $1^{\circ}$ modo & $2^{\circ}$ modo \\
\hline$-5 \%$ & 0,1900 & 0,2100 & 9,5782 & 10,5986 \\
$-4 \%$ & 0,1920 & 0,2080 & 9,6761 & 10,5172 \\
$-3 \%$ & 0,1940 & 0,2060 & 9,7725 & 10,4361 \\
$-2 \%$ & 0,1960 & 0,2040 & 9,8659 & 10,3571 \\
$-1 \%$ & 0,1980 & 0,2020 & 9,9514 & 10,2850 \\
$0 \%$ & 0,2000 & 0,2000 & 9,9797 & 10,1362 \\
$1 \%$ & 0,2020 & 0,1980 & 9,9514 & 10,2850 \\
$2 \%$ & 0,2040 & 0,1960 & 9,8659 & 10,3571 \\
$3 \%$ & 0,2060 & 0,1940 & 9,7725 & 10,4361 \\
$4 \%$ & 0,2080 & 0,1920 & 9,6761 & 10,5172 \\
$5 \%$ & 0,2100 & 0,1900 & 9,5782 & 10,5986 \\
\hline
\end{tabular}

Tabela 6.1 - Freqüências naturais versus grau de desordem na espessura. 
As curvas na Figura 6.5, mostram gráficos da variação das freqüências naturais correspondentes aos dois primeiros modos de vibração versus $\varepsilon$. Pode-se observar a forma marcantemente não-linear e rápida com que essas duas curvas se afastam uma da outra. Este fenômeno é conhecido, em inglês, por curve veering. Foi pela identificado pela primeira vez por LEISSA [46] em 1970, no contexto de freqüências de vibração de placas.

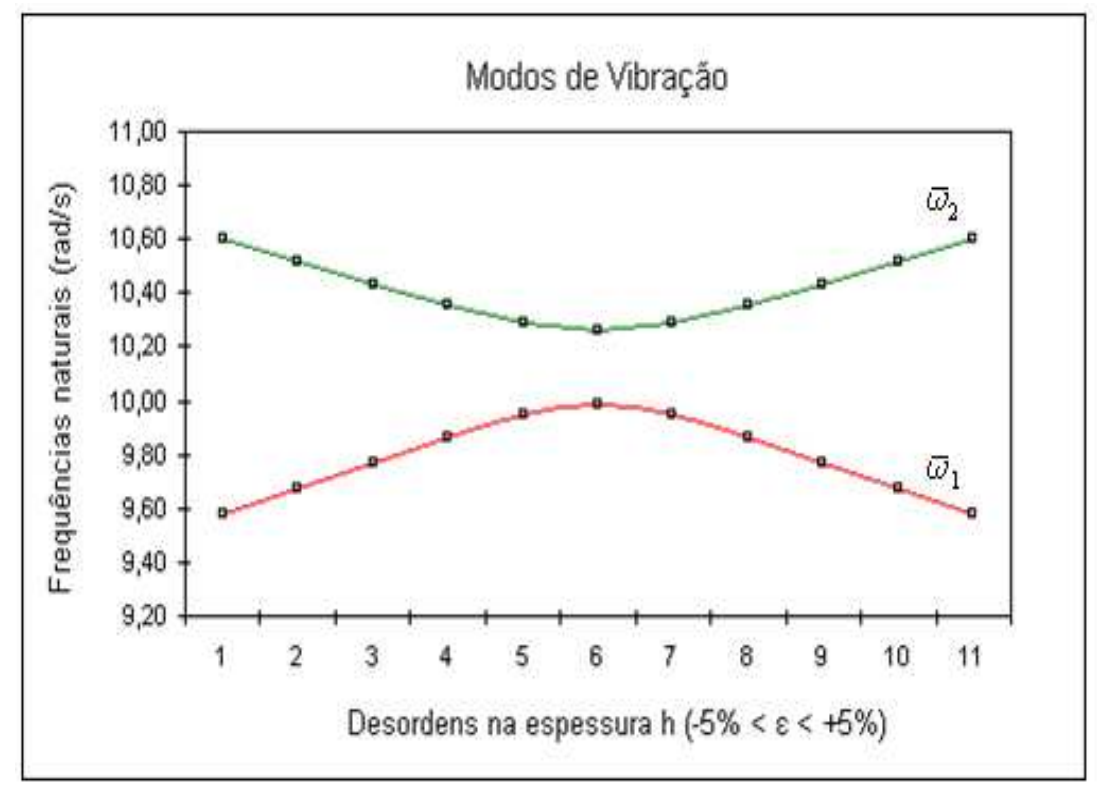

Figura 6.5 - Freqüências naturais versus grau de desordem na espessura.

b) Estudo do efeito da variação da rigidez flexional $(\bar{E} I)$ das placas na forma:

$$
\begin{aligned}
& E I_{1}=\bar{E} I(1+\varepsilon) \\
& E I_{2}=\bar{E} I(1-\varepsilon)
\end{aligned}
$$

onde se introduziu $\varepsilon$ um parâmetro pequeno relacionado com o grau de desordem, variando no intervalo de $-5 \%$ a $+5 \%$. 
A seguir a Tabela 6.2, mostra os valores obtidos para as freqüências naturais para os dois primeiros modos de vibração, obtidos pelo programa DYMPLATE, para a variação na rigidez flexional de referência $\left(\bar{E} I=2,1 \times 10^{10} \mathrm{~N} \cdot \mathrm{m}^{2}\right)$ das placas.

\begin{tabular}{ccccc}
\hline $\begin{array}{c}\text { Grau de } \\
\text { desordem }\end{array}$ & $L_{1}$ & $L_{2}$ & \multicolumn{2}{c}{ Freqüências naturais (rad/s) } \\
\hline $\mathcal{E}(\%)$ & $E I_{1}\left(N . m^{2}\right)$ & $E I_{2}\left(N . m^{2}\right)$ & $1^{\circ}$ modo & $2^{\circ}$ modo \\
\hline$-5 \%$ & $1,9950 \mathrm{E} 10$ & $2,2050 \mathrm{E} 10$ & 9,8175 & 10,4040 \\
$-4 \%$ & $2,0160 \mathrm{E} 10$ & $2,1840 \mathrm{E} 10$ & 9,8648 & 10,3634 \\
$-3 \%$ & $2,0370 \mathrm{E} 10$ & $2,1630 \mathrm{E} 10$ & 9,9101 & 10,3242 \\
$-2 \%$ & $2,0580 \mathrm{E} 10$ & $2,1420 \mathrm{E} 10$ & 9,9519 & 10,2880 \\
$-1 \%$ & $2,0790 \mathrm{E} 10$ & $2,1210 \mathrm{E} 10$ & 9,9872 & 10,2574 \\
$0 \%$ & $2,1000 \mathrm{E} 10$ & $2,1000 \mathrm{E} 10$ & 10,0108 & 10,2382 \\
$1 \%$ & $2,1210 \mathrm{E} 10$ & $2,0790 \mathrm{E} 10$ & 9,9872 & 10,2574 \\
$2 \%$ & $2,1420 \mathrm{E} 10$ & $2,0580 \mathrm{E} 10$ & 9,9519 & 10,2880 \\
$3 \%$ & $2,1630 \mathrm{E} 10$ & $2,0370 \mathrm{E} 10$ & 9,9101 & 10,3242 \\
$4 \%$ & $2,1840 \mathrm{E} 10$ & $2,0160 \mathrm{E} 10$ & 9,8648 & 10,3634 \\
$5 \%$ & $2,2050 \mathrm{E} 10$ & $1,9950 \mathrm{E} 10$ & 9,8175 & 10,4040 \\
\hline
\end{tabular}

Tabela 6.2 - Freqüências naturais versus grau de desordem na rigidez flexional.

As curvas na Figura 6.6 mostram gráficos da variação das freqüências naturais correspondentes aos dois primeiros modos de vibração versus $\varepsilon$ para desordens na rigidez flexional das placas, onde se pode verificar claramente a ocorrência do fenômeno curve veering.

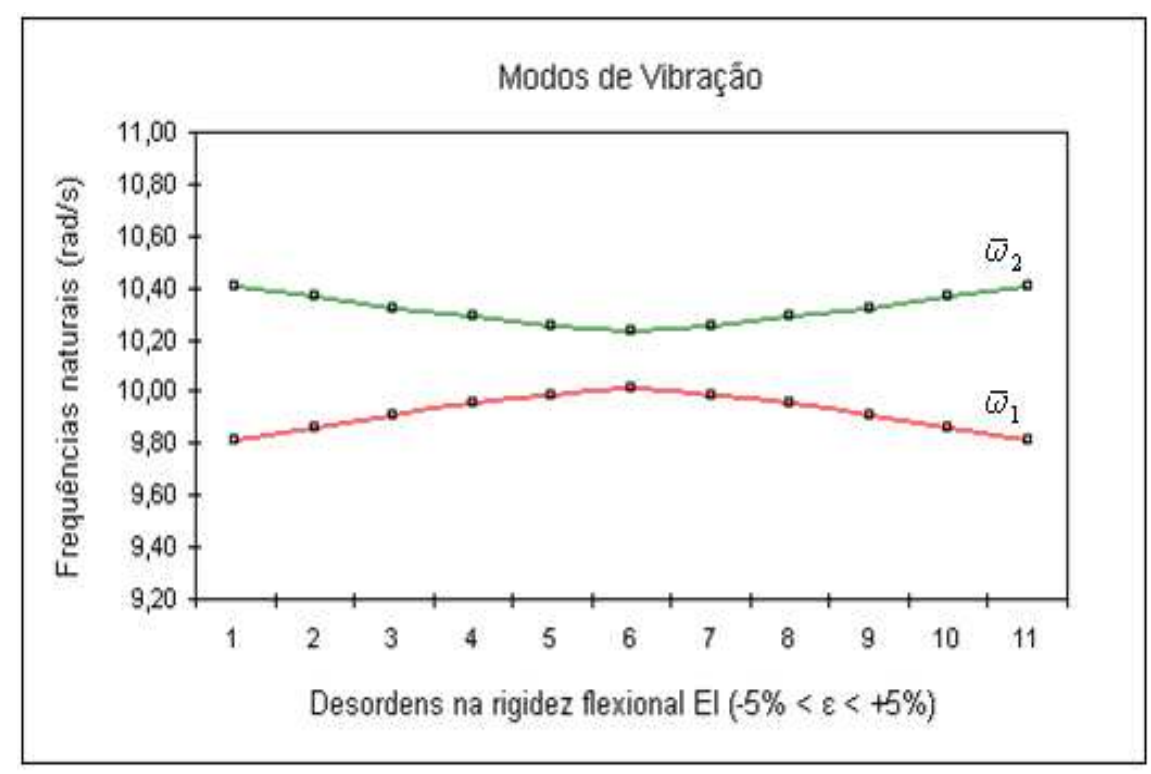

Figura 6.6 - Freqüências naturais versus grau de desordem na rigidez flexional. 
c) Estudo do efeito da variação da massa específica $(\bar{\rho})$ das placas na forma:

$$
\begin{aligned}
& \rho_{1}=\bar{\rho}(1+\varepsilon) \\
& \rho_{2}=\bar{\rho}(1-\varepsilon)
\end{aligned}
$$

onde se introduziu $\varepsilon$ um parâmetro pequeno relacionado com o grau de desordem, variando no intervalo de $-5 \%$ a $+5 \%$.

A seguir a Tabela 6.3, mostra os valores obtidos para as freqüências naturais para os dois primeiros modos de vibração, obtidos pelo programa DYMPLATE, para a variação da massa específica de referência $\left(\bar{\rho}=2500 \mathrm{~kg} / \mathrm{m}^{3}\right)$ das placas.

\begin{tabular}{ccccc}
\hline $\begin{array}{c}\text { Grau de } \\
\text { desordem }\end{array}$ & $L_{1}$ & $L_{2}$ & \multicolumn{2}{c}{$\begin{array}{c}\text { Freqüências naturais } \\
(\mathrm{rad} / \mathrm{s})\end{array}$} \\
\hline$\varepsilon(\%)$ & $\rho_{1}\left(\mathrm{~kg} / \mathrm{m}^{3}\right)$ & $\rho_{2}\left(\mathrm{~kg} / \mathrm{m}^{3}\right)$ & $1^{\text {o }}$ modo & $2^{\text {o } \text { modo }}$ \\
\hline$-5 \%$ & 2375 & 2625 & 9,8834 & 10,3831 \\
$-4 \%$ & 2400 & 2600 & 9,9246 & 10,3354 \\
$-3 \%$ & 2425 & 2575 & 9,9626 & 10,2923 \\
$-2 \%$ & 2450 & 2550 & 9,9942 & 10,2572 \\
$-1 \%$ & 2475 & 2525 & 10,0127 & 10,2367 \\
$0 \%$ & 2500 & 2500 & 10,0108 & 10,2382 \\
$1 \%$ & 2525 & 2475 & 10,0127 & 10,2367 \\
$2 \%$ & 2550 & 2450 & 9,9942 & 10,2572 \\
$3 \%$ & 2575 & 2425 & 9,9626 & 10,2923 \\
$4 \%$ & 2600 & 2400 & 9,9246 & 10,3354 \\
$5 \%$ & 2625 & 2375 & 9,8834 & 10,3831 \\
\hline
\end{tabular}

Tabela 6.3 - Freqüências naturais versus grau de desordem na massa específica. 
As curvas na Figura 6.7, mostram gráficos da variação das freqüências naturais correspondentes aos dois primeiros modos de vibração versus $\varepsilon$ para desordens na massa específica das placas do painel e novamente a forma não-linear das curavas, caracterizando novamente o fenômeno de curve veering.

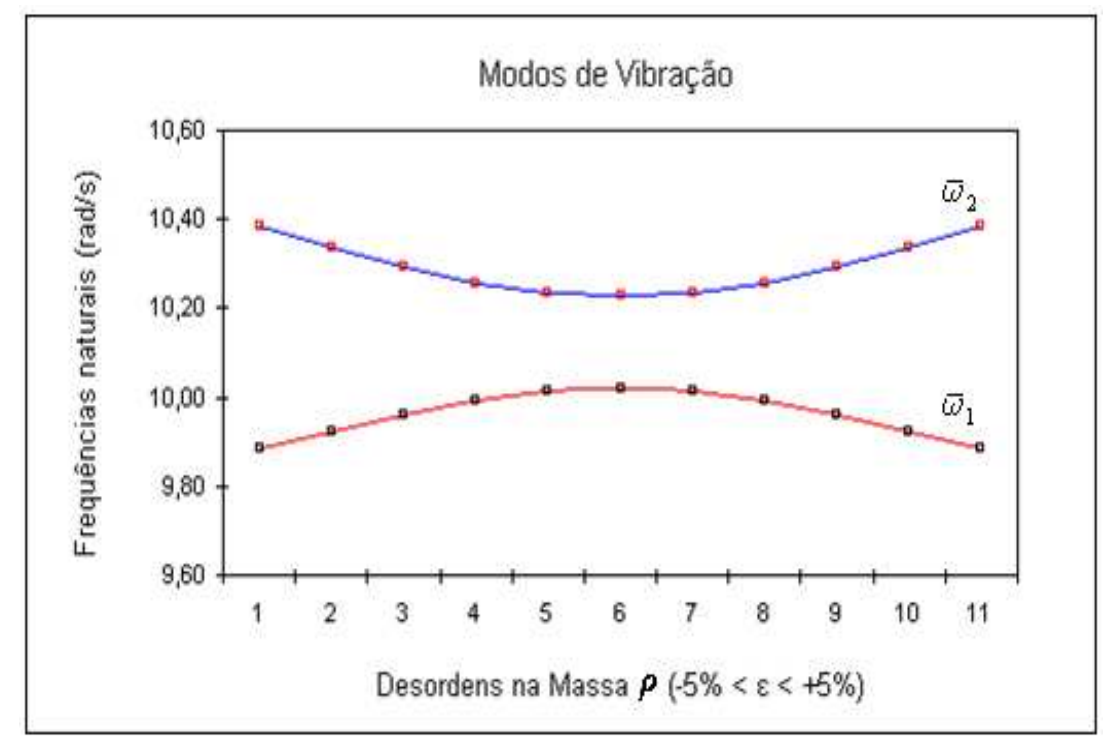

Figura 6.7 - Freqüências naturais versus grau de desordem na massa específica.

d) Estudo do efeito da variação da força de protensão $(\bar{N} x)$ das placas na forma:

$$
\begin{aligned}
& N x_{1}=\bar{N} x(1+\varepsilon) \\
& N x_{2}=\bar{N} x(1-\varepsilon)
\end{aligned}
$$

onde se introduziu $\varepsilon$ um parâmetro pequeno relacionado com o grau de desordem, variando no intervalo de $-100 \%$ a $+100 \%$. 
A seguir a Tabela 6.4 , mostra os valores em radianos das freqüências naturais dos dois primeiros modos de vibração, obtidos pelo programa DYMPLATE, com variação nas forças de protensão de referência $\left(\bar{N} x=1 \times 10^{6} N\right)$ para o painel de placas.

\begin{tabular}{ccccc}
\hline $\begin{array}{c}\text { Grau de } \\
\text { desordem }\end{array}$ & $L_{1}$ & $L_{2}$ & \multicolumn{2}{c}{$\begin{array}{c}\text { Freqüências naturais } \\
(\mathrm{rad} / \mathrm{s})\end{array}$} \\
\hline $\mathcal{E}(\%)$ & $\bar{N} x_{1}(N)$ & $\bar{N} x_{2}(N)$ & $1^{\text {o }}$ modo & $2^{\text {o } \text { modo }}$ \\
\hline-100 & 0 & 2000000 & 9,2034 & 10,1651 \\
-80 & 200000 & 1800000 & 9,2949 & 10,0875 \\
-60 & 400000 & 1600000 & 9,3832 & 10,0105 \\
-40 & 600000 & 1400000 & 9,4667 & 9,9358 \\
-20 & 800000 & 1200000 & 9,5411 & 9,8679 \\
0 & 1000000 & 1000000 & 9,5913 & 9,8218 \\
20 & 1200000 & 800000 & 9,5411 & 9,8679 \\
40 & 1400000 & 600000 & 9,4667 & 9,9358 \\
60 & 1600000 & 400000 & 9,3832 & 10,0105 \\
80 & 1800000 & 200000 & 9,2949 & 10,0875 \\
100 & 2000000 & 0 & 9,2034 & 10,1651 \\
\hline
\end{tabular}

Tabela 6.4 - Freqüências naturais versus grau de desordem na protensão.

As curvas na Figura 6.8, mostram gráficos da variação das freqüências naturais correspondentes aos dois primeiros modos de vibração versus $\varepsilon$ para desordens nas forças de protensão das placas do painel. 
Observa-se a forma marcante não-linear das curvas, sendo que a ocorrência do fenômeno de curve veering neste exemplo, marca uma das grandes contribuições desta pesquisa para o âmbito dos estudos de localização de modos, até onde se pode verificar na literatura científica existente.

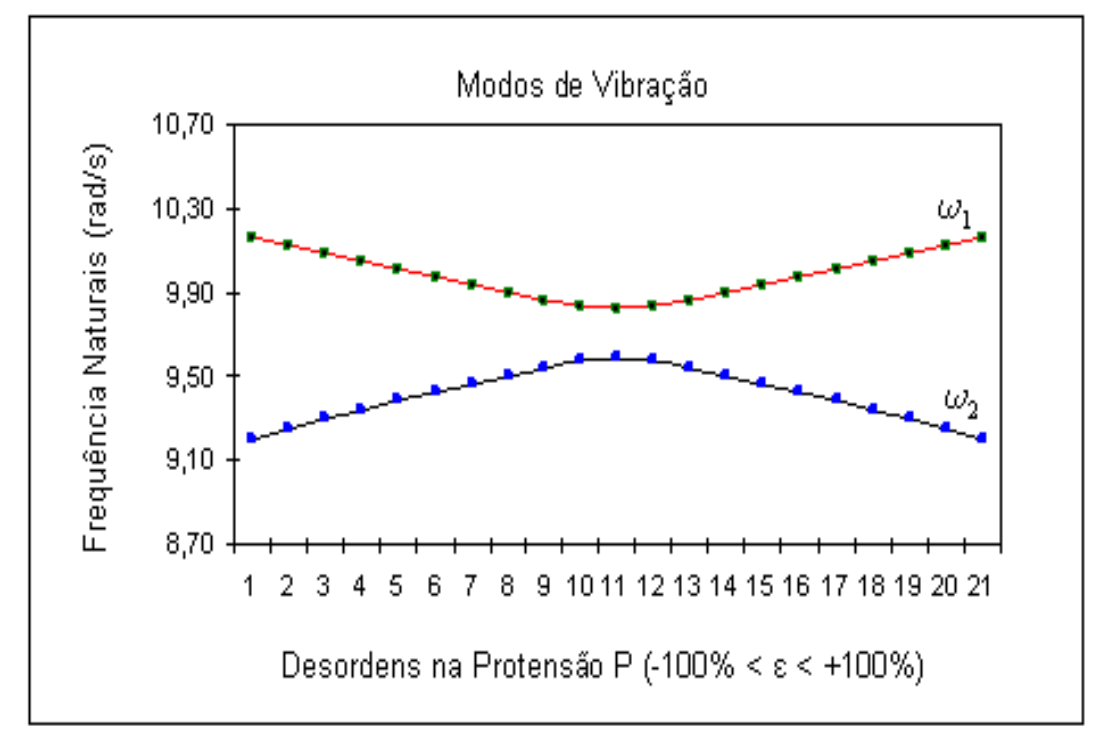

Figura 6.8 - Freqüências naturais versus grau de desordem na força de protensão.

e) Comparação entre um sistema ordenado com outro desordenado, sendo que o grau de desordem $\varepsilon$ nas espessuras das placas é da ordem de $5 \%$ do valor de referência $\bar{h}=0,20 m$, calculado pelas equações (5.1) e (5.2) definidas anteriormente.

A Tabela 6.5 mostra os valores obtidos para as freqüências naturais de vibração de um sistema desordenado, com grau de desordem $\varepsilon=5 \%$ na espessura das placas. Esses valores foram extraídos da última linha da Tabela 6.1, e transcritos aqui novamente.

\begin{tabular}{|c|c|c|c|c|}
\hline $\begin{array}{c}\text { Grau de } \\
\text { desordem }\end{array}$ & $L_{1}$ & $L_{2}$ & \multicolumn{2}{|c|}{$\begin{array}{c}\text { Freqüências naturais } \\
(\mathrm{rad} / \mathrm{s})\end{array}$} \\
\hline $\mathcal{E}(\%)$ & $h_{1}(m)$ & $h_{2}(m)$ & $1^{\circ}$ modo & $2^{\circ}$ modo \\
\hline $5 \%$ & 0,2100 & 0,1900 & 9,5782 & 10,5986 \\
\hline
\end{tabular}

Tabela 6.5 - Freqüências naturais obtidas com desordens na espessura. 
A Tabela 6.6 a seguir, mostra os valores obtidos para o primeiro e segundo modos de vibrações naturais do sistema ordenado, ou seja, as duas placas com espessuras iguais. Esses valores foram extraídos da sexta linha da Tabela 6.1, e transcritos aqui novamente.

\begin{tabular}{|c|c|c|c|c|}
\hline $\begin{array}{c}\text { Grau de } \\
\text { desordem }\end{array}$ & $L_{1}$ & $L_{2}$ & \multicolumn{2}{|c|}{$\begin{array}{c}\text { Freqüências naturais } \\
(\mathrm{rad} / \mathrm{s})\end{array}$} \\
\hline $\mathcal{E}(\%)$ & $h_{1}(m)$ & $h_{2}(m)$ & $1^{\circ}$ modo & $2^{\circ}$ modo \\
\hline $0 \%$ & 0,2000 & 0,2000 & 9,9797 & 10,1362 \\
\hline
\end{tabular}

Tabela 6.6 - Freqüências naturais de vibração para o sistema ordenado.

A seguir nas Figuras 6.9 a 6.12, apresentam-se o primeiro e segundo modos de vibração, do painel formado por duas placas quadradas, para os sistemas ordenados e desordenados respectivamente.

A Figura 6.9 mostra o primeiro modo de vibração obtido para o sistema ordenado do painel de placas com espessuras iguais, obtidos pelo DYMPLATE.

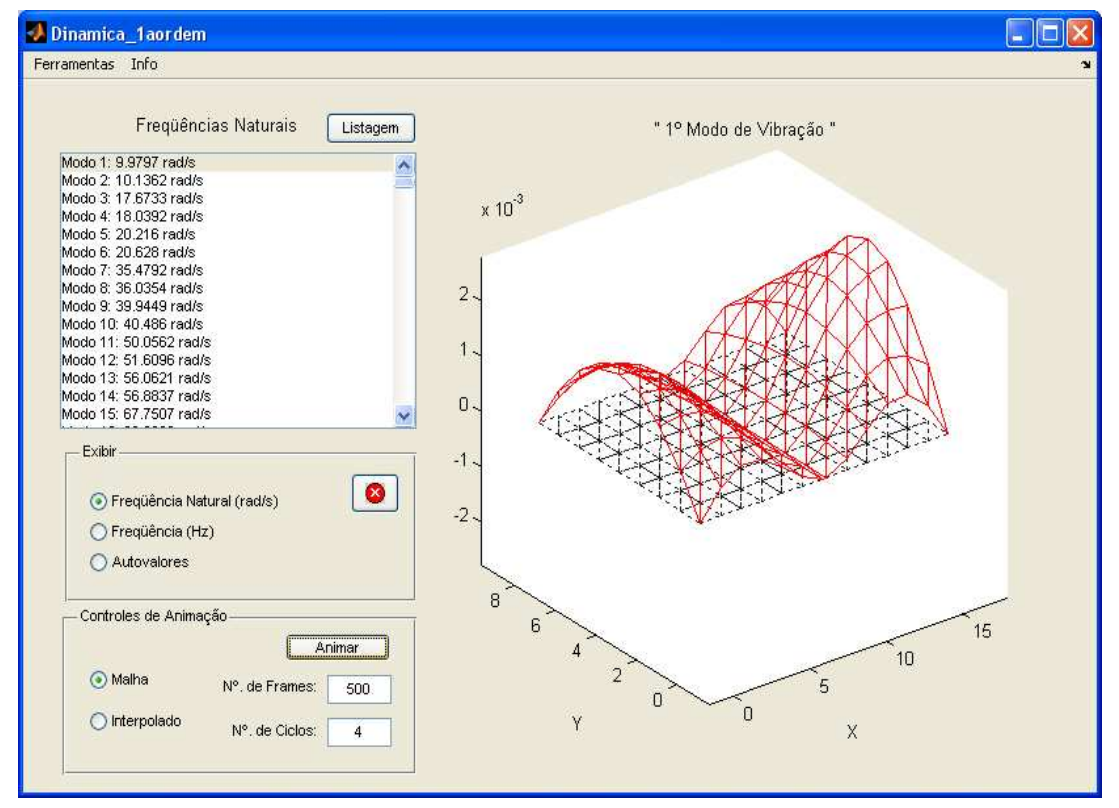

Figura 6.9 - Primeiro modo de vibração das placas com espessuras iguais. 
A Figura 6.10 mostra o primeiro modo de vibração obtido para o painel de placas com desordens em suas espessuras, obtidos pelo programa DYMPLATE.

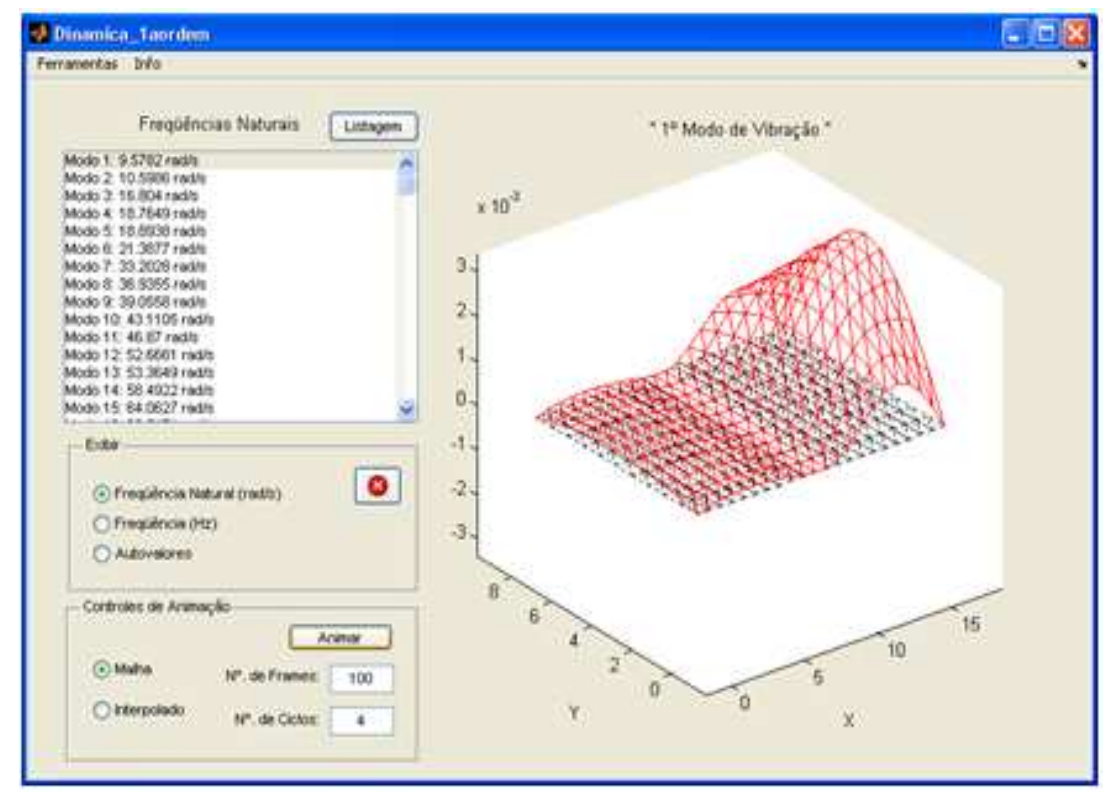

Figura 6.10 - Primeiro modo de vibração das placas com desordens na espessura.

A Figura 6.11 mostra o segundo modo de vibração obtido para o sistema ordenado do painel de placas com espessuras iguais, obtidos pelo programa.

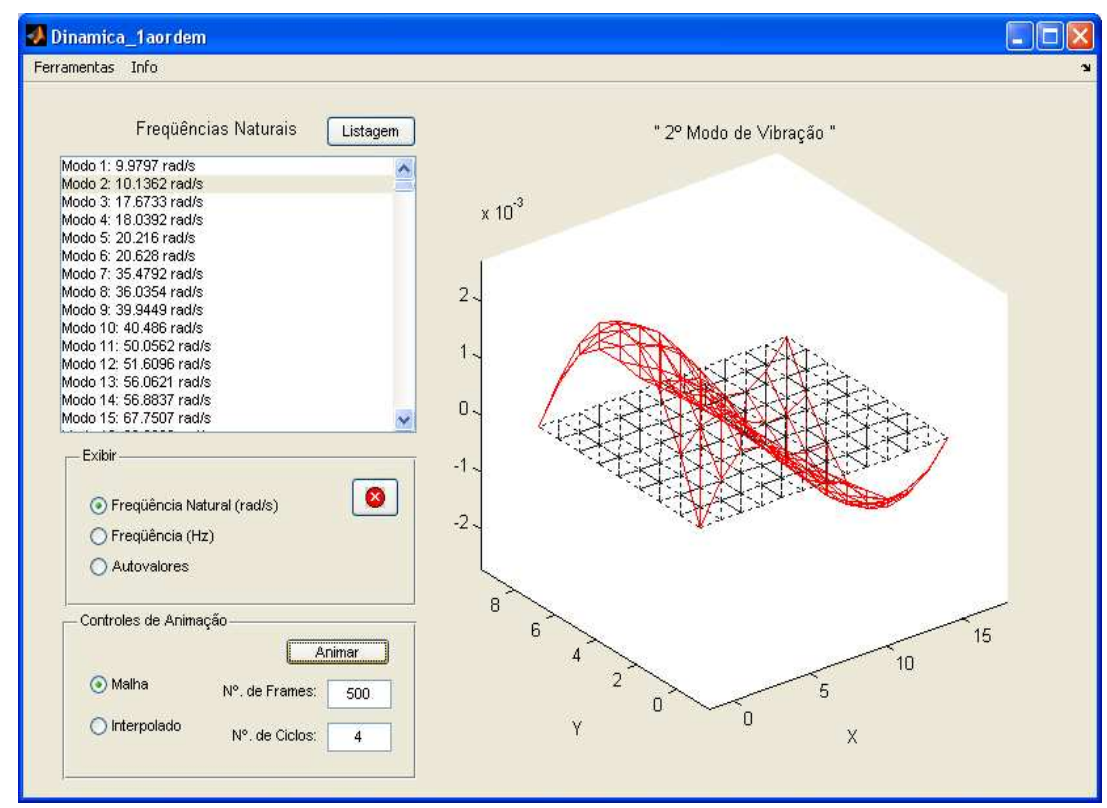

Figura 6.11 - Segundo modo de vibração do sistema com espessuras iguais. 
A Figura 6.12 mostra o segundo modo de vibração obtido para o painel de placas com desordens nas espessuras das placas, obtidos pelo programa DYMPLATE.

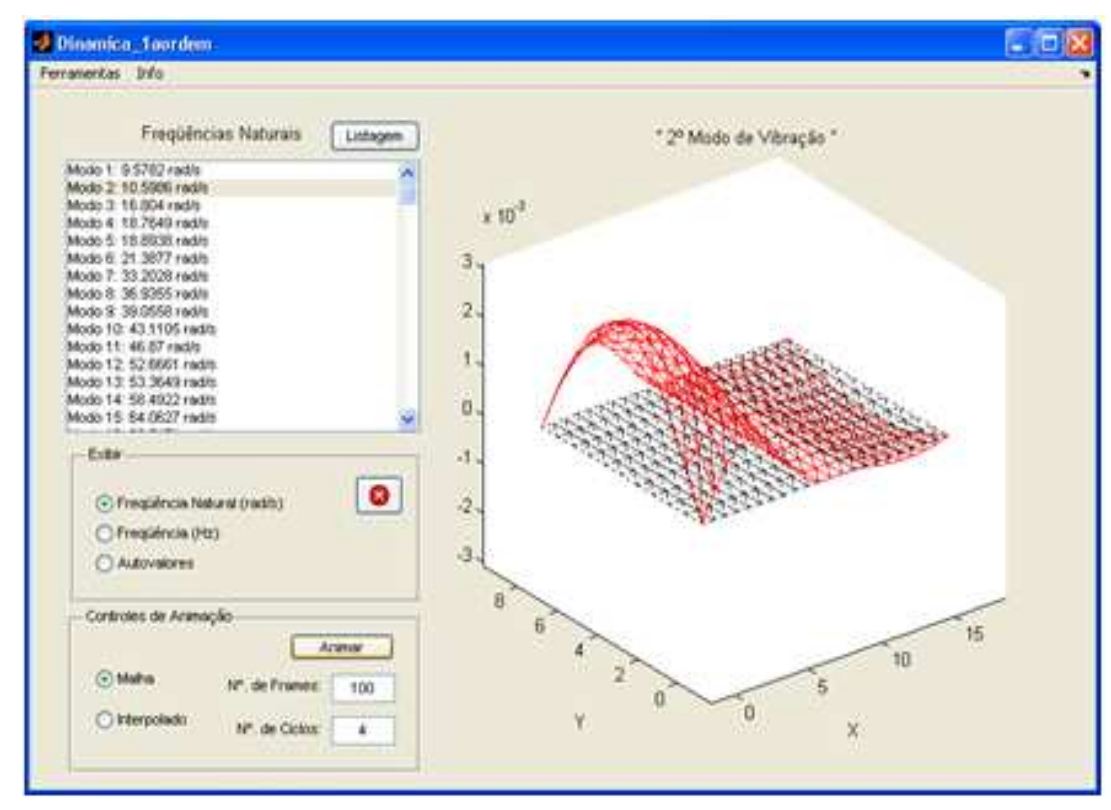

Figura 6.12 - Segundo modo de vibração do sistema com desordens na espessura.

f) Comparação entre um sistema ordenado com outro desordenado, sendo que o grau de desordem $\varepsilon$ na protensão é da ordem de $40 \%$ do valor de referência $\left(\bar{N} x=1,0 \times 10{ }^{6} N\right)$, calculado pelas equações (6.7) e (6.8) definidas anteriormente.

A Tabela 6.7, mostra os valores obtidos para o primeiro e segundo modos de vibrações naturais do sistema ordenado, ou seja, as duas placas com forças de protensão iguais. Esses valores foram extraídos da sexta linha da Tabela 6.4, e transcritos aqui novamente.

\begin{tabular}{|c|c|c|c|c|}
\hline $\begin{array}{c}\text { Grau de } \\
\text { desordem }\end{array}$ & $L_{1}$ & $L_{2}$ & \multicolumn{2}{|c|}{$\begin{array}{c}\text { Freqüências naturais } \\
(\mathrm{rad} / \mathrm{s})\end{array}$} \\
\hline $\mathcal{E}(\%)$ & $\bar{N} x_{1}(N)$ & $\bar{N} x_{2}(N)$ & $1^{\circ}$ modo & $2^{\circ}$ modo \\
\hline 0 & 1000000 & 1000000 & 9,5913 & 9,8218 \\
\hline
\end{tabular}

Tabela 6.7 - Freqüências naturais de vibração com protensão ordenada. 
A Tabela 6.8 mostra os valores obtidos para as freqüências naturais de vibração dos dois primeiros modos do sistema desordenado, isto é, com graus de desordem de $\varepsilon=40 \%$ na força de protensão. Esses valores foram extraídos da oitava linha da Tabela 6.4, e transcritos aqui novamente.

\begin{tabular}{|c|c|c|c|c|}
\hline $\begin{array}{c}\text { Grau de } \\
\text { desordem }\end{array}$ & $L_{1}$ & $L_{2}$ & \multicolumn{2}{|c|}{$\begin{array}{c}\text { Freqüências naturais } \\
(\mathrm{rad} / \mathrm{s})\end{array}$} \\
\hline $\mathcal{E}(\%)$ & $\bar{N} x_{1}(N)$ & $\bar{N} x_{2}(N)$ & $1^{\text {o }}$ modo & $2^{\text {o }}$ modo \\
\hline 40 & 1400000 & 600000 & 9,4667 & 9,9358 \\
\hline
\end{tabular}

Tabela 6.8 - Freqüências naturais obtidas com desordens na protensão.

A seguir nas Figuras 6.13 a 6.16, apresentam-se o primeiro e segundo modos de vibração do painel formado por duas placas quadradas, com o sistema com forças de protensão ordenadas e desordenadas respectivamente.

A Figura 6.13 mostra o primeiro modo de vibração para o sistema ordenado com forças de protensão iguais, para o painel formado por duas placas quadradas.

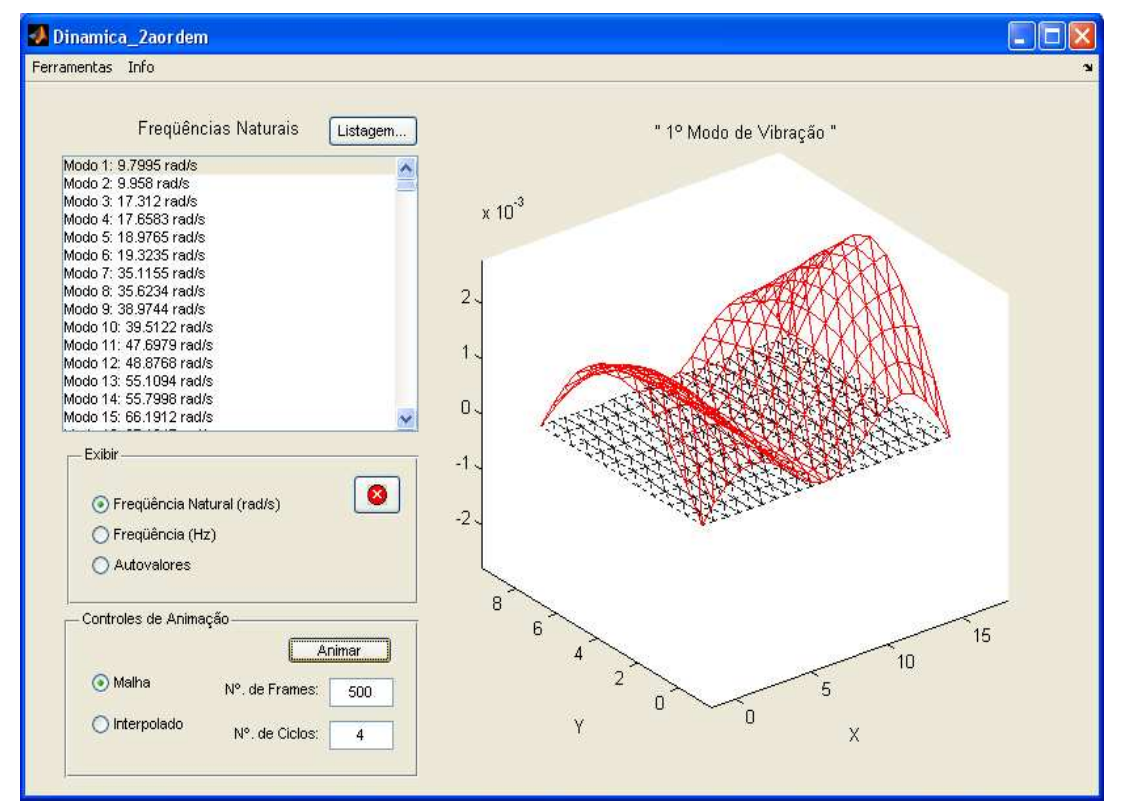

Figura 6.13 - Primeiro modo de vibração do painel com forças de protensão iguais. 
A Figura 6.14 mostra o primeiro modo de vibração para o sistema desordenado, com forças de protensão diferentes, para o painel com duas placas.

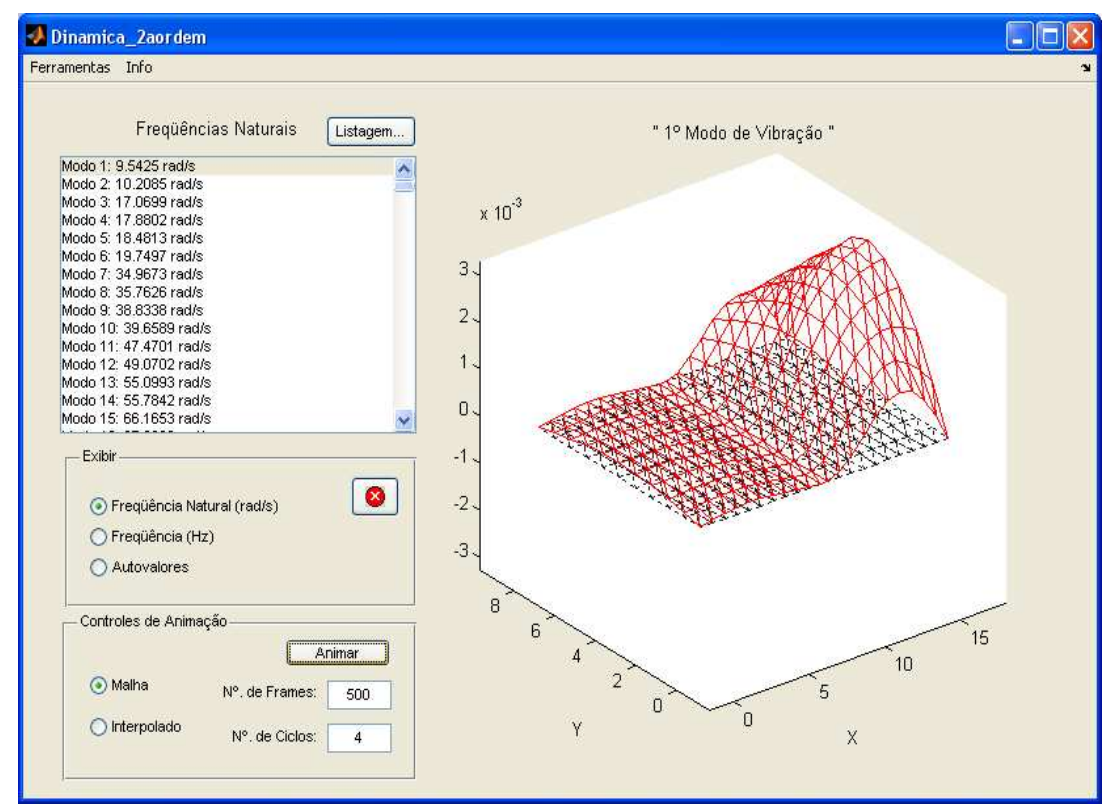

Figura 6.14 - Primeiro modo de vibração do painel com forças de protensão diferentes.

A Figura 6.15 mostra o segundo modo de vibração para o sistema ordenado, com forças de protensão iguais, para o painel formado por duas placas quadradas.

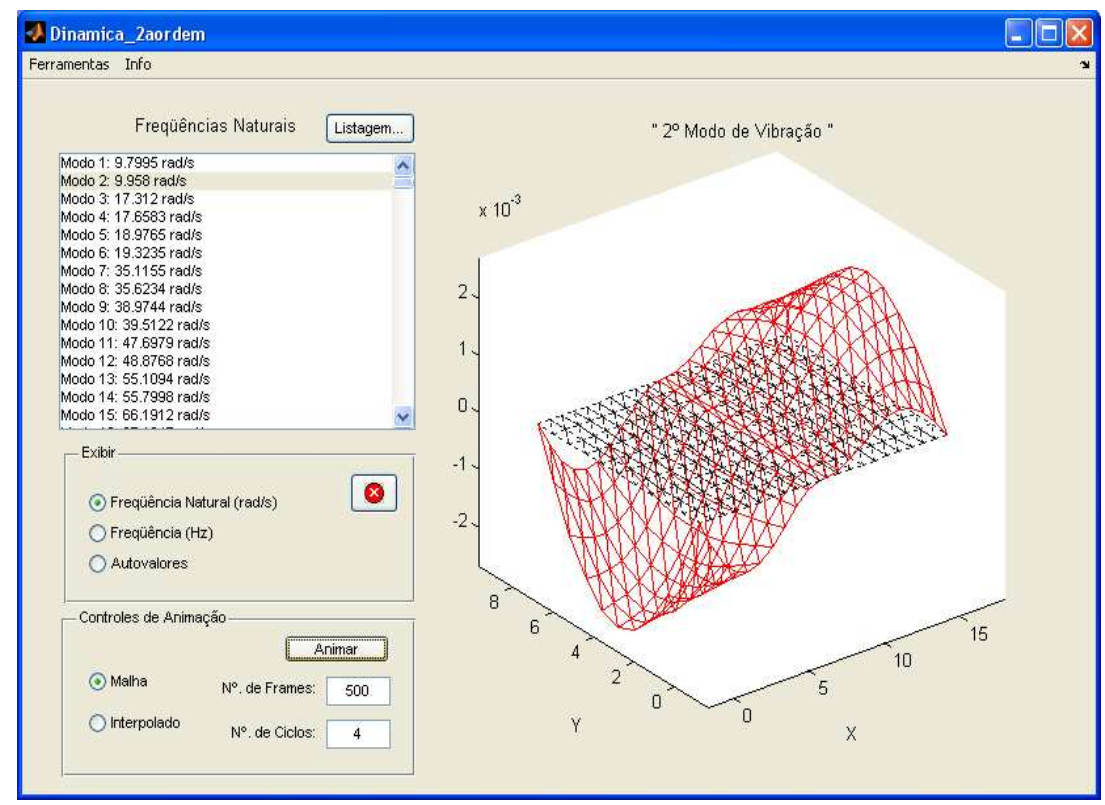

Figura 6.15 - Segundo modo de vibração do painel com forças de protensão iguais. 
A Figura 6.16 mostra o segundo modo de vibração para o sistema desordenado, com forças de protensão diferentes, para o painel formado por duas placas quadradas.

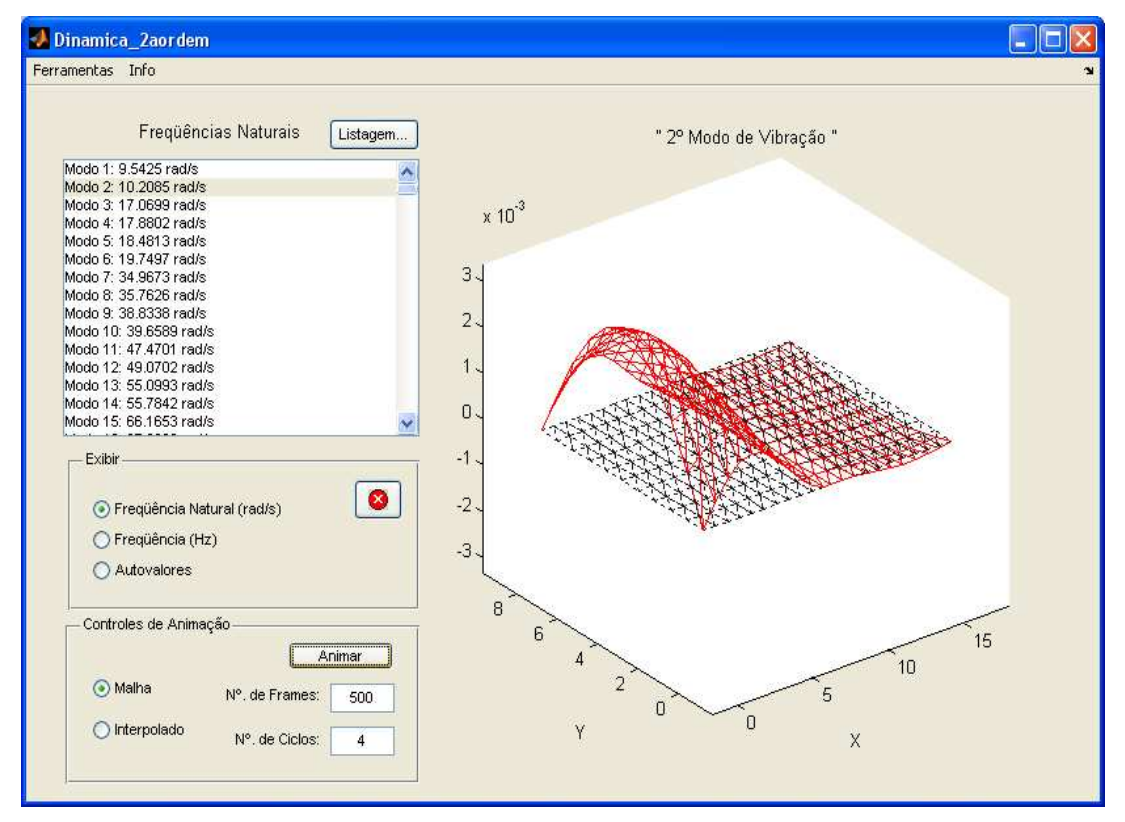

Figura 6.16 - Segundo modo de vibração do painel com forças de protensão diferentes.

Nota-se com base nas figuras anteriores, tanto no primeiro quanto no segundo modo de vibração, que quando os sistemas de placas estão desordenados, isto é, com espessuras diferentes ou com forças de protensão diferentes, ocorre uma forte localização nos modos de vibrar. Isto se deve principalmente ao fato de suas rigidezes geométricas, serem afetadas pela característica não-linear do problema. 


\section{2 - Painel formado por quatro placas alinhadas}

Para um estudo qualitativo, considere-se uma estrutura quase periódica, formada de um painel composto por quatro placas quadradas homogêneas e isotrópicas, alinhadas na mesma direção x e acopladas a vigas de grande rigidez, as quais são representadas por molas de rigidez rotacional "k", conforme é mostrado na Figura 6.17 a seguir:

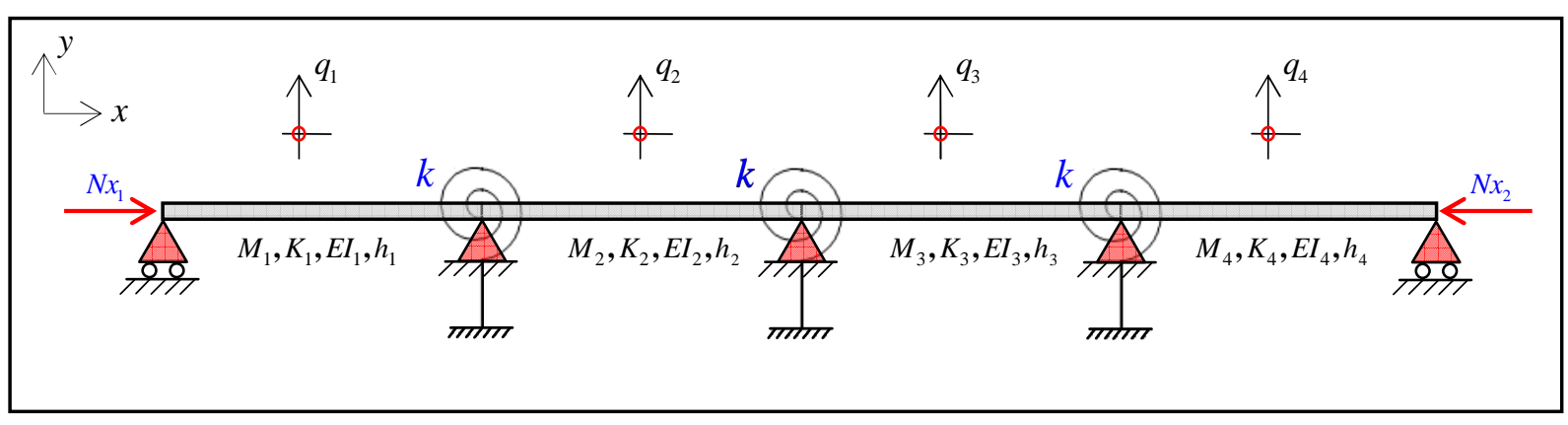

Figura 6.17 - Modelo de um sistema quase periódico de quatro placas alinhadas na direção longitudinal e acopladas a molas de rigidez rotacional "k".

$\mathrm{Na}$ ausência de desordem, o segundo exemplo de um modelo físico real a ser analisado, trata-se de um painel composto por quatro placas quadradas, de material homogêneo e isotrópico, dimensões $L x=L y=8,00 \mathrm{~m}$, Módulo de Elasticidade $E=2,1 \times 10^{10} \mathrm{~N} / \mathrm{m}^{2}$, espessura $\bar{h}=0,20 \mathrm{~m}$ e coeficiente de Poisson $v=0,25$. Este painel está simplesmente apoiado nas vigas intermediárias de largura $\bar{l}_{x}=L x / 20 \mathrm{e}$ cuja altura $h=0,60 m$, conforme é mostrado na Figura 6.18.



Figura 6.18 - Modelo físico real do painel formado por quatro placas alinhadas. 
A estrutura real que foi mostrada na Figura 6.18, é então substituída pelo modelo estrutural aproximado da Figura 6.19, desta forma, estaremos modelando de modo a não termos interferência das vigas nas lajes e tornar o programa de cálculo de elementos finitos de maior tamanho e dificuldades.

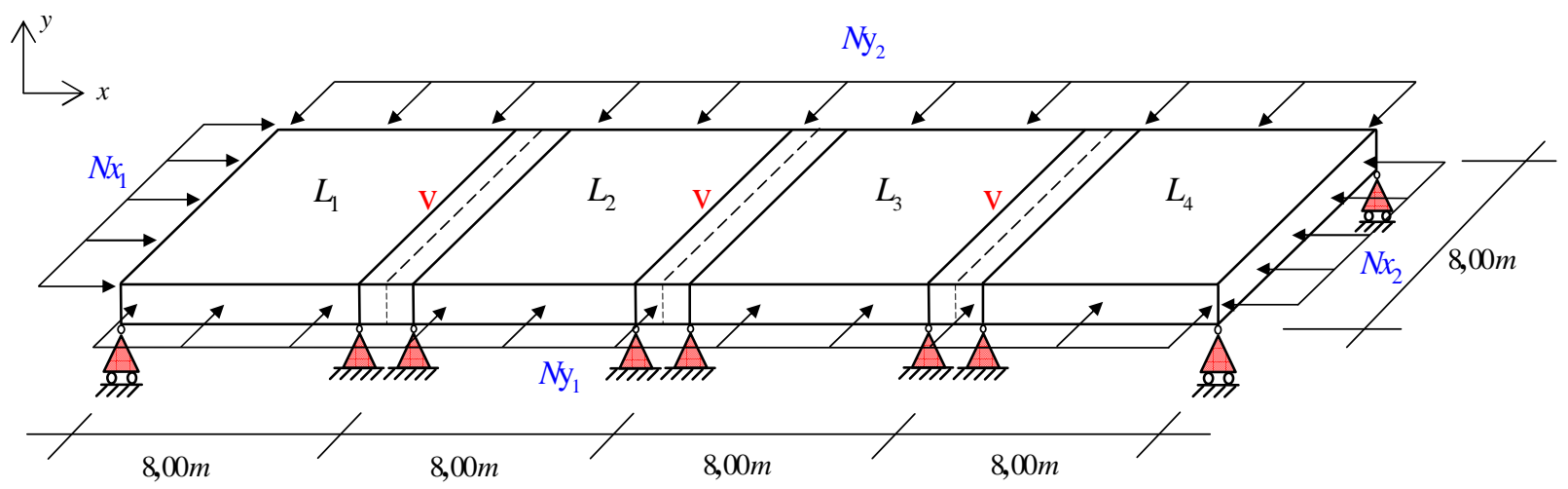

Figura 6.19 - Modelo estrutural simplificado do painel com quatro placas acopladas.

A Figura 6.20 a seguir, mostra a vista em planta do painel formado por quatro placas quadradas acopladas a vigas de grande rigidez e com carregamento de protensão aplicado nas direções " $x$ " e " $y$ ".

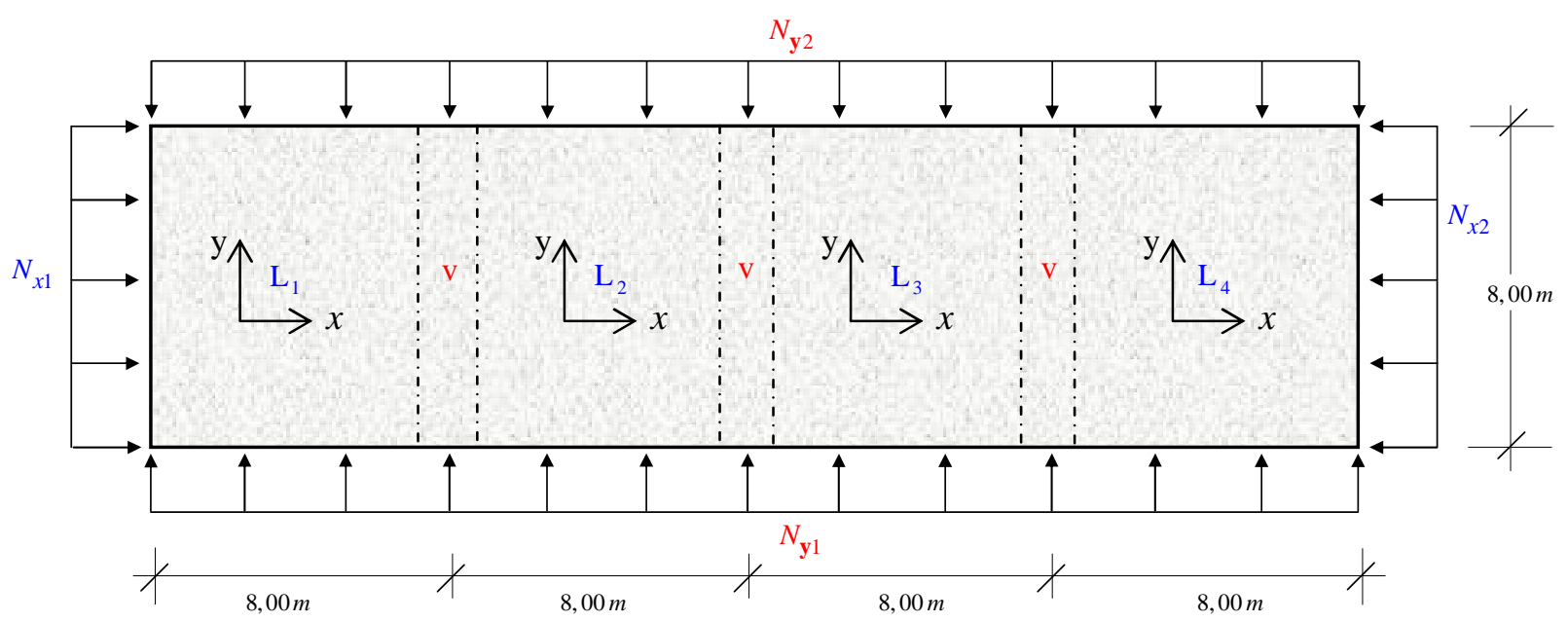

Figura 6.20 - Vista em planta do painel formado por quatro placas alinhadas. 
a) Estudo do efeito da variação da espessura de referência $(\bar{h})$ das placas na forma:

$$
\begin{aligned}
& h_{1}=\bar{h}(1+\varepsilon) \\
& h_{2}=\bar{h}(1-\varepsilon)
\end{aligned}
$$

onde se introduziu $\varepsilon$ um parâmetro pequeno relacionado com o grau de desordem, variando no intervalo de $-5 \%$ a $+5 \%$ aleatoriamente.

A Tabela 6.9 mostra os valores obtidos para as freqüências naturais dos dois primeiros modos de vibração, obtidos pelo programa DYMPLATE, para a variação da espessura $(\bar{h}=0,20 \mathrm{~m})$ do painel formado por quatro placas quadradas.

\begin{tabular}{cccccccccc}
\hline \multicolumn{2}{c}{$L_{1}$} & \multicolumn{2}{c}{$L_{2}$} & \multicolumn{2}{c}{$L_{3}$} & \multicolumn{2}{c}{$L_{4}$} & \multicolumn{2}{c}{$\begin{array}{c}\text { Frequiências naturais } \\
(\mathrm{rad} / \mathrm{s})\end{array}$} \\
\hline $\mathcal{E}_{1}(\%)$ & $h_{1}(m)$ & $\mathcal{E}_{2}(\%)$ & $h_{2}(m)$ & $\mathcal{E}_{3}(\%)$ & $h_{3}(m)$ & $\mathcal{E}_{4}(\%)$ & $h_{4}(m)$ & $1^{\circ}$ modo & $2^{\circ}$ modo \\
\hline$-5 \%$ & 0,1900 & $5 \%$ & 0,2100 & $-1 \%$ & 0,1980 & $1 \%$ & 0,2020 & 9,5142 & 10,0660 \\
$-4 \%$ & 0,1920 & $4 \%$ & 0,2080 & $-2 \%$ & 0,1960 & $2 \%$ & 0,2040 & 9,6138 & 10,1653 \\
$-3 \%$ & 0,1940 & $3 \%$ & 0,2060 & $-3 \%$ & 0,1940 & $3 \%$ & 0,2060 & 9,7133 & 10,2646 \\
$-2 \%$ & 0,1960 & $2 \%$ & 0,2040 & $-4 \%$ & 0,1920 & $4 \%$ & 0,2080 & 9,8129 & 10,3639 \\
$-1 \%$ & 0,1980 & $1 \%$ & 0,2020 & $-5 \%$ & 0,1900 & $5 \%$ & 0,2100 & 9,9125 & 10,4633 \\
$0 \%$ & 0,2000 & $0 \%$ & 0,2000 & $0 \%$ & 0,2000 & $0 \%$ & 0,2000 & 10,0120 & 10,0122 \\
$1 \%$ & 0,2020 & $-1 \%$ & 0,1980 & $5 \%$ & 0,2100 & $-5 \%$ & 0,1900 & 9,5522 & 10,1117 \\
$2 \%$ & 0,2040 & $-2 \%$ & 0,1960 & $4 \%$ & 0,2080 & $-4 \%$ & 0,1920 & 9,6518 & 10,2113 \\
$3 \%$ & 0,2060 & $-3 \%$ & 0,1940 & $3 \%$ & 0,2060 & $-3 \%$ & 0,1940 & 9,7513 & 10,3109 \\
$4 \%$ & 0,2080 & $-4 \%$ & 0,1920 & $2 \%$ & 0,2040 & $-2 \%$ & 0,1960 & 9,8509 & 10,4105 \\
$5 \%$ & 0,2100 & $-5 \%$ & 0,1900 & $1 \%$ & 0,2020 & $-1 \%$ & 0,1980 & 9,9504 & 10,5100 \\
\hline
\end{tabular}

Tabela 6.9 - Freqüências naturais versus grau de desordem na espessura.

A seguir nas Figuras 6.21 a 6.24, apresentam-se o primeiro e segundo modos de vibração, do painel formado por quatro placas quadradas e alinhadas, relativos aos valores apresentados na sexta e na primeira linha da Tabela 6.9, para os sistemas ordenados e desordenados respectivamente, que foram obtidos pelo programa de cálculo computacional, DYMPLATE. 
A Figura 6.21 mostra o primeiro modo de vibração obtido para o sistema ordenado do painel formado por quatro placas alinhadas com espessuras iguais.

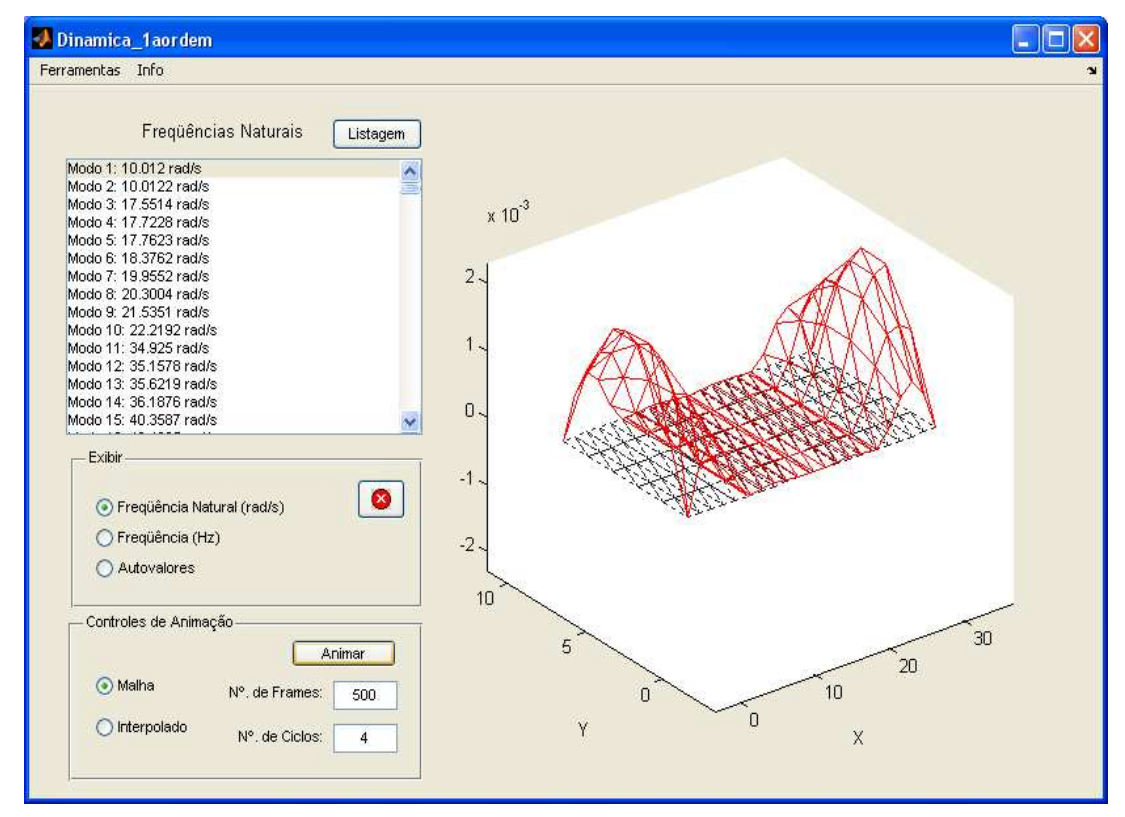

Figura 6.21 - Primeiro modo de vibração das placas com espessuras iguais.

A Figura 6.22 mostra o primeiro modo de vibração obtido para o sistema desordenado do painel formado por quatro placas com desordens nas espessuras.

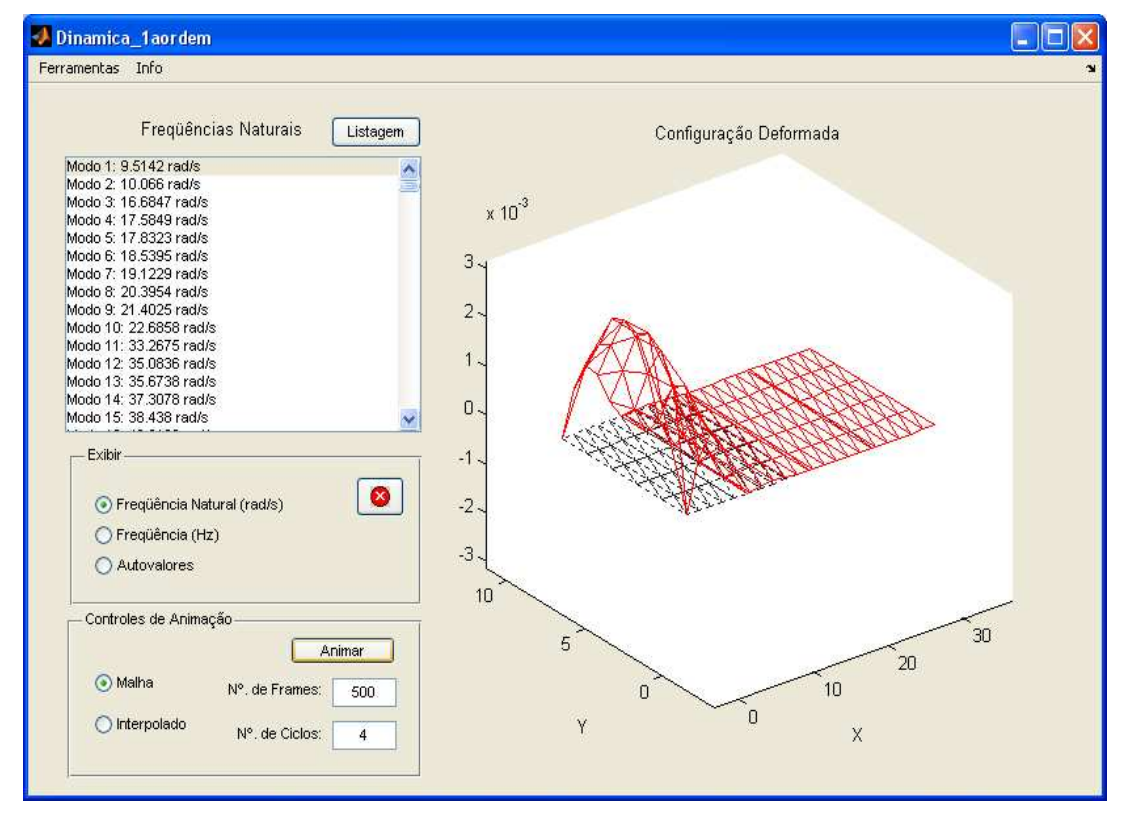

Figura 6.22 - Primeiro modo de vibração das placas com desordens nas espessuras. 
A Figura 6.23 mostra o segundo modo de vibração obtido para o sistema ordenado do painel formado por quatro placas alinhadas com espessuras iguais.



Figura 6.23 - Segundo modo de vibração do sistema com espessuras iguais.

A Figura 6.24 mostra o segundo modo de vibração obtido para o sistema desordenado do painel formado por quatro placas com desordens nas espessuras.

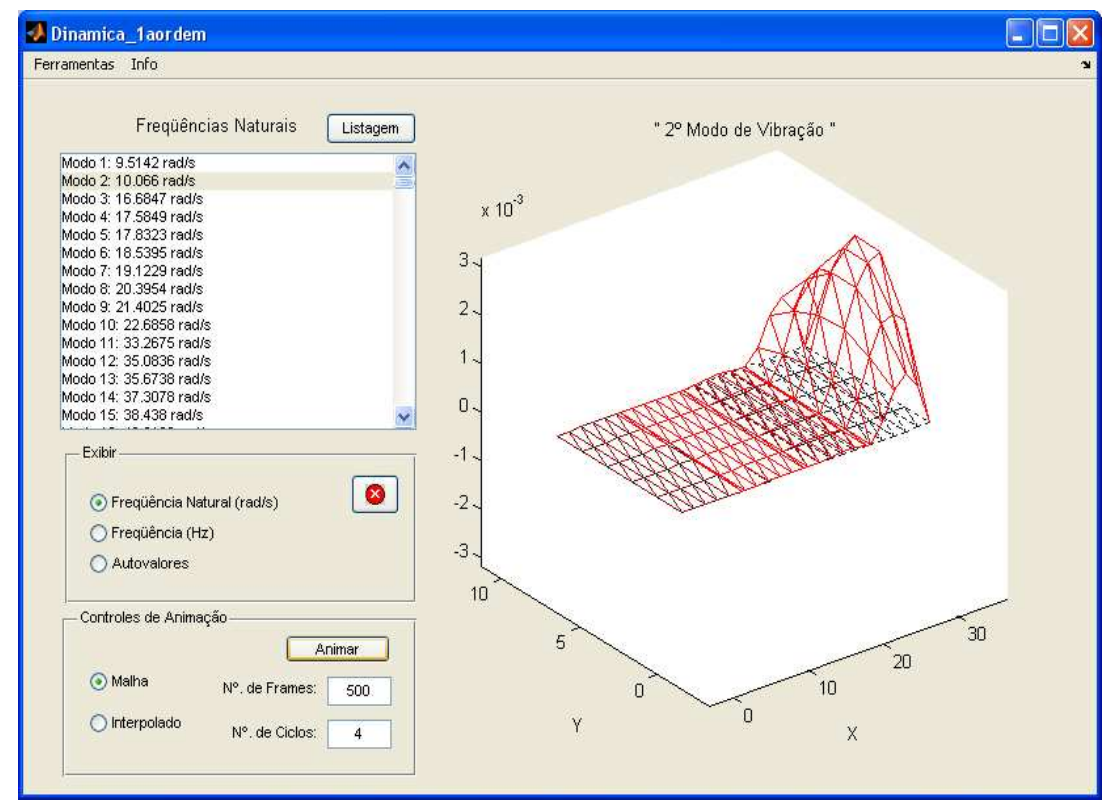

Figura 6.24 - Segundo modo de vibração do sistema com desordens nas espessuras. 
b) Estudo do efeito da variação da força de protensão $(\bar{N} x)$ das placas na forma:

$$
\begin{aligned}
& N x_{1}=\bar{N} x(1+\varepsilon) \\
& N x_{2}=\bar{N} x(1-\varepsilon)
\end{aligned}
$$

onde se introduziu $\varepsilon$ um parâmetro pequeno relacionado com o grau de desordem, variando no intervalo de $-100 \%$ a $+100 \%$

A Tabela 6.10 a seguir, mostra os valores obtidos para as freqüências naturais para os dois primeiros modos de vibração, obtidos pelo programa DYMPLATE, para a variação das forças de protensão de referência $\left(\bar{N} x=\bar{N} y=1 \times 10^{6} N\right)$ para o painel formado por quatro placas quadradas, homogêneas e isotrópicas.

\begin{tabular}{cccccccccc}
\hline \multicolumn{2}{c}{$L_{1}$} & \multicolumn{2}{c}{$L_{2}$} & \multicolumn{2}{c}{$L_{3}$} & \multicolumn{2}{c}{$L_{4}$} & \multicolumn{2}{c}{$\begin{array}{c}\text { Frequiências } \\
\text { naturais (rad/s) }\end{array}$} \\
\hline $\mathcal{E}_{1}(\%)$ & $\bar{N} x_{1}(N)$ & $\mathcal{E}_{2}(\%)$ & $\bar{N} x_{2}(N)$ & $\mathcal{E}_{3}(\%)$ & $\bar{N} x_{3}(N)$ & $\mathcal{E}_{4}(\%)$ & $\bar{N} x_{4}(N)$ & $1^{\circ}$ modo & $2^{\circ}$ modo \\
\hline$-100 \%$ & $0,00 \mathrm{E}+00$ & $100 \%$ & $2,00 \mathrm{E}+06$ & $-20 \%$ & $8,00 \mathrm{E}+05$ & $20 \%$ & $1,20 \mathrm{E}+06$ & 9,7205 & 10,8280 \\
$-80 \%$ & $2,00 \mathrm{E}+05$ & $80 \%$ & $1,80 \mathrm{E}+06$ & $-40 \%$ & $6,00 \mathrm{E}+05$ & $40 \%$ & $1,40 \mathrm{E}+06$ & 9,5666 & 10,6940 \\
$-60 \%$ & $4,00 \mathrm{E}+05$ & $60 \%$ & $1,60 \mathrm{E}+06$ & $-60 \%$ & $4,00 \mathrm{E}+05$ & $60 \%$ & $1,60 \mathrm{E}+06$ & 9,4088 & 10,5574 \\
$-40 \%$ & $6,00 \mathrm{E}+05$ & $40 \%$ & $1,40 \mathrm{E}+06$ & $-80 \%$ & $2,00 \mathrm{E}+05$ & $80 \%$ & $1,80 \mathrm{E}+06$ & 9,2469 & 10,4181 \\
$-20 \%$ & $8,00 \mathrm{E}+05$ & $20 \%$ & $1,20 \mathrm{E}+06$ & $-100 \%$ & $0,00 \mathrm{E}+00$ & $100 \%$ & $2,00 \mathrm{E}+06$ & 9,0805 & 10,2758 \\
$0 \%$ & $1,00 \mathrm{E}+06$ & $0 \%$ & $1,00 \mathrm{E}+06$ & $0 \%$ & $1,00 \mathrm{E}+06$ & $0 \%$ & $1,00 \mathrm{E}+06$ & 9,9746 & 10,0248 \\
$20 \%$ & $1,20 \mathrm{E}+06$ & $-20 \%$ & $8,00 \mathrm{E}+05$ & $100 \%$ & $2,00 \mathrm{E}+06$ & $-100 \%$ & $0,00 \mathrm{E}+00$ & 9,7625 & 10,7624 \\
$40 \%$ & $1,40 \mathrm{E}+06$ & $-40 \%$ & $6,00 \mathrm{E}+05$ & $80 \%$ & $1,80 \mathrm{E}+06$ & $-80 \%$ & $2,00 \mathrm{E}+05$ & 9,6042 & 10,6301 \\
$60 \%$ & $1,60 \mathrm{E}+06$ & $-60 \%$ & $4,00 \mathrm{E}+05$ & $60 \%$ & $1,60 \mathrm{E}+06$ & $-60 \%$ & $4,00 \mathrm{E}+05$ & 9,4413 & 10,4955 \\
$80 \%$ & $1,80 \mathrm{E}+06$ & $-80 \%$ & $2,00 \mathrm{E}+05$ & $40 \%$ & $1,40 \mathrm{E}+06$ & $-40 \%$ & $6,00 \mathrm{E}+05$ & 9,2737 & 10,3584 \\
$100 \%$ & $2,00 \mathrm{E}+06$ & $-100 \%$ & $0,00 \mathrm{E}+00$ & $20 \%$ & $1,20 \mathrm{E}+06$ & $-20 \%$ & $8,00 \mathrm{E}+05$ & 9,1007 & 10,2188 \\
\hline & & & & & & & & &
\end{tabular}

Tabela 6.10 - Freqüências naturais versus graus de desordem protensão.

Nas Figuras 6,25 a 6.26 a seguir, apresentam-se o primeiro e segundo modos de vibração, do painel formado por quatro placas, relativos aos valores apresentados na sexta e na nona linha da Tabela 6.10, para os sistemas ordenados e desordenados, respectivamente. 
A Figura 6.25 mostra o primeiro modo de vibração obtido para o sistema ordenado, ou seja, com forças de protensão iguais.

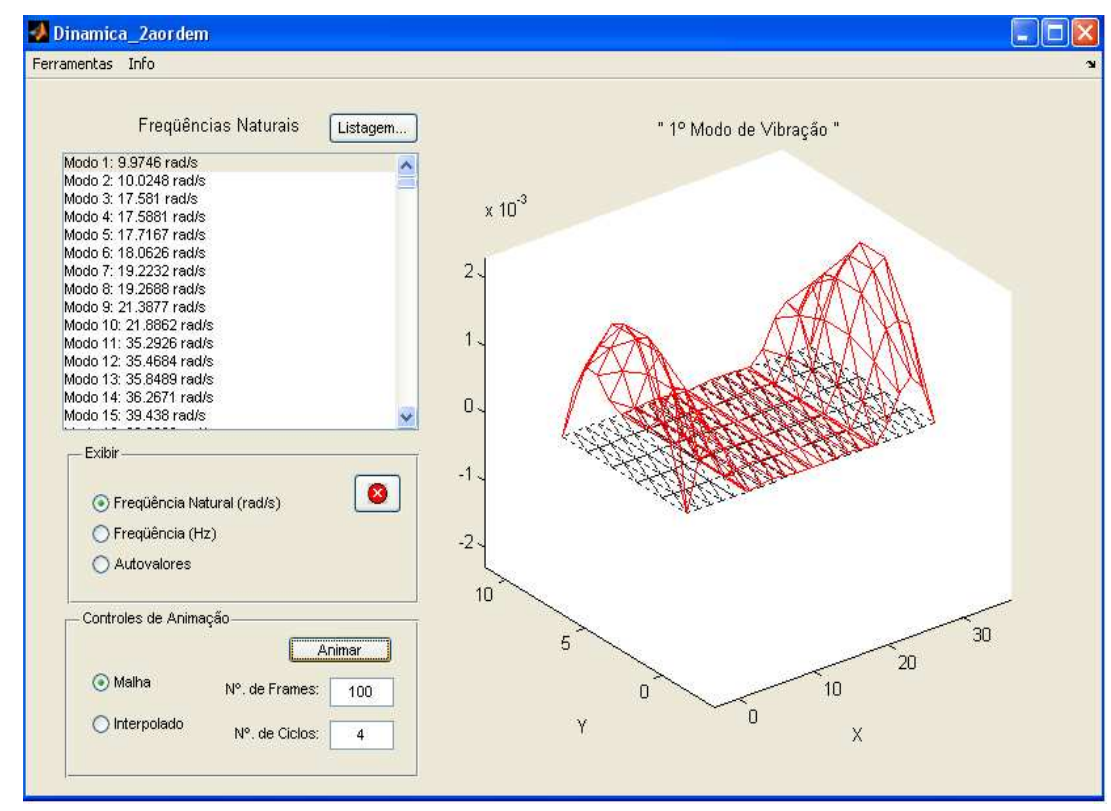

Figura 6.25 - Primeiro modo de vibração do sistema de placas com protensão ordenada.

A Figura 6.26 mostra o primeiro modo de vibração obtido para o sistema com desordens nas forças de protensão.

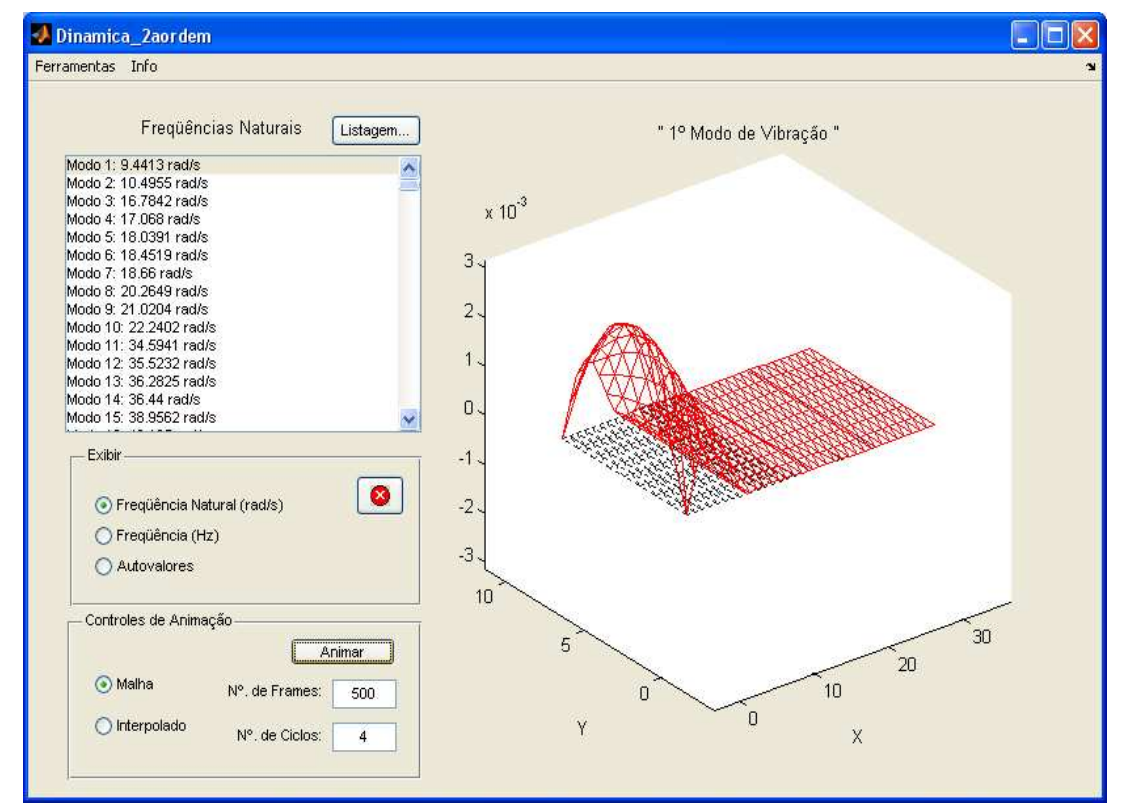

Figura 6.26 - Primeiro modo de vibração do sistema com desordens na protensão. 
A Figura 6.27 mostra o segundo modo de vibração obtido para o sistema ordenado, ou seja, com forças de protensão iguais.

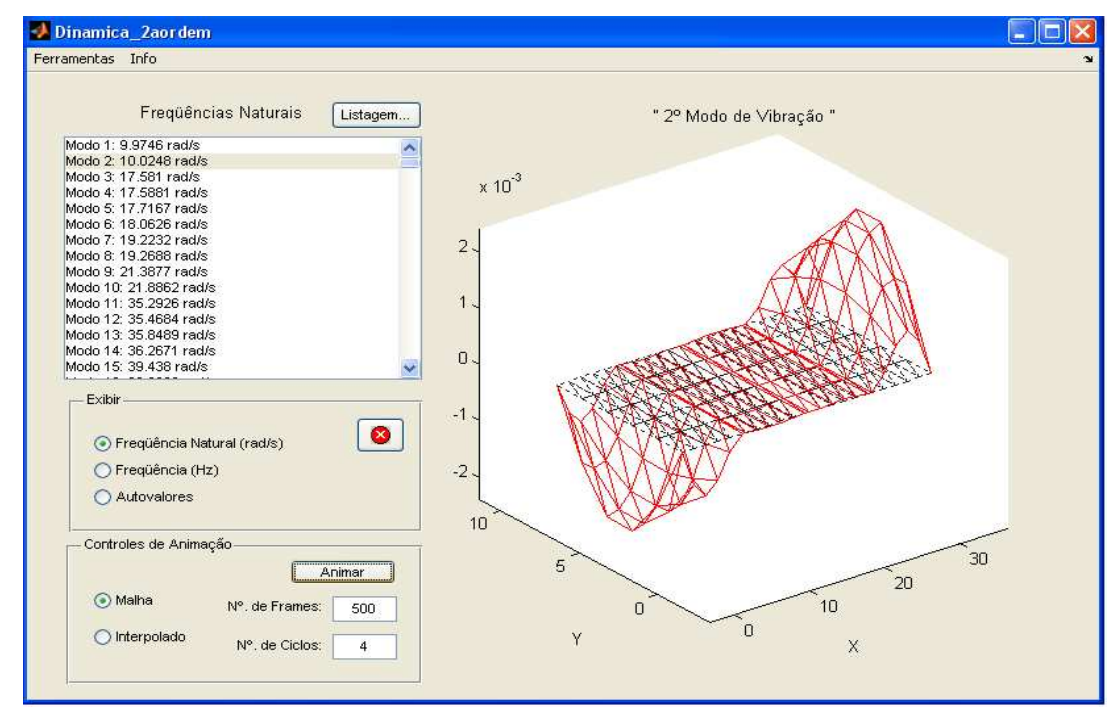

Figura 6.27 - Segundo modo de vibração do sistema de placas com protensão ordenada.

A Figura 6.28 mostra o segundo modo de vibração obtido para o sistema com desordens nas forças de protensão.

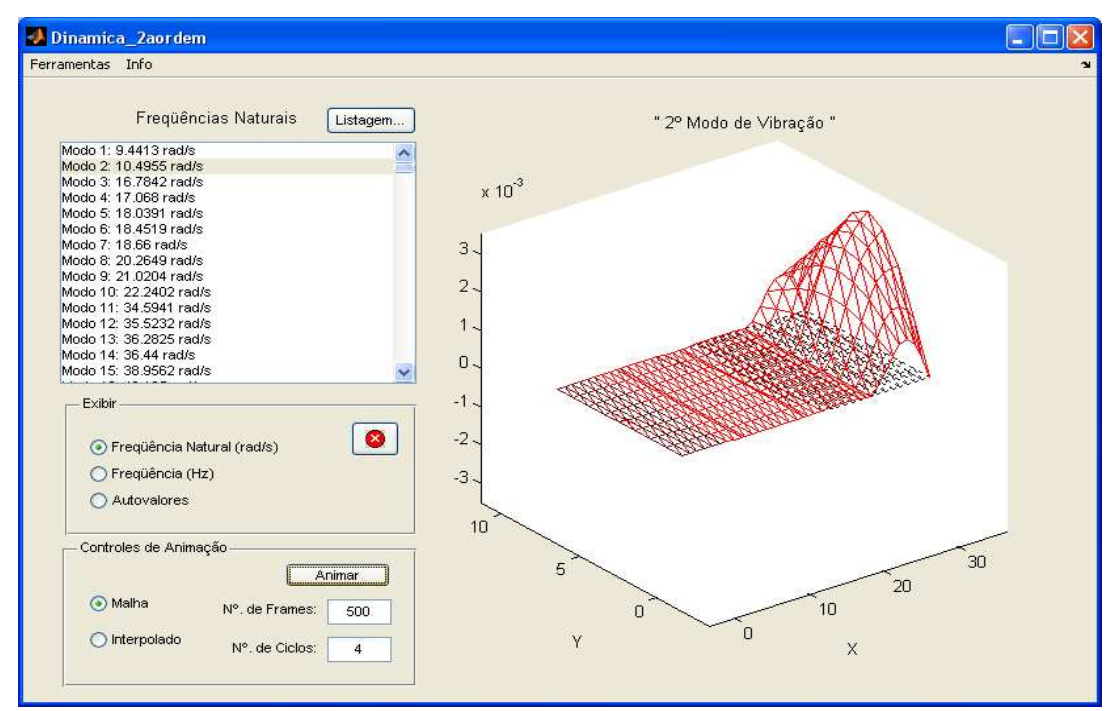

Figura 6.28 - Segundo modo de vibração do sistema com desordens na protensão. 
Nota-se com base nas figuras anteriores, tanto no primeiro quanto no segundo modo de vibração, que quando os sistemas de placas estão desordenados, isto é, com espessuras diferentes ou com forças de protensão diferentes, ocorre uma forte localização nos modos de vibrar na estrutura. Isto se deve ao fato de suas rigidezes geométricas, serem afetadas pela característica não-linear do problema.

\section{3 - Painel formado por quatro placas não alinhadas}

Para um estudo qualitativo, considere-se uma estrutura quase periódica, formada de um painel composto por quatro placas quadradas não alinhadas, acopladas a vigas de grande rigidez, as quais são representadas por molas de rigidez rotacional.

Na ausência de desordem, o terceiro exemplo de um modelo físico real a ser analisado, trata-se um painel composto por quatro placas quadradas de material homogêneo e isotrópico com dimensões $L x=L y=8,00 m$, módulo de elasticidade $E=2,1 \times 10^{10} \mathrm{~N} / \mathrm{m}^{2}$, espessura $\bar{h}=0,20 \mathrm{~m}$ e coeficiente de Poisson $v=0,25$. Este painel está simplesmente apoiado nas vigas intermediárias de largura $\bar{l}_{x}=L x / 20$ e cuja altura $h=0,60 m$, conforme é mostrado na Figura 6.29.

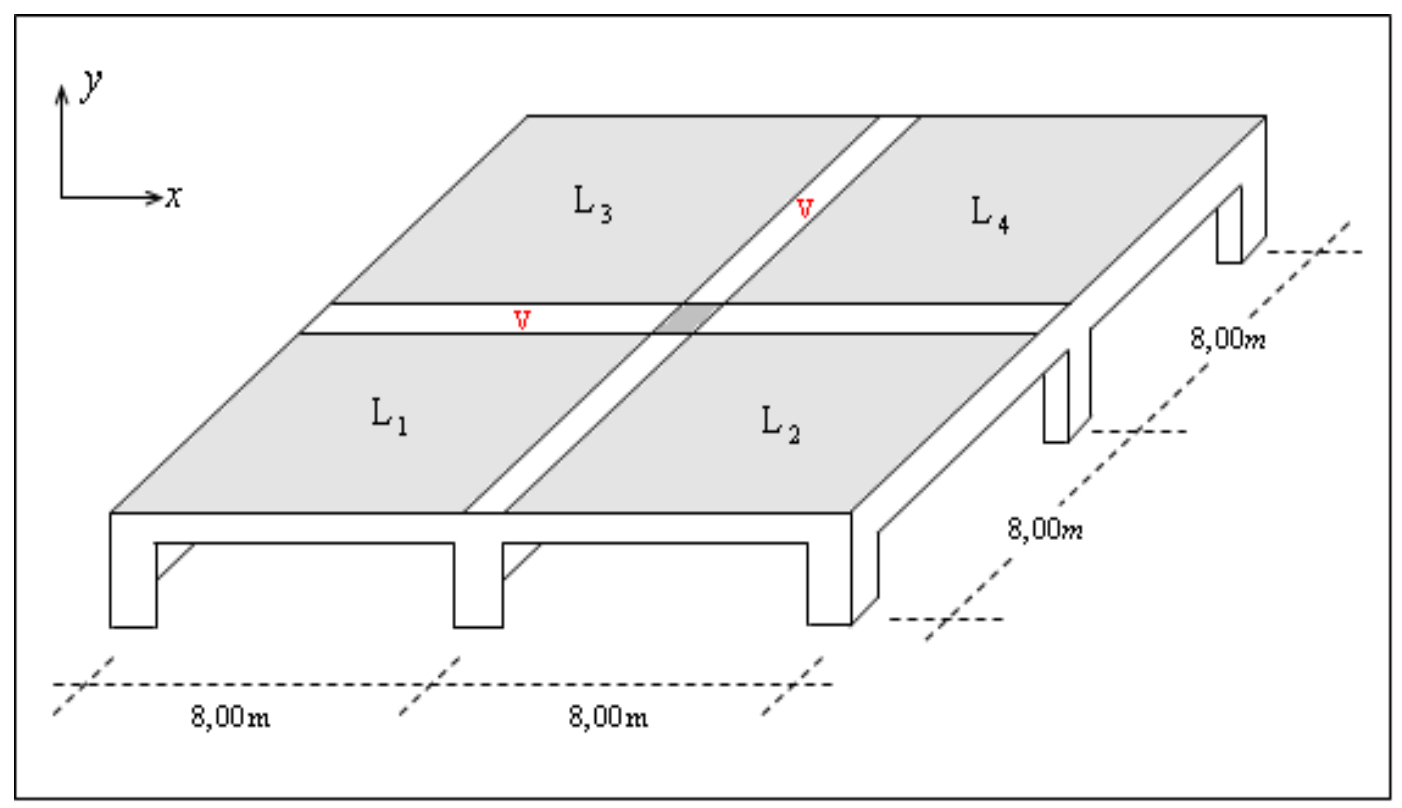

Figura 6.29 - Modelo físico real do painel formado por quatro placas acopladas. 
A estrutura real que foi mostrada na Figura 6.29, é então substituída pelo modelo estrutural aproximado da Figura 6.30, desta forma, estaremos modelando de modo a não termos interferência das vigas nas lajes e tornar o programa de cálculo de elementos finitos de maior tamanho e dificuldades.

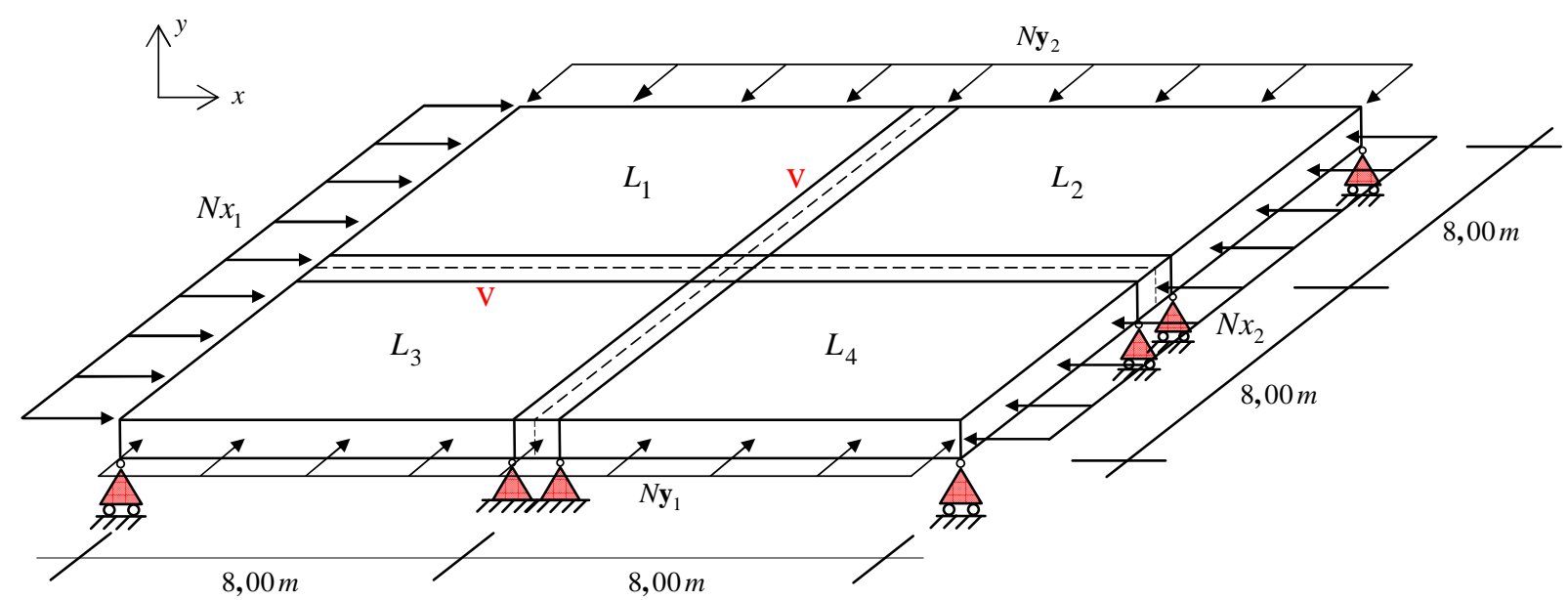

Figura 6.30 - Modelo estrutural simplificado do painel com quatro placas.

A Figura 6.31 a seguir, mostra a vista em planta do painel formado por quatro placas quadradas acopladas a vigas de grande rigidez e com carregamento de protensão aplicado nas direções " $x$ " e " $y$ ".

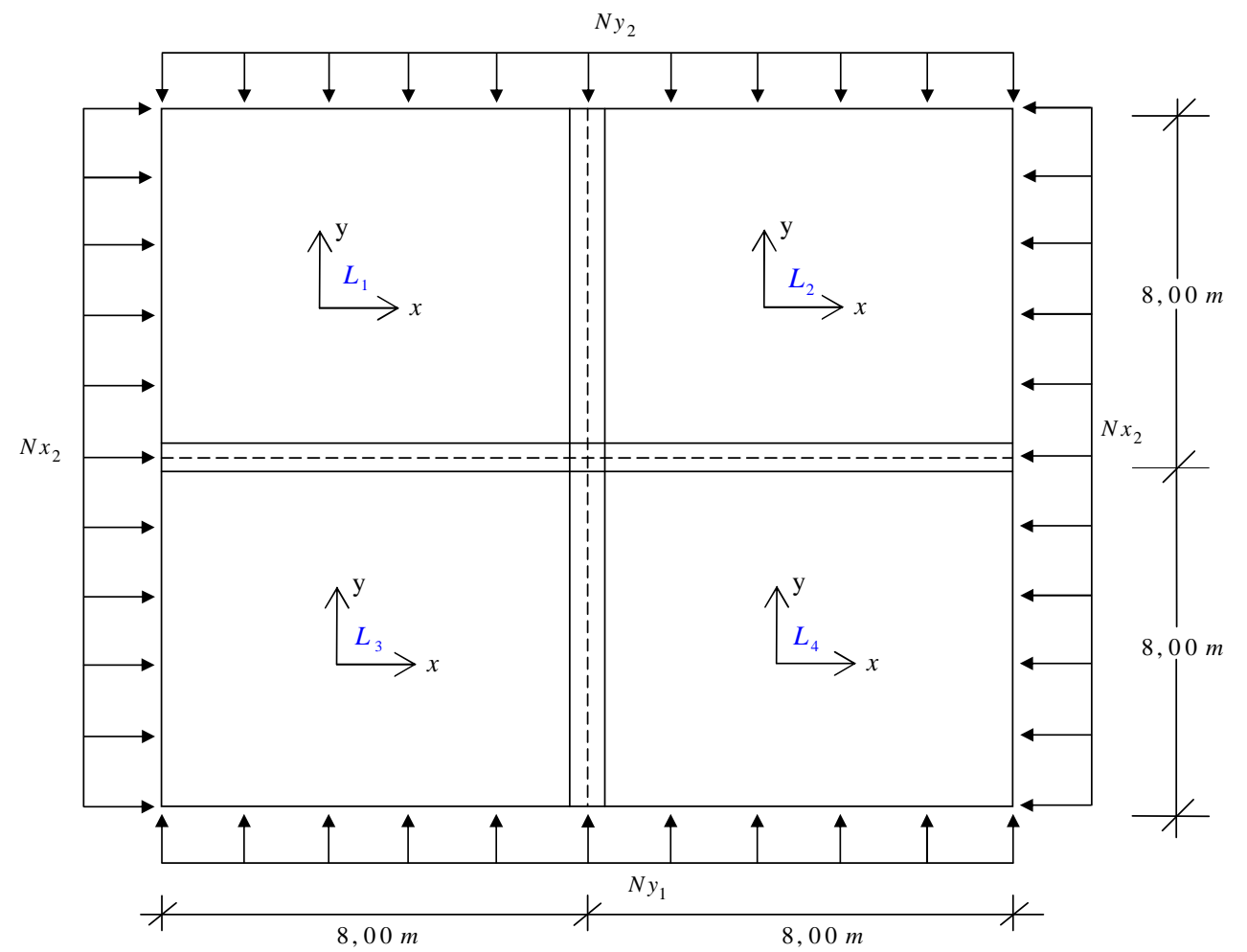

Figura 6.31 - Vista em Planta do painel formado por quatro placas. 
a) Estudo do efeito da variação da espessura de referência $(\bar{h})$ das placas na forma:

$$
\begin{aligned}
& h_{1}=\bar{h}(1+\varepsilon) \\
& h_{2}=\bar{h}(1-\varepsilon)
\end{aligned}
$$

onde se introduziu $\varepsilon$ um parâmetro pequeno relacionado com o grau de desordem, variando no intervalo de $-5 \%$ a $+5 \%$ aleatoriamente.

A Tabela 6.11 mostra os valores obtidos para as freqüências naturais dos dois primeiros modos de vibração, obtidos pelo programa DYMPLATE, para a variação na espessura de referência $(\bar{h}=0,20 \mathrm{~m})$ do painel formado por quatro placas quadradas.

\begin{tabular}{cccccccccc}
\hline \multicolumn{2}{c}{$L_{1}$} & \multicolumn{2}{c}{$L_{2}$} & \multicolumn{2}{c}{$L_{3}$} & \multicolumn{2}{c}{$L_{4}$} & \multicolumn{2}{c}{$\begin{array}{c}\text { Frequências naturais } \\
\text { (rad/s) }\end{array}$} \\
\hline $\mathcal{E}_{1}(\%)$ & $h_{1}(m)$ & $\varepsilon_{2}(\%)$ & $h_{2}(m)$ & $\mathcal{E}_{3}(\%)$ & $h_{3}(m)$ & $\mathcal{E}_{4}(\%)$ & $h_{4}(m)$ & $1^{\circ}$ modo & $2^{\circ}$ modo \\
\hline$-5 \%$ & 0,1900 & $5 \%$ & 0,2100 & $-1 \%$ & 0,1980 & $1 \%$ & 0,2020 & 12,2448 & 12,7809 \\
$-4 \%$ & 0,1920 & $4 \%$ & 0,2080 & $-2 \%$ & 0,1960 & $2 \%$ & 0,2040 & 12,3609 & 12,7025 \\
$-3 \%$ & 0,1940 & $3 \%$ & 0,2060 & $-3 \%$ & 0,1940 & $3 \%$ & 0,2060 & 12,4471 & 12,6393 \\
$-2 \%$ & 0,1960 & $2 \%$ & 0,2040 & $-4 \%$ & 0,1920 & $4 \%$ & 0,2080 & 12,4261 & 12,6760 \\
$-1 \%$ & 0,1980 & $1 \%$ & 0,2020 & $-5 \%$ & 0,1900 & $5 \%$ & 0,2100 & 12,3354 & 12,7709 \\
$0 \%$ & 0,2000 & $0 \%$ & 0,2000 & $0 \%$ & 0,2000 & $0 \%$ & 0,2000 & 12,7577 & 12,9231 \\
$1 \%$ & 0,2020 & $-1 \%$ & 0,1980 & $5 \%$ & 0,2100 & $-5 \%$ & 0,1900 & 12,3615 & 12,7960 \\
$2 \%$ & 0,2040 & $-2 \%$ & 0,1960 & $4 \%$ & 0,2080 & $-4 \%$ & 0,1920 & 12,4736 & 12,7195 \\
$3 \%$ & 0,2060 & $-3 \%$ & 0,1940 & $3 \%$ & 0,2060 & $-3 \%$ & 0,1940 & 12,5225 & 12,6952 \\
$4 \%$ & 0,2080 & $-4 \%$ & 0,1920 & $2 \%$ & 0,2040 & $-2 \%$ & 0,1960 & 12,4554 & 12,7810 \\
$5 \%$ & 0,2100 & $-5 \%$ & 0,1900 & $1 \%$ & 0,2020 & $-1 \%$ & 0,1980 & 12,3561 & 12,8896 \\
\hline
\end{tabular}

Tabela 6.11 - Freqüências naturais versus grau de desordem na espessura.

A seguir nas Figuras 6.32 a 6.35, apresentam-se o primeiro e segundo modos de vibração, do painel formado por quatro placas quadradas, relativos aos valores apresentados na sexta e na primeira linha da Tabela 6.11, para os sistemas ordenados e desordenados que foram obtidos pelo programa DYMPLATE, respectivamente. 
A Figura 6.32 mostra o primeiro modo de vibração obtido para o sistema ordenado do painel formado por quatro placas quadradas com espessuras iguais.

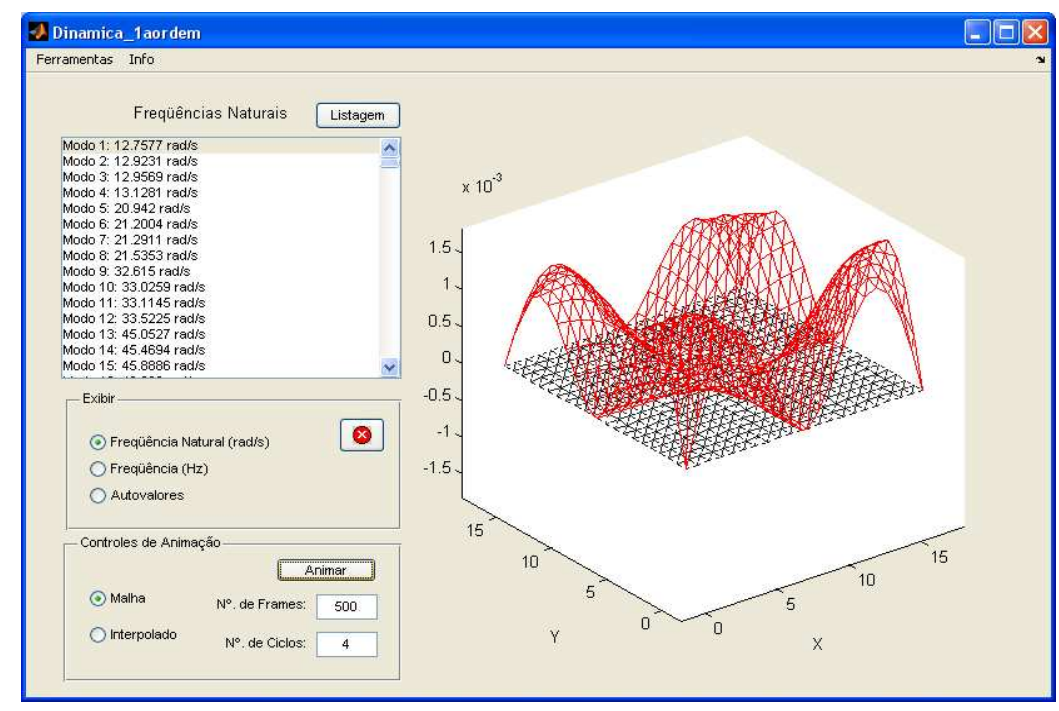

Figura 6.32 - Primeiro modo de vibração das placas com espessuras iguais.

A Figura 6.33 mostra o primeiro modo de vibração obtido para o sistema desordenado do painel formado por quatro placas com desordens nas espessuras.

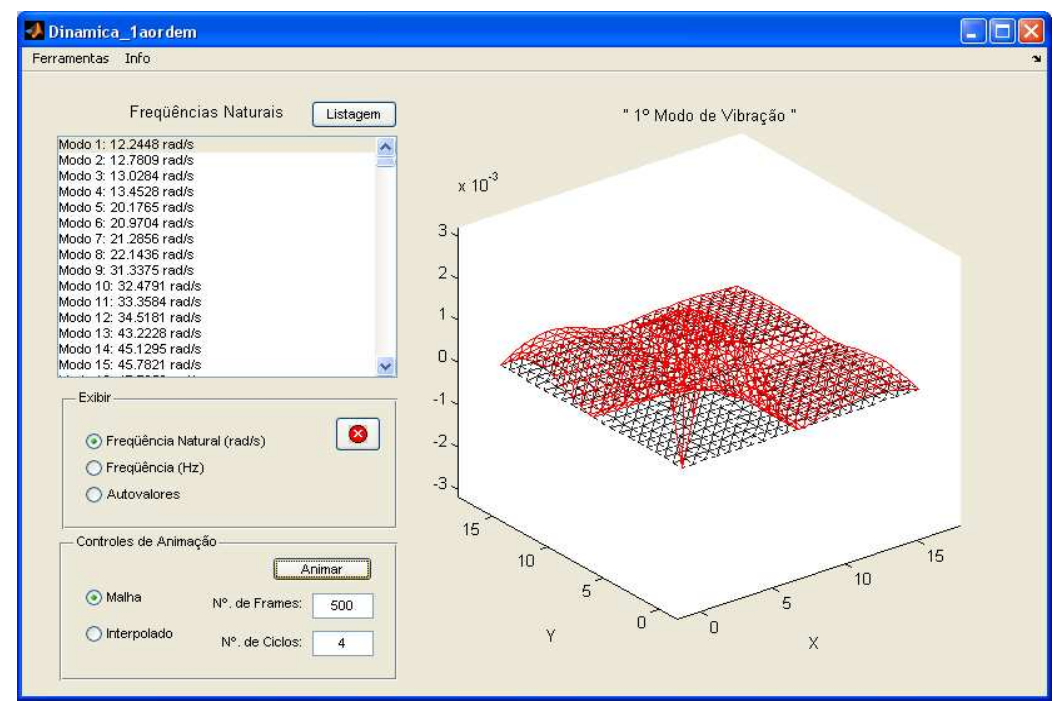

Figura 6.33 - Primeiro modo de vibração das placas com desordens nas espessuras. 
A Figura 6.34 mostra o segundo modo de vibração obtido para o sistema ordenado do painel formado por quatro placas quadradas com espessuras iguais.

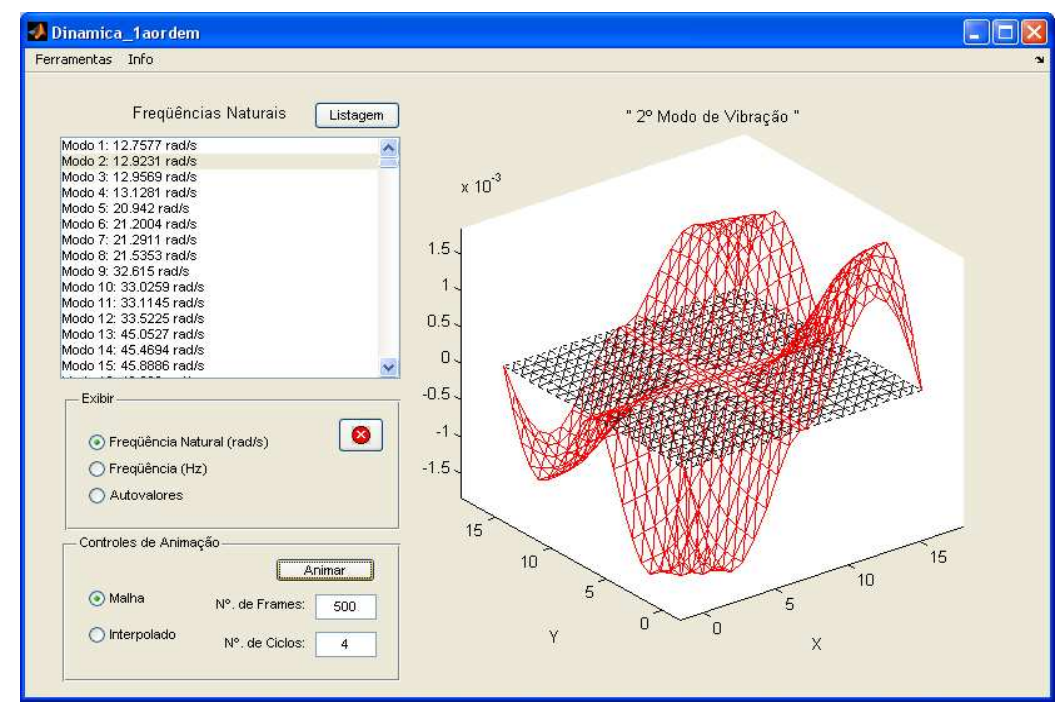

Figura 6.34 - Segundo modo de vibração das placas com espessuras iguais.

A Figura 6.35 mostra o segundo modo de vibração obtido para o sistema desordenado do painel formado por quatro placas com desordens nas espessuras.

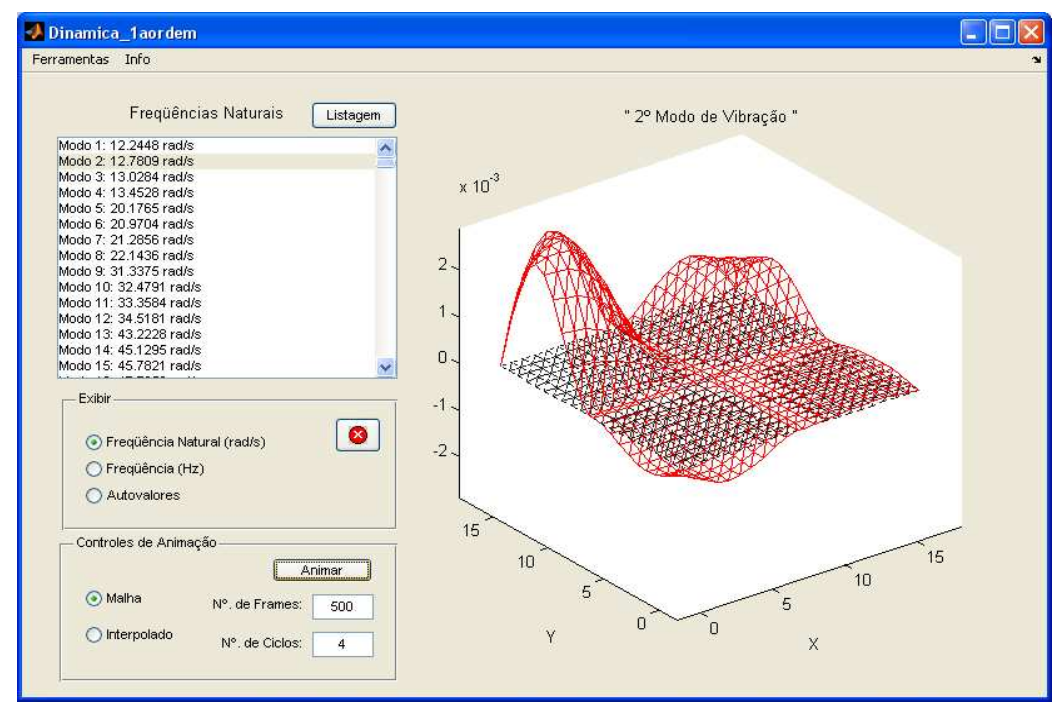

Figura 6.35 - Segundo modo de vibração das placas com desordens nas espessuras. 
b) Estudo do efeito da variação da força de protensão de referência $(\bar{N} x)$ das placas na seguinte forma:

$$
\begin{aligned}
& N x_{1}=\bar{N} x(1+\varepsilon) \\
& N x_{2}=\bar{N} x(1-\varepsilon)
\end{aligned}
$$

onde se introduziu $\varepsilon$ um parâmetro pequeno relacionado com o grau de desordem, variando no intervalo de $-100 \%$ a $+100 \%$

A Tabela 6.12 a seguir, mostra os valores obtidos para as freqüências naturais para os dois primeiros modos de vibração obtidos pelo programa DYMPLATE, para a variação das forças de protensão de referência $\left(\bar{N} x=4 \times 10^{6} N\right)$ do painel formado por quatro placas quadradas, homogêneas e isotrópicas.

\begin{tabular}{cccccccccc}
\hline \multicolumn{2}{c}{$L_{1}$} & \multicolumn{2}{c}{$L_{2}$} & \multicolumn{2}{c}{$L_{3}$} & \multicolumn{2}{c}{$L_{4}$} & \multicolumn{2}{c}{$\begin{array}{c}\text { Frequiencias } \\
\text { naturais (rad/s) }\end{array}$} \\
\hline $\mathcal{E}_{1}(\%)$ & $\bar{N} x_{1}(N)$ & $\varepsilon_{2}(\%)$ & $\bar{N} x_{2}(N)$ & $\mathcal{E}_{3}(\%)$ & $\bar{N} x_{3}(N)$ & $\mathcal{E}_{4}(\%)$ & $\bar{N} x_{4}(N)$ & $1^{\circ}$ modo & $2^{\circ}$ modo \\
\hline$-100 \%$ & $0,00 \mathrm{E}+00$ & $100 \%$ & $8,00 \mathrm{E}+06$ & $-20 \%$ & $3,20 \mathrm{E}+06$ & $20 \%$ & $4,80 \mathrm{E}+06$ & 11,0464 & 12,1776 \\
$-80 \%$ & $8,00 \mathrm{E}+05$ & $80 \%$ & $7,20 \mathrm{E}+06$ & $-40 \%$ & $2,40 \mathrm{E}+06$ & $40 \%$ & $5,60 \mathrm{E}+06$ & 12,2117 & 12,4276 \\
$-60 \%$ & $1,60 \mathrm{E}+06$ & $60 \%$ & $6,40 \mathrm{E}+06$ & $-60 \%$ & $1,60 \mathrm{E}+06$ & $60 \%$ & $6,40 \mathrm{E}+06$ & 12,1980 & 12,4364 \\
$-40 \%$ & $2,40 \mathrm{E}+06$ & $40 \%$ & $5,60 \mathrm{E}+06$ & $-80 \%$ & $8,00 \mathrm{E}+05$ & $80 \%$ & $7,20 \mathrm{E}+06$ & 12,1269 & 12,4453 \\
$-20 \%$ & $3,20 \mathrm{E}+06$ & $20 \%$ & $4,80 \mathrm{E}+06$ & $-100 \%$ & $0,00 \mathrm{E}+00$ & $100 \%$ & $8,00 \mathrm{E}+06$ & 10,6707 & 12,0657 \\
$0 \%$ & $4,00 \mathrm{E}+06$ & $0 \%$ & $4,00 \mathrm{E}+06$ & $0 \%$ & $4,00 \mathrm{E}+06$ & $0 \%$ & $4,00 \mathrm{E}+06$ & 12,3895 & 12,5252 \\
$20 \%$ & $4,80 \mathrm{E}+06$ & $-20 \%$ & $3,20 \mathrm{E}+06$ & $100 \%$ & $8,00 \mathrm{E}+06$ & $-100 \%$ & $0,00 \mathrm{E}+00$ & 11,088 & 12,2775 \\
$40 \%$ & $5,60 \mathrm{E}+06$ & $-40 \%$ & $2,40 \mathrm{E}+06$ & $80 \%$ & $7,20 \mathrm{E}+06$ & $-80 \%$ & $8,00 \mathrm{E}+05$ & 12,2205 & 12,3531 \\
$60 \%$ & $6,40 \mathrm{E}+06$ & $-60 \%$ & $1,60 \mathrm{E}+06$ & $60 \%$ & $6,40 \mathrm{E}+06$ & $-60 \%$ & $1,60 \mathrm{E}+06$ & 12,1790 & 12,4488 \\
$80 \%$ & $7,20 \mathrm{E}+06$ & $-80 \%$ & $8,00 \mathrm{E}+05$ & $40 \%$ & $5,60 \mathrm{E}+06$ & $-40 \%$ & $2,40 \mathrm{E}+06$ & 12,0274 & 12,4618 \\
$100 \%$ & $8,00 \mathrm{E}+06$ & $-100 \%$ & $0,00 \mathrm{E}+00$ & $20 \%$ & $4,80 \mathrm{E}+06$ & $-20 \%$ & $3,20 \mathrm{E}+06$ & 10,6102 & 12,0895 \\
\hline
\end{tabular}

Tabela 6.12 - Freqüências naturais versus grau de desordem na protensão.

Nas Figuras 6.36 a 6.39 apresentam-se o primeiro e segundo modos de vibração, do painel formado por quatro placas, relativos aos valores apresentados na sexta e na nona linha da Tabela 6.12, para os sistemas ordenados e desordenados, respectivamente. 
A Figura 6.36 mostra o primeiro modo de vibração obtido para o sistema ordenado, ou seja, com forças de protensão iguais.

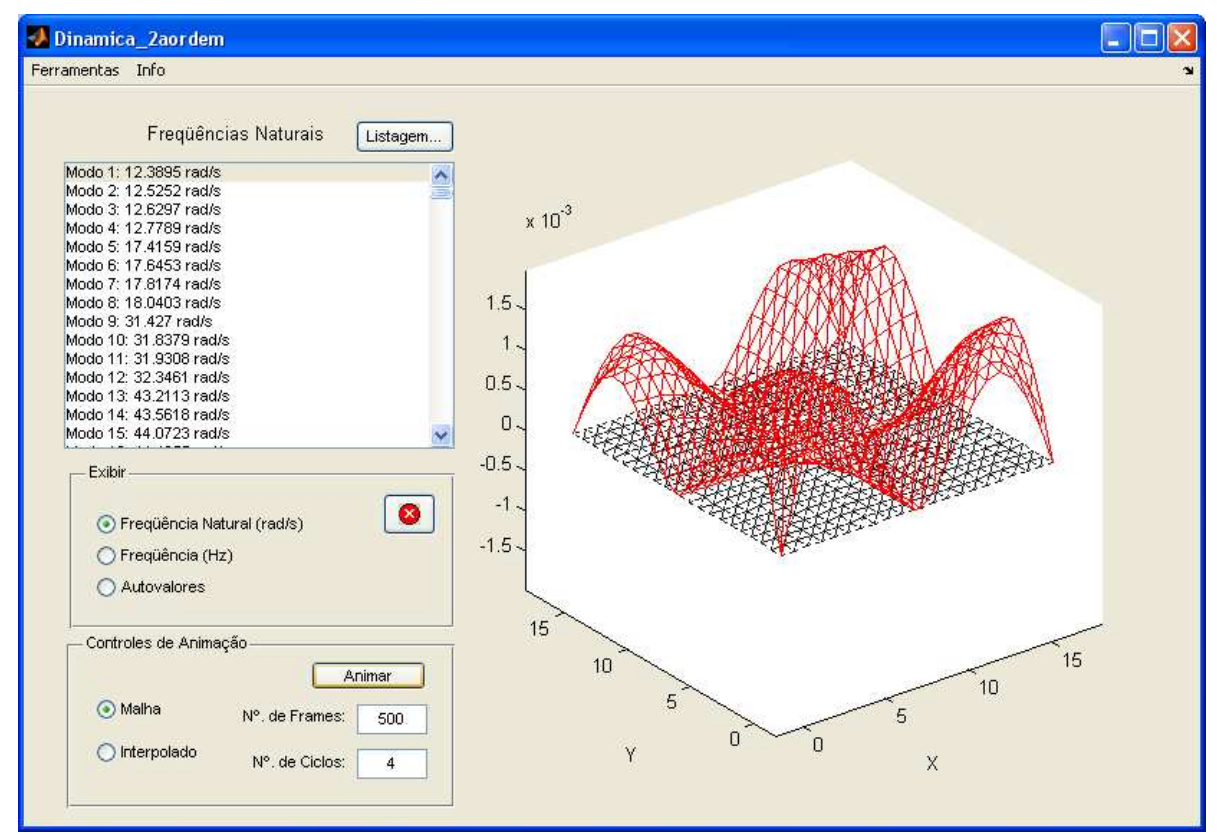

Figura 6.36 - Primeiro modo de vibração do sistema de placas com protensão ordenada.

A Figura 6.37 mostra o primeiro modo de vibração obtido para o sistema com desordens nas forças de protensão.

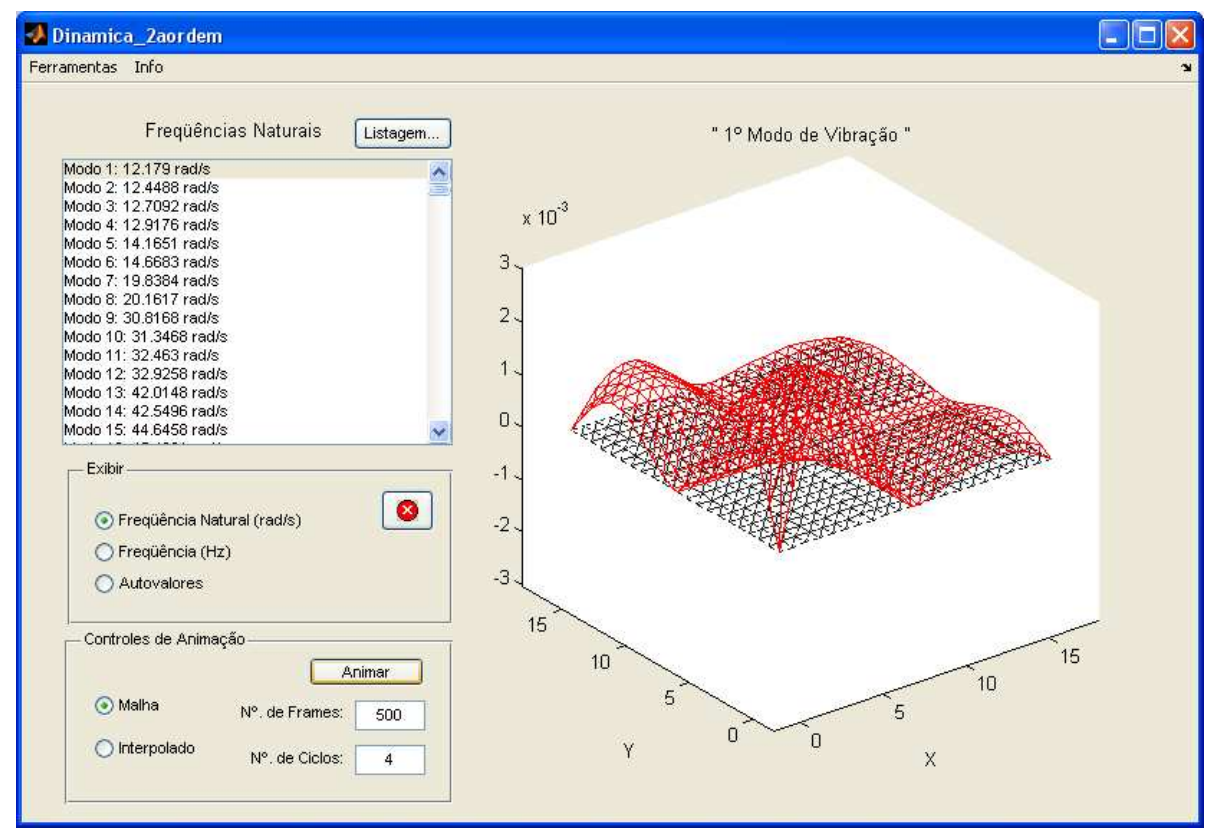

Figura 6.37 - Primeiro modo de vibração do sistema com desordens na protensão. 
A Figura 6.38 mostra o segundo modo de vibração obtido para o sistema ordenado, ou seja, com forças de protensão iguais.

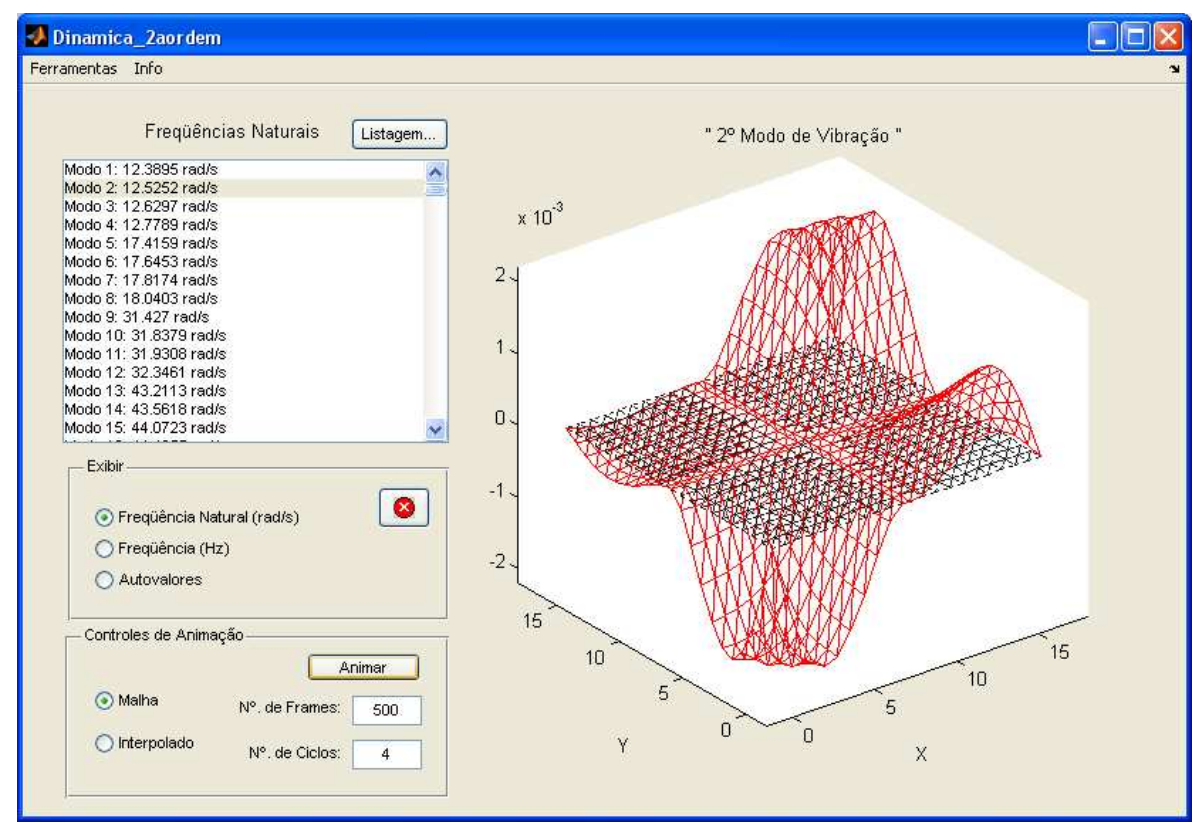

Figura 6.38 - Segundo modo de vibração do sistema de placas com protensão ordenada.

A Figura 6.39 mostra o segundo modo de vibração obtido para o sistema com desordens nas forças de protensão.

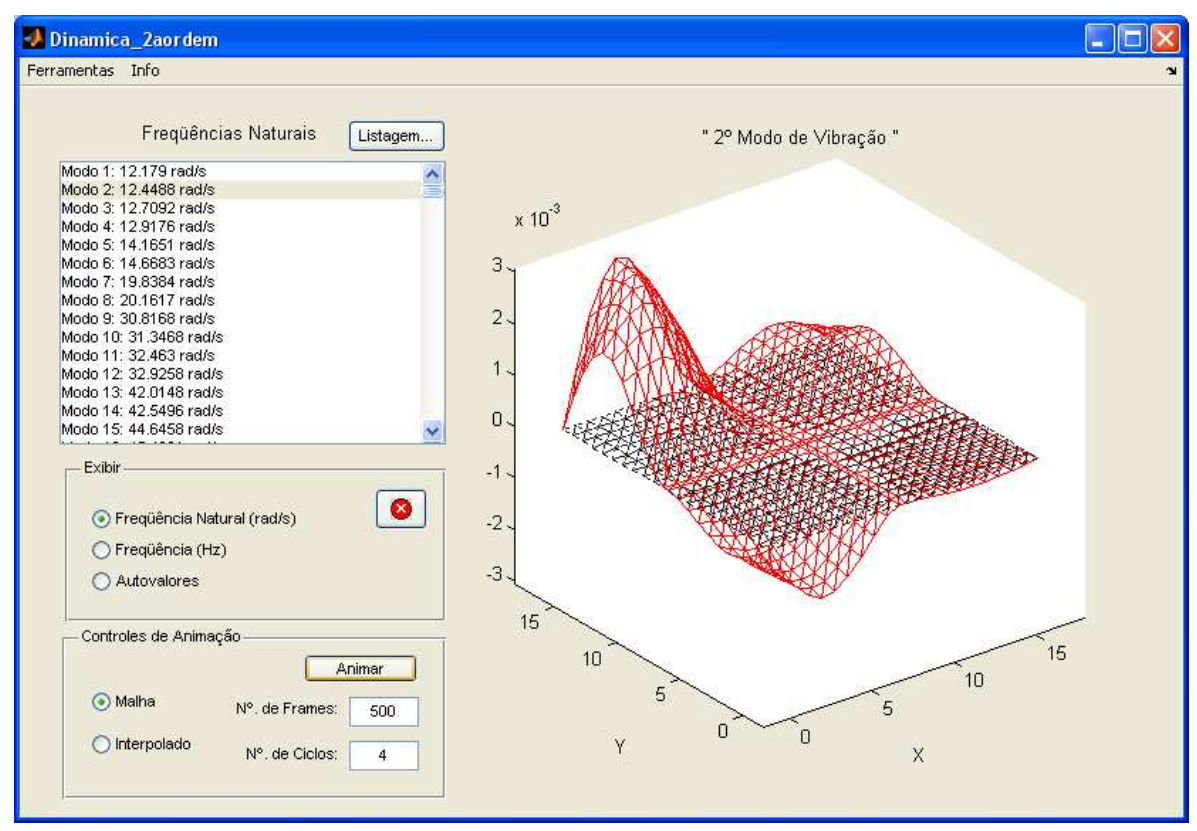

Figura 6.39 - Segundo modo de vibração do sistema com desordens na protensão. 


\section{Capítulo 7}

\section{Conclusão}

\section{1 - Conclusões Finais}

No curso desta pesquisa, conseguiu-se sucesso no estudo da Localização de Modos de vibrar de painéis de placas repetitivos com leve acoplamento entre si e na presença de pequenas imperfeições, em particular devido a forças de membrana.

Em detalhe, realizou-se:

- revisão bibliográfica a mais completa possível;

- consolidação da teoria subjacente;

- implementação computacional dos procedimentos numéricos;

- extração de resultados.

Notou-se, nos resultados, sucesso total na observação do fenômeno de localização buscado. Assim, em modelos de placas, inicialmente idênticas, conectadas por vigas de grande rigidez torcional, nota-se que uma delas experimenta grande amplitude de vibração enquanto as outras pouco se deslocam quando se introduz pequenas variações em suas características dinâmicas. Tais variações podem ser de natureza dimensional, mas a de maior interesse é o efeito de cargas de membrana diferentes nas placas, afetando suas matrizes de rigidez geométrica.

A determinação das freqüências e modos de vibração é feita em torno de uma configuração deformada obtida por uma análise não-linear por Newton. A matriz de rigidez tangente final do modelo nessa configuração é a que é utilizada, junto com a matriz de massa, no problema generalizado de autovalores e autovetores. 
Como exemplo, numa análise linear da estrutura, uma máquina muito pesada montada sobre uma placa gerando carregamento dinâmico numa freqüência que estaria em ressonância com uma das freqüências naturais obtidas. Em uma análise não-linear, o próprio peso do equipamento poderia alterar de tal forma essas freqüências a ponto de atenuar o problema. $O$ contrário também poderá acontecer, isto é, uma placa suportando um equipamento vibratório que numa análise linear não tivesse problema de ressonância, passe a tê-lo ao se considerar a configuração deformada, em uma análise não-linear.

Nos casos submetidos à análise, utilizado o programa desenvolvido, pode-se concluir que o engenheiro deve estar sempre atento ao comportamento dinâmico geometricamente não-linear de placas devido ao carregamento aplicado. A teoria não-linear pode, nesses casos, conduzir a avaliações muito diferentes das previstas pela teoria linear.

\section{2 - Sugestões para Trabalhos Futuros}

Como sugestão para trabalhos futuros, destaca-se, em primeiro lugar, a implementação de algoritmo para análise de vibrações forçadas.

A seguir, procurar-se-á determinar uma forma de usar o fenômeno de Localização de Modos como um mecanismo de controle passivo de vibrações. Assim, uma determinada placa poderá ser deliberadamente definida como aquela que sofrerá grandes deslocamentos, em benefício das demais do pavimento que terão vibrações de pequena amplitude.

Outra sugestão para trabalhos futuros é a adaptação do programa computacional a outras linguagens de programação fazendo o uso de bibliotecas orientadas a objeto. Assim, se torna possível produzir um algoritmo totalmente compilado, com maior ganho na rapidez de processamento dos cálculos, diminuição do tamanho do programa e, finalmente, gerar um programa executável de maneira que possa ser instalado em qualquer sistema operacional independente da plataforma. 


\section{Anexo A}

\section{Obtenção das Funções de Forma}

Funções de forma para o elemento triangular de chapa de deformação constante (CST).

$$
\gamma_{j}=\frac{1}{2 A}\left(a_{i}+b_{j} x+c_{k} y\right)
$$

Por meio de uma permutação cíclica, são definidas as seguintes constantes:

$\left\{\begin{array}{l}\left\{\begin{array}{l}a_{1}=x_{2} y_{3}-x_{3} y_{2} \\ b_{1}=y_{2}-y_{3} \\ c_{1}=x_{3}-x_{2}\end{array} \rightarrow \text { coordenadas do nó } 1\right. \\ \left\{\begin{array}{l}a_{2}=x_{3} y_{1}-x_{1} y_{3} \\ b_{2}=y_{3}-y_{1} \\ c_{2}=x_{1}-x_{3}\end{array} \rightarrow \text { coordenadas donó } 2\right. \\ \left\{\begin{array}{l}a_{3}=x_{1} y_{2}-x_{2} y_{1} \\ b_{3}=y_{1}-y_{2} \\ c_{3}=x_{2}-x_{1}\end{array} \rightarrow \text { coordenadas donó } 3\right.\end{array}\right.$

onde:

$$
A=\frac{1}{2}\left[\begin{array}{lll}
1 & x_{1} & y_{1} \\
1 & x_{2} & y_{2} \\
1 & x_{3} & y_{3}
\end{array}\right] \text { (área do elemento) }
$$


Funções de Forma para o elemento triangular de placa de ZIENKIEZICZ [82].

$$
\begin{aligned}
& \phi_{1}=L_{1}+L_{1}^{2} L_{2}+L_{1}^{2} L_{3}+L_{2}^{2} L_{1}+L_{3}^{2} L_{1} \\
& \psi_{1}=-b_{3}\left(L_{1}^{2} L_{2}+\frac{1}{2} L_{1} L_{2} L_{3}\right)+b_{2}\left(L_{1}^{2} L_{3}+\frac{1}{2} L_{1} L_{2} L_{3}\right) \\
& \eta_{1}=-c_{3}\left(L_{1}^{2} L_{2}+\frac{1}{2} L_{1} L_{2} L_{3}\right)+c_{2}\left(L_{1}^{2} L_{3}+\frac{1}{2} L_{1} L_{2} L_{3}\right) \\
& \phi_{2}=L_{2}+L_{2}^{2} L_{1}+L_{2}^{2} L_{3}-L_{1}^{2} L_{2}-L_{3}^{2} L_{2} \\
& \psi_{2}=-b_{1}\left(L_{2}^{2} L_{3}+\frac{1}{2} L_{1} L_{2} L_{3}\right)+b_{3}\left(L_{2}^{2} L_{1}+\frac{1}{2} L_{1} L_{2} L_{3}\right) \\
& \eta_{2}=-c_{1}\left(L_{2}^{2} L_{3}+\frac{1}{2} L_{1} L_{2} L_{3}\right)+c_{3}\left(L_{2}^{2} L_{1}+\frac{1}{2} L_{1} L_{2} L_{3}\right) \\
& \phi_{3}=L_{3}+L_{3}^{2} L_{1}+L_{3}^{2} L_{2}-L_{1}^{2} L_{3}-L_{2}^{2} L_{3} \\
& \psi_{3}=-b_{2}\left(L_{3}^{2} L_{1}+\frac{1}{2} L_{1} L_{2} L_{3}\right)+b_{1}\left(L_{3}^{2} L_{2}+\frac{1}{2} L_{1} L_{2} L_{3}\right) \\
& \eta_{3}=-c_{2}\left(L_{3}^{2} L_{1}+\frac{1}{2} L_{1} L_{2} L_{3}\right)+c_{1}\left(L_{3}^{2} L_{2}+\frac{1}{2} L_{1} L_{2} L_{3}\right)
\end{aligned}
$$

As coordenadas triangulares $L_{1}, L_{2}, L_{3}$ são obtidas através das seguintes relações em termos das coordenadas cartesianas:

$$
\begin{aligned}
& L_{1}=\left(a_{1}+b_{1} x+c_{1} y\right) /(2 \cdot \text { Area }) \\
& L_{2}=\left(a_{2}+b_{2} x+c_{2} y\right) /(2 \cdot \text { Area }) \\
& L_{3}=\left(a_{3}+b_{3} x+c_{3} y\right) /(2 \cdot \text { Area })
\end{aligned}
$$




\section{Anexo B}

\section{Integração por Partes}

Para um problema bidimensional, as equações para integração por partes são:

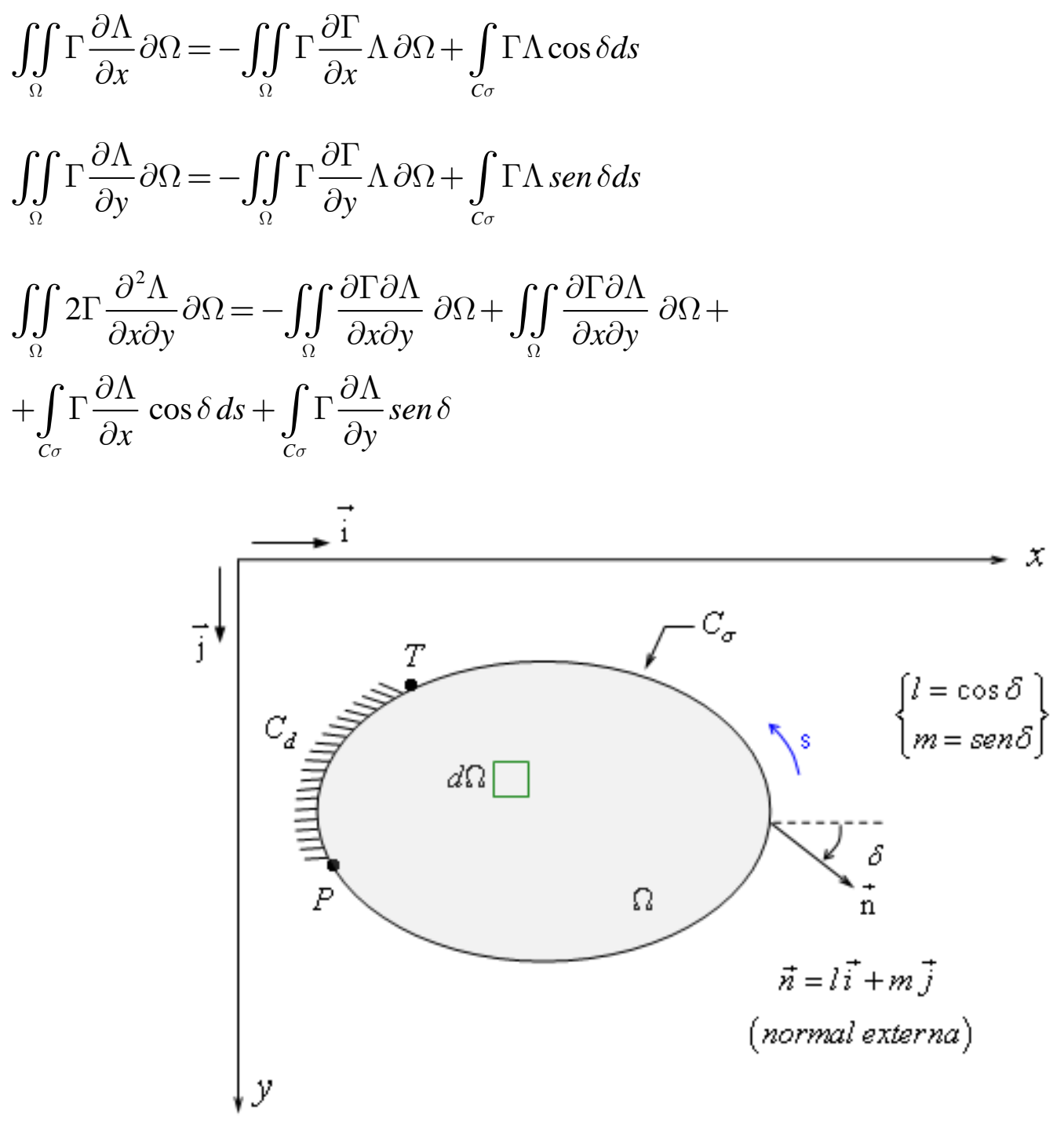

Figura 7.1 - Domínio " $\Omega$ ” e contorno "C " a duas dimensões. 


\section{Anexo C}

\section{Forças de Superfície Aplicadas no Contorno}

As forças de protensão aplicadas no contorno das placas resultam no seguinte vetor:

$\left(f^{p}\right)^{e}=h \int_{c \sigma} \bar{X} \cdot\left\{\begin{array}{l}\gamma_{1}^{e} \\ \gamma_{1}^{e} \\ \gamma_{2}^{e} \\ \gamma_{2}^{e} \\ \gamma_{3}^{e} \\ \gamma_{3}^{e}\end{array}\right\}$

$F_{1}^{x}=\frac{l_{12}}{2} \cdot \bar{X} \cdot h \cdot \cos \delta ; F_{1}^{y}=\frac{l_{12}}{2} \cdot \bar{X} \cdot h \cdot \operatorname{sen} \delta$
$F_{2}^{x}=\frac{l_{12}}{2} \cdot \bar{X} \cdot h \cdot \cos \delta ; F_{2}^{y}=\frac{l_{12}}{2} \cdot \bar{X} \cdot h \cdot \operatorname{sen} \delta$
$F_{3}^{x}=\frac{l_{12}}{2} \cdot \bar{X} \cdot h \cdot \cos \delta ; F_{3}^{y}=\frac{l_{12}}{2} \cdot \bar{X} \cdot h \cdot \operatorname{sen} \delta$

sendo:

- $\quad h$ é a espessura da chapa constante.

- $l_{12}$ é o comprimento do lado 1-2 do elemento.

- $\bar{X}$ é a carga normal do lado 1-2 do elemento por unidade de comprimento (protensão).

- $\delta$ é o ângulo formado entre o eixo x e a direção da normal ao lado 1-2 do elemento. (ver Figura 7.1). 


\section{Referências Bibliográficas}

[1] ADINI, A. Analysis of Shell Structures by the Finite Element Method. Tese (PósDoutorado), Departamento de Engenharia Civil, Universidade da Califórnia, Berkeley, CA, 1961.

[2] ALMEIDA F. M. Estruturas de Pisos de Edifícios com a Utilização de Cordoalhas Engraxadas. Dissertação (Mestrado) - Escola de Engenharia de São Carlos. São Carlos, 2002.

[3] ANDERSON, P. W. Absence of Diffusion in Certain Random Lattices. Physical Review, v.109, p.1492-1505, 1958.

[4] ANDERSON, P. W.; MOTT. Nobel Lectures in Physics. Review of Modern Physics, v.50, p.191-208, 1978.

[5] ARGYRIS, J. H.; KELSEY, S. Energy Theorems and Structural Analysis. Collection of Papers Published in Aircraft Engineering. Butterworth, London, 1960.

[6] BALTHAZAR, J. M.; BRASIL, R. M. L R. F. On Nonlinear Normal Modes of a 2-Dof Model of a Structure with Quadratic Nonlinearities. Journal of Sound and Vibration, v.182, n.4, p.656-664. Grã-Bretanha, UK, 1995.

[7] BAZELEY, G. P.; CHEUNG, Y. K.; IRONS, B. M.; ZIENKIEWICZ, O. C. Triangular Elements in Plate Bending - Conforming and Nonconforming Solutions, in Proceeding 1rs Conference Matrix Method Structures Mechanics. Ed. by J. Przemieniecki et al, AFFDL - TR-66-80, p.547-576. Air Force Institute of Technology, Dayton, Ohio, 1966.

[8] BENDIKSEN, O. O. Aeroelastic Stabilization by Disorder and Imperfection. In: XVI IUTAM Congress of Theoretical and Applied Mechanics, Proceedings Paper $\mathrm{n}^{\circ}$ 583P. Lyngby, Denmark, 1984.

[9] BLIVEN, D. O.; SOONG, T. T. On Frequencies of Elastic Beans with Random Imperfections. Journal of Franklin Institute, v.287, p.297-304, 1960.

[10] BRASIL, R. M. L. R. F.; HAWWA, M. The Localization of Buckling Modes in Nearly Periodic Trusses. Computers and Structures, Estados Unidos, v.56, n.6, p. 927-932. 1995. 
[11] BRASIL, R. M. L. R. F.; MAZZILLI, C. E, N. Influence of Loading on Mode localization in Periodic Structures. Applied Mechanics Reviews, Estados Unidos, v. 48, n.11, p.132-137, 1995.

[12] BRASIL, R. M. L. R. R. O Fenômeno de Localização de Modos em Dinâmica e Estabilidade de Estruturas Moduladas de Comportamento Linear ou Não-Linear. Tese (Livre Docência) - Escola Politécnica, Universidade de São Paulo. São Paulo, 1996.

[13] BRASIL, R. M. L. R. F.; COSTA, S. N. J.; CLAEYSSEN, J. R. Mode Localization by Using the Dynamical Basis Approach. 19rd International Congress of Mechanical Engineering, Brasília, 2007.

[14] BRILLOUIN, L. Wave Propagation in Periodic Structures. Dover Publications, London, 1963.

[15] CHA, P. D.; PIERRE, C. Vibration Localization by Disorder in Assemblies of MonoCoupled, Multi-mode Component Systems. In: Dynamics Specialist Conference, Long Beach, CA. Proceedings. AIAA Paper 90-123-CP, 1990.

[16] CHAllamel, N.; LANOS, C.; CASANDJIAN, C. Localization in the Buckling or in the Vibration of a Two-Span Weakened Column. Journal Engineering Structures, v.28, p.776-782, 2006.

[17] CHEN, Z;; XIE, W. C. Vibration Localization in Plates Rib-Stiffened in Two Orthogonal Directions. Journal of Sound and Vibration, v.280, p.235-262, 2003.

[18] CLOUGH, R. W. The Finite Element Method in Plane Stress Analysis. Proceeding of Second ASCE Conference on Electronic Computation, Pittsburgh, PA, p.345-378, 1960.

[19] COLlinS, M. P.; MITCHELL, D. Prestessed Concrete Basics. Prestessed Concrete Institute. Ottawa, Canadian, 1987.

[20] CORNWELL, P. J.; BENDIKSEN, O. O. A Numerical Study of Vibration Localization in Disordered Cyclic Structures. In: 30rd AIAA/ASME/ASCE/AHS Structures, Structural Dynamics and Materials Conference, Mobile, Al. Proceedings. AIAA Paper no 89-1181CP, 1989.

[21] CORRÊA, M. R. S.; MEllo, G. S.; MARTINS, P. C. Comportamento ao Puncionamento de Lajes Cogumelo Protendidas com Cabos não aderentes. 43º Congresso Brasileiro do Concreto - IBRACON, Foz do Iguaçu, p.16, 13 a 18 de agosto de 2001. ANAIS [CD-ROM]. 
[22] COSTA, H. B. Elementos Finitos (via Resíduos Ponderados) na Resolução do Problema de Segunda Ordem das Placas. Tese (Doutorado) - Escola Politécnica, Universidade de São Paulo. São Paulo, 1986.

[23] DAWE, D. J. Finite Elements for Plate Bending Analysis. In: Matrix and Finite Element Displacement Analysis of Structures, Clarendon Press, p.410-462. Oxford, 1984.

[24] DEAN, P.; BACON, M. D. The Nature of Vibrational Modes in Disordered Systems. Proceedings of the Physical Society, v.81, p.642-647, 1963.

[25] DUARTE, E. P. Projeto e Cálculo de Lajes Protendidas (MAC-Protensão).

[26] DYE, R. C. F.; HENRY, T. A. Vibration Amplitudes of Compressor Blades Resulting from Scatter in Blade Natural Frequencies. ASME Journal of Engineering for Power, v.91, p.182-188, 1969.

[27] EL-BAYOUMI, L. E.; SRINIVASAN, A. V. Influence of Mistuning on Rotor-Blade Vibrations. AAII Journal, v.13, p.460-464, 1975.

[28] EMERICK, A. A. Projeto e Execução de Lajes Protendidas. Brasília, 2005.

[29] ENGELS, R. C. Response of Infinite Periodic Structures. Journal of Sound and Vibration, v.69, nº 2, p. 181-197, 1980.

[30] EWINS, D. J. Vibration Modes of Mistuned Bladed Disks. ASME Journal of Engineering for Power, p.349-355, 1976.

[31] FERNANDES, C. F. C. Análise de Lajes com Protensão sem Aderência. Dissertação (Mestrado) - Escola Politécnica, Universidade de São Paulo. São Paulo, 2001.

[32] FREYSSINET. Catálogo Técnico, 1998.

[33] FURSTENBERG, H. Noncom Muting Random Products. Transactions of the American Mathematical Society, v. 108, nº 3, p. 377-428, 1963.

[34] GALERKIN, B. G. Solução de alguns Problemas de Equilíbrio de Barras e Placas, Viestnik Injenerov (Boletim dos Engenheiros), v.1, p.879-908, 1915.

[35] GANTE, J. A. S. Curso Básico de Concreto Protendido, Associação Brasileira de Cimento Portland. São Paulo, 1996

[36] GARZERI, F. J. Elementos Finitos (via Resíduos Ponderados) na Análise Dinâmica de Placas de Comportamento Linear. Dissertação (Mestrado) - Escola Politécnica, Universidade de São Paulo. São Paulo, 1991. 
[37] GATTULLI, V.; LEPIDI, V. Modal Interactions Around a Multiple Frequency Veering in Cable-Stayed Structures. 7rd European Conference on Structures Dynamics (EURODYN). Southampton, UK, 2008.

[38] HODGES, C.H. Confinement of Vibration by Structural Irregularities. Journal of Sound and Vibration, v.82, $\mathrm{n}^{\mathrm{o}} 3, \mathrm{p} .411-424,1982$.

[39] HODGES, C. H.; WOODHOUSE, J. Vibration Isolation from Irregularity in a Nearly periodic Structure: Theory and Measurements. Journal of the Acoustical Society of America, v.74, nº 3, p. 894-905, 1983.

[40] IDE, P. S. Análise de Vibrações Livres em Torno de Configurações Deformadas em Placas de Comportamento Geometricamente Não-Linear pelo Método dos Elementos Finitos. Tese (Doutorado) - Escola Politécnica, Universidade de São Paulo. São Paulo, 1995.

[41] ISHII, K. Localization of Eigenvalues and Transport Phenomena in One Dimensional Disordered System. Supplement of the Progress of Theoretical Physics, n.53, p.77-138, 1973.

[42] JOSEPH, K. T.; RAO, S. A fast Algorithm for Triangular Plate Bending Elements. International Journal for Numerical Methods in Engineering, v.14, p. 1100-1103, 1979.

[43] KAZA, K. R. L. E.; KIELB, R. E. Flutter on Turbofan Rotors with Mistuned Blades. AIAA Journal, v.22, p.1618-1625, 1984.

[44] KISSEL, S. J. Localization in Disordered periodic Structures. In: 28rd AIAA / ASME / ASCE / AHS STRUCTURES, STRUCTURAL DYNAMICS AND MATERIALS CONFERENCE, Monterey, CA. Proceedings. AIAA Paper n.87-0819, 1987.

[45] LEISSA, A. W. The Historical Bases of the Rayleigh and Ritz Methods. Journal of Sound and Vibration, v. 287, p.961-978, 2005.

[46] LEISSA, A. W. Rectangular Plates. Vibration of Plates. NASA SP-160, US Government Printing Office, Washington, DC, p.41-160, 1969 (reprinted in 1993 by The Acoustical Society of America).

[47] LEONHARD, F. Construções de Concreto, v.5, ed. Interciência, Rio de Janeiro, 1979. 
[48] LIN, Y. K.; YANG, J. N. Free Vibration of a Disordered Periodic Beam. Journal of Applied Mechanics, p.383-391, 1974.

[49] LIN, T. Y. Load-Balancing Method for Design and Analysis of Prestressed Concrete Structures. ACI Proceeding, v.60, p.719-741, 1963.

[50] LIN, T. Y.; BURN, N. H. Design of Prestressed Concrete Structures. 3ed. John Wiley and Sons, p.641. In: New York, 1981.

[51] LIU, J. K.; CHAN, H. C. Mode Localization and Frequency Loci Veering in Disordered Engineering Structures. Chaos, Solitons and Fractais, v.11, p.1493-1504, 2000.

[52] LUCIA, A. V. M. Cálculo de Lajes Lisas com Protensão Parcial e Limitada. Dissertação (Mestrado) - Universidade Federal de São Carlos. São Carlos, 2005.

[53] MATLAB - The Language of Technical Computing. User's Guide, The Math Works. Versão 7.4a, Release 15, 2007.

[54] MEAD, D. J. Free Wave Propagation in Periodically Supported Infinite Beams. Journal of Sounds and Vibration, v.11, p.181-197, 1970.

[55] MEIROVITCH, L. Computational Methods in Structural Dynamics. Alphen Ann Den Rijn, Sijthoff \& Noordhoff, 1980.

[56] MELGES, J. L. P.; PINHEIRO, M. L.; DUARTE, E. P. Análise Experimental da Punção de Lajes Protendidas Pós-Tração. 43 Congresso Brasileiro do Concreto - IBRACON, Foz do Iguaçu, 13 a 18 de agosto de 2001. ANAIS [CD-ROM].

[57] MELOSH, R. J. Basis for Derivation of Matrices for the Direct Stiffness Method. AIAA Journal, v.1, n.7, p.1631-1637, 1963.

[58] MENDES, J. H. Contribuição ao cálculo automático de perdas progressivas em peças de concreto protendido. Tese (Doutorado) - Escola de Engenharia de São Carlos, Universidade de São Paulo. São Carlos, 1993.

[59] NATSIAVAS, S. Mode Localization and Frequency Veering in a Nonconservative mechanical System with Dissimilar Components. Journal of Sound and Vibration, v.165, p.137-147, 1993.

[60] NAYFEH, A. H.; HAWWA, M. A. The Use of Mode Localization in the Passive Control of Structural Bucking. AIAA Journal (ISSN 0001-1452), v.32, n.10, p.21312133, 1994. 
[61] PARLET, B. The Symmetric Eigenvalue Problem. Englewood Cliffs, Prentice-Hall, 1980.

[62] PAPPALARDO, A. J. Uma Notável Simplificação na Análise de Segunda Ordem das Placas pelo Método dos Elementos Finitos. Dissertação (Mestrado) - Escola Politécnica, Universidade de São Paulo. São Paulo, 1992.

[63] PFEIL, W. Concreto Protendido, v.1 ed. LTC, 2ed. Rio de Janeiro, 1988.

[64] PIERRE, C.; TANG, D. M.; Dowell, E. H. Localized Vibrations of Disordered Multispan Beams: Theory and Experiment. AIAA Journal, v.25, p.1249-1257, 1987.

[65] PIERRE, C. Mode Localization and Eigenvalue Loci Veering Phenomena in Disordered Structures. Journal of Sound and Vibration, v.126, p.485-502, 1988.

[66] RAYLEIGH, L. The Theory of Sound. v.1, The Macmillan Company, 1877 (reprinted by Dover Publications, New York, 1945).

[67] RITZ, W. Über Eine Neue Methode Zur Lösung Gewisser Variations Probleme der Mathematischen Physik. Journal für Reine und Angewandte Mathematik, v.135, p.0161, 1908.

[68] SCHMID, M. T. Lajes Planas Protendidas, Publicação Técnica de RUDLOFF-VSL Industrial Ltda. São Paulo, 1993.

[69] RÜSCH, H. Concreto Armado e Protendido. Propriedades dos Materiais e Dimensionamento. Ed. Campus, 396p. Rio de Janeiro, 1981.

[70] SILVA, R. J. C. Projetos de Lajes Maciças Protendidas de Edifícios. Dissertação (Mestrado) - Escola Politécnica, Universidade de São Paulo. São Paulo, 1998.

[71] SILVA, R. J. C.; MELLO, G. S. Resistência à Punção de Lajes Cogumelo Protendidas com Cabos Engraxados e Pilares de Várias Dimensões. $45^{\circ}$ Congresso Brasileiro do Concreto - IBRACON, Vitória, p.15, 2003. ANAIS [CD-ROM].

[72] SLYPER, H. A. Development of Explicit Stiffness and Mass Matrices for a Triangular Plate Element. In: J. Solids Structures, v.5, p.241-249, 1969.

[73] SOONG, T. T.; BOGDANOFF, J. L. On the Impulsive Admittance and Frequency Response of a Disordered Linear Chain of N-Degrees of Freedom. International Journal of Mechanical Sciences, v.6, p.225-237, 1964. 
[74] SOUZA, V. C. M.; CUNHA, A. J. P. Lajes em Concreto Armado e Protendido. 2ed. Rio de Janeiro, 1998.

[75] TIMOSHENKO, S.; GOODIER, J. N. Theory of Elasticity. Ed. Mc Graw-Hill, 2ed. New York, 1951.

[76] TIMOSHENKO, S.; WOINOWKY, S. Theory of Plates and Shells, 2ed, Mc-Graw-Hill, New York, 1959.

[77] TURnER, M. J.; ClOUGH, R. W.; MARTIN, H. C.; TOPP, L. J. Stiffness and Deflection Analysis of Complex Structures. Journal Aeronautical Science, v.23, p.805$824,1956$.

[78] VASCONCELOS, A. C. O Concreto no Brasil: recordes, realizações e história, edição patrocinada pela Camargo Corrêa, São Paulo, 1985.

[79] VERÍSSIMO, G. S.; CESAR, K. L. M. Concreto Protendido. Fundamentos Básicos, 4ed, Universidade Federal de Viçosa, 1998.

[80] WEI, S. T.; PIERRE, C. A Statistical Analysis of the Effects of Mistuning on the Forced Response of Cyclic Assemblies. In: 30rd AIAA / ASME / ASCE / AHS STRUCTURES, STRUCTURAL DYNAMICS AND MATERIALS CONFERENCE, Mobile, AL. Proceedings. AIAA Paper nº. 89-1357-CP, 1989.

[81] ZIENKIEWICZ, O. C.; CHEUNG, Y. K. The Finite Element Method for Analysis of Elastic Isotropic and Orthotropic Slabs. Proceeding Institute Civil Engineering, n.28, p.471-488, 1964.

[82] ZIENKIEWICZ, O.C.; TAYLOR, R.L. The Finite Element Method: Basic Formulation and Linear Problems. 4ed. Mc Graw-Hill, v.1. London, 1989. 
